
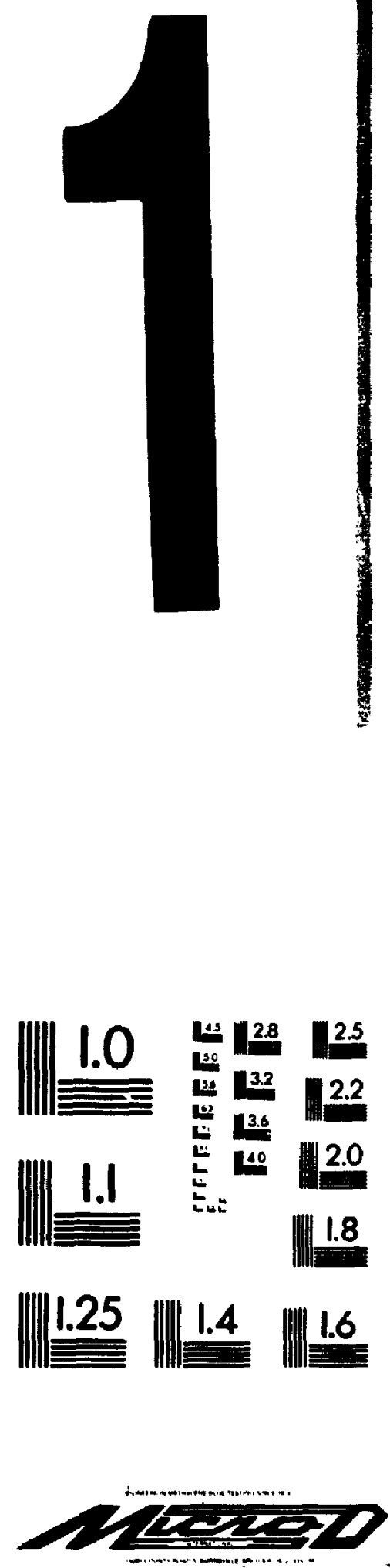
Ounwa, Canede

K1A ON4

\section{Service des thises canadiennes}

\section{NOTICE}

The quality of this microform is heavily dependent upon the quality of the original thesis submitted for microtilming. Every effort has been made to ensure the highest quality of reproduction possible.

If pages are missing. contact the university which gramed the degree.

Some pages may have indistinct prim especially it the original pages were typed with a poor typewriter ribbon or if the university sent us an inferior photocopy.

Reproduction in full or in part of this microlorm is governed by the Canadian Copyright ACt, R.S.C. 1970, C.C-30, and subsequent amendments.

\begin{abstract}
AVIS
La qualité de cette microtorme dépend grandement de la qualité de la these soumise au microfilmage. Nous avons tout tait pour assurer une qualite superieure de reproduc. tion.

S'il manque des pages, veuillez communiquer avec runiversite qui a contéré le grade.

La qualité d'impression de certaines pages peut laisser à désirer, surtout si les pages originales ont été dactylographiées à laide d'un nuban usé ou si luniversité nous a tait parvenir une photocopie de qualite interieure.

La reproduction, méme partielle, de cette microlome est soumise a la Loi canadienne sur le droit d'auteur. SRC 1970, c. C-30, et ses amendements subséquents.
\end{abstract}




\title{
An Approach to Computer-Based Support for Work Breakdown Structure Development
}

\author{
by \\ Jasbinder Singh Chimni, B.A. (Honours)
}

\author{
A thesis submitted to \\ the Faculty of Graduate Studies and Research \\ in partial fulfillment of \\ the requirements for the degree of \\ Master of Management Studies \\ School of Business \\ Carleton University \\ Ottawa, Ontario \\ August 1, 1989 \\ Q copyright \\ 1989, Jasbinder S. Chimni
}


Canadian Theses Service Service des théses canadiennes

Ottawa, Canada

K1A ON4

The author has granted an irrevocable nonexclusive licence allowing the National Library of Canada to reproduce, loan, distribute or sell copies of his/her thesis by any means and in any form or format, making this thesis available to interested persons.

The author retains ownership of the copyright in his/her thesis. Neither the thesis nor substantial extracts from it may be printed or otherwise reproduced without his/her permission.
L'auteur a accordé une licence irrévocable et non exclusive permettant a la Bibllotheque nationale du Canada de reproduire, preter, distribuer ou vendre des copies de sa thése de quelque manière et sous quelque forme que ce soit pour mettre des exempleires de cette thèse à la disposition des personnes intéressées.

L'auteur conserve la propriété du droit d'auteur qui protége sa thèse. Ni la thèse ni des extraits substantiels de celle-ci ne doivent etre imprimés ou autrement reproduits sans son autorisation. 
The undersigned recommend to the Faculty of Graduate Studies and Research acceptance of the thesis

\title{
An Approach to Computer-Based Support for Work Breakdown Structure Development
}

\author{
submitted by Jasbinder Singh Chimni, B.A. (Honours)
}

in partial fulfillment of the requirements for the degree of Master of Management Studies

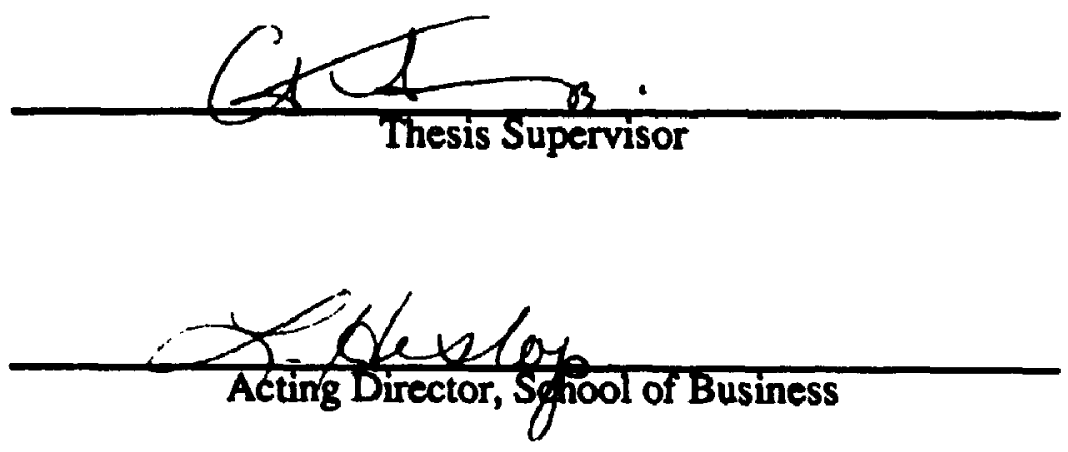

Carleton University

September 12, 1989 


\section{Abstract}

A work breakdown structure is a hierarchical representation of a project. It is considered to be one of the most important activities in project management. Important as it is, it is equally difficult to develop due to the large size and complex nature of the projects. This difficulty necessitates support for its development. This thesis presents an approach for computer-based support for WBS development and implementation. This approach makes it possible to integrate information about WBSs developed for projects in the past, with the information about: 1) the rules and ways of developing WBSs; and 2) the relevance of WBS to other project management activities. The approach integrates expert system and database management technologies. Based on this approach, a prototype using PC Easy and Xi Plus, two expert system shells, and dBase III, has been developed. An architecture of an integrated project management tool is also presented. 


\section{Acknowledgements}

I would like to thank a number of people without whose input and support this thesis would not have been completed. I am grateful to the faculty and the staff for their cooperation and assistance. I would also like to thank Tony Koziol. Though he was not directly involved in my thesis, he helped me learn a lot. Special thanks to Greg Schmidt for his assistance and advice. It was a pleasure working for him. I am thankful to Mr. DiPietro and Mr. Newell for taking the time to verify the prototype and for providing comments.

I would like to thank Prof. Mallory, Prof. Haines and Prof. Chinneck for their assistance during the entire process, from the formulation of the research question till the completion of the thesis. Their input was valuable.

I am indebted to my peers for their support. It was comforting to know that I was not alone in this "mess". Joelle's support in the first term was invaluable. Paul was always there encouraging me to go on. And there were the dangerous two, Lisa and Jennifer, without whose threats I might still be writing this thesis. To all of you, thanks for being my friends.

I would like to express my gratitude to Gregory (Prof. Kersten). He is a guide, a friend, a well wisher and a source of encouragement and inspiration. He whetted my interest in this topic; assisted me to formulate the research question; and spent valuable time reading the various drafts of the thesis proposal and the thesis, and suggesting improvements. I am especially appreciative of him for his considerate attitude. He would come to school even on weekends to help me resolve problems.

I have learnt a lot during the last two years. This would not have been possible without my interaction with Gregory. He made the difference. 
I would like to thank my family, especially my parents, for their support. Without their assistance I wouldn't have had the opportunity to come to Canada to atudy. For all the love and sacrifices you have made for me, I hope I have lived up to your expectations.

Finally, I would like to thank the person who was more patient, supportive and understanding than I could ever have been. To my fiancee, Sabina, I dedicate this thesis. 


\section{Table of Contents}

Acceptance Sheet

Page

Abstract

ii

Acknowledgements

iii

Table of Contents

iv

List of Figures

vi

ix

Introduction

Chapter 1: Work Breakdown Structure

1.1 Project Management Activities 4

1.2 WBS Development 6

Chapter 2: Support for WBS Development 11

2.1 Areas for Support 11

2.2 Sources of Support 12

2.3 Computer-Based Support for WBS 14

2.4 Existing Computer-Based Support 15

2.5 Research Question 17

Chapter 3: Methodology 18

3.1 Collection and Analysis $\quad 19$

3.2 Framework Representation 20

3.3 Prototype Development 20

3.4 Prototype Verification 22

3.5 Integrated Project Management Architecture 22

Chapler 4: Structure and Procedures 23

4.1 Information 23 
4.1.1 Structure 23

4.1.2 Considentions for the Procedure 25

4.1.3 A Procedure 26

4.2 Development 28

4.2.1 WBS Structuring 28

4.2.2 An Approech 29

4.2.3 An Altemate Approach 34

4.2.4 Procedures 37

Chapter 5: Integration of Technology 41

5.1 Database and Expert System Technologies 41

5.2 The Approach 44

5.3 Prototype Architecture 45

Chapter 6: Representation 49

6.1 Data Models 49

6.1.1 EBS Data Model 51

6.1.2 Support WBS Data Model 55

6.2 Rule-Based Representation 56

Chapter 7: Prototype and PM Architecture 60

7.1 Software and Hardware 60

7.2 Example 61

7.3 Prototype Verification 65

7.4 Project Management Architecture $\quad 70$

Chapter 8: Discussion 75

8.1 Pros and Cons of Rule-based Formalism and ES Technology 75

8. 2 Limitations and Benefits of the Research 77 
8.2.2 Benefits of the Research 82

8.3 Future Developments 83

Chapter 9: Conclusion 85

References $\quad 88$

Appendices $\quad 92$

1. Project Management Advantage 92

2. Text and Initialization Rules 94

3 Database Access Rules 101

4. Knowledge Bases - Information Module 139

5. Knowledge Base - Development Module 155

6. Data and Program Files 172

$\begin{array}{ll}\text { 7. Screens } & 219\end{array}$

8. Example 240

9. System Flow Chart of the Information Module 250

10. System Flow Chart of the Development Module 251

11. User Manual 254 
Figure 1 Menus
a) Main menu
b) Topics
c) Level of detail
d) Genend information

Figure 2 Airernt class

Figure 3 Air Vehicle class

Figure 4 Propulsion Unit class

Figure 5 Relationships between elements

Figure 6 Architecture of the prototype

Figure 7 EBS related to one other EBS

Figure 8 EBS related to one specific EBS

Figure 9 EBS related to two specific EBSs

Figure 10 Normalized model

Figure 11 Data model - Support WBS 56

Figure 12 Aircraft system - 1 62

Figure 13 Aircraft system - 2 63

Figure 14 Aircraft system - 3 66

Figure 15 Project management architecture 73

$\begin{array}{lll}\text { Figure } 16 & \text { Structure of the information module } & 78\end{array}$ 


\section{Introduction}

Formal project management rechniques are of relatively recent origin. Frame (1987) and Meredith and Mantel (1985) regard them as a byproduct of the second world war, undertaken for the first time during the Manhattan Project, for the development of the atomic bomb. Stuckenbruck (1981a) regards the Atlas project, undertaken in 1954 for the development of the Inter Continental Ballistic Missiles, as the first project where they were employed. Despite this discrepancy about the origin of formal project management techniques, from here on referred to as project management, the reason for their introduction is clear: to effectively manage complex projects.

Project management facilitates coordination of budgets, schedules, resource allocations and other activities necessary to accomplish these projects. It aims at completing the project: 1) on time; 2) within budget; and 3) according to specifications. It assigns the responsibility for the success or failure of the project to the project manager.

Over time, projects have been getting larger and more complex. This growth in size and complexity resulted in the introduction of a new project management tool, the Work Breakdown Structure (WBS) in the early 1960s (Stuckenbruck 1981a; Huot 1979). WBS is defined as "a product-oriented family tree division of hardware, software, services and other work tasks which organizes, defines and graphically displays the product to be produced, as well as the work to be accomplished to achieve the specified product." (Lavold 1983, 283). Initially work breakdown structures were area specific - different work breakdown structures for each functional area, such as engineering. However, this was not an effective approach for large projects which required the coordination of several interdependent functional areas and their environment. Accordingly, a decision was taken 
by the Department of Defense (U.S.A.), in 1968, to introduce a WBS for an entire project (Nucci and Jackson 1979) - the project WBS.

The project WBS is in accordance with the systems approach i.e., the project is regarded as a system which can be decomposed into interrelated subsystems composed of hardware, software and services. The decomposition begins at the highest level - the project - and continues until manageable subsystems (work packages) are achieved. These subsystems are at the lowest-level, and, as a rule of thumb, should take no more than eighty hours to complete (Stuckenbruck 1981a). The summation of all the elements in a particular WBS level equals the elements in the next level. Thus, the WBS is a hierarchical representation of a project.

A work breakdown structure forms the basis for nearly all project management activities. Although during the last 20 years its usefulness has been widely accepted, it still poses methodological challenges and its creation is considered to be one of the most difficult tasks in project management. As a result of this research a framework of support and a support prototype for assisting project managers in the construction of work breakdown structures have been developed.

This thesis has nine chapters and eleven appendices. Chapter 1, based on the literature review, discusses the importance of the work breakdown structure; and the reasons for the delay in WBS development and/or development of inappropriate WBSs. In Chapter 2, the areas to be supported in the construction of WBS; the sources of support; the need for computer-based-support; the shortcomings of the existing computer-based support; and the research questions are presented. The methodology of the research is discussed in Chapter 3. The procedures for presenting information and for assisting WBS development are presented in Chapter 4. A discussion on expert system and database 
technologies; the approach used; and the prototype architecture are presented in Chapter S. In Chapter 6, the data models and the rule based representations are presented. The implementation of the prototype; illustrations of its use; its verification; and the architecture of an integrated project management tool are presented in Chapter 7. The pros and cons of rule based formalism and expert system technology; the limitations and benefits of the research; and future directions for research are presented in Chapter 8. Finally, the conclusion is presented in Chapter 9. 


\section{Chapter 1: Work Breakdown Structure}

Various authors have stressed the importance of a WBS. According to Huot (1979, H.3.1) "The work breakdown structure is a tool absolutely necessary from the concept development to the end of a project to control the scope definition of a project and its subdivision in systems, subsystems etc., to the level of work packages". The WBS is considered as the most important part of planning as it forms a "common framework" for a number of project management activities such as scheduling, responsibility assignment, and resource allocation (Kerzner 1984). "The WBS is extremely important as it can tie all of the implementing and control actions of the project manager together." (Stuckenbruck 1981a). The indispensability of WBS to project management is also highlighted by Lackman (1987, H.3.1) as follows: "If I were to be stranded on a desert project with only one management and control tool, I would want that tool to be a Work Breakdown Structure." This view is also supported by such authors as Lavold (1983), Aptman (1986), Oldham, Ripberger and Cook (1986), and Johnson (1985).

\subsection{Pruject Management Activities}

The WBS forms the basis for nearly all project management activities: development of the scope statement, responsibility assignment, budgeting, scheduling, control, and establishing communication channels. The dependency of these activities on WBS is discussed below.

Scope Statement: Scope refers to all the activities which need to be performed, the resources consumed, and the end products produced. WBS facilitates the development of the scope statement (Lavold 1983) by assisting in the identification of the work to be done. This is accomplished by representing the complex project by all its components and the 
relations between them, and thus the entire work, as the sum of the work required for obtaining/developing the components and assembling them. Once the work is defined, the needed resources can be procured and the vendors and subcontractors who may be involved, determined.

Besponsibility Assignment: Responsibility assignment is a function of paramount importance in any project management assignment. The WBS forms the basis for this function (Lavold 1983; Lanford and McCann 1983; Saynisch 1983). By interfacing the organization's structure with the WBS, it helps ensure the assignment of functional responsibilities for each task.

Budgeting: WBS facilitates the preparation of the budget (Lackman 1987; Bitner 1985; Kerzner 1984). This is true for both the top-down and the bottom-up approaches of budget preparation. In the former approach, the budgetary assignments are primarily based on experience from previous projects, while in the latter, the sum of the budgets of the 'subtasks' forms the budget for the 'task'. In this manner the budget for the entire project is estimated. The budget must be developed in accordance with the WBS (Lackman 1987; Bitner 1985) to eliminate budgetary overlaps and to ensure no task is left unbudgeted.

Scheduling: This is a very important aspect of project management and the development of PERT/CPM (scheduling techniques) in 1957/1958 facilitated automatic scheduling (Huot 1979). Mos . of the project management software facilitates the development of schedules. However, independent of the software used, all the tasks have to be defined prior to the use of such software. WBS provides the basis for the identification of all activities and helps to ensure that all are accounted for (Lackman 1987).

Control: WBS also provides a means for "baseline project control". Since WBS is considered to form the baseline for nearly all project management activities, it provides a 
basis for controlling performance (time and cost) using the project control system. The information used by the project control system consists of such items as progress reports, productivity reports, and earned value. All of these are collected and reported via the WBS (Lavold 1983). This process ensures that the data are consistent and can be traced back to the baseline. In essence, the WBS is an integral part of the control system.

Communication Channels: In addition to being central to the activities mentioned above, WBS facilitates establishing information channels by various participants. Projects tend to have multiple owners, often involve government departments, and involve project managers, contractors, and various functional groups. They all need information regarding the project. In order for them to have access to consistent and pertinent information, it is essential to have a common baseline. The WBS provides this common baseline, and thus is considered important for communication (Kerzner 1984).

Further, WBS facilitates horizontal (functional) integration. Project management for large projects requires coordination of various functional activities. By interrelating the functional areas, the WBS (Lanford 1983) facilitates this coordination. It does this by displaying the flow of work required to complete the project. This flow chart clearly illuminates the inter-dependencies, e.g., engine parts should be manufactured before the engine can be assembled. These inter-dependencies become clearer when the organizational structure is interfaced with the WBS. Thus the WBS provides a framework for horizontal (functional) integration.

\subsection{WBS Development}

A WBS is required for nearly all project management activities. Therefore, its establishment early in the life of a project is essential (Lavold 1983; Bitner 1985). Although it may seem inconsistent, this may not happen often. According to Huot (1979), in the 
construction industry, "WBS procedures are not created early enough in the conceptual stage". The same could be applicable in other industries too. Four reasons may account for this delay. First, as a consequence of the limited research undertaken in this area, the methodologies in the literature are inadequate aids for project managers; second, common errors can be committed in WBS development which may result in the development of inappropriate WBSs; third, project managers' may often lack experience which, in addition to delaying the development of the WBS, may increase the possibility of developing inappropriate WBSs; and finally, there may be a shortage of time for developing WBSs. These are further discussed below.

Methodologies - inadequate aids: Though the importance of the WBS is well documented in the literature, it has received less attention than it warrants. For instance, in their project management handbooks Kerzner (1984), Meredith and Mantel (1985), and Frame (1987) have devoted only small sections of various chapters to WBS, while complete chapters have been devoted to other WBS dependent activities.

Further, the emphasis has not been on WBS development procedures, but on illustrating the importance of WBS and on providing generic WBS methodologies. This is clearly inadequate since project managers require procedures which they can use either directly or by adapting them to meet their requirements. Lavold (1983) in Developing and Using the Work Breakdown Structure discusses the importance of the WBS but does not illustrate how a WBS can be developed, as the title of his work suggests. This lack of attention to the development of WBS is even more acute in project management journals there are no articles on WBS in the Project Management Journal and only one, "Subdivision of Work on Construction Projects" by W.D. Tiner (1985) in the International Journal of Project Management, since 1983. Although other journals, e.g., Journal of Systems Management, carry a few articles on WBS, here too the emphasis is not on the 
WBS development procedures, but on project management activities that are a "follow-up" of WBS.

Project managers are therefore disadvantaged since the development of a WBS is a very difficult task (Stuckenbruck 1981b). The difficulties arise due to the large size and complex nature of the projects. While WBSs for small projects allow flexibility, the same is not possible for large projects (Frame 1987). Once developed and implemented, major changes can result in adverse time and cost consequences.

Errors in WBS development: A review of the literature revealed that project managers commit two types of errors in developing WBSs. First, it is possible to develop a WBS along existing "easily differentiable organization lines" rather than in accordance with the project hardware, software and services requirements. This is often the case (Stuckenbruck 1981b) and is not appropriate. A WBS should provide a complete and precise definition of the project, and ensure that all parts fit together. However, if developed along the organization structure, the required fit/interrelationships, which are very important, may be lost (Stuckenbruck 1981b). For this purpose it is essential that a WBS be developed in terms of the hardware, software and the services required for the project rather than in accordance with the organizational structure.

The second potential failing is the appropriate level of detail. It is possible that while developing the WBS, either it is not done in enough detail or is too detailed (Johnson 1985). If the former happens, certain tasks will be omitted and the WBS will not perform its intended goal to account for all the activities and to ensure their proper fit. This will have adverse repercussions on all WBS dependent activities and eventually result in cost and time overruns. The latter, on the other hand, would result in a waste of time (Kerzner 1984), may increase the complexities, and also have adverse time and cost implications. 
Broject managers' inexperience: The probability of these errors occurring increases because project managers are usually not trained to be project managers. They are usually: 1) good technical personnel; 2) well trained or experienced line managers; or 3) young professionals (Stuckenbruck 1984) and therefore lack the training and/or experience needed for undertaking project management activities, especially the development of the WBS. This situation is exemplified by the Project Management Office of the Low Level Air Defence which, in an attempt to reduce the disadvantage and try to support inexperienced project managers, has undertaken to prepare a "user friendly" and concise handbook for WBS development. Without assistance the inexperienced project managers may be unable, first, to decompose the project properly - some subsystems might be overlooked; and second, they may not be able to organize the elements of the WBS. This can result in the loss of relationships between the subsystems and thus defeat the very purpose of developing the WBS.

Time pressure: A discussion with some project managers has revealed yet another reason for the delay and/or development of inappropriate WBSs - shortage of time. It has been found that generally there is insufficient time for project managers to develop WBSs.

Further Bitner (1985) has listed a few reasons which contribute to inadequate project start-up preparation. Some of these may also be applicable for explaining the delays and/or development of inappropriate WBSs. These are:

1) Project managers may lack the experience to deal with the size of the project being undertaken.

2) They may be selected because they are the best available and might not have the ability to manage the projects.

3) There may be insufficient "carry over of experience from previous projects", for the following reasons: 
10

i) Successful project managers are often promoted and therefore are not available to manage subsequent projects.

ii) Absence of company training programs to translate experience from previous projects into education for future project teams.

iii) Project management procedures are seldom accurately documented.

iv) Project procedures from previous projects can only be applicable after they have been adapted.

An important issue is the lack of well structured approaches and aids to develop a WBS. This introduces an additional difficulty to the development process which is magnified by the lack of experience. The complexity of the process itself on one hand, and the importance of WBSs on the other lead to the question of the possible means and scope of support for project managers in this process. 


\section{Chapter 2: Support for WBS Development}

In the previous chapter, several causes for inefficient WBS development and the need to support project managers in the development of WBSs were discussed. This chapter covers the areas for which support is required; the sources of support; illustrates the need for computer-based support for WBS development; given this need, it demonstrates the inadequacy of the existing computer-based support; and finally presents the research question.

\subsection{Areas for Support}

Support in WBS development should reflect requirements of project managers. Because they may be either experienced or inexperienced they require support in two areas:

Information: Project managers who lack experience in the construction of WBSs require information about the following:

i) what is a WBS?

ii) the reasons for its development;

iii) the activities involved in its development; and

iv) the activities dependent on it.

These will be referred to as WBS fundamentals and dependent activities. The information about the WBS fundamentals and dependent activities provides the prerequisite for the actual development of the WBS. It provides the "What" and "Why" of a WBS.

Developmenti All project managers, experienced and inexperienced, require support in the actual development of a WBS. This support includes the following: 
i) decomposition of a project into its parts, i.c., elements which should be included in the various WBS levels;

ii) verification of the completeness of the WBS;

iii) verification of the appropriateness of the level of detail; and

iv) verification of the WBS for: a) non-repetition of elements in various levels; b) hierarchical flow of the WBS, i.e., elements cannot be in level three without having a source in level two; and c) appropriateness of the WBS for the project.

\subsection{Sources of Support}

There are five sources of support for the two areas mentioned above. Of these, four are non-computer-based, and one is computer-based. The four non-computer-based sources of support are:

1) project management handbooks;

2) project management and WBS articles;

3) manuals containing WBS nodels/standards; and

4) experience of project managers, both former and present.

The computer based source of support is the computer programs which allow the development of WBSs.

Handbooks and articles primarily provide information about WBS fundamentals and dependent activities, the importance of WBSs and a few WBS illustrations. The WBS development models/standards which are developed by large organizations, e.g., Department of Defense or NASA, mainly support WBS development. Experience of project managers caters to both information about the WBS fundamentals and dependent activities, and the actual WBS development. Computer programs allow development of the WBS. 
Each source of support supplements the other - information about WBS fundamentals and dependent activities is necessary before WBSs can be developed. It is essential to know how to develop WBSs if computer programs are to be effective. Used independently, each has some drawbacks - either they do not sufficiently cater to both the support groups or their use as support does not address all the requirements of project managers. The reasons are as follows:

1) Handbooks and articles generally do not provide procedures for developing WBSs. The examples/cases are generally small and abstract.

2) WBS development models/standands fumish limited support about WBS fundamentals and dependent activities. Further, these models/standards are organization specific and are not widely available. This limits their use for support by project managers external to the organization. Also, because they are paper-based documents, the manipulation, aggregation and joining of one or more standards is difficult.

3) Experience has always been a crucial factor for successful project management. Since it is primarily obtained through actual practice and its transfer has been very difficult (Hosley 1987), new project managers are disadvantaged. For instance, successful project managers get promoted and new ones are appointed. They are forced to learn through their own mistakes. This method of learning through trial and error is time consuming, expensive and risky. Experience, if captured in some form that could be available to other project managers, would provide an effective support tool. So far, the use of experience for support appears limited.

4) Most existing software assumes prior development of the WBS (Yik 1987). This is confirmed by the reviews of the project management packages such as "Microsoft Project Manager" (Smith 1986), "MicroMan II Project Control System" (Smith 1987b), and 
"Project Vision" (Smith 1988). The few programs which allow the development of a WBS provide little or no help. This is discussed later in greater detail.

Although there are some important sources of support for developing WBSt, they are either not generally available to project managers (e.g., the knowledge gained through experience with or taken from WBS development models/standards) or fail to provide adequate support for WBS development (e.g., WBS fundamentals and dependent activities, and computer software). Fuwever, if all the support mentioned acove could be made available in one integrated form, it would be more effective due to the resultant synergy. Software technology does provide an opportunity for developing such an integrated support tool. Before using software technology for developing an integrated support tool, the need for computer-based WBS development is further illustrated.

\subsection{Computer-Based Support for WBS}

Computers are considered to be an essential tool for effective project management. Thamhain (1987) states that it is difficult to manage complex projects without computeraided tracking and decision support systems. Large projects require computer based support to handle large volume of information which is used in scheduling, budgeting, resource allocation, control, etc.

WBSs for these projects require "computerized handling of data" (Huot 1981) due to the large volume of data involved. Huot (1979) has stressed the "need for a computerized, WBS oriented methodology". This is essential for keeping track of project components, their scope, scope changes and the decomposition of the work. A computerized WBS, it was anticipated, would become a "common management framework". It would facilitate faster development of the WBS, which in tum would facilitate timely development of the WBS dependent activities. To date, the majority of the 
project management software does not facilitate WBS development, but uses it for such activities as scheduling, costing and progress analysis.

Thisner, Teicholz and Havas (1987) have identified four potential areas for the development of new project management software. 1) Work Breakdown Structure (WBS); 2) Information Sharing: project management being a team effort requires communication among various groups, and often involves sharing of the same information; 3) Project management database: contains information pertaining to such activities as design specifications, cost and budget, schedules, purchasing documents; and 4) Project management language.

The development of an information sharing system and a project management database depend on the development of the WBS. WBS facilitates the identification of the groups involved in the project and their interaction and thus is a prerequisite for setting up the communication channels (information sharing). Similarly, the data for various project management activities, e.g., scheduling, budgeting, should have a common information source, which is, again, provided by the WBS. Thus prior development of computer-based WBS support is necessary if computer-based information sharing and project management databases are to be effective.

Since the WBS forms the basis for nearly all the project management activities, most of which are computer-based, to make project management more effective it is c sential that WBS development also be computer-based.

\subsection{Existing Computer-Based Support}

In keeping with these requirements, moves towards the development of software for WBS and the inclusion of WBS development in project management software would be 
expected. After a thorough investigation of project management software, however, it was possible to find only four project management software packages which allow for the development of a WBS.

The four project management packages are 'Viewpoint, version 2.5', (Smith 1987a), 'Super Project Expert' (Computer Associates), Harvard Total Project Manager II: Increased Options' (Smith 1987b) and Project Management Advantage' (All - Tech Project Management Services, Inc. 1987). The first three are 'conventional' software packages and have utilities for storing WBS but do not provide the user with information about "Why" and "How" a WBS should be developed.

'Project Management Advantage' is an expert system. It has received an enthusiastic reception by its users and is also regarded as a good training device (Hosley 1987). However, it has a shortcoming. Its WBS section does nut have an adequate knowledge base and it uses an oversimplified example of a WBS. The only assistance it provides is general advice about developing the WBS levels if not already developed. This is illustrated in Appendix 1, which presents the exchange of information between "Project Management Advantage" and the user who wants to develop a WBS.

Project managers may require support for both WBS fundamentals and dependent activities, and for developing WBSs. 'Project Management Advantage' does not provide assistance in either area.

Existing project management packages represent only a minor change in the underlying assumption of the project management software. These packages assume the ability of the project manager to develop the $W$ SS. This assumption, however, may be unfounded. 
Therefore, it is evident that the existing project management software does not provide the desired support for WBS development. This research illustrates how an integrated and effective support tool can be developed. This has been done by developing a framework which includes procedures and models for embodying the information about WBS fundamentals and dependent activities, and about the actual WBS development. This framework was then used to develop the support prototype.

\subsection{Research Question}

The research therefore, addressed the following question: How can computer-based support be developed to assist project managers in constructing work breakdown structures?

This in tum suggests the following questions:

1) How should the procedure for furnishing information about WBS fundamentals and dependent activities be structured?

2) How should a WBS development procedure be structured ?

3) How can the procedures in question 1 and 2 be embodied in the prototype?

4) What should an integrated support tool for project management contain?

The last question is an attempt to combine the existing project management support with the concept behind the prototype. 


\section{Chapter 3: Methodology}

The concept of WBS support as a topic for this research was developed during the preliminary analysis of the literature on project management, decision support systems, expert systems and computer aided learning. It aims at providing support in two areas: Information and Development. While the former deals with presenting information about WBS fundamentals and dependent activities, the latter will assist the users in the actual development of a WBS. To assist the user in the actual development, a preliminary analysis revealed two possible approaches: 1) Procedure based: which involves using a general procedure to develop WBSs; and 2) Example/Case based: which uses WBSs developed for previous projects as references for developing WBSs for new projects.

The procedure based approach is not feasible due to the nonexistence of such procedures. This is because WBS development is a modelling process with both "arts" and "science" components and thus involves both creativity and knowledge. Each new WBS is a new model. Thus to provide assistance, a procedure has to be devised to develop models. Research for developing such a procedure is still in the formative stages (Geoffrion 1987).

The latter approach, on the other hand, is more practical and therefore is the one chosen for this research. The decision to use the case based approach stems from the fact that cases, like WBS standards, have been used as references for developing new WBSs. Also of late qualitative models, e.g., cases, can be embodied in a computer support system and the verification of the applicability of such systems can be determined.

The methodology used for this research can be separated into five parts. 1) The collection and analysis of the WBS fundamentals and dependent activities and WBS standards; 2) Representation of the support framework; 3) Development of the prototype; 
4) Prototype verification; and 5) Design of an architecture for an integrated project management support tool.

\subsection{Collection and Analysis}

The material pertaining to WBS fundamentals and dependent activities was collected from the following sources: 1) project management handbooks; 2) project management and WBS articles; and 3) documents of organizations such as Department of Defense (U.S.) and Department of National Defense. No attempt was made to cover or exhaust all the available information/sources of information but to present a subset of this information in a structured way so it can be embodied in the prototype. The WBS standards have also been collected from the available sianuals of the same two organizations.

A qualitative analysis of both was performed. The analysis of the information involved positioning and characteristics of the WBS activities within the project management process and the interaction of the WBS with other project management activities. The analysis of the WBS standards involved the analysis of the subdivision of the project; the elements in each level; and the assembly of the WBSs, e.g., separation of hardware from software and services. From this analysis, it was possible to develop procedures and models for structuring a WBS and fur providing information about WBS fundamentals and dependent activities. These procedures and models together provided the framework for the support prototype. This framework shows how the various sections are to be interconnected, e.g., how information about the 'WBS dependent activities' is connected with the information about the 'Types of WB's's' and how WBS examples can be used for development of a new WBS. 


\subsection{Framework Representation}

Rule based formalism (Kersten and Szpakowicz 1988; Liebowitz 1988) was used to represent the problems encountered by the project managers in WBS development. Rules were used to structure qualitative information (knowledge) and facilitate both the structure and the control of the decision process, e.g. which WBS element to include and at what level. They were used because of the flexibility and ease by which they can be represented. Further, they provide modularity and thus addition or deletion of rules would not radically affect the procedure. This is an advantage over standard computer programs, in which changes in instructions result in a chaos due to the sequential nature of programs. Also, in standard computer languages, the interpretation of the instructions are position-dependent, i.e., the effect depends on the position of the instruction in the sequence of the instructions surrounding it. Rules are not dependent on other rules surrounding them. Further, rules represent the reasoning process in decision making (Holland et al. 1986).

In addition to rule based formalism, data models (Litton 1987) were used to design the subdivision and the management of data to be stored in the databases. This was done to simplify the system to a stage where it could be represented by some type of a database. The simplification involved identifying the important/key variables and their structuring so as to provide a model of the database to be developed.

\subsection{Prototype Development}

The prototype has 3 components:

1) Databases are based on the data models developed earlier. These databases contain adaptions of WBS standards which project managers use to develop new WBSs, rather than WBSs developed for particular projects, e.g., the maintenance of the CF-18 aircraft. 
Although the WBS for the maintenance of a CF-18 aircraft is more complex than the aircreft standard, its st iscture is very similar. Therefore by showing how project managers can use and manipulate the standards given in the databases to develop customized WBSs, the use and manipulation of larger and more complex WBS models is illustrated.

There are two advantages of storing WBSs in data bases. First, changes to the WBS standards or models can be made with the help of an appropriate database management system. Second, project management software have interfaces to various extemal applications. For example, applications like PROMIS, Time Line and Super Project Plus, have interfaces to spreadsheets, and Open Plan has an interface to a database management systems - dBase III - (Wasil and Assad 1988). Storing the WBS models in databases would enable such packages to access the WBSs and thus provide a basis for an integrated project management tool.

2) Knowledge bases have been developed using rule based formalism. They contain rules which define procedures for developing the WBSs and also for providing information about WBS fundamentals and dependent activities.

3) Expert system shells ${ }^{1}$ have been used to store and process knowledge bases. One of the shells has an interface to a database application. The use of these shells provides two advantages. First, it facilitates relatively faster development of the prototype by eliminating a substantial amount of time required for computer coding, testing and debugging, than would otherwise be required for the development of the shell. Second, it details specific ways of representing the knowledge (procedures), inference and control.

\footnotetext{
1 An expert system shell is a tool for developing expert systems.
} 


\subsection{Prototype Verification}

The prototype was verified by profestionals who have experience and knowledge of this area, i.e., who are project managers and are supervising or developing WBSs. Their comments have been considered and are presented in Chapter 7.

\subsection{Integrated Project Management Architecture}

Finally a design for an integrated project management support tool was developed by using existing project management software literature, and the experience from the prototype developed. In this thesis there is an emphasis on integration, e.g., integration of various sources of information. It is believed that integration is essential to make project management more effective as it enhances the effectiveness due to the resultant synergy. 


\section{Chapter 4: Structure and Procedures}

In this chapter two sections, Information and Development, are presented. The structuring of the information, and the procedure for providing the information is discussed in the Information section. The Development section discusses the structuring of the WBSs; presents an approach to manipulate WBSs; and finally provides an alternate approach. These two sections provide the basis for developing the two modules, information and development, for the prototype. This chapter addresses the first two research questions.

\subsection{Information}

In this section, first the structuring of the information is presented followed by the procedure used to access the information.

\subsubsection{Sinucture}

The structure of this section is similar to the structure found in project management handbooks and journals. Information about an area, say WBS, consists of a number of topics which in turn may consist of a number of sub-topics. Further, the information about a topic is always provided in increasing degree of detail, i.e., the introduction to a topic presents an overview of the topic while the information about a subtopic is more specific. Also the level of detail of the information within a sub-topic increases incrementally.

A similar approach has been used for structuring the information used to develop the information module. The WBS area consists of topics, which in turn consist of subtopics. Further the information about the topics is also provided in an increasing degree of detail, from the overview to specific information about the various sub-topics. 
This structuring of the information acconding to the progreasive level of detail, apan from being based on the structure found in project management handbooks and journals, is based on the following consideration:

The aim of the support is not to encompase all the knowledge pertaining to the WBS but to provide meaningful, precise and helpful information.

In keeping with this consideration, a sub-topic generally does not consist of more than two or three screens of information. In cases where too much information is present, further classification can be made.

The information about WBS fundamental and dependent activities is classified into four topics: General Information; Types of WBSs; WBS Coding a:d Dictionary; and WBS Dependent Activities. Tht four topics have been chosen because they encompass most of the information project managers may require. Each topic in tum consist of sub-topics.

General Information: WBS definition, aims of a WBS, WBS examples and components of the WBS.

Types of WBSs: summary WBS, contract WBS and project WBS.

WBS Dictionary and Coding: WBS dictionary, and coding of the elements.

WBS Dependent Activities: scope statement, budgeting, scheduling, control, responsibility assignment, and communication.

While the first three topics deal with the information about the WBS and the activities involved in its development, the fourth topic presents the interaction of the WBS with the other project management activities. 


\subsubsection{Considentions for the Procedure}

The procedure for providing information is based on three considerations:

1) Project managers' knowledge about the WBS area differs.

2) In future the information about the WBS should be accessed from within the development module of the prototype.

3) It may be required to view the information more than once.

Each project manager has a different level of knowledge of the WBS. One may know everything about the WBS but want an overview of one particular topic; the second may know a little about the WBS and may require detailed information about some specific WBS topics; and the third may not know much about the WBS and require information about all the topics and at all the levels of detail.

In order to meet all these requirements the procedure has to be flexible. This flexibility has been provided by eliminating the limitation of sequential access. Information about the WBS area is stored in a modular form. This makes it possible to get information about a topic without having to view information about another topic. Further the information about a topic can be viewed at either level of detail, overview or sub-topic, without having to view information at the other level of detail. Also, within the sub-topic level of detail, information about any sub-topic can be accessed without having to access information about the other sub-topics. In addition, it is also possible to view the information sequentially by moving between the topics and the sub-topics progressively.

This modular structure of the information is in accordance with future integration potential of the information module of the prototype rith the development module. 
Currently these modules are separate and the information about the various WBS topics cannot be accessed from within the development module.

The aim of the information module is to provide assistance to the project manager in understanding the WBS and its relationship with other project management activities. This assistance can be regarded as an extend form of the help function provided by some software packages. The effectiveness of this assistance would increase if the information could be accessed from within the development module. However, it would be cumbersome if all the information had to be viewed in order to view information about one topic. The modular structure eliminates this problem. The elimination of the limitation of sequential access is in keeping with the first two considerations. Moreover such an approach will make it possible to obtain context sensitive help from within the development module.

Further, a project manager may require access to the same information more than once. This has been taken into account while developing the procedure and any information can be accessed as many times as required. This aspect of accessing the same information any number of times presents more flexibility as it allows the user to proceed to any topic regardless of whether or not it has already been accessed.

\subsubsection{A Procedure}

The procedure described below shows how the information about the various topics and the sub-topics can be accessed. This procedure is part of the overall procedure which allows access to the two modules, information and development.

At the onset, a menu (Figure 1a) is presented from which one of the three options can be selected. The first two options facilitate access to the two modules, information and development, while the third allows exit from the system. Since this section pertains to the 
information module it is assumed that the Information Module option has been selected. After the selection, the topic about which information is required has to be chosen (Figure 1b) followed by the selection of the level of detail (Figure 1c). In addition to the two levels of detail, Overview and Subtopics, two other selections, Other Topics and Quit can be made from this menu.

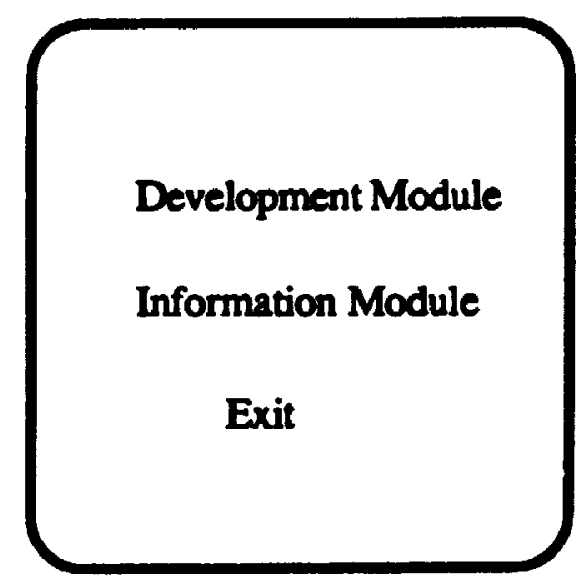

a: Main menu

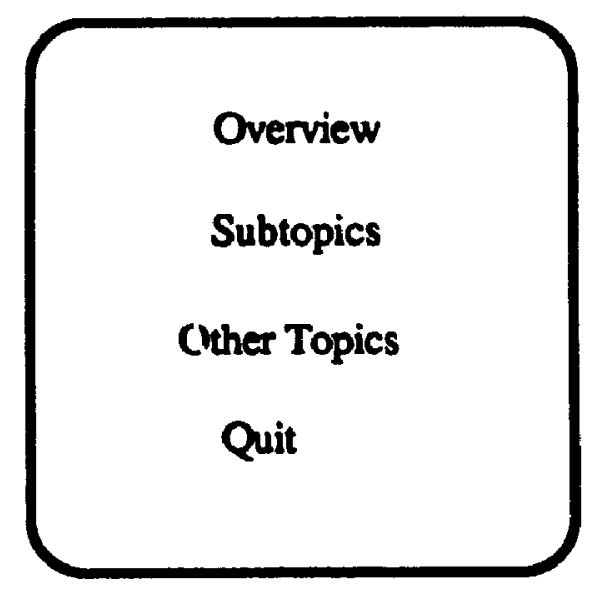

c: Level of detail
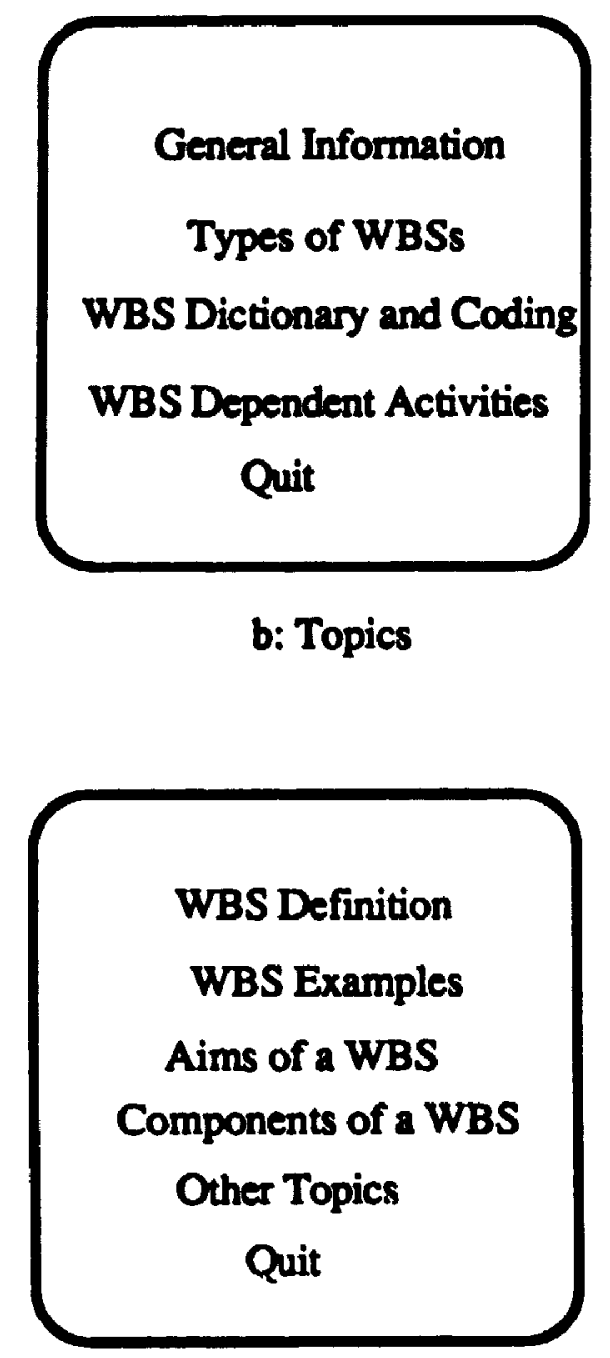

d: General information

Figure 1: Menus 
If Overview is selecied, a topic overview is presented and the sume menu (Figure 1c) is presented again. As before, any one of the four selections can be made. If Sublopic is selected, another menu, listing all the subtopics along with options to view information about other topics or to quit, is presented. For instance, the topic General WBS Information (Figure 1d) has the following sub-topics: WBS Definition, WBS examples, Aims of a WBS and Components of a WBS. Any one of these subtopics can be selected and the information viewed. After the information has been viewed the same menu (Figure 1d), is presented again. It is possible to select another subtopic or select one of the other options.

If the Other Topics option is selected, the topic menu (Figure 1b) is presented again and any topic can be selected ani the information presented in the same manner as before. Quit results in exiting the information module. The main menu (Figure 1a) is presented once again, and any one of the options can be selected.

\subsection{Development}

This section consists of three other sub-sections dealing with the structuring of the WBS; an approach to manipulating WBSs; and finally the presentation of an alternate approach.

\subsubsection{WBS Structuring}

The WBS standards were analyzed. Based on this analysis, it was concluded that for providing support, WBS development has to be classified into two parts. Part one, the development of the Equipment Breakdown Structure (EBS), includes the hardware and software required for the product being developed, e.g., the wings and the engine would be components of an aircraft EBS. The second part, the Support Work Breakdown 
Structure (Support WBS), includes the supporting activities required for the product, e.g., training for maintaining and operating the engine would be a component of the support WBS.

This separation of EBS from the Support WBS is required because the support requirements for a product can only be determined once the components of the product being developed are known. The lowest level elements of the support WBSs are related to the EBS elements. This is because support is required for some EBS element, e.g., training for engine maintenance. Thus the procedure for WBS development consists of two subprocedures, one for developing the EBS and the other for developing the support WBS.

The classification of the WBS into an EBS and a support WBS may suggest that this approach can be used only for construction type projects. However, this is not necessarily the case. It can he used for any project which can be decomposed into a hierarchical structure, consisting of two parts which are related in the same way as the support WBS is related to the EBS.

\subsubsection{An Approach}

As stated in chapter 2, two sources of support, WBS development models/standards and experience, are available to the project manager to develop a WBS. To develop a WBS for a new project, a project manager has the following options:

1) Develop the WBS using past WBS development experience and the project requirements. The WBS would be structured based on the experience and the WBS would be built based on the project requirements .

2) Develop the WBS using the WBS(s) of one or more related projects or WBS development standards, as reference. The reference WBS(s) would help to structure 
the new WBS while also providing elements which are common to the new project. This approach would be used primarily by inexperienced project managen.

In both approaches the WBS is structured first and then developed according to the project requirements. Both approaches have their advantages. The advantages of the first approach are obvious - there is no substitute for experience in project management. The second approach allows an inexperienced project manager to use the experience of experienced project maragers in structuring the WBS. It also facilitates the use of some of the elements common to the reference WBS and the undertaken project to develop the new WBS. Further, experienced managers can develop WBSs more efficiently reusing parts of the old WBS. Thus, the second approach is indispensable for inexperienced managers and useful for experienced managers.

The second approach has been used in the development module of the prototype. This approach involves groupung or classifying projects and the components of the WBSs. Each class consists of mutually exclusive elements and a list of classes at the next lower level. The user chooses the class of projects or elements and then chooses one element from the class - all the elements in a class are mutually exclusive.

This approach assumes that analysis and classification of the cases is done by experts prior to the development of the databases. These classes are created based on the similarity of the projects. For instance, all aircraft would be stored in one class. This class could be further sub-classified contingent on the types of aircraft, e.g., military and commercial. The commercial aircraft class can be further sub-classified into private, regional and trans-Atlantic aircraft, while the military class can be sub-classified into fighters, bombers and reconnaissance aircraft. Thus all the projects undertaken to develop 
bomber aircraft would be stored under the class, Bomber (Figure 2). Similarly, all projects undertaken to develop regional aircraft are stored in the class, Regional.

\begin{tabular}{|c|l|c|}
\multicolumn{1}{r}{ Sub-class } & \multicolumn{1}{c|}{ Level 2} \\
\hline $\mathbf{B}$ & Bomber & AV \\
\hline $\mathbf{R}$ & Regional & AV \\
\hline
\end{tabular}

Figure 2: Aircraft class

These two classes are mutually exclusive for selection, i.e., while developing a WBS either class can be chosen. Based on the class selected the next element classes, which belong to this class, are presented. These classes are present under the title, LEVEL_N, where N represents the next lower level of the WBS. In Figure 2, there is only one element class which can be present in level 2. This is the AV class, AV is the short form for Air Vehicle.

The Air Vehicle (AV) class (Figure 3) consists of all the possible types of air vehicles for the various projects undertaken, all of which are mutually exclusive. Thus only one air vehicle can be selected.

\begin{tabular}{|c|c|c|c|c|c|c|c|}
\hline \multicolumn{3}{|r|}{ Sub-Class } & \multicolumn{3}{|c|}{ Level 3} & & \\
\hline AVB-1 & B & AIR VEHICLE - 1 & $\mathbf{A F}$ & PU & COM & FC & WD \\
\hline AVB-2 & B & AIR VEHICLE - 2 & $\mathbf{A F}$ & PU & COM & FC & WD \\
\hline AVR-1 & $\mathbf{R}$ & AIR VEHICLE - 1 & $\mathbf{A F}$ & PU & COM & & \\
\hline AVR-2 & $\mathbf{R}$ & AIR VEHICLE - 2 & $\mathbf{A F}$ & PU & $\infty O M$ & & \\
\hline
\end{tabular}

Figure 3: Air Vehicle class

Now assume that the new WBS being developed belongs to the Bomber class. After selecting the Bomber from the project class, the next element class, Air Vehicle, is presented for selection. Once selected, the types of air vehicles (Figure 3) which are present in the AV class are presented for selection. 
The AV class consists of two air vehicles belonging to the bomber class and two belonging to the regional class. The air vehicles belonging to the Regional class do not have elements belonging to the FC (Fire Control System) and the WD (Weapons Delivery) classes. This is because the elements in these classes are specific to the bombers. It should be noted that in a particular class, say Bomber Air Vehicle, these are no common elements.

Since Bomber was selected in the previous class, two types of air vehicles, AIR VEHICLE - 1 and AIR VEHICLE - 2 belonging to the bomber class would be presented for selection. Of these either can be selected. These in turn have element classes which are represented by AF (Airframe), PU (Propulsion Unit), COM (Communication), FC and WD. Assuming that AIR VEHICLE - 1 is selected, the five element classes Air Frame, Propulsion Unit, Communication, Fire Control and Weapons Delivery would then be presented for selection. Assuming that all are selected, the various types of components present in each class wouid then be presented for selection.

AIR VEHICLE - 1, represented by AVB - 1 (Figure 3), can have two types of propulsion units identified by PROPULSION UNIT - 1B, and PROPULSION UNIT - 2B (Figure 4). These two would be presented for selection and one can be selected. In the same way the elements belonging to the other two classes would be presented.

Addition from the other WBSs is facilitated in two ways. First, from within the class and second from the other classes. Adding from within the class refers to selecting the element from the class selected at the beginning. In the example presented above this would be the Bomber class. Adding from other classes refers to the classes other than the one selected - Regional, in the above example.

In the above example, the user selected AIR VEHICLE - 1 and then selected the five element classes associated with it. If AIR VEHICLE - 2 had some element class which 
was different from the ones associated with AIR VEHICLE - 1, the user, if he/she wanted, could select elements from that class. Since both the air vehicles belong to the same class, Bomber, this selection would be referred to as selecting from within the class.

While developing the WBS, the user may want to select elements from other classes, e.g., regional air vehicles. This too can be accomplished, and the user would be presented with the list of other air vehicle classes. In this case there is only one other air vehicle class, Regional. It can be selected in order to choose one of the regional air vehicles. This selection is referred to as selecting from other classes. In case some air vehicles in the regional aircraft class are common with those in the bomber class, they would not be presented for selection.

In addition to selecting the elements from other classes, additional classes can be entered using the keyboard. First the class name has to be entered and then the type of element which has been used in the class.

\begin{tabular}{|l|l|l|l|l|}
\multicolumn{5}{c}{ Sub-Class } \\
\hline PUB-1 & AVB-1 & PROPULSION UNT - 1B & E & TR \\
\hline PUB-2 & AVB-1 & PROPULSION UNIT - 2B & E & TR \\
\hline PUB-3 & AVB-2 & PROPULSION UNT - 3B & E & TR \\
\hline PUR-1 & AVR-2 & PROPULSION UNTT - 1R & E & TR \\
\hline
\end{tabular}

Figure 4: Propulsion Unit class

The lower levels are also developed in a similar manner. In this way the new WBS is developed using the previously developed WBSs. Though this approach is flexible and simple, it could not be implemented using the software available for computer implementation. As a result the alternate approach is presented. This approach has been implemented. 


\subsubsection{An Alremate Aporoach}

While the previous approach required the aggregation of projects and elements into classes, this approach does not. In this approach, specific WBS elements are presented to the user instead of element classes. Using this approach the user can develop a WBS in one of the two ways:

1) Use of one WBS as a reference to develop a new WBS, referred to as single manipulation.

2) Use of more than one reference WBS to develop a new WBS, referred to as multiple manipulation.

In multiple manipulation, first a primary WBS has to be selected followed by the selection of secondary WBSs. The primary WBS forms the main reference WBS which is used to structure the new WBS and also provide some of the components of the new WBS. The secondary WBSs increase the variety of elements available. For instance, to develop a WBS for an aircraft with movable wings, a WBS of a project to develop a fixed wing aircraft may be selected as the primary WBS and that of a project to develop movable wings may be the secondary WBS. The structure of the new WBS would be based on the primary WBS. The components would be drawn from both the WBSs. The new WBS would not contain the fixed wings and its components from the primary WBS but the movable wings and its components from the secondary WBS.

In order to manipulate the various WBSs, relationships have to be established between the elements of the WBSs. For instance, in the above illustration, it would have to be established that the two types of wings are mutually exclusive. This would ensure that only one type of a wing is added to the new WBS. While maninulating the WBSs, the relationships of the elements of the secondary WBSs have to be considered with respect to 
the primary WBS. This is because the primary WBS is assumed to be most closely related to the new WBS and thus provides the structure for it and also most of the components.

Since relationships must be established, multiple manipulation is more complex than the single manipulation, where relationships do not have to be established because only one WBS is used to develop a new WBS. The complexity in multiple manipulation arises because the elements in the various secondary WBSs can have two possible relationships with those in the primary WBS:

1) In the new WBS, some of the secondary WBS elements can be added as parts of a system which has been added from the primary WBS.

2) Some elements may be mutually exclusive with those in the primary WBS. Of these mutually exclusive elements only one can be added to the new WBS.

The manipulation is not very complicated if there is only one secondary WBS. The relationships are easily determined. Consider a simple example. Two WBSs, $X$ and $Y$ (Figure $i)$ are used to develop a new WBS. $X$ is the primary WBS and $Y$ is the secondary WBS. In this case, the relationship of the elements in WBS Y have to be determined with respect to those in WBS X. y2 is mutually exclusive to $x 2$ and y11 can be added to $x 1$, if $x 1$ is present in the new WBS. These relationships are simple and clear.

However, now consider another secondary WBS Z (Figure 5c). The element 22 can also be added to $x 1$ too, but, y11 and 22 are mutually exclusive. Thus in this case, in order to ensure logical development of the WBS it is necessary to determine not only relationships of the elements in the secondary WBSs with those in the primary WBS, but also the relationships among the elements in the secondary WBSs themselves.

The complication is compounded when elements from the secondary WBSs are added to the new WBS. This is because earlier the relationships of the elements of the 
secondary WBSs were determined with respect to the elements in the primary WBS, i.e., which elements are additive to the elements in the primary WBS and which are

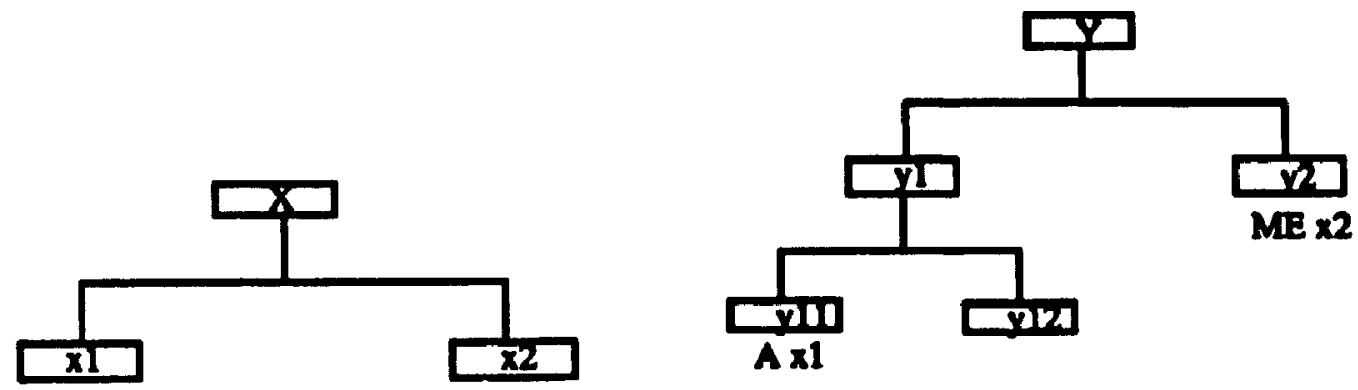

a: WBS X

b: WBS Y

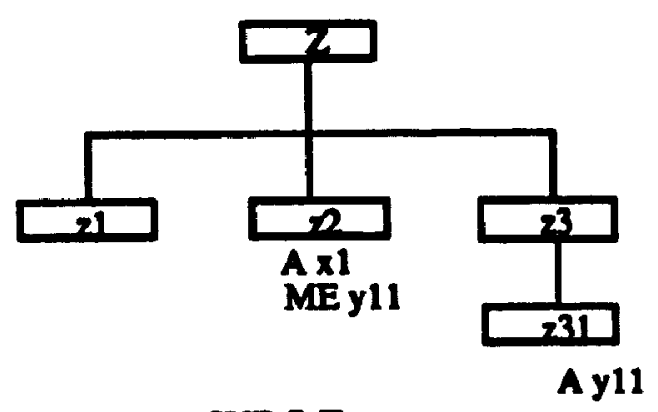

c: WBS Z

Figure 5: Relationships between elements

mutually exclusive. But after the addition of the element from the secondary WBS, the relationships of the elements of the primary and the other secondary WBSs vis-a-vis the added element must be determined. In a sense, the WBS from which the element has been added becomes the primary WBS. For instance, if $y 11$ is added to the new WBS under $x 1$, then to develop the next level, the elements have to be selected from the secondary and the primary WBS based up: heir relationships with y11. Only then would it be possible to consider 231 , for addition under y11 ( $231 \mathrm{can}$ be added to y11).

The number of relationships, and thus the complexity, increases with the number of secondary WBSs being used. This poses a question: Is the time spent in determining the relationships of the various elements between the WBSs worth the benefits which may 
result from it? Further, as new WBSs are added to the database, the relationships of the elements of all the WBSs vis-a-vis the elements of the new WBS must be determined.

To overcome this complexity certain restrictions can be imposed. The number of WBSs used in any one manipulation can be restricted to 2-3. Further, fixed groups can be formed for manipulation. For instance, if there are five WBSs, A, B, C, D and E in the databases, then to limit the number of relationships, two groups consisting of three WBSs each, e.g., A, B, and C and B, D and E, can be formed. In this case relationships between the elements of all the WBS do not have to be determined. However, these restrictions reduce the flexibility of the approach.

\subsubsection{Procedures}

The procedures for developing the EBS and the support WBS are presented below: The procedure for developing the EBS has to take into account the fact that the number of levels in the WBSs for various projects differ. It is assumed that the number of levels in the new WBS would depend on the number of levels in the reference WBS, in single manipulation, and on the number of levels in the primary reference WBS, in multiple manipulation. Thus, at the beginning the number of levels present in the (primary) reference WBS has to be determined. Level 1 is always the name of the project, level 2 includes the major subsystems and each subsequent level contains elements at a greater degree of detail.

There is a difference between multiple manipulation and single manipulation procedures. In the former, the elements presented for selection belong to more than one EBSs and selection between mutually exclusive elements, if any, may be required. Further EBS elements from the secondary WBSs can also be added. In the latter, the elements presented belong to one WBS and there are no mutually exclusive or additive elements. 
Thus the procedure for developing the EBS consists of two procedures, one for developing the EBS using single manipulation, and the other using multiple manipulation. These two procedures are presented separately.

\section{Single Manipulation:}

At the onset, the WBS being developed has to be named. The name forms the fint level of the WBS. Next, a choice has to be made between single and multiple manipulation. Assuming that the former is chosen, a list of the projects is presented from which one project which relates to the undertaken project has to be selected.

Once the project has been named and the related project is chosen for manipulation, the second level has to be developed. Elements belonging to the second level are retrieved from the database and presented to the user for selection. The user has the option to select none, some or all the elements. If the elements are selected they are added to the database. Next, the user has the option to add additional elements, if required, or move to the next step. If the first option is accepted, additional elements are entered by the user and added by the system to the database as the second level elements. However, if none of the retrieved elements were selected, the user has the option to enter the elements using the keyboard. If the option is accepted, the elements can be entered and added to the database. Else development of the next level commences.

The next level is also developed in a similar manner. If additional level 2 elements had been added in the previous step, the user has the option to add level three elements for them. In this manner all the levels are developed. 


\section{Multiple Manipulation:}

If instead of selecting single manipulation multiple manipulation is selected, first the primary WBS has to be chosen, and subsequently the secondary WBSs. The primary WBS forms the reference WBS which is adapted by deleting and adding additional elements. These additional elements added to the new WBS may either belong to the secondary WBSs or may be added externally, i.e., by the user.

Once the related WBS(s) have been chosen for manipulation, the second level has to be developed. Elements belonging to the second level are retrieved from the database and presented to the user for selection in two steps. First, the mutually exclusive elements are retrieved from the primary and the secondary WBSs and presented for selfection. The user can select only one of these elements. The selected element is then added to the database. Once all the mutually exclusive elements have been retrieved and presented for selection, the second level elements, in the primary WBS, which are not mutually exclusive, are retrieved along with the elements from the secondary WBSs which can be added to the second level. The user has the option to select none, some or all of the retrieved elements. Once the elements are selected, the user has two options: one, to add additional elements if required and, two, to move to the next step. If the first option is accepted, additional elements are entered by the user and are added to the database as the second level elements. If none of the retrieved elements were selected, the user again has the option to enter the elements using the keyboard. If the option is accepted, the elements can be entered and added to the database, otherwise the development of the next level commences.

The next level is also developed in the similar manner. If additional level 2 elements had been added in the previous step, then the user has the option to add level three elements for them. In this manner all tine levels are developed. 
Once the EBS has been developed, the support WBS has to developed. To a large extent this is developed without the user's interference. The system developt this on the basis of the EBS elements added to the new EBS. For each EBS element added to the new EBS it looks up in the primary and secondary support WBSs to determine the support that may be required. The support WBSs consists of the support activities along with the EBS element for which they are required. The EBS element is always related to the element in the lowest level of the support WBS. If found, the support elements are added to the new support WBS. Further, the higher level elements are also added. For instance, the support for the EBS element may be present in level 3. In such a case, the level 2 element, to which the level three element belongs, also has to be added to the new support WBS.

For the EBS elements which were entered externally, it is possible to add the support elements present in the database. In addition, it is also possible to input additional support, i.e., those support elements not present in the system, for : 1) all the EBS elements; 2) only those EBS elements input earlier using the keyboard ; or 3) only those EBS elements selected from within the system. If additional support elements are added, the appropriate EBS elements are presented for which the supporting activities can be added. In this manner the support WBS is developed. Once the support WBS has been developed, the entire WBS is displayed. 


\section{Chapter 5: Integration of Technology}

The procedures for providing assistance in the two areas, information and development, were discussed in chapter 4. This chapter cites the technological requirements for the support being developed. The main functions of the support are, first, to provide information about WBS fundamentals and dependent activities; and second, to assist in the actual WBS development. Given the functions, the support requires the integration of two different types of technologies: database management systems (DBMS) and expert systems (ES). This section partially addresses the third research question by citing the technologies which would be used to develop the prototype.

\subsection{Database and Expert System Technologies}

Integration of technology to increase productivity has been an ongoing process. The recent, and related to this work, example is the development of expert database systems (EDS) which are expected to be one of the most important application products by the 1990s (Smith 1986). EDS is the integration of an expert system with a database management system (DBMS) aimed at automatic analysis and synthesis of the information stored in large databases. In the prototype too these two technologies are integrated and are therefore briefly discussed below:

Expert Systems: An expert system is considered to be intelligent software capable of simulating human decision making (Lin 1986). It uses "knowledge and inference procedures to solve problems that are difficult enough to require significant human expertise for their solution" (Harmon and King 1985).

An expert system consists of two parts. The first is the knowledge base (which consists of predicates and relations between them) and the working memory. The second 
consists of the inference engine, knowledge acquisition and explanation subsystems and the user interfaces (Harmon and King 1985). Expert systems are usually rule based (Forsyth 1984; Lin 1986) and consist of a number of rules of the form, IF <<antecedent〉>THEN 《consequent〉> [ELSE «<consequent»)]. For example, a statement, "For the WBS to be developed the equipment breakdown structure (EBS) and the support WBS have to be developed" can be represented by the following rule:

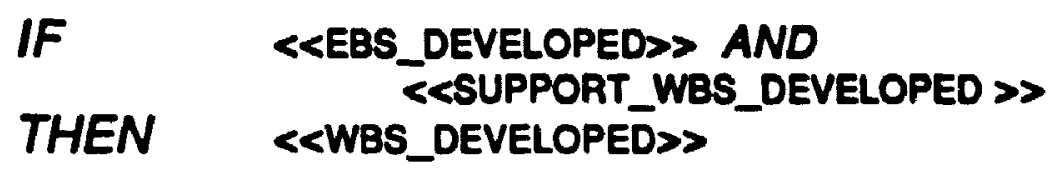

The most common inferencing strategy used in expert systems is modus ponens (Harmon and King 1985; Turban 1988). Modus ponens states that if $X$ is true and a rule states, "If $X$ then $Y$ ", then it can be concluded that $Y$ is true. To be effective, inferencing has to be controlled. This control can be provided by two control strategies, backward chaining and forward chaining. Backward chaining refers to tracing the solution from the goal down to the facts. Forward chaining, on the other hand, refers to tracing the solution from the fact level. While the former is effective only when the possible outcomes are known and are reasonably small in number, the latter is used when the number of outcomes is large and the solution needs to be constructed. In some cases both strategies are used to provide greater flexibility.

Database Management System; A data base management system is software used to create and update databases (Ostie 1985). It performs three main functions: 1) facilitates storage of data in databases; 2) facilitates retrieval of data from the databases; and 3) controls the databases, e.g., provides data security and prevents unauthorized access (Turban 1988).

The expert system component of the EDS performs intelligent processing on the data stored in the databases. It also provides three other functions: "How", "Why" and 
"Help". An important feature of expert systems is their ability to provide explanations for the advice/decision provided. This is done by the "How" function. "Why" allows the user to query the system as to why it needs the information for which the user has been prompted. "Help" provides assistance to the user - 2 user, if uncertain of what action to perform, can get assistance by using this function. The DBMS component of the EDS facilitates the manipulation of the data in the databases.

An implemented example of the use of integrated database and expert system technologies can be seen at the Mutual Life Insurance Co. of New York (Popolizio and Cappelli 1989) The system, Comprehensive Life Insurance Underwriting Expert System (CLUES) is used to approve insurance cases. The applications are entered into the New Business System (NBS), a conventional transaction processing system. Depending on the requirements, data is accessed from data files. Once the data has been retrieved from the files it is sent to the knowledge base which assesses the application viability and approves the application. $40 \%$ of the applications are approved by the system immediately and a release message is sent to the conventional system, NBS, which carries out a number of transactions such as sending a message to the local agency which sent the application, that the case has been approved. In cases where immediate approval is not sent, the cases are assigned to the respective underwriters. The underwriters have the option to override CLUES decision if a case is rejected. In cases where more information is required the case is added to the pending file and the local agents are asked for the additional information. $A$ similar approach of integrating database management and expert system technologies has been used to provide assistance in the development of a WBS. 


\subsection{The Approach}

Complete support for WBS development consists of support for two areas, i.e., providing information and assisting in the development. The support is provided to both the areas by their respective modules. The module which provides the information is referred to as the Information module and the one providing assistance for WBS development is referred to as the Development module.

The approach used in the development module is partially similar to that of an EDS. The development module requires the integration of expert system and database management technologies. The expert system component provides the "How", "Why" and "Help" functions to give a user the ability to determine the strategy undertaken in developing the WBS. However, unlike an EDS the knowledge base of the development module does not consist of heuristics and facts. Rather it consists of the rules used in the development of a WBS and in relating the existing WBSs stored in the databases to the new WBS. The knowledge base consists of rules which guide the user, retrieve the required data, and control the development of a new WBS. The major strength of the system lies in the WBSs which are stored in the databases rather than in the knowledge base.

The development module also has some characteristics similar to those of a decision support system. A decision support system can be considered as a combination of three modules (Reimann 1985; Turban 1988): (1) Database; (2) Model Base; and (3) Interface. The database consists of the data required for any area, e.g., financial data. This data is manipulated by the models/procedures, e.g., financial models, which are stored in the model base. Finally the interface is the combination of hardware and software which allows the user to communicate with the DSS (Turban 1988). Similarly, the WBSs are stored in the databases and manipulated by the WBS development procedures stored in the 
model/knowledge base. The function of the development module, too, is like that of a DSS - to support the user and to provide assistance for resolving semi-structured problems. Further, the ultimate decision is also made by the user.

The development module is not an ES, EDS or a DSS but has characteristics common to both the areas for the following reasons: An ES or an EDS assists in the resolution of problems in a narrow and a well defined domain. WBS development does not fulfill either criteria. First, the domain is not narrow because each project, to a large extent, is different from the rest. Second, as stated earlier, WBS development is a modelling problem. Thus the expert system would require a procedure to develop models, which, thus far, is not feasible. On the other hand a DSS would not be as effective as the proposed system, because it would lack the expert system component.

The second part of the support, the information module, has characteristics similar to computer assisted leaming (CAL). CAL is defined as an interactive dialogue between the computer and the student, under the control of the teaching program written in any of the CAL languages like TUTOR, PILT etc. (Beech 1983). The support developed has two characteristics similar to those of CAL. These are: first, to disseminate information; and second, to provide on-demand information. This pertains to the portion of the support which provides information about WBS fundamentals and dependent activities.

\subsection{Prototype Architecture}

The architecture of the prototype is a set of the systems elements (procedures, databases and knowledge bases) and their relationships. It is displayed in Figure 6. The functions of the element" depicted in Figure 6 are discussed below. 


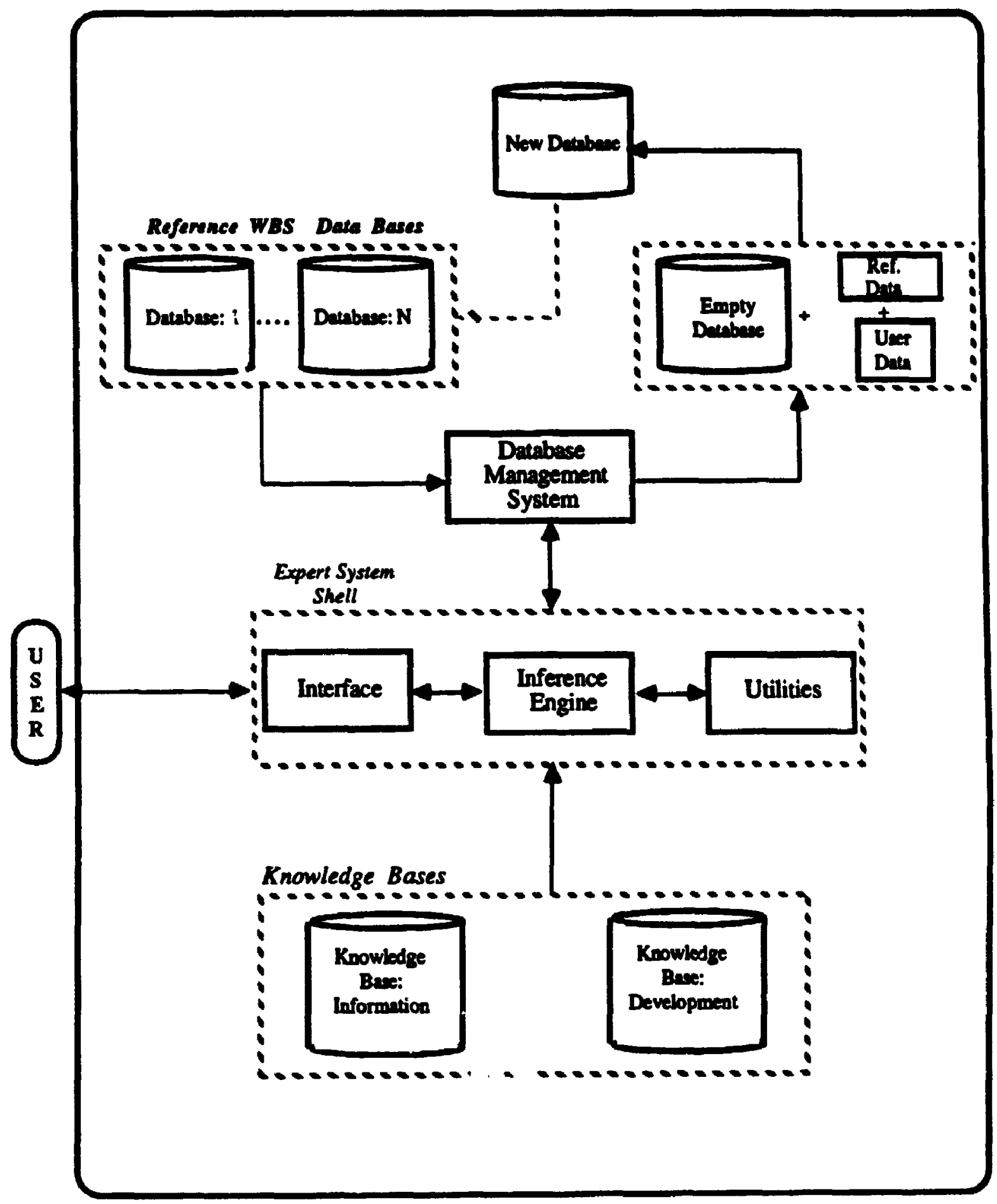

Figure 6: Architecture of the prototype 
The information about the WBS fundamentals and dependent activities is stored in the fint knowledge base, "Knowledge Base: Information". The user can access any information that is present in this knowledge base through the expert system shell. The "Knowledge Base: Development" contains information required to access and manipulate the WBS standards which are stored in the databases. The databases are represented by "Reference WBS Databases". The user interacts with the system by the "Expert System Shell". The access of information and manipulation of WBSs is done with the help of the interface, the inference engine and utilities of the expert system shell. While accessing information about the WBS fundamentals and dependent activities, based on the user requirements, some rules are initiated in the "Knowledge Base: Information", and the information is presented to the user. Similarly, while developing the WBS, based on the requirements of the user, rules in the "Knowledge Base: Development" are initiated, which result in the expert system shell making a call io the "Database Management System" to retrieve some specified data. This data is retrieved from the "Reference WBS Databases" and sent to the "Expert System Shell" which presents it to the user for selection. The selected data is sent to the "Database Management System" through the "Expert System Shell" to be added to the "Empty Database". Additional elements can be added to the WBS in a similar way. In this manner, during a session, a user can build a customized WBS based on the WBS(s) from the "Reference WBS Databases". This customized WBS is stored in a separate database, "New Database" and consists of some data from the "Reference WBS Databases" and the rest input by the user ("Ref. Data" and "User Data" in Figure 6).

The "New Database" can be added to the "Reference WBS Databases" (indicated by the shaded line in Figure 6) and used as a reference for future WBS development. All the databases in the "Reference WBS Databases" can be edited and/or deleted with an appropriate DBMS. It is assumed that the WBSs stored in the reference databases are 
developed and maintained by experts and new WBSs are not added until they have been approved. 


\section{Chapter 6: Representation}

The procedures and the technologies to be used were discussed in chapters 4 and 5, respectively. These procedures are modeled using data and symbolic models so as to implement them using the technologies discussed earlier. This chapter presents the data models and the symbolic models used. The former are used to develop the databases and the latter to develop the knowledge bases. Part of the third research question which was not addressed by chapter 5 is addressed, showing how the procedures can be modeled for implementation.

\subsection{Data Models}

A WBS is composed of hardware, software, and services required to accomplish a project. These components can be stored in a database. In order to develop databases, the data models have to be developed based on the following considerations:

(1) A WBS is always developed in terms of the hardware, software and services (Stuckenbruck 1981b).

(2) Elements can be added to WBSs as long as they do not disturb the logical flow of the WBS.

(3) Two mutually exclusive elements cannot be added to the new WBS.

The first consideration is derived from the literature. The second consideration ensures that a WBS is indeed a conceptual model of the project and therefore should represent the project as closely as possible. The elements in a lower level should relate to those in the next higher level in a logical manner. For instance, it would not be possible to add wings to the wheels of the aircraft as a logical relationship between the two does not exist. 
The third consideration is a result of the case/example based approach used and is required for computer manipulations. The new WBS is developed by extracting datn from other WBSs and also by entering data externally. In such a situation it is quite possible to add certain elements to the WBS which would make it look unrealistic. For example, the addition of both fixed and movable wings from two WBSs, to a newly developed aircraft WBS should be prohibited since such types of elements are mutually exclusive. Thus while developing a new WBS it has to be ensured that mutually exclusive elements are not added. On the other hand as many complementary elements as possible should be considered.

Due to the nature of the problem, two types of data models, hierarchical and network (McFadden and Hoffer 1988), could be used. The former could be used for modelling the EBS, while the latter could be used for modelling the support WBS. A hierarchical data model is characterized by a set containing two classes of elements, the owner and the member. An owner element can have any number of member elements but a member element can have only one owner (McFadden and Hoffer 1988). This model is applicable because the EBS elements in a level $\mathrm{n}$, can have any number of member elements in level $n+1$, but these $n+1$ level elements can belong only to one element in level $n$.

In the network model a member element can have more than one owner element (McFadden and Hoffer 1988). This suits the requirements for the support WBS because an EBS element (member element) can have more than one supportive requirement (owner element). However, because most of the existing DBMSs are relational or relational like, in the sense that the databases are built with a flat file structure, this type of structure is used to model the data. Separate data models have been developed for both EBS and the support WBS. 


\subsubsection{EBS DataModel}

In the EBS file the elements have six attributes: LEVEL, CODE, NAME, PART OF, CHARACTERISTIC and ELEMENT. The first four attributes describe the relationship between the EBS elements within the database, while the other two represent the relationship of these EBS elements with those in other EBSs.

LEVEL represents the level at which the element is present in the EBS. CODE provides a unique identification for an element in the EBS. NAME represents the name of the element. The PART OF attribute identifies the owner element to which a membsr elements belong. For instance, in Figure 7 the element, AR VEHICLE, (code AV) belongs to AIRCRAFT SYSTEM - 1 identified in the PART OF column by AS-1.

In simple manipulation the relationships of the elements in one EBS do not have to be established with those in other EBSs. However, they have to be established during multiple manipulation. In multiple manipulation, the relationships of the elements in the secondary EBSs are considered with respect to the elements in the primary EBS.

Each element in a secondary EBS can have one of the three relationships with those in the primary:

1) An element in the secondary EBS may be the same as one in the primary EBS.

2) Others may be mutually exclusive with some other elements in the primary.

3) Finally, an element from the secondary EBSs can be added to the new EBS. Such an element can be added as a part of a system or subsystem which was added from the primary EBS.

The first relationship indicates that, since the same elements are present in the secondary and primary EBSs, either could be presented to the user for selection and added 
to the EBS being developed. This is a special case of the second relationship, mutual exclusivity.

The second relationship is required to prevent the addition of mutually exclusive elements. In such a situation, all the elements which are mutually exclusive with one another have to be presented together for selection. Of these, the user can select only one element for addition to the new EBS.

Finally, the third relationship signifies a situation where additional components can be added as parts of a system/sub-system present in the EBS being developed. These components, along with the original components present in the primary EBS, must be presented for selection. Of these, the user can choose one or more for addition to the new EBS.

It may seem that while developing the databases, only the relationships of the elements in the secondary EBSs have to be established with those in the primary EBSs. This is not so. First, there are no permanent primary and secondary EBSs. Depending on the situation an EBS may be primary during one manipulation and secondary during another. Second, as stated in chapter 4, after an element has been added to the new EBS from a secondary EBS, its member elements would be present in that secondary EBS. To develop the next level, the relationships of the elements in the primary and the other secondary EBSs have to be considered with respect to these member elements. Therefore, in all the EBS databases, the relationships of the elements have to be established with all other EBS elements in order to ensure that the appropriate elements are presented for selection.

The function of ensuring that only the appropriate elements are presented for selection is controlled by the attribute, CHARACTERISTIC, represented by CHAR. EBS 
elements can have one of the three CHARACTERISTIC values: same, add, or mutually cxclusive, represented by S, A and ME respectively.

The attribute CHAR describes the type of relationship the EBS element has with elements in other EBSs. These elements, represented by their codes, with which the relationships are determined, are present under the ELEMENT attribute, represented by ELEM.

\begin{tabular}{|c|c|c|c|c|c|}
\hline LEVEL & CODE & NAME & PART OF & CHAR & ELEM \\
\hline 1 & AS-1 & ARCRAFT SYSTEM - AS1 & & & \\
\hline 2 & AV & AIR VEHICLE & AS-1 & S & AV \\
\hline 3 & AF & ARFRAME & AV & S & AF \\
\hline 3 & WD & WEAPONS DEIIVERY & AV & A & AV \\
\hline
\end{tabular}

Figure 7: EBS related to one other EBS.

Figure 7 displays the EBS for a project, ARCRAFT SYSTEM - 1, represented by AS1. It can be seen that the three elements, AIR VEHICLE, AIRFRAME and WEAPONS DELIVERY, are related to two other elements, represented by $A V$ and AF, present under the ELEM attribute. The AR VEHICLE is the same as the one in the other project and so is the airframe. However, the WEAPONS DELIVERY system can be added to the air vehicle of the other project.

This representation is appropriate if there is only one other EBS present in the databases to which the elements of AS-1 are related. In case there is more than one EBS present, it is necessary to specify the name of the EBS to which the characteristic values apply. This is illustrated in Figure 8. The name of the project is added on top of the CHARACTERISTIC and ELEMENT attributes to indicate that the relationship is established with elements belonging to a specific project. 


\begin{tabular}{|c|c|c|c|c|c|}
\hline LEVEU & CODE & NAME & PART OF & \multicolumn{2}{|c|}{ CHSE2 } \\
\hline 1 & AS-1 & ARCRAFT SYSTEM - AS1 & & & \\
\hline 2 & AV & AIR VEHCLE & AS-1 & S & AV \\
\hline 3 & AF & ARFRAME & AV & S & AP \\
\hline 3 & WD & WEAFONS DELIVERY & AV & A & AV \\
\hline
\end{tabular}

Figure 8: EBS related to one spocific EBS.

The representation given in Figure 8, still has a shortcoming. It assumes a 1:1 relationship. That is, it assumes that the elements in one EBS can be related to those in one other EBS only. It is possible for elements in one EBS to be related to elements in more than one EBS and these relationships may be different. For instance the Air Vehicle in one EBS can be related to Air Vehicles in two different EBSs. Further, in one case the Air Vehicles may be exactly the same, while in the other they may be different and thus mutually exclusive.

\begin{tabular}{|c|c|c|c|c|c|c|c|}
\hline LEVEU & CODE & NAME & \multirow{2}{*}{ PART OF } & \multicolumn{2}{|c|}{ AS-2 } & \multicolumn{2}{|c|}{ MS-1 } \\
\hline 1 & AS-1 & AIRCRAFT SYSTEM - AS1 & & & & & \\
\hline 2 & AV & AIR VEHICLE & AS-1 & S & AV & ME & AV \\
\hline 3 & AF & AIRFRAME & AV & S & AF & & \\
\hline 3 & WD & WEAPONS DELIVERY & AV & A & AV & & \\
\hline
\end{tabular}

Figure 9: EBS related to two specific EBSs.

In order to accommodate the different characteristic values for the elements in different EBSs, there have to be as many pairs of CHAR and ELEM columns as the number of elements to which an element is related. For instance, Air Vehicle (Figure 9) may be related to two other Air Vehicles, one in the EBS for an aircraft project, AS-2, and the other in a missile project, MS-1. 
Compare Figures 8 and 9. The columns added result in development of an unnormalized data model. This unnormalized model has to be normalized in order to reduce it to a set of simple relations. A normalized model (third normal form) is presented below:

\begin{tabular}{|c|l|l|l|}
\hline LEVEL & CODE & NAME & PART OF \\
\hline 1 & AS-1 & ARCRAFT SYSTEM & \\
\hline 2 & AV & ARR VEHICLE & AS-1 \\
\hline 3 & AE & ARFRAME & AV \\
\hline 3 & WD & WEAPONS DELIVERY & AV \\
\hline
\end{tabular}

\begin{tabular}{|c|c|c|c|}
\hline CODE & CHAR & ELEM & PROJECT \\
\hline AV & $S$ & $A V$ & $A S-2$ \\
\hline$A V$ & $M E$ & $A V$ & $M S-1$ \\
\hline $\mathbf{W D}$ & $A$ & $A V$ & $A S-2$ \\
\hline
\end{tabular}

Figure 10 : Normalized model

\subsubsection{Suppon WBS Data Model}

The first four attributes of the support WBS data model are the same as those of the EBS data model. However, instead of using the CHARACTERISTIC and the ELEMENT attributes another attribute, EBS ELEMENT, represented by EBS ELEM, is used. EBS ELEMENT contains the EBS elements, represented by their codes, for which the suppert activities/equipment is required. In the model presented in Figure 11, ENGINEERING DATA is required for AIR VEHICLE and WEAPONS DELIVERY represented by AV and WD respectively, and DITIAL SPARE PARTS are required for the AIRFRAME and WEAPONS DELIVERY, represented by AF and WD respectively.

This model does not require the CHARACTERISTIC and the ELEMENT attributes since its development is based on the development of the EBS. Once the EBS has been developed, the system searches in the EBS ELEMENT column of all the support WBSs, if multiple manipulation has been used, or one support WBS, if single manipulation has been used, for elements which match those in the EBS. If they are found, all the values of the attributes LEVEL, CODE, NAME, PART OF and EBS ELEM are added to the new support WBS. Further, since the ERS elements are related to the lowest support WBS elements, the 
higher level elements of the support WBS must also be added to the new support WBS. For instance, if the new EBS developed contains AV then since AV is present in the BBS ELEMENT Column, ENONEERINO DATA and the other values associated with it would be added to the new support WBS. However, ENONEERINO DATA belongs to DATA. Thus DATA along with its associated values would also be added to the support WBS. Similar operations would be performed for each of the other elements.

\begin{tabular}{|c|c|c|c|c|}
\hline LEVEL & CODE & NAME & PART OF & EBS ELEM \\
\hline 2 & D & DATA & AS-1 & \\
\hline 3 & ED-1 & ENGINEERNNG DATA - 1 & D & AV \\
\hline 3 & ED-2 & ENGINEERING DATA - 2 & D & WD \\
\hline 2 & ISP-1 & NITIAL SPARE PARTS - 1 & AS-1 & AF \\
\hline 2 & ISP-2 & INITIAL SPARE PARTS - 2 & AS-1 & WD \\
\hline
\end{tabular}

Figure 11: Data model - Support WBS

\subsection{Rule-Based Representation}

Rule based formalism is used to represent both the problem of development of a WBS and the provision of the information. In each case, the problem can be decomposed into a hierarchical structure composed of goals and sub-goals. For the WBS development problem, at the top of the hierarchy is the goal describing successful development of the WBS. This goal is decomposed into sub-goals describing aggregate activities required to achieve the goal, down to the detailed activities level. For the provision of information, the goal is the successful provision of the required information, the sub-goals are the topics, decomposed into the degree of detail, down to the subtopic level.

Predicate calculus (Harmon and King 1985) has been used to represent the problem structure. The primary reason for using predicate calculus is that it provides flexibility to store complex qualitative information. Further, while predicate calculus is one of the ways 
of representing the information in a knowledge base, logic programming (predicate calculus is used for logic programming) is expected to outline the future of databases. The interface between logic programming and databases is regarded as an important aspect of the confluence of the information sciences (Parker et al.1986). Since a part of this research integrates expert system and DBMS technologies, using predicate calculus for representation does appear appropriate.

The basic unit in prerlicate calculus is an object. The statement about the object is the predicate. For instance, apple is red is an assertion that the apple, the object, is red; is red being the predicate. Using predicate calculus, it can be represented as RED(APPLE). Similarly LEVEL_2(AIR_VEHICLE) is an assertion that AIR_VEHICLE belongs to LEVEL_2. Generalizing, this can be written as LEVEL_2( $x)$, where $X$ is a variable. The generalized expression states that all $X$ belong to LEVEL_ 2 .

Predicates can address more than one object. For example,

BELONG_TO(AIRFRAME, AR_VEHICLE)

states that AIRFRAME belongs to AIR_VEHICLE. It is possible to be more specific by identifying the location of the AIRFRAME and the AIR_VEHICLE. This is represented by,

BELONG_TO(LEVEL_3(AIRFRAME), LEVEL_2(AIR_VEHICLE)).

This states that the AIRFRAME, which is in LEVEL_3, belongs to AIR VEHICLE, which is in LEVEL_2. Together, the predicate and the object(s) form an assertion or a proposition which, in two valued logic, can either be TRUE or FALSE (Harr.1on and King 1985; Copi 1973).

BELONG_TO(LEVEL_3 $(X)$, LEVEL_2( $Y)$ ) is a generalized expression of BELONG_TO(LEVEL_3(AIRFRAME), LEVEL_2(AIR_VEHICLE)). It states that all $x$ in LEVEL_3 belong to $Y$ in LEVEL_2. $X$ and $Y$ are variables. Together, the predicate and the 
variables are referred to as 'propositional functions' (Copi 1973). A propositional function becomes a proposition by substituting the variable by a value. This substitution is roferned to as instantiation (Copi 1973).

In some cases the variable may represent a list of values, e.8., $X=\left\{X_{1}, X_{2} \ldots X_{N}\right\}$. In a propositional function this can be represented as,

$$
\text { BELONG_TO(LEVEL_3( } x) \text {, LEVEL_2( }(n)
$$

where $X$ is a list belonging to a variable $Y$. Both the list and the variable are instantiated by values.

Consider the following example. AIR_VEHICLE may have three values, AIRFRAME, PROPULSION_UNIT and FIRE_CONTROL, belonging to it. Using the above stated representation, this can be represented as, BELONG_TO(LEVEL_3(PROPULSION_UNIT, AIRFRAME, FIRE_CONTROL), LEVEL_2(AIR_VEHICLE)).

The variables/lists are instantiated by values (symbols) belonging to certain domains. The difference in domains is represented by the different predicates. The two propositional functions, LEVEL_2( $T)$ and LEVEL_3( $T)$ are different because their predicates are different, and thus the variables would be instantiated by values from two different domains. In the development module, these values can either be present in the database or input by the user. The new WBS being developed has some elements which belong to the WBSs in the databases and some are input by the user. However, for the information module, these values are present in the knowledge base itself. This is because these values are the names of the topics, subtopics or the degree of detail, and are present in the knowledge base.

Both the modules, development and information, consist of goals and sub-goals which are represented by propositions and propositional functions. 
DEVELOP(EBS_LEVEL_3) is a sub-goal which is proposition and BELONG_TO(LEVEL_3(X), LEVEL_2( $(y)$ is a sub-goal $u$ 'hich is a propositional function.

There is a relationship between the goal, and the sub-goals. This relationship is embodied in rules. These rules constitute the inowledge base which is processed in order to determine the value of the goal. This processing is referred to as inferencing. As stated in chapter 5 , inferencing has to be controlled.

In the prototype the control is provided by both backward and forward chaining. While backward chaining is the primary control strategy used, forward chaining has been used for two functions: 1) to display text; and 2) for initializing values of the propositional functions. The rules used to perform these functions are referred to as rext and initialization rules (Appendix 2) respectively. Another type of a rule referred to as the database access rule (Appendix 3) is used to access the information in the database and to add selected information to a WBS database. This rule is controlled by backward chaining.

The rules used to model the information and the development procedures are presented in a form which is similar to the one used in the expert system shells. This representation is a generalization of the syntax used by the two expert system shells, PC Easy (T:xas Instruments) and Xi Plus (Expertech). It has been used because the prototype has been partly developed using PC Easy and partly using Xi Plus. Hence this representation helps to maintain the continuity of the description presented, i.e., from the overall description (Chapter 2, and 4), to symbolic, (Chapter 6, Appendices 2 and 3) to specific - the computer implementation (Appendices 4 and 5). 


\section{Chapter 7: The Prototype and PM Architecture}

In this chapter the development of the prototype, an illustration of its use, and the architecture of a project management tool are presented. In section 7.1 the software and the hardware used to develop the prototype and the reasons for using them are cited. Section 7.2 presents an illustration of the use of the development module. Section 7.3 presents the evaluation of the prototype. Finally, the architecture of the project management tool is presented in section 7.4 .

\subsection{Software and Hardware}

The prototype is developed on IBM PS/2 microcomputers. This has been done primarily because IBM computers are standard at the School of Business. Two expert system shells and a database package have been used to develop the prototype. The two expert system shells are PC Easy and Xi Plus. dBase III (Ashton-Tate) is the database package used.

The lack of capability of either shell to accommodate all the requirements of the approach resulted in the use of both shells. PC Easy and dBase III have been used to develop the development module of the prototype, while Xi Plus was used to develop the information module. Xi Plus allows the use of the initialization rule. The initialization rule, as stated earlier, results in the reuse of a rule. However, Xi Plus does not access a DBMS, though it does allow access to delimited files. PC Easy, on the other hand, does not allow the use of the initialization rule, but does allow comparatively easier access to a DBMS dBase III, and the use of its functionalities. The use of these shells does not advocate their superiority to other shells. These were chosen because of their ease of use and availability. 
dBase III was used because it was the only database package with which PC Easy had an interface.

The information module consists of 29 rules and 16 report files. These files contain the information about the various topics. The rules and the report files are presented in Appendix 4. The development module consists of 59 rules and 37 program and data files. The rules and the files are listed in Appendices 5 and 6 respectively. The system flowcharts of the two modules are given in Appendices 9 and 10 respectively and the user manual of the prototype is in Appendix 11.

\subsection{Example}

In this section, an example of WBS development using the development module of the prototype is presented. It consists of two scaled down and adapted versions of an aircraft WBS from the MIL-STD - 881A. This is the standard developed by Department of Defense to develop WBSs for defence projects. The two WBSs in the databases are referred to as AIRCRAFT SYSTEM - 1 (Figure 12) and AIRCRAFT SYSTEM - 2 (Figure 13). It is assumed that the user is a male.

The session with the prototype commences with the presentation of the initial screen ( sc - 1, all the screens are present in Appendix 7) which provides the user with the brief purpose of the prototype. After reading the purpose he continues to the next screen (sc - 2). Here he is asked to enter the name of the project for which he wants to develop the WBS. He names the project, Bomber - 234 (sc - 3) and presses the ENTER key to move to the next screen. At this screen (sc - 4) the user is presented with two options, Single Manipulation and Multiple Manipulation. 


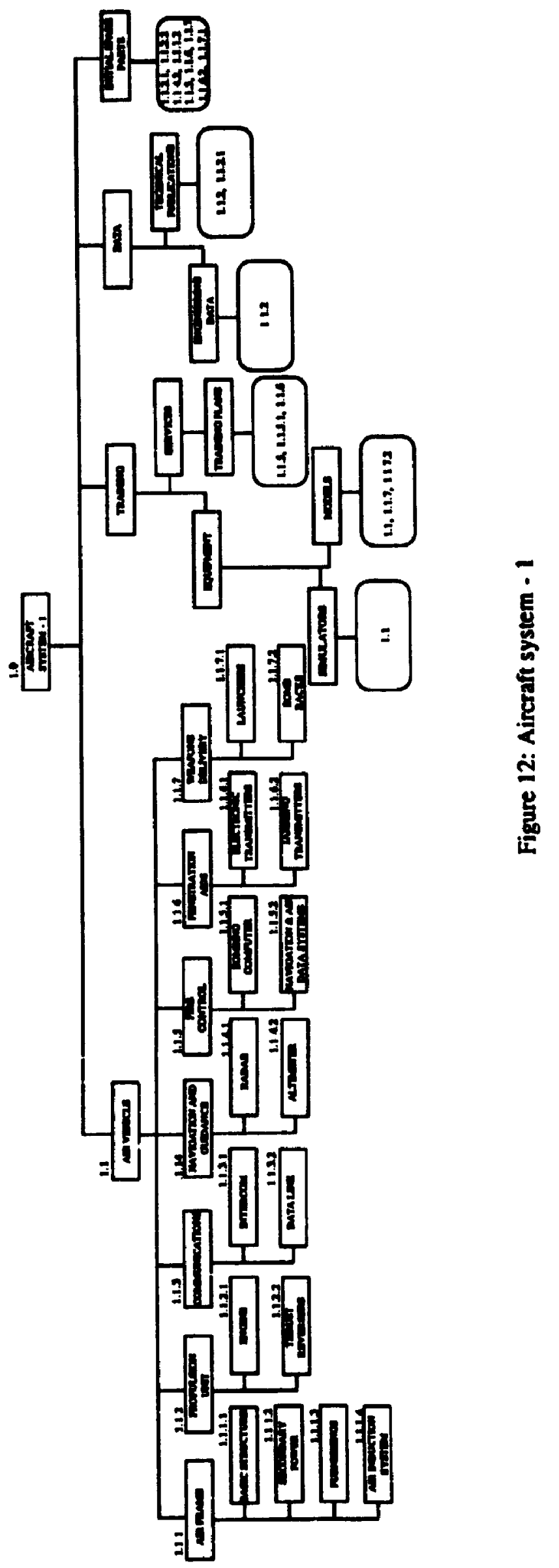




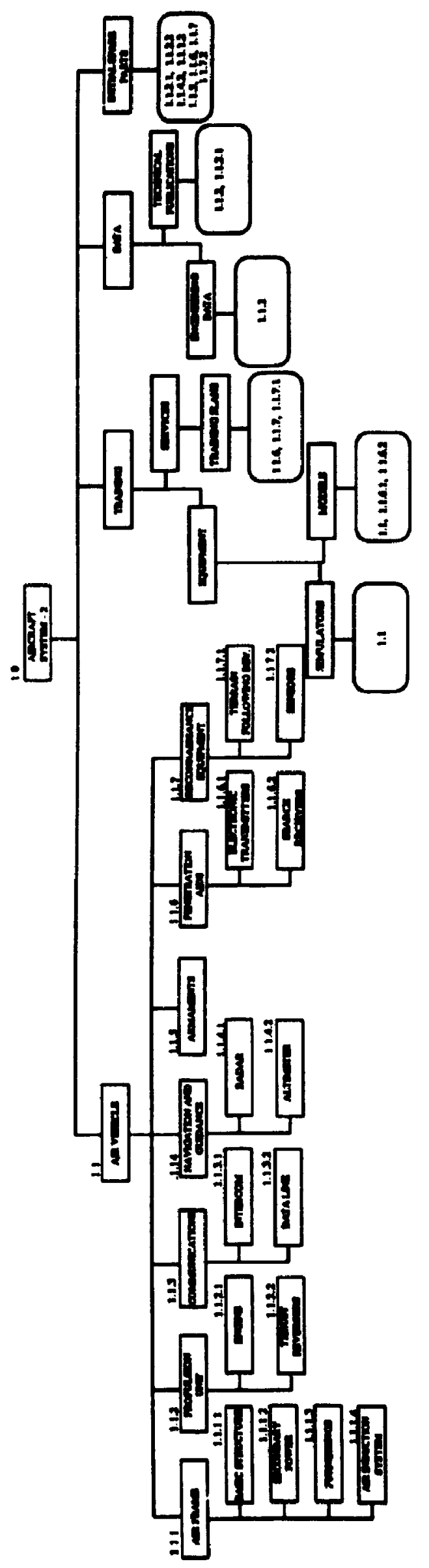

63

? 
At this stage the user should have had the capability to browse through the list of the WBSs which are present in the databases and their contents. Due to software limitations, this function could not be included. Thus the user has to select one of the options and move to the next step. To understand the meaning of the two types of manipulations he can use the help function available.

Since the user wants to input the minimum number of elements for his WBS, he selects the Multiple Manipulation option (sc - 5). This option would allow him to select elements belonging to more than one WBS. Having selected the option he moves on to the next screen (sc - 6). Here he was presented with the names of two WBSs, Aircraft System - 1 and Aircraft System - 2. Of these he has to select one which will be used as the primary WBS - the primary WBS is used to structure the WBS being developed. The user selects Aircraft System - 2 (sc - 7). The system next presents the user with the name of the secondary WBS (sc - 8). In this case there is only one secondary WBS, Aircraft System - 1. Since there is no other option, the user selects it (sc - 9) and moves to the next screen (sc - 10). Here he was presented with the second level element. which he selects (sc - 11). It is possible that the user may want to add some more elements at this level. To facilitate this, the user is asked whether he wants to add additional elements in level $2(\mathrm{sc}-12$ ). Not having a need to add more elements at this stage, the user selects No (sc - 13) and moves to the next screen (sc - $14 \& 15$ ) where he was presented with the nine level 3 elements belonging to Air Vehicle present in level 2. The user can select one or more applicable elements.

Having a need for all the elements the user selects all the elements (sc-16 \& 17). Next, he was presented with an option to input additional elements (sc - 18). Wanting to add one additional element, he accepts the option to input additional elements (sc - 19). He is next presented with a screen (sc - 20) on which he has to enter the additional EBS 
element. He inputs, Antisubmarine Warfare as the additional element, enters the code and $N$ for the answer (sc - 21).

Ideally a unique code should have been generated by the system itself. Currently the system places a "*" sign in front of the code entered. This facilitates the identification of the elements entered by the user. Before the new WBS can be used as reference, it would be necessary to establish unique codes for the elements input by the user.

The user is next presented with the fourth level elements for the third level element which he adds. After presenting the level four elements belonging to the level three elements, the system notifies the user that an additional element had been added in level three and queries if the user wants to add the level four elements for it (sc - 56). The user decides against adding the level four elements (sc-57).

Since there were only four levels in the primary WBS, this ends the development of the EBS. Next the system commences the development of the support WBS. After adding the support activities for the EBS elements which were retrieved from the reference EBSs, the system asks the user if he wants to add some supporting activities for the additional element he input (sc - 58). The user opts against it (sc-59). At the next screen (sc-60) he is asked if he wants to add additional support elements to the support WBS. Once again he opts against it (sc - 61). This ends the WBS development process and the WBS is shown to the user (Figure 14) - this is a graphic version of the WBS shown on the screen.

\subsection{Prototype Verification}

The prototype was verified by two project managers, Mr. M. Newell, from Low Level Air Defence (LLAD), and Mr. P. DiPietro, from Bell Northem Research (BNR). 


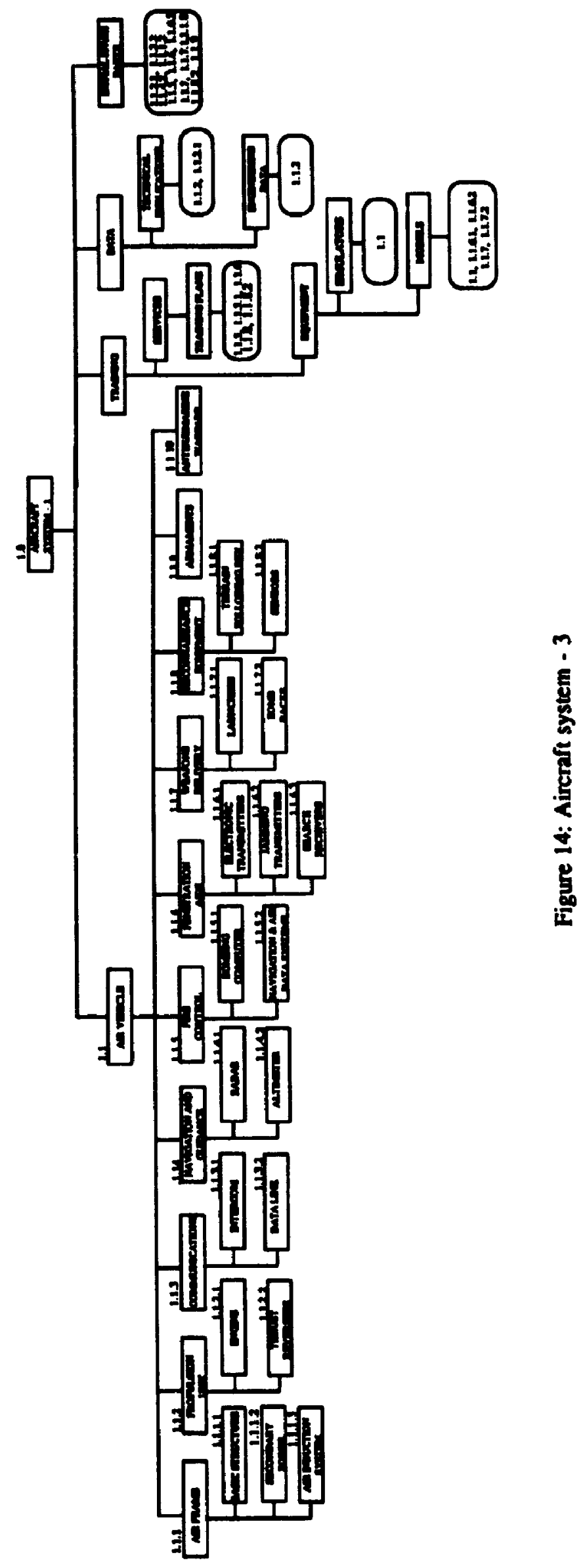


Both managen are experienced in managing complex projects, though in different areas. In addition, because of Mr. Newell's understanding of the needs of both experienced and inexperienced managers, he became involved in the preparation of computerized and noncomputerized support tools for WBS development at LLAD.

The two project managers were invited to the School of Business premises to verify the prototype. To facilitate uninterrupted verification, a separate room was set up with an IBM PS/2, model 60 computer. The two managers verified the prototype separately. The verification process consisted of three stages: 1) introduction, 2) use of the prototype, and 3) discussion.

During the introduction stage the project managers were informed of the purpose of the prototype, its components (the two modules - information and development), the working of each module, and the software used. They were given handouts containing two aircraft WBSs (see Figures 12 and 13) which could be manipulated to develop new WBSs. These handouts were given to help them understand what they were dealing with. The managers were also informed that they could do anything within the capabilities of the system. This meant that they could adapt either one WBS or manipulate the two WBSs to develop a new WBS. They were told that they had the choice of accepting only those elements which they required. In addition they could also add elements using the keyboard.

First the managers used the information module of the prototype and then used the development module. Both managers opted for multiple manipulation (use the two WBSs to develop a new one) and were successful in developing new WBSs. Mr. Newell took forty minutes to understand the working of the prototype and develop his own WBS. Mr. DiPietro spent thirty minutes to do the same. 
After the project managers had used the prototype, they were asked questions addressing the following issues:

1) The need for the information module.

2) The need for computer-based WBS development.

3) The ability to manipulate the WBSs, which included the following functions:

i) Ability to enter additional elements;

ii) Ability not to accept some elements; and

iii) Ability to accept the WBS without any changes.

4) The usefulness of the approach and possible applications.

Recognizing the needs of inexperienced project managers, Mr. Newell stated that the information module would be of great assistance because often, even in large organizations, no one has qualifications in project management. Mr. Newell said, "The project managers do not understand the importance of a WBS and in many cases do not even develop it." Mr. DiPietro also found the information module to be helpful. He would like to see it integrated with the development module to get context specific help.

Both managers were of the view that computer-based development of the WBS was a necessity. According to Mr. DiPietro, WBS is the most important part of project management. The managers indicated that with so many activities involved, there was no doubt that a computer-based approach is superior to develuping the WBSs by hand.

The managers did not encounter any major problems while developing their WBS. They experimented with the prototype by accepting, deleting and adding elements. However, for future development, Mr. DiPietro would like to see the functionalities expanded so that the users could first develop a portion of the WBS on their own and then retrieve any WisS or part of a WBS and make it subservient to their WBS. 
Both managers stressed that adaption and manipulation is better than creating a WBS from scratch. According to them, the case-based approach, used to develop new WBSs would encourage project managers to develop their own. To quote Mr. Newell "The concept is not only good but worth a lot of money. It is almost surprising that there is no such system available in the market today." He commented that he would have liked to have this prototype, if not a system based on it, when he started the LLAD project. It would have reduced many of the problems he encountered. According to him, the system could be used for any capital acquisition project in government departments. Mr. DiPietro stated that this approach could be used for any systems related project.

In addition to the questions asked, the managers made some additional comments. While both the managers found that the prototype was easy to use, they would prefer a graphic interface in a production system. According to Mr. DiPietro, it is very important that the project management tool be easy to use to encourage the project managers to use it. A graphic interface would make the existing system more user-friendly. Such an interface would facilitate relatively faster development since the user would be able to view the entire WBS rather than just a portion of it. Also, users would see the WBS in the form to which they are accustomed, a graphical representation. Further they did like the context specific help function which was included. The How and the Why functions were also considered as helpful functions, though due to the software limitations, they did not work as desired.

In conclusion, the approach used to develop the prototype did meet the requirements of the project managers, though some limitations exist. A production system based on this approach should incorporate all the functions present in the prototype. In addition, it should have a graphic interface and also allow the users to develop a part of the WBS on their own and then add to it WBSs or some of their components, from the databases. In addition the How and the Why functions should be included. 


\subsection{Project Management Architecture}

Finally a design for an integrated project management support tool has been developed. This is based on the existing project management software literature, and architecture of the prototype developed. Reviews of most of the project management software indicate that most of the software such as PROMIS, Harvard Total Project Manager, Qwiknet, Super Project Plus, Time Line and Microsoft Project (Wasil and Assad 1988) have at least two of the four main modules: scheduling, resource allocation/management, project costing and reporting/output.

The ability of a software package to support WBS development, though not common, is regarded as an advanced feature. Furthermore, the WBS development activity is considered, by Wasil and Assad (1988), to be a part of the project schedule module. A similar approach is used by the MacProject - a WBS can be developed, though with some difficulty, in the schedule module. The main activities in each of the four modules supported by most of the project management software are given below:

\section{PROJECT SCHEDULE}

Gantt Chart

\#sort and onder activities by code \#activity name displayed on chart *multiple calendars at activity level *breakdown project into sub-systems *specify activity finish date, lead/time

PERT network

\#"true" network diagram \#activity information entered and displayed on node \#reduced view of the network \#time-scale diagram RESOURCE MANAGEMENT 
"graphic display of resource allocations and loading

* automatic resource leveling

- resource leveling across projects

" "roll up" sub-project resources and costs

\section{PROJECT COSTING}

\# fixed, variable, unit costs per resource

\# accrue costs at start, end or over the duration of the projecc

\# project cost and actual vs. planned cost histograms

\# cost reports by time period, activity or resource

* eamed value analysis

* multi-project cost analysis

\section{REPORTING/OUTPUT}

\#Wide range of on-line reports

\# sideways printing of the network

\# customized reports through sorting, tagging or filtering

\# actual vs. planned (baseline) reports

* print report while working

*batch processing of reports

* government reporting

\# indicates normal activities present in the project management software

* indicate advanced activities

Fersko-Weiss (1989) has stated that the WBS development facility is present in most of the advanced software such as Time Line, ViewPoint, Qwiknet Professional, Promis, Plantrac and Open Plan. A review of the article has indicated that while these software packages allow for WBS development, they present the same problem - they do not assist the user in the development of the WBS, rather they provide storage for a WBS.

The appro: th being presented diverges from the existing general approach on which most of the project management software is based. In addition to the four modules 
mentioned above, another module is introduced - the WBS module (Figure 15), and the "breakdown of project into sub-systems" is removed from the schedule module. Since WBS forms the basis of nearly all project management activities, it is reasonable to regard it as the central module upon which are based all the other modules. This module, unlike conventional systems, is based on the development module presented earlier. This approach results in greater simplicity and ease of use. This architecture is a result of the analysis the the literarure on WBS and project management software.

Given below is an example of the use of this approach. Consider the WBS in Appendix 8. For simplicity it is assumed that two functional activities, design and development, are required and two project management activities, costing and scheduling, are undertaken. The cost for development and design forms the total cost for the project and the two schedules for design and development together form the overall schedule (Appendix 8).

Figures 8.1, 8.2 and 8.3 (Appendix 8) have been developed using the schedule module of MacProject. For each element the date of commencement and accomplishment is given along with the cost for the functional activity, i.e, designing or development. Figure 8.2, "Schedule and Cost for Designing and Development ", in Appendix 8, is a cumulative representation of the functional and the project management activities. The next two figures (8.3 and 8.4) represent the two project management activities for the functional activities being undertaken. Similarly, cumulative schedule (8.5) and cost (8.8) figures aud also independent schedules (8.6 and 8.7) and cost figures for the functional activities (8.9 and 8.10) are also presented.

This approach uses the WBS as a cornmon framework and thus facilitates uniformity, i.e., "airframe" means the same thing to all the functional departments, and 


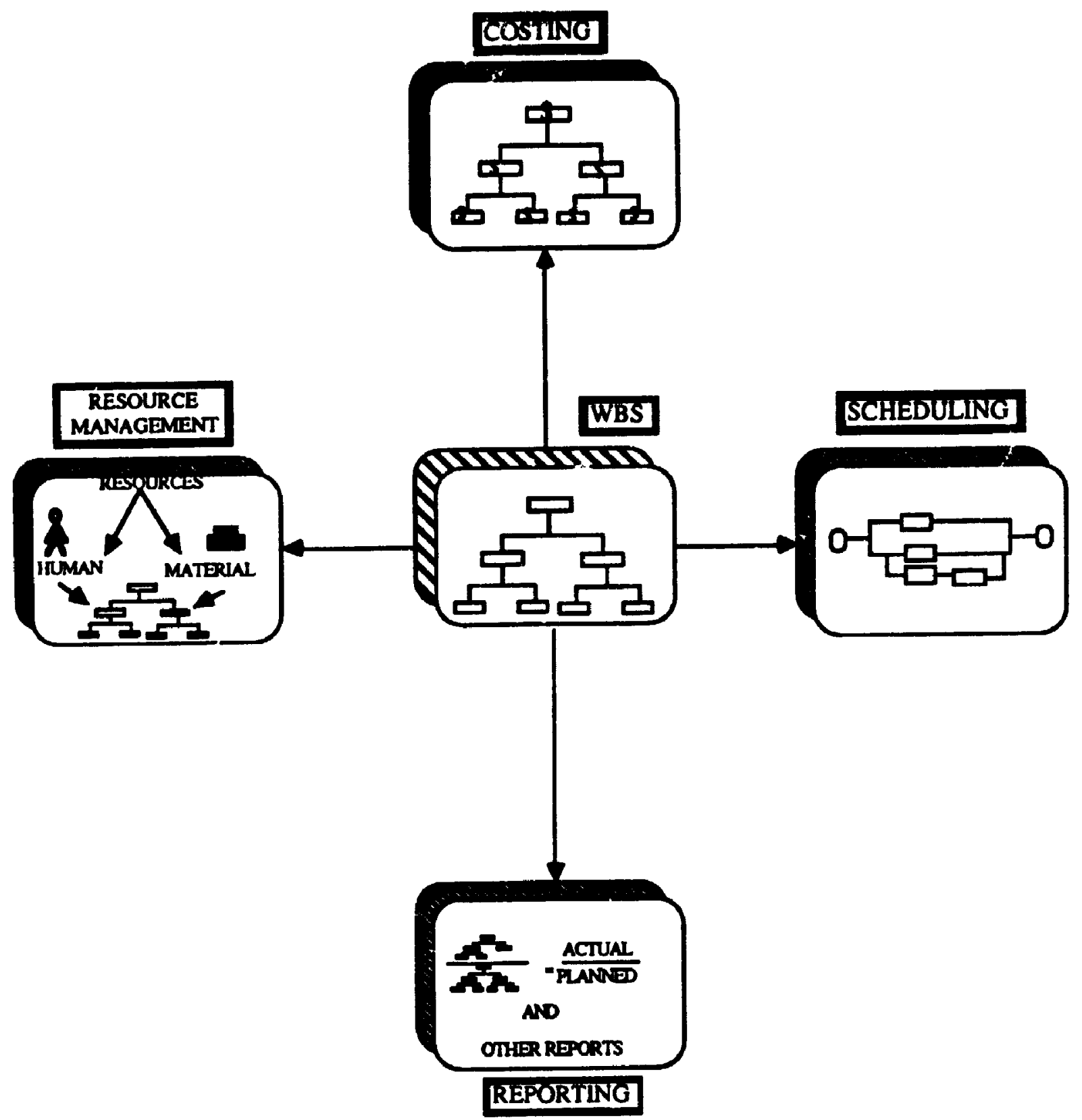

Figure 15: Project management architecture 
74

thus it is easy to coordinate the activities of all the functional departments. For instance, the development of the engine is dependent on the design being completed. Since the same WBS is used for both the functional activities, it is possible to coordinate schedules and ascertain the total costs.

The costing has been done using the bottom-up approach, ie., the cost of designing the engine and the thrust reverser would be the cost of the propulsion unit and the cost of designing and developing the propulsion unit would be its total cost. Thus using a bottom-up approach, the cost for the entire project would be the sum of the cost for the components plus some miscellaneous expenses, i.e, assembly of the parts to develop the project. The cost and schedule figures are fictitious.

The important point in this approach is that all the activities are based on the WBS. Thus, a change in the WBS will automatically reflect in all the modules. 


\section{Chapter 8: Discussion}

In this chapter a discussion se research is presented. In section 8.1, the pros and cons of the use of rule based fr.tnalism and expert system technology are discussed. Section 8.2 presents the limit' ions and benefits of research. Finally, the directions for future developments are pres .nted in section 8.3.

\subsection{Pros and Cons of Rule-based Formalism and ES Technology}

In this thesis, rule based formalism has been used to model two different kinds of problems, the development of a WBS and the provision of the information about a WBS. Both problems are procedure based and represent another area where rule based formalism can be used. Further, the development of the WBS is a sequential process, i.e., level $n-1$ is developed before level $n$. Generally, procedural languages such as BASIC, COBOL, PASCAL etc. have been used for such procedural problems. The use of rule based formalism to represent them, incorporates all the advantages of rule based formalism while allowing for the incorporation of procedural functions such as loops.

The main purpose of this thesis was to develop, implement and verify a model to support WBS development. Computer technology was used to implement this model. Integration of databases and expert system technologies was viewed as the approach to be used. This involved the integration of the DBMS functions with some ES functions. In many cases the integration is viewed as the retrieval of the data from the database and its use by the knowledge base for determining the solution for some problem. The knowledge base in these cases consists of heuristics and facts. However, in the case of WBS development, integration refers to integrating the procedural functions of the DBMS with 
the How and Why functions of expen systems. Further, the knowledge base consists of rules used in the development of a WBS.

The importance of the How and Why features results from the fact that the user can get an explanation of how the WBS was developed. This would assist the user in understanding the WBS development process. During WBS development the How function would allow the user to understand how, say, a particular level was developed, or how the support WBS was developed. On the other hand the Why function would help the user understand why the system requires certain input.

From the point of view of ease of representation, these problems should have been represented using procedural representation rather than rule based since use of rule based formalism to represent the two problems did pose some problems. The first major problem arose due to the need to incorporate the procedural functions, such as retrieval and addition of values to and from the data files, into the rules. In the representation it had to be defined explicitly from where the values are being retrieved and where they are being added. The conditions used to retrieve and add the values also had to be specified. In a sense some of the DMBS functions had to be incorporated into the rules. Second, because of the procedural nature of the problems, there was a need to loop the rules. The problem was even more difficult because the clarity of the rules had to be maintained.

However, the encouraging aspect was that prototyping with expert system shells was relatively much faster and inore efficient. This was primarily because of the more English-like syntax used in writing rules and also beconse these shells provide a much more user-friendly environment in which to work than most of the procedural languages, even 4GL languages. This was especially true in the development of the information 
module using Xi Plus. The use of an expert system shell for such a function, though quite unorthodox, shows a great deal of promise.

Consider Figure 16, which depicts the structure of the information module. The information about each topic is stored in one of the knowledge bases surrounding the control knowledge base. Due to the flexibility provided by the modularity of rules, information within a topic can be added or deleted relatively easily. Further topics can be added or deleted with the same ease. Thus, an expert system shell can be used in other areas such as developing software tutorials for various applications. However, some of the functions such as How and Why would be wasted.

\subsection{Limitations and Benefits of the Research}

\subsubsection{Limitations}

The limitations can be classified as research and software limitations and are discussed below:

\section{Research Limitations}

The major limitation of the research is that the support concept is model/data dependent i.e., only that information will be provided which is present in the databases. Thus, for example, if the databases for aircraft do not contain wings, the prototype will not prompt the user that wings and its sub-components are components of the aircraft WBS. Therefore, the WBS developed will not contain wings unless they are added by the user. Given this, it is not possible to check the consistency of the WBS developed with the project for which it is developed. 


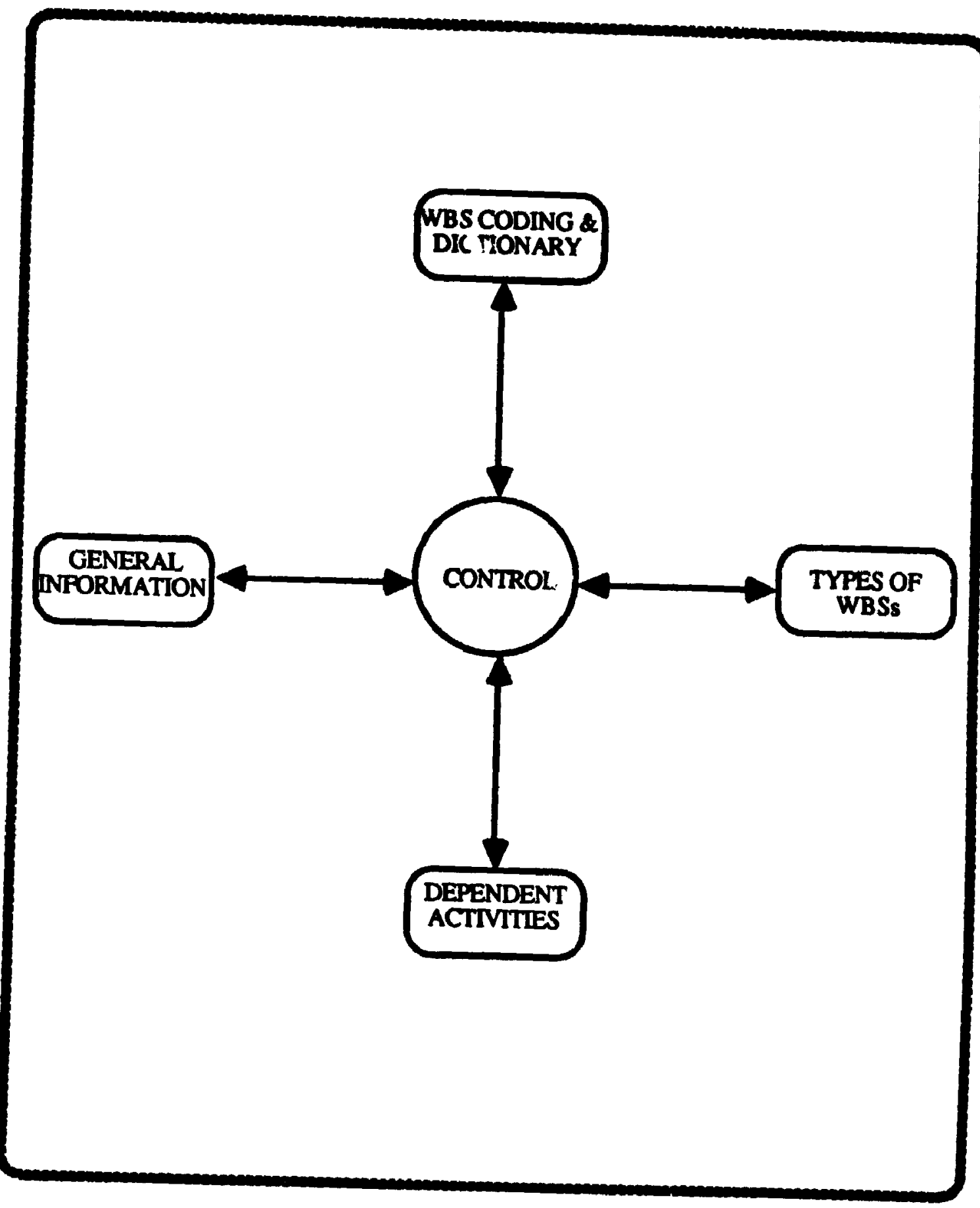

Figure 16: Structure of the information module 
Another limitation of this research follows from the goal of the research of designing and verifying a framework for WBS development. While the proposed prototype is not meant to be used directly by project managers, it will serve its purpose if it is used as a basis for future computer-based support for WBS development.

\section{Software Limitation}

The use of three different software packages to develop the prototype was one of the major software limitations. Apart from this, the major software problems were encountered while developing the development module. This was primarily because PC Easy is designed as a "Diagnostic/Prescription" shell and thus does not have all the capabilities for developing a WBS. Though it has been possible to implement the model and develop the prototype, the way it has been done is not the most effecient. Two different packages have been used to develop the module. This has caused developmental as well as operational problems.

In the symbolic models created for the development module, variables which have a list of values have been used to retrieve values from the databases. They have also been used to add values to the database. In PC Easy, while the retrieval of the values is very similar to that discussed in the model, the addition is different. It is not possible to use a list to add the values to the database. In fact, the knowledge base has to know the values which are to be added, i.e., it does not use a variable which is instantiated by the value of the list but instead each value has to be known a priori. To do this, a rule similar to the text rule has been used. The difference is that while the text rule displays information, these rules add values to the database. An example is given below.

IF

LEVEL_3(AIRFRAME) 
THEN

ADD(LEVEL_3(AIRFRAME), NEW_EBS, LEVEL_2(AIR_VEHICLE)).

This rule states that if the level 3 element is airframe, then add it to the file NEW_EBS under AIR_VEHICLE which is in level 2. Similar rules have been used to add the other values in the database. Such an implementation is very inefficient because to add the values to the database, it requires the presence of as many rules in the knowledge base as the number of values present in the databases. Thus if there are two hundred possible values to be added, there have to the 200 different rules to add the values. Furiher, since PC Easy does not support the initialization rule, it does not allow looping. Thus, additional rules must be added for each owner element which has member elements. Consider the sule given below.

IF

BELONG_TO(LEVEL_3( $Z$ ), LEVEL_2(T)) AND
BELONG_TO(USER_LEVEL_3(K), LEVEL_2(T))

THEN

CHECK (INITIALIZE(BELONG_TOL, J)) AND

DEVELOPED(EBS_LEVEL_3).

In this case, the values of the member element belonging to an owner element in level 2 instantiate the variable 2 . Further, in case some more level 2 values are present in the data file for the EBS being developed, then the level three values for those elements need to be retrieved. This is facilitated by the initialization rule. As such, another value would instantiate the variable $T$ and the value belonging to it would instantiate the variable 2. However, the use of such rules and variables is not possible in PC Easy, In PC Easy, there would have to be a rule for each owner element rather than an all encompassing rule. Again this is inefficient. 
In addition, the data is transferred between two different environments - PC Easy, the expert system shell, and ABase III, the DBMS. As a result the How and the Why functions cannol be used because the elements are either retrieved or added to the database through the interface. PC Easy is unaware why the data has been retrieved, from where it has been retrieved and the condition for which it was retrieved. The only reasoning available when the How function is used is that the database has been accessed. There is a further limitation in that it can access only one data file, i.e relationships between two or more files cannot be established. In order to do this, a special function has to be used which allows the development of program files. These program files in turn facilitate the manipulation of the data. Here too, the sanje problem persists: the function being performed in the program file is unknown to PC Easy. This operation in two different environments completely eliminates the advantages of the How and the Why functions.

The levels of a WBS for each WBS can be different. This requires the introduction of a function which would create rules dependant upon the number of levels in the reference WBS. The creation process is simple as the rules for each level are similar. The only difference is in the propositional functions used. However, this function, too, could not be implemented due to software limitations.

Further, since predicates cannot address variables in PC Easy, it is not possible to manipulate the new databases without adding additional rules to the knowledge bases. Also, due to software limitations, selecting between mutually exclusive elements is not possible. Because of these limitations, the prototype does not perform two of the seven functions required by it. These are designated by the * sign.

1) Provide the information about WBS fundamentals and dependent activities and facilitate easy movement between different topics, e.g., levels of the WBSs and the types of the 
WBSs;

2) Allow users to accept the existing WBS standards without any alterations;

3) Allow adaption (additions and deletions of data) of any standands;

4) Facilitate the development of a WBS by linking various models;

*5) Add the new WBS developed to the database, to be used as an additional reference model; and

6) Provide an automatic check of the hierarchical flow of the WBS by ensuring the addition of elements/components to higher levels before adding their sub-components to the lower levels.

*7) Provide the reasoning for the solution arrived at (How) and present an explanation for why it is querying the user.

\subsubsection{Benefits of the Research:}

Despite the limitations cited above, the major benefit of the research results from the implementation of the concept of computer-based support for WBS development. The concept itself is domain independent, i.e., irrespective of what is stored in the databases WBS standards, cases or models - the concept is the same. Note, although the prototype is developed using simple expert system shells, it provides five of the required seven functions. The other benefits of the research are given below:

1) This research resulted in the development of procedures for WBS development.

2) It illustrates the use of rule-based formalism in procedural areas and thus showed how some of the DBMS and other procedural functions can be integrated with rules. It represents the integration of expert system tools and techniques and those of mainstream computing. 
3) It has shown a way to capture WBS development expertise and experience and facilitate its reuse for other projects. Further, it facilitates leaming. Since, changes can be made to the WBS and stored during the life of the project, it helps ensure that the same mistakes are not repeated.

4) It provides a basis upon which to build and develop a computer-based production system.

5) Finally, it has presented an architecture for an integrated project management tool.

\subsection{Future Developments}

Using the approaches to WBS development presented in chapter 4, a system which could allow the complete implementation of the models has to be developed. It is necessary that it be able to handle the procedural aspect of the problem as well as the How and the Why functions. In addition it has to have another very important function - the capability to accommodate a variable number of levels - each reference WBS may have a different number of levels. The capability to check the consistency of the WBS being developed should also be included. Further it should have a graphic user interface. After incorporating the requisite changes, the system should again be verified.

Using the proposed approach, it would not be necessary to make any change to the knowledge base. The only change to be made would be the addition and deletion of data files to and from the databases. This is extremely useful as only the databases would have to be maintained and the knowledge base would not require any maintenance. 
Another area that can be looked at is the implementation of the recommended approach for WBS development. That approach is simpler than the one used and would require much less time for implementation.

Further, it could be possible to integrate the development and the information modules so as to be able to access the information from within the development module. This development module could further be used as a central module of a project management tool. 


\section{Chapter 9: Conclusion}

The aim of this research was to develop, implement and verify a model to support WBS development. The model was successfully developed, implemented, and verified. Due to the novel nature of the approach used .or supporting WBS development, em.jpasis was placed on the technology.

The primary research question addressed was, "How can computer-based support be developed to assist project managers in constructing work breakdown structures?" This question in tum suggested the following questions:

1) How should the procedure for furnishing information about WBS fundamentals and dependent activities be structured?

2) How should a WBS development procedure be structured ?

3) How can the procedures in questions 1 and 2 be embodied in the prototype?

4) What should an integrated support tool for project management contain?

The first two questions pertained to developing procedures, one for providing information about the WBS and the other for developing a WBS. Both the procedures were successfully developed.

For the information procedure, the primary consideration was modularity of information. The information is provided in an increasing degree of detail. Further, the information about a topic can be accessed non-sequentially.

The development procedure consisted of two parts, one for developing the equipment breakdown structure and the second for developing the support WBS. It was necessary that the equipment breakdown structure be developed before the support WBS. 
The approach presented to manipulate WBSs to develop new WBSs required aggregating WBS components into classes. Each class consisted of mutually exclusive elements and a list of classes present at the next lower level.

Though this approach was simple and flexible, it could not be implemented using the software available. As a result, an alternate approach was developed and implemented. This approach did not require aggregating the WBS components into classes. In this approach the WVBSs were stored separately. These WBSs could be manipulated, either by single manipulaiton or by multiple manipulation, to develop a new WBS. While developing a new WBS, it was possible to accept a reference WBS in its original form or adapt it by adding or deleting elements.

The support WBS was primarily developed by the system without user interference. User input was required to add support elements for the EBS elements added by the user using the keyboard. These support elements belonged to the support WBS/s) of the reference WBS(s). The user also hiad the option of a ' ling additional support elements using the keyboard.

The third research question referred to embodying the proce Jures in the prototype. This was done by representing the procedures using rule-based formalism and data models. Knowledge bases and the databases were developed using rule-based models and data models. While the latter stored the WBSs to be used as references to develop new WBSs, the former contained information about how these WBSs could be manipulated to develop new ones, and also how information about the WBS could be provided.

The final question addressed the contents of an integrated project management tool. Since the WBS forms the basis for every project management activity, such a tool integrates scheduling, costing, resource management and reporting modules with the WBS 


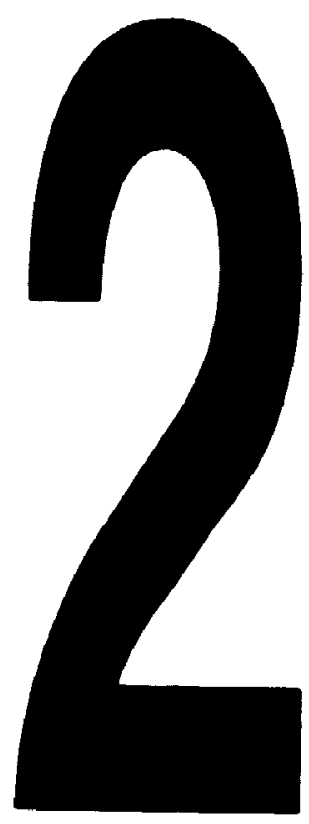

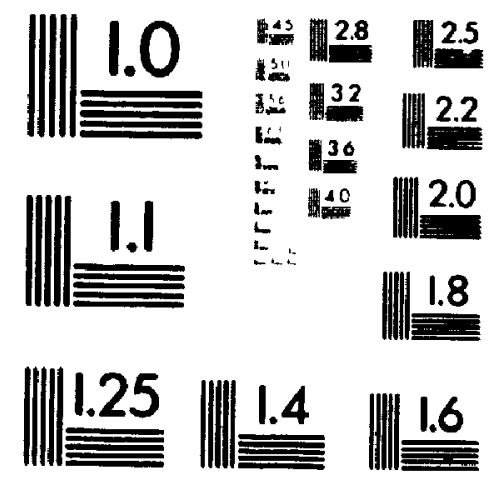

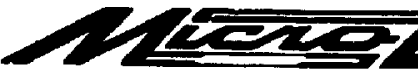

19 
development module. These components were derived from the project management literature, existing project management software and the approach used to develop the prototype.

The research emphasized the necessity of an information module because one of the two groups of project managers are novices. Further research is necessary to determine the specific needs of project managers so that these needs can be incorporated into the information module. The information module for the research was developed using rulebased formalism. This novel and promising approach is used by Microsoft Inc. and Apple Inc. in "help systems" (Johnston 1989). 


\section{References}

Aptman, Leonard H. 1986. Project Management: Criteria for Good Planning. Management Solutions 31, no. 10 (September) : 22 - 27.

Beech, Graham. 1983. Compuser Based Learning : Practical Methods for Microcomputers. Cheshire : Signio Technical Press.

Bitner, L.M.1985. Project Management: Theory Versus Application. Project Management Journal 16, no.2 (June) : 64 - 73.

Copi, I.M. 1973. Symbolic Logic. Fourth edition. New York: Macmillan Company.

dBase III Version 1.0 (Torrance, CA.: Ashton-Tate).

Design/2.0 (Cambridge, MA.: Meta Software) ).

Fersko-Weiss, Henry. 1989. One Project, 3000 Tasks - High-End Project Managers Make the Plans. PC Magazine 8, no.9 (May) : 155 - 195.

Forsyth, Richard. 1984. The Architecture of Expert Systems. In Expert Systems Principles and Case Studies, ed. Richard Forsyth, 9-17. London, England : Chapman and Hall.

Frame, J. Davidson. 1987. Managing Projects in Organizations. San Francisco : JosseyBass Publishers.

Geoffrion, Arthur M. 1987. An Introduction to Structured Modeling. Management Science, 33 no. 5 (May) : 547 - 588.

Harmon, Paul and David King. 1985. Artificial Intelligence in Business - Expert Systems. New York : John Wiley \& Sons Inc.

Holland, John H., Keith J. Holyoak, Richard E. Nisbett and Paul R. Thagard. 1986. Induction - Processes of Inference, Learning, and Discovery. Cambridge, Massachusetts : MTT Press.

Hosley, William N. 1987. The Application of Artificial Intelligence Software to Project Management. Project Management Journal 18, no. 3 (August) : 73 - 75.

Huot, Jean-Claude. 1979. Integration of Cost and Time with The Work Breakdown Structure (WBS). AACE Transactions : H.3.1 - H.3.6.

1981. Productivity Defined. AACE Transactions : 1.4.1 - 1.4.7.

Johnson, Raymond K. 1985. Program Control from the Bottom Up - Explaining the Working Side. Project Management Journal 16, no. 1 (March) : 80 - 88. 
Johnston, Stuart. 1989. AI Techniques Emerging in Familiar Applications. Info World 11, no. 35 (August 28) : 5 .

Kersten, Gregory E and S. Szpakowicz. 1988. Rule-Based Formalism and Preference Representation: An Extension of Negoplan. Technical Report TR-88-19, Computer Science Department, University of Ottawa.

Kerzner, Harold. 1984. Project Management - A Systems Approach to Planning, Scheduling and Controlling, $2 \mathrm{~d}$ ed. New York : Van Nostrand Reinhold Company Inc.

Lackman, Michael. 1987.Controlling the Project Development Cycle Part 3 - Tools for Successful Project Management. Journal of Systems Management 38, no. 2 (February) : 16 - 27.

Lanford, H.W. and T.M. McCann. 1983. Effective Planning and Control of Large Projects - Using Work Breakdown Structure. Long Range Planning 16, no.2 : 38 - 50.

Lavold, Garry D. 1983. Developing and Using the Work Breakdown Structure. In Project Management Handbook, ed. David I. Cleland and William R. King, 283 - 302. New York : Van Nostrand Reinhold Company Inc.

Liebowitz, Jay. 1988. An Introduction to Expert Systems. Santa Cruz, California: Mitchell Publishing, Inc.

$T$ in, Engming. 1986. Expert Systems for Business Applications: Potentials and Limitations. Journal of Systems Management 37, no. 7 (July) : 18 - 21.

Litton, Gerry M. 1987. Introduction to Database Management - A Practical Approach. Dubuque, Iowa : Wm. Z.Brown Publisher.

McFadden, Fred R. and Jeffrey A. Hoffer. 1988. Database Management. Menlo Park, Califomia: The Benjamin/Cummings Publishing Company, Inc.

Meredith, Jack R., and Samuel J. Mantel, Jr. 1985. Project Management - A Managerial Approach. New York : John Wiley \& Son.

Nucci, E.J, and A.L. Jackson, Jr. 1979. Work Breakdown Structure for Defense Material Items. In Systems Management, by Stanley J. Baumgartner, $196-208$. Washington D.C. : The Bureau of National Affairs, Inc.

Oldham, Connisue.B, Carl T. Ripberger and Judith E. Cook. 1986. Project Management in Federal Research and Development Laboratory : An Application of the Elusive Budgeted Cost of Work Performed. Project Management Journal 17, no. 4 (September) : 79 - 86.

Ostle, Judson R. 1985. Information Systems Analysis and Design. Minneapolis, Minnesota : Burgess Communications.

Parker, Scott D. Jr., Michael Carey, Forouzan Golshani, Matthias Jarke, Edward Sciore and Adrian Walker. 1986. Logic Programming and Databases. In Expert Database Systems - Proceedings from the First international Workshop, ed. Larry 
Kerschberg, 3 - 15. Menlo Park, California : The Benjamin/Cummings Publishing Company, Inc.

PC Easy Version 2.01 (Austin, Texas: Texas Instruments).

Popolizio, John J. and William S. Cappelli. 1989. New Shell for Old Iron. Datamation 35, no. 8 (April) : 41 - 48.

Project Management Advantage (Rochester. N.Y.: All - Tech Project Management Services, Inc.)

Reimann, Bernard C. 1985. Decision Support Systems: Strategic Management Tools for the Eighties. Business Horizons 28, no.5 (September-October) : 71 - 74.

Saynisch, M. 1983. Project Management System for a Large International Project. International. Journal of Project Management 1, no. 2 (May) :115 -121.

Smith, John Miles. 1986. Expert Database Systems: A Database Perspective. In Expert Database Systems - Proceedings from the First international Workshop, ed. Larry Kerschberg, 3 - 15. Menlo Park, California : The Benjamin/Cummings Publishing Company, Inc.

Smith, Larry. 1986. Software Review. Project Management Journal 17, no.1 (March) : 31 - 33 . $21-22$.

1987a. Software Review. Project Management Journal 18, no.3 (Aug:st) :

1987b. Software Review. Project Management Journal 18, no. 4 (September) : 33 - 37 .

1988.PM Software Review. Project Management Journal 19, no.1 (February) : 21- 23.

Smith, L.A., and J. Mills. 1983. Reporting Characteristics of Automated Project Management Systems. International Journal of Project Management 1, no.3 (August) : $155-159$.

Stuckenbruck, Linn C. 1981a. The Implementation of Project Management : The Professional's Handbook. London, England : Addison- Wesley Inc.

1981b. Project Integration in the Matrix Organization. In Project Management Handbook, ed. David I. Cleland and William R. King, 37 - 58. New York: Van Nostrand Reinhold Company Inc.

1984. Educating Potential Project Managers. Project Management Journal - Special Summer Issue (August) : 11 - 16.

Super Project Expert (Vancouver, B.C.: Computer Associates).

Thamhain, Hans J. 1984. Engineering Program Management. New York : John Wiley \& Sons. 
91

Thamhain, Hans J. 1987. The New Project Management Software and its Impact on Management Style. Project Management Journal 18, no. 3 (August) : 50 - 54.

Thisner, Adders , Paul M. Teicholz and George Haves. 1987. PM and the Computer : The Year 2001. Project Management Journal 18, no. 3 (August) : 39 - 45.

Timer, W.D. 1985. Subdivision of Work on Construction Projects. International Journal of Project Management 3, no. 1 (February) : 13 -18.

Turban, Efrain. 1988. Decision Support Systems and Expert Systems - Managerial Perspectives. New York : Macmillan Publishing Company.

Visible Analyst Workbench Version 3 ( Newton, MA : Visible Systems Corporation).

Wasil, Edward A. and Arjang A. Assad. 1988. Project Management on the PC: Software, Applications, and Trends. Interfaces 18, no.2 (March - April) : 79 - 84.

Xi Plus Version 2.0 (Berkshire, England: Expertech).

Yik, Shirley. 1987. The Utilization of Project Management Techniques and Software in the Software Development Companies. Masters diss., School of Business, Carleton University. 


\section{Project Management Advantage}

WBS is a bierarchical tree that breaks down the project ectivity, goins from major to datailed takk. The braxches of the tree are Sub-projects (Lovel I), dividing ide Subyetems (Level II), dividing into Components (Level III), dividing ino Sub-componenter Punctions (Level IV), dividing into Partertasks (Level V).

Do you whit to proceed with WBS prompt?

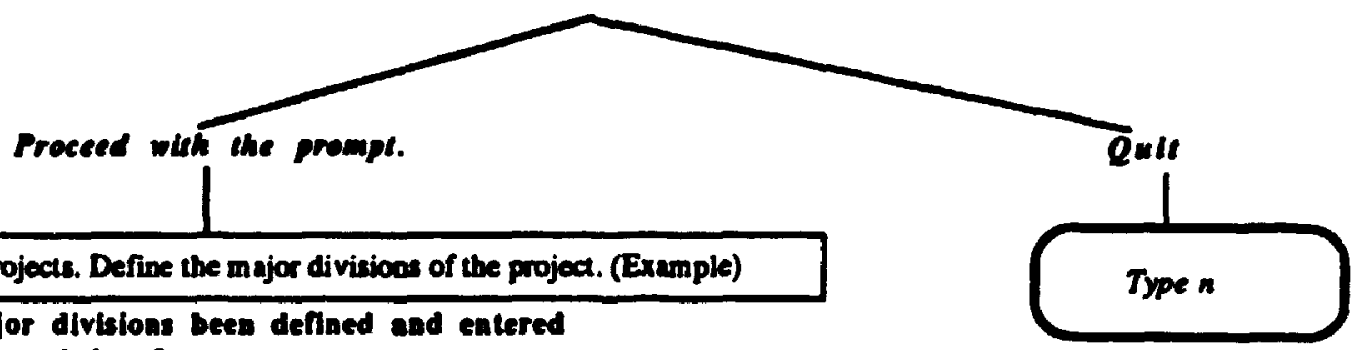

Level I. Subprojects. Define the major divisions of the project. (Example)

Have the mojor divisions been defined and entered on the WBS worksheet?

Begin the preparation of WBS and the project activity list by listing the major sub-projects of the project and enter them on the worksheet, UST. in the lemplate for use with LOTUS 1-2-3.

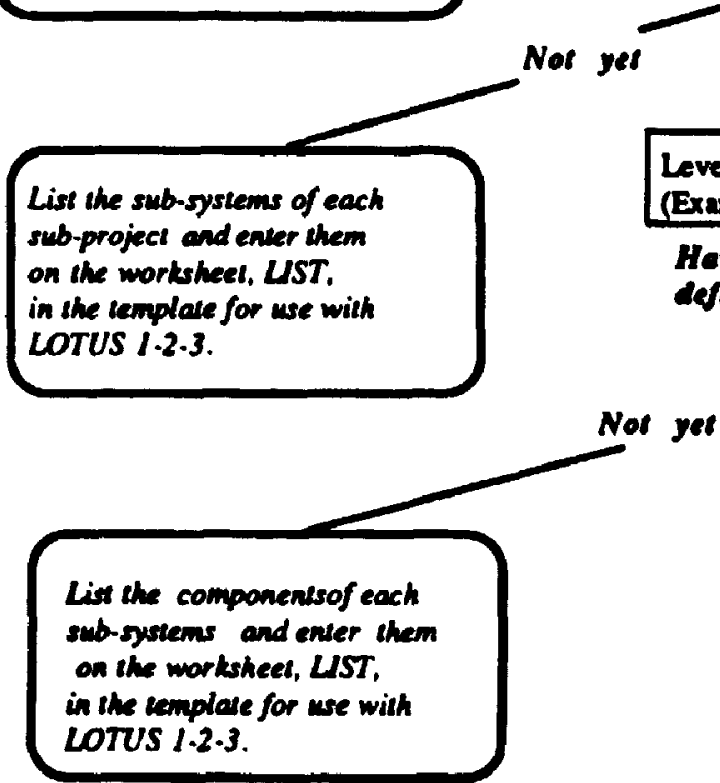

Level II. Subsyatems. Divide the major abbprojects into wbsystems. (Exemple)

Have the major abdivlstons of the sub-project been defined and satered on the WBS worksheet?

\section{(Example)}

Heve the components of the subsystems been chined and encered on the WBS worksheat?

in the cemplate for use with coTUS 1.2 .3

List the componentsof each mb-systems and enter them on the morksheet, LSST. cotus 1.2.3.
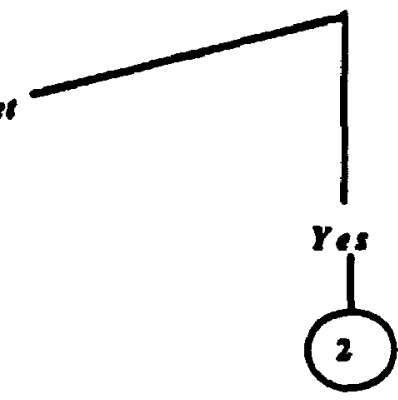


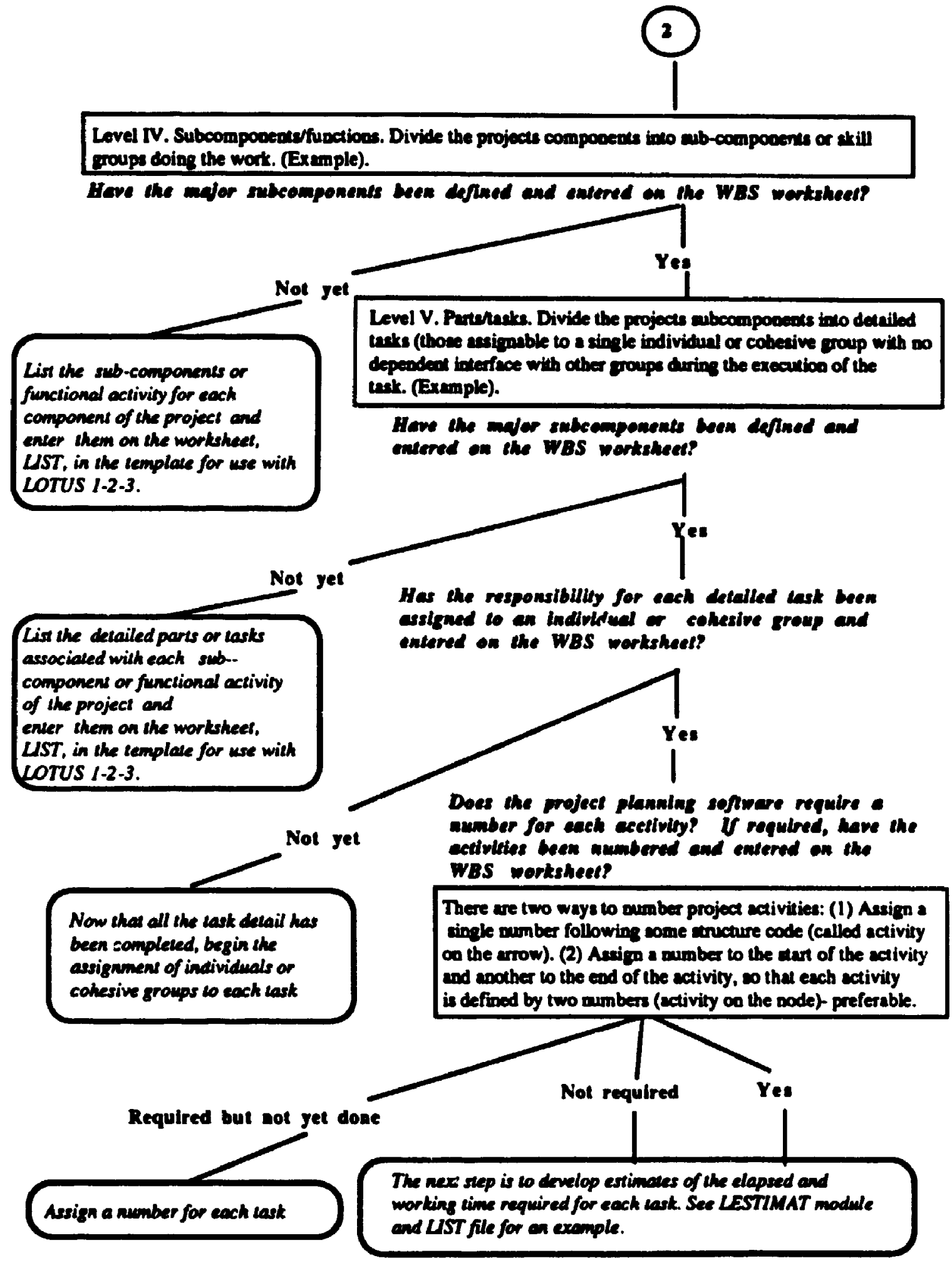




\section{APPENDIX 2}

\section{Text and Initialization Rules}

For any given problem the value of the goal is determined only once during a consultation. In the information module this would mean that information about only one topic can be provided at any one time. This is because the goal, DISPLAY, (rule 1) is to display information about a particular topic. Its value, which is the text to be displayed, depends on two other sub-goals TOPIC and LEVEL_OF_DETAIL. Once their values are determined the information is displayed and the goal is achieved.

IF

TOPIC(TYPES_OF_WBS) AND

LEVEL_OF_DETAIL(OVERVIEW)

THEN

DISPLAY(TEXT_TYPES_OF_WBS).

However the purpose of the information module is to provide information about the different topics at different levels of detail and as many times as required. Similarly, in the deveiopment module, the rules have to be repeated in order to retrieve from the database, member elements for more than one owner element.

Thus certain additional controls have to be introduced in these two modules. First, to increase the clarity of the representation, text rules have been used; and second, to display the information about all the topics without exiting the module, and for retrieving from the database member elements belonging to more than one owner element, the initialization rules have been introduced. The use of the two types of rules is discussed below. 


\subsection{TextRulex}

In order to display information about other topics, rules similar to rule 1 would have to be repeated. For instance to display information about another topic, GENERAL_INFORMATION, rule 2 would be used.

IF

TOPIC(GENERAL_INFORMATION) AND

LEVEL_OF_DETAIL(OVERVIEW)

THEN

DISPLAY(TEXT_GENERAL_INFORMATION).

Similar rules have to be included to facilitate displaying information about other topics too. This representation is not efficient because all the rules in the knowledge base would then be goal rules, i.e., have the goal DISPLAY in the consequent.

The representation is improved if, instead of using propositions such as TOPIC(TYPES_OF_WBS), a propositional function TOPIC $(x)$ is used. Further a new goal PROVIDED(INFORMATION) is introduced and the information about the topic is displayed by the text rule. The modified goal rule and the text rules are presented below:

IF

TOPIC $(X)$ AND

LEVEL_OF_DETAIL (OVERVIEW)

THEN

PROVIDED(INFORMATION).

IF

TOPIC(TYPES_OF_WBS) AND

LEVEL_OF_DETAIL(OVERVIEW) 
THEN

DISPLAY(TEXT_TYPES_OF_WBS).

The variable $X$ can be instantiated by the name of the topic about which information is required. Assuming that $X$ is instantiated by TYPES_OF_WBS and the level of detail is OVERVIEW, the control would then be transferred to rule 4 which would cisplay the information about this topic. The control would be transferred because rule 4 uses forward chaining (as soon as the values in the antecedent part of the rule are determined to be true, the consequent is initiated). After the information has been displayed, the control would be transferred back to rule 3 where the value of the goal would be determined to be true. Similar text rules are used to displiey information about the other topics.

A similar approach would be used for the other level of detail, SUBTOPIC. However, the introduction of this level of detail requires the addition of a goal rule for each topic. This is because each topic has different subtopics. For instance, the topic General Information has four different subtopics: WBS definition, Aims of a WBS, WBS examples and Components of a WBS.

Similarly, the topic Types of WBSs has three subtopics: Summary WBS, Contract WBS and Project WBS. Each topic must have a different set of subtopics in order to ensure that for each topic, the appropriate subtopic values are presented for selection. It is for this purpose that additional rules have been added.

Each rule identifies the name of the topic, and contains a variation of the NAME_SUBTOPIC_N(Z) propositional functions. For instance, for the topic GENERAL_INFORMATION, the subtopic propositional function is represented by NAME_SUBTOPIC_1(Z) (rule 5) which is ifferent from the one in rule 6. These variations 
have been used to indicate that each variable in these propositional functions is instantinted by values from different domains.

IF

TOPIC(GENERAL_WBS_INFORMATION) AND

LEVEL_OF_DETAIL(SUBTOPIC) AND

NAME_SUBTOPIC_1(Z)

THEN

PROVIDED(INFORMATION).

IF

TOPIC(TYPES_OF_WBSS) AND

LEVEL_OF_DETAIL(SUB_TOPIC) AND

NAME_SUBTOPIC_2(Z)

THEN

PROVIDED(INFORMATION).

$Z$ is instantiated by the names of the subtopics belonging to each topic. The information about the subtopics is also displayed by the text rules.

\section{$2.2 \quad$ Initialization Rule}

Thus far it has been possible to view the information about one topic only before the value of the goal was established to be true and the session was ended. To enable viewing information about more than one topic, and also to view the same information as many times as required, the goal should not be determined to be TRUE until all the required information has been viewed. This is done by making four changes.

The first change is made to the domain of the values which can instantiate the variable $X$ in TOPIC $(X)$. An additional value QUIT is added to establish the value of the goal as TRUE and thus end the session. In the previous section QUIT was not required because 
the the value of the goal was established to be TRUE and the session was ended after the information about a topic was displayed.

The second change has been made to the values which can be used with the LEVEL_OF_DETAIL predicate. Earlier only two values OVERVIEW and SUBTOPIC could be used. Now two additional values QUIT and OTHER_TOPICS have been added. While, the function of the former is the same as discussed above, the latter facilitates the provision of the information about other topics. This is discussed later in more detail.

The third change has been made to the values in all the subtopic domains. Earlier, the variables in the various subtopic propositional functions could be instantiated only by the names of the subtopics. Two additional values, OTHER_TOPICS and OUIT, have been introduced to perform addditional functions.

The final change is the introduction of the initialization command and the initialization rule. The former is used in conjunction with the text rule while the latter is a separate rule. Like the text rule, it also uses forward chaining.

The initialization command is used in cases where automatic initialization is required and the user interaction is not needed. For instance, after viewing the overview of a topic, it may be required to view the information about the subtopic. In order to facilitate this, it is required to initialize LEVEL_OF_DETAIL(X), and then instantiate the variable with a new value, SUBTOPIC. The initialization would be done without the user's input. Rule 7 has an initialization command, INITIALIZE(LEVEL_OF_DETAIL(X)). This indicates that LEVEL_OF_DETAIL(X), has to be initialized.

IF

TOPIC(TYPES_OF_WBS) AND

LEVEL_OF_DETAIL (OVERVIEW) 
THEN

DISPLAY(TEXT_TYPES_OF_WBS) AND

INITIALIZE(LEVEL_OF_DETAIL(X)).

The initialization rule, on the other hand, is used in cases where the user input is required. For instance, after viewing the information about a particular topic, it may be required to view information about other topics. In this case the user input would be required to select the value OTHER_TOPIC. This would result in determining LEVEL_OF_DETAIL(OTHER_TOPIC) to be true and thus would activate the initialization rule to initialize the value of TOPIC(x). Rule 8 is an initialization rule.

IF

LEVEL_OF_DETAIL(OTHER_TOPICS)

THEN

INITIALIZE(TOPIC(X)).

The propositional function which is present in the initialization command/rule is initialized along with the propositions and propositional functions which followis. After the initialization, the search to achieve the goal commences by attempting to determine the value of the predicate identified in the initialization command.

Consider the given example. Assume that TYPES_OF_WBS is the selected topic, and the level of detail is OVERVIEW. At this juncture, the text pertaining to the topic would be displayed by rule 7. Next, to prevent establishing the value of the goal to be TRUE, the value of LEVEL_OF_DETAIL( $X$ ) would be initialized by the initialization command, i.e., INITIALIZE(LEVEL_OF_DETAIL(X)), present in rule 7, and the search would commence by determining the value which would instantiate the variable $x$.

This would result in presenting the four values, OVERVIEW, SUBTOPIC, OTHER_TOPIC and QUIT for selection. While OVERVIEW and SUBTOPIC provide 
information at tie two levels of detail, OTHER_TOPIC initiates an initialization rule to initialize the value of the predicate TOPIC. This would facilitate the selection of other topies. Finally, to end the session and quit the system, QUIT has to be selected. 
APPENDIX 3

\section{Database Access Rules}

To develop a new WBS by manipulating other WBSs in the development module, first the EBS has to be developed and then the support WBS. The WBSs can be developed using either single or multiple manipulation. In this Appendix, first, the database access rules for EBS development using single manipulation are presented, followed by those for multiple manipulation. Finally the rules for the development of the support WBS are presented. The development of the EBS and the support WBS is controlled by the main goal rule given below:

IF

$$
\begin{aligned}
& \text { DEVELOPED(EBS) AND } \\
& \text { DEVELOPED(SUPPORT_WBS) }
\end{aligned}
$$

THEN

DEVELOPED(WBS).

The development of the EBS, in turn, is controlled by the following rule:

IF

$$
\begin{aligned}
& \text { DEVELOPED(EBS_LEVEL_1) AND DEVELOPED(EBS_LEVEL_2) AND } \\
& \text { DEVELOPED(EBS_LEVEL_3) AND DEVELOPED(EBS_LEVEL_4) }
\end{aligned}
$$

THEN

DEVELOPED(EBS).

\subsection{Single Manipulation}

Using the case based approach, each level of the EBS is developed by retrieving the elements from the reference WBS, presenting them to the user for selection and adding the selected values to the database.The user may also want to add additional elements. If 
additional elements are added, the user has to have the ability to add elements belonging to these elements, at the next level.

The development of each level of the EBS can be broken down into four parts: First, the values are retrieved from the database and the retrieved values are presented for selection. Second, the values are selected and the selected values are added to the database. Third, the user is queried if he/she wants to add additional values. If he/she does, the values are accepted and added to the databases. Finally, it is determined if additional values have been added at the previous level. If they have, the user is given the opportunity to add elements belonging to the values entered earlier. This process is represented by the rules discussed below.

In order to facilitate the above mentioned functions, new propositional functions have been introduced. The italicized names are replaced by the names of the predicates, propositional functions, and the name of a datafile, or by a variable which would be instantiated by the name of the datafile.

To facilitate the addition and retrieval of elements, the propositional functions have the following structure: ACTION(WHAT, WHERE, CONDITION). ACCEPT( $X$ ) is used to accept the additional values added. Another propositional function $\operatorname{CHECK}(X)$ is used to transfer the control during the inferencing process. Finally,

\section{NEXT(WHAT, WHERE, CONDITIOM)}

is used $u$ determine two things: first, the presence of another element at a higher level for which the lower level has to be developed; and second, if the presence is determined, whether the lower level elements belonging to it are present in the databases, or does the user have to add them. These propositional functions are discussed below. 
The ACTION in ACTION(WHAT, WHERE, CONOITIOM) refers to the action to be performed and is either SELECT or ADD. SELECT refers to retrieving and presenting elements for selection. WHAT refers to the values on which the action has to be performed, e.g., EBS_NAME $(X)$. This means that the action has to be performed on the list $X$. WHERE refers to the database where the action has to be performed, i.e., reference database from which the values have to be retrieved and also the new database to which the selected values have to be added. This can either be a variable or a name. The variable is represented by EBS and is instantiated by the name of the EBS database.

CONDITION represents the condition for which the action is being performed. For instance, it may be required to retrieve the names of the elements in level 3 belonging to an element in level 2. In order to do this, the level and the element to which these elements belong have to be identified. In this case the condition would be represented as PART_OF(T, LEVEL(2)). Thus the entire propositional function for retrieving the level 3 values for an element in level 2 and presenting for selection can be written as,

SELECT(EBS_NAME(X), EBS, PART_OF(T, LEVEL(2)).

It is read as "retrieve all the names from the data file EBS, which belong to the element $T$ in level 2 and present them to the user for selection" ( $T$ is instantiated by a value from level 2). In some cases there may not be any condition. Such a situation would exist when the second level of the EBS is being developed. This is because the newly developed EBS does not have any elements of its own for which the member elements have is be retrieved. It is only after the second level has been developed that the member elements belonging to second level elements are retrieved. Thus, the condition would only exist after the second level has been developed.

The propositional function for adding the values is slightly different. This is because, while only the name of the element is retrieved to be presented to the user, while 
adding, the values of the all other attributes, such as level, code etc. have also to be added. To facilitate this an additional predicate ALL is introduced. ALL(EBS_NAME( $(x)$ ) indicates to the system that all the attributes for the list of names have to be added. Further, there is no condition involved while adding. Thus the propositional function to add the level 3 values belonging to an element in level 2, to the new WBS database, is represented as: ADD(ALL(EBS_NAME $(X))$, NEW_EBS , _). Here NEW_ERS is the actual name of the database where the values have to be added.

To facilitate addition of external elements, i.e, elements added by the user, a propositional function ACCEPT( $K$ ) has been introduced. It allows the user to add additional values. These values instantiate the list $K$.

The elements added externally do not have a code, though the values for the other attributes are the same as those for the other elements in that level and belonging to a particular element in the higher level. In such cases the code has to be created. Additionally, the element may be the first element under a particular higher level element. In such a situation, the values of all the attributes must be created. The creation of the code and the other attribute values is facilitated by a proposition CREATE(ATTRIBUTE_VALUES). After the values have been created, they are added by the ALL(EBS_NAME $(x)$ ) propositional function.

CHECK is used to transfer the control during inferencing. It transfers the control to the predicate or a propositional function to which it refers. For instance, CHECK(INITIALIZE $\sqcup)$ would transfer the control to the rule which contains INITIALIZE $\square$ ) in its consequent, and then determine its value using backward chaining. In order to send the control to a specific propositional function, the propositional function replaces the place holder , e.g., CHECK(INITIALIZE(BELONG_TO(LEVEL_2(G), LEVEL_1(T))). 
Finally, in NEXT(WHAT, WHERE, CONDITION), WHAT refers to the value of the attribute in the database. It can be LEVEL(M, $\operatorname{NAME}(H)$ or $\operatorname{CODE}(\boldsymbol{\eta})$. LEVEL(M) refers to the element in level $N, \operatorname{NAME}(H)$ refers to the next list of the names, and $\operatorname{CODE}(\eta)$ refers to the codes of the elements.

WHERE refers to the database in which the element has to be searched. Finally CONDITION is the condition of the database. In onder to determine the presence of another element in level 2, for which the third level has to be developed, the following representation is used:

$$
\text { NEXT(LEVEL(2), NEW_EBS, NOT_EMPTY). }
$$

On the other hand, to determine if the lower level elements for an element in level 2, in the data file NEW_EBS, exist in a datafile EBS, the following representation is used:

NEXT(LEVEL(3), EBS, PART_OF(T, LEVEL(2)) \& NOT_EMPTY)).

In order to illustrate the use of these propositional functions, an example is given below. Rules 1 and 2 are the goal rules. In order for the goal

$$
\text { DEVELOPED(EBS_LEVEL_3) }
$$

to be true the conditions in the antecedent part of either rules must be true. These conditions in tum are determined by rules 3 through 5 .

IF

BELONG_TO(LEVEL_3(Z), LEVEL_2(T)) AND

BELONG_TO(USER_LEVEL_3(K), LEVEL_2(T))

THEN

$$
\begin{aligned}
& \text { ADD(ALL(EBS_NAME(Z)), NEW_EBS, J) AND } \\
& \text { ADD(ALL(EBS_NAME(K)), NEW_EBS, ) AND } \\
& \text { CHECK(INITIALIZE(BELONG_TOL. J))AND } \\
& \text { DEVELOPED(EBS_LEVEL_3). }
\end{aligned}
$$


IF

BELONG_TO(LEVEL_3(Z), LEVEL_2(T)) AND

NOT BELONG_TO(USER_LEVEL_3(K), LEVEL_2(T))

THEN

ADD(ALL(EBS_NAME(Z)), NEW_EBS, J AND

CHECK(INITIALIZE(BELONG_TOL. J)) )AND

DEVELOPED(EBS_LEVEL_3).

Rule 3 determines the value of BELONG_TO(LEVEL_3( $Z$ ), LEVEL_2(T)), by retrieving the level 3 values belonging to level 2 and presenting them for selection. The consequent is initiated after the values have been selected by the user.

IF

SELECT(EBS_NAME(H),WBS, PART_OF(T, LEVEL(2)))

THEN

BELONG_TO(LEVEL_3(Z), LEVEL_2(T)).

IF

REQUIRE(ADDITIONAL_LEVEL_3_ELEMENTS)

THEN

ACCEPT(K) AND

BELONG_TO(USER_LEVEL_3(K), LEVEL_2(T)) AND

CREATE(ATTRIBUTE_VALUES).

IF

NOTREQUIRE(ADDITIONAL_LEVEL_3_ELEMENTS) THEN

NOT BELONG_TO(USER_LEVEL_3(K), LEVEL_2(T)).

Assume that the values have been retrieved and selected, and the consequent has been initiated. Next the system would try to determine the value of the second part of the antecedent of the goal rule, BELONG_TO(USER_LEVEL_3(K), LEVEL_2(T)). This can be done either by rule 4 or 5 . To determine its value, the system would query the user to 
determine if he/she wants to add additional level 3 elements belonging to the level 2 element. If the response is positive, the proposition

\section{REQUIRE(ADDITIONAL_LEVEL_3_ELEMENTS)}

would be determined as being true and the consequent,

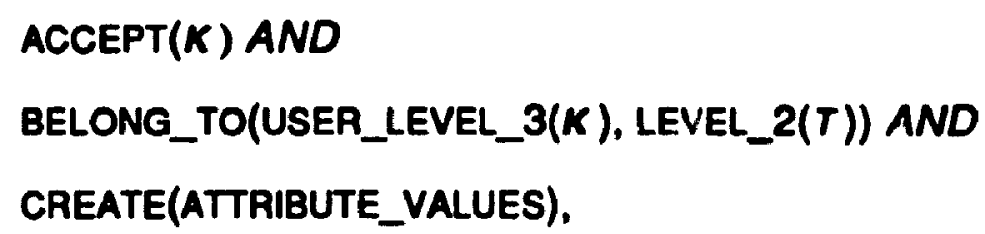

would be initiated. The additional values would be accepted, assigned to level 3 under the level 2 element, the attribute values would be created and

$$
\text { BELONG_TO(USER_LEVEL_3(K), LEVEL_2(T)) }
$$

would be determined to be true. On the other hand if the user does not want to add additional elements, NOT REQUIRE(ADDITIONAL_LEVEL_3_ELEMENTS) would be determined to be true and the consequent would be initiated, thereby determining

NOT BELONG_TO(USER_LEVEL_3(K), LEVEL_2(T))

to be true.

In either case the antecedent conditions of one of the goal rules would be met and the consequent would be initiated. If additional elements were entered, the antecedent conditions of rule 1 would be met. On the other, hand if they were not required, the antecedent conditions of rule 2 would be satisfied and the consequent would be initiated. In both cases the values would be added to the database, NEW_EBS.

Next, CHECK(INITIALIZE(BELONG_TOL, J)), in the consequent of the goal ruie, would transfer the control to the rule which contains the INITIALIZE(BELONG_TO $L\lrcorner$,$) )$ proposition in its consequent. In this case the control would be transferred to either rules 6 or 7. After the control has been transferred, an attempt would be made to determine whether BELONG_TO $L$,$\rfloor should be initialized. This initialization is required because,$ 
thus far, the third level values for only one second level element have been added. There could be more than one element in the second level for which the level 3 values have to be retrieved and added. This is determined by the initialization rule, rule 6 , and if more elements are found, facilitated by it too.

IF

NEXT(LEVEL(2), NEW_EBS, NOT_EMPTY) AND

NEXT(EBS_NAME(K), EBS, PART_OF(T, LEVE!(2)) \& NOT_EMPTY)

THEN

INITIALIZE (BELONG_TOL. J).

IF

NEXT(LEVEL(2), NEW_EBS, NOT_EMPTY) AND

NEXT(EBS_NAME(K), EBS, PART_OF(T, LEVEL(2)) \& EMPTY)

THEN

NOT INITIALIZE (BELONG_TOL. J) AND

INITIALIZE (BELONG_TO(LEVEL_3(G), LEVEL_2(T))) AND

CHECK(BELONG_TO(LEVEL_3(G), LEVEL_2(T)).

After the control has been transferred, in order to determine INITIALIZE(BELONG_TO $L$, J) as true, NEXT(LEVEL(2), NEW_EBS, NOT_EMPTY) and NEXT(EBS_NAME(K), EBS, PART_OF(T, LEVEL(2)) \& NOT_EMPTY) must be determined to be true. The second propositional function is for determining whether the level three values are present in the database.

In order to determine these values, the system would search for the next element in level 2 in the NEW_EBS database. If it is found,

NEXT(LEVEL(2), NEW_EBS, NOT_EMPTY)

would be determined to be true. Next it would search in the reference database for the names of the level three elements belonging to it. The reference EBS databases would be searched because at least a few of the level 2 elements present in the NEW_EBS have been 
added from the reference EBS. Thus, these elements have lower level elements present in the reference EBS. If found, the value of

NEXT(EBS_NAME(K), EBS, PART_OF(T, LEVEL(2)) \& NOT_EMPTY)

would be determined to be true and the consequent of rule 6 would be initiated. This would result in initializing the value of all the BELONG_TOL_ J predicates and the search to achieve the goal would commence once again because DEVELOPED(LEVEL_3) would not be determined to be true.

However, this time the level 3 values for the next level 2 element, the element found by the system before the initialization took place, would be retrieved. This process of retrieval and addition would continue until the level 3 values for all the level 2 elements have been retrieved and presented for selection.

However, if NEXT(LEVEL(2), NEW_EBS, NOT_EMPTY) were determined to be true and NEXT(EBS_NAME(K), WBS, PART_OF(T, LEVEL(2)) \& EMPTY) were determined to be true, the consequent of rule 7 would be initiated. Such a situation would arise if the user input additional elements at the previous level, i.e, level $\mathbf{2}$ in this case. The initiation of the consequent of rule 7 would determine,

NOT INITIALIZE(BELONG_TOL. J), and

INITIALIZE(BELONG_TO(USER_LEVEL_3(G), LEVEL_2(T)) and

CHECK (BELONG_TO(USER_LEVEL_3(G), LEVEL_2(T)) to be true.

CHECK (BELONG_TO(USER_LEVEL_3(G), LEVEL_2(T)) would transfer the control to rule 8. In this rule BELONG_TO(USER_LEVEL_3(G), LEVEL_2(T) would be determined to be true if the user wanted to add level three elements for the level 2 elements added earlier. If he/she does want to add the level three values, the value of the antecedent would be established to be true and the consequent would be initiated. This would result in the level three values being accepted and added to the database. Next, another CHECK 
predicate would transfer the control back to the initialization rules 6 and 7 to determine if there are any more level 2 elements for which the third level has to be developed. In case there are, the same process would continue. If not, the control would be transferred back to the goal rule, where DEVELOPED(EBS_LEVEL_3) would be determined to be true. All the levels of the WBS are develuped in this manner.

IF

$$
\text { REOUIRE(LEVEL_3_ELEMENT) }
$$

\section{THEN}

$\operatorname{ACCEPT}(G)$ AND

BELONG_TO(USER_LEVEL_3(G), LEVEL_2(T))AND

CREATE(ATTRIBUTE_VALUES) AND

ADD(ALL(EBS_NAME(G)), NEW_EBS, _)AND

CHECK(INITIALIZE(BELONG_TOL, $L)$ ).

The predicate BELONG_TO is used to establish the relationship between the level 2 and the level 3. By establishing this relationship, it can be used to provide explanations for the How and the Why functions.

\subsection{Multiple Manipulation}

While the propositions and the propositional functions used in the rules for multiple manipulation are nearly all the same as those in single manipulation, the rules are different. The main difference lies in the retrieval of values from the databases and their presentation to the user for selection.

To retrieve the values, the database in which they are present must be determined since the member elements for an element in the EBS being developed can be present in the primary EBS or in one of the secondary EBSs. Next, the elements which may be related to the member elements must be determined. This is done in two stages. In the first stage, the 
relationship between mutually exclusive elements is assessed. In the second stage the relationship between additive elements is determined.

Once this process is complete, the elements are retrieved and presented to the user. This is done in two steps. First the mutually exclusive elements are retrieved, presented for selection, and the selected elements are added. In the second step the non-mutually exclusive elements from the primary, and the additive elements (elements having $A$ as the CHARACTERISTIC value) from the secondary EBSs, are retrieved and presented for selection. The selected elements are added to the new EES database.

Before the commencement of the development, the values for the second level elements are present in the primary EBS database. Thus the primary EBS database is searched and the elements are retrieved. In addition, the secondary EBSs have to be searched to determine the presence of the elements related to those in the primary EBS.

In the development of the lower level for an element in the higher level, one of three possibilities can occur:

1) Only elements which are mutually exclusive with the member elements are present;

2) Only elements which are additive under the higher level elements exist; or 3) Both mutually exclusive and additive elements exist, i.e. one element may be additive under the higher level element present in the EBS being developed, while another may be mutually exclusive with a member element present in the primary EBS.

In order to determine the presence of these elements in the databases, a propositional function of the form: PRESENT(WHAT, WHERE, CONDITIOM, is used. It has two variants. The first variant, PRESENT(EBS_NAME(X), EBS, PART_OF(T, LEVEL(2)), is similar to SELECT(EBS_NAME( $X$ ), EBS, PART_OF(T, LEVEL(2)). The difference being 
that, while the latter retrieves the level 3 values belonging to $T$ in level 2, the former simply determines their presence.

The second variant of PRESENT(WHAT, WHERE, CONDITIOM) differs from the first in the WHERE and CONDITION clauses. The former has a list, while the latter includes the characteristic values, e.g., EBS(CHAR(ME), ELEM( $(\eta$. The presence of element(s), in the secondary EBSs, which may be mutually exclusive to an element in the primary EBS is represented as,

PRESENT(EBS_NAME(H), EBS_S, EBS(CHAR(ME), ELEM( $(\eta)$ ).

Here EBS_S represents the list of the names of the secondary EBSs. Similarly, PRESENT(EBS_NAME(H), EBS_S, EBS(CHAR(A), ELEM( $Y)$ ), is used to determine the presence of the additive elements in the various secondary EBSs. Consider the example given below.

Rules 9 and 10 are the goal rules. They are same as the goal rules used for single manipulation. The values of the antecedents of these goal rules depend on rules 11,12 and 13. These rules differ from the ones used in single manipulation in that the database in which the member elements may be present must be determined first followed by the location of the other related elements. In this example, it is assumed that the member elements are present initially in the primary EBS. This assumption will be relaxed later.

IF

BELONG_TO(LEVEL_3(Z), LEVEL_2(T)) AND

BELONG_TO(USER_LEVEL_3(K), LEVEL_2(T))

THEN

CHECK (INITIALIZE(BELONG_TOL, J)) AND

DEVELOPED(EBS_LEVEL_3). 
$F$ THEN

BELONG_TO(LEVEL_3(Z), LEVEL_2(T)) AND

NOT BELONG_TO(USER_LEVEL_3(K), LEVEL_2(T))

CHECK (INITIALIZE(BELONG_TO)) AND

DEVELOPED(EBS_LEVEL_3).

The difference between rules, 11, 12 and 13 lies in the propositional functions, in the antecedents, which determine the presence of the elements in the various databases, and the propositional functions which retrieve these elements. For the antecedent of rule 11 to be true, a member element (only one element) for a higher level element which instantiates the variable $T$, must be present in the primary EBS, and the elements which are mutually exclusive with it have to be present in the secondary EBSs. Similarly, for the antecedent of rule 12 to be true, the member elements (which do not have mutually exclusive elements in the secondary EBSs) must be present in the primary EBS and the additive elements have to be present in the secondary EBSs. Finally the antecedent of rule 13 would be true if only the member elements are present in the primary EBS and there are no mutually exclusive or additive elements present.

It can be seen that at any one time the presence of only one type of element is determined, i.e., mutually exclusive (rule 11) or additive (rule 12). In cases where neither mutually exclusive nor additive elements are present, the presence of the member elements is determined in the primary EBS only (13). Based on which antecedent is determined to be true, the consequent would be initiated and the elements would be retrieved and presented for selection.

It should be noted that in the determining and the retrieval processes first the mutually exclusive elements are determined and retrieved, followed by the additive and the non-mutually exclusive elements. 
IF

PRESENT(EBS_NAME(J), EBS, PART_OF(T, LEVEL(2)) AND

PRESENT(EBS_NAME(H), EBS_S, EBS(CHAR(ME), ELEM(Y)

THEN

SELECT(EBS_NAME(J), EBS, PART_OF(T, LEVEL(2)) AND

SELECT(EBS_NAME(H), EBS_S, EBS(CHAR(ME), ELEM(Y)) AND

BELONG_TO(LEVTL_3(Z), LFVEL_2(T)) AND

ADD(ALL(EBS_NAME(Z),NEW_EBS, J.

IF

PRESENT(EBS_NAME(I), EBS, PART_OF(T, LEVEL(2)) AND

PRESENT(EBS_NAME(T), EBS_S, EBS(CHAR(A), ELEM(Y))

THEN

SELECT(EBS_NAME(I), EBS, PART_OF(T, LEVEL(2)) AND

SELECT(EBS_NAME(T), EBS_S, EBS(CHAR(A), ELEM(Y)) AND

BELONG_TC(LEVEL_3(Z), LEVEL_2(T)) AND

ADD(ALL(EBS_NAME(Z), NEW_EBS, ).

F

PRESENT(EBS_NAME( 1$), E B S$, PART_OF(T, LEVEL(2)) AND

NOT PRESENT(EBS_NAME(H), EBS_S, EBS(CHAR(ME), ELEM(Y)) AND

NOT PRESENT(EBS_NAME(T), EBS_S, EBS(CHAR(A), ELEM(Y)

THEN

SELECT(EBS_NAME( $)$, EBS, PART_OF( $T$, LEVEL(2)) AND

BELONG_TO(LEVEL_3(Z), LEVEL_2(T)) AND

ADD(ALL(EBS_NAME(Z), NEW_EBS, ).

The consequent in each of the three rules, 11 through 13, have a proposition and a propositional function in addition to the propositional functions for recrieving the values. The first, BELONG_TO(LEVEL_3(Z), LEVEL_2(T)), establishes the value of level 3 elements which belong to the level 2 element. Once this has been done it would be determined to be true. Next these values are added to the NEW_EBS database by ADD(ALL(EBS_NAME(Z),NEW_EBS, J. 
After BELONG_TO(LEVEL_3(Z), LEVEL_2(T)) has been determined to be true and the values have been added, the value of the the second propositional function,

BELONG_TO(USER_LEVEL_3(K), LEVEL_2(T)),

in the antecedent of the goal rule, has to be determined. Its value would be determined by the rules 14 and 15. In order for its value to be true the antecedent, REQUIRE(ADDITIONAL_LEVEL_3_ELEMENTS), must be true. This would be true if the user wants to add additional values. If it is determined to be true, the additional values would be accepted and assigned to the level 2 element and added to the database. This would result in determining,

BELONG_TO(USER_LEVEL_3(K), LEVEL_2(T)) and ADD(ALL(EBS_NAME(Z), NEW_EBS, 」) as being true.

However, if the user does not want to add additional values, NOT REQUIRE(ADDITIONAL_LEVEL_3_ELEMENTS), would be determined to be true and the consequent would be initiated. This would result in determining the value of NOT BELONG_TO(USER_LEVEL_3(K), LEVEL_2( $T)$ ) as being true. In either case, the antecedent conditions of one of the goal rules would be determined to be true. If the additional values were added, the antecedent of goal rule 9 would be determined to be true. If they were not added, the value of the antecedent of goal rule 10 would be determined as being being true.

IF

REQUIRE(ADDITIONAL_LEVEL_3_ELEMENTS)

THEN

ACCEPT(K) AND

CREATE(ATTRIBUTE_VALUES) AND

BELONG_TO(USER_LEVEL_3(K), LEVEL_2(T)) AND

ADD(ALL)(EBS_NAME( $Z$ ), NEW_EBS, 」). 
IF

NOT REOUIRE(ADDITIONAL_LEVEL_3_ELEMENTS)

THEN

NOT BELONG_TO(USER_LEVEL_3(K), LEVEL_2(T)).

This would result in initiating the consequent of one of the rules. The CHECK(INITIALIZE(BELONG_TO $L\lrcorner$,$) ) proposition present in the consequent of the goal$ rules would transfer the control to the initialization rules, 16 through 19 . This transfer of control is required because there could be other elements, under the higher level element, which could be added.

IF

NEXT(LEVEL(3), EBS, PART_OF(T, LEVEL(2)) \& NOT_EMPTY) THEN

INITIALIZE(BELONG_TOL. J).

IF

NEXT(LEVEL(3), EBS, PART_OF(T, LEVEL(2)) \& EMPTY) AND

NEXT(LEVEL(2), NEW_EBS, PART_OFL , LEVEL(1)) \& NOT_EMPTY) AND

NEXT(LEVEL(3), EBS, PART_OF(T, LEVEL(2)) \& NOT_EMPTY) THEN

INITIALIZE(BELONG_TO $(\lrcorner$,$) ).$

In the previous case when element(s) were added, one of the three actions could have been performed:

1) A member element which was mutually exclusive with elements from the secondary EBSs was found, and all these mutually exclusive elements were presented for selection. Of these one was selected and added to the databases.

2) No mutually exclusive elements were foun: but additive elements were. These along with the non-mutually exclusive member elements were presented for selection and some or all were selected and added. 
3) Finally, no mutually exclusive or additive elements were found and only the member elements were presented for selection and added.

In the second and the third cases there would no more remaining member elements belonging to that particular higher level element, which could be added. This is because first the mutually exclusive elements are presented followed by the additive and the nonmutually exclusive elements, and if neither mutually exclusive nor additive elements exist, only then the member elements are presented.

However if a member element were found to be mutually exclusive with some secondary element(s), in the next round, three other situations could exist which would require the retrieval of the other member elements:

1) There could be other mutually exclusive element(s) among the member elements (these elements are mutually exclusive with elements in the other EBSs and not among themselves) along with other non-mutually exclusive elements, which would have to be retrieved and presented for selection.

2) There could be additive elements present along with other non-mutually exclusive member elements.

3) Finally, only other non-mutually exclusive elements could be present.

This would require the repetition of rules in order to determine where these elements are present, retrieve them, present them to the user for selection and finally add the selected elements to the database. This is facilitated by the initialization rules.

Rule 16 initializes the predicate BELONG_TO $L, J$ if some other member elements are found. In case no ocher member elements are found for that particular higher level element, it has to be determined if some higher level (level 2 in this case) elements are 
present for which the lower level (level 3 in this case) has to be developed. In case the level two elements are present, NEXT(LEVEL(2), NEW_EBS, NOT_EMPTY) in rule 17, would be determined to be true.

Next, it must be determined whether the level three elements for the level 2 element are in the databases or have to be entered by the user. If they are present in the database, then NEXT(LEVEL(3), EBS, PART_OF(T, LEVEL(2)) \& NOT_EMPTY), in rule 17, is determined to be true. The consequent is initiated and the predicate BELONG_TOL, $J$ is initialized. This results in the re-commencement of the attempt to determine the value of the goal, by repeating the previous rules.

If NEXT(LEVEL(3), EBS, PART_OF(T, LEVEL(2)) \& NOT_EMPTY) were determined to be false, i.e., level three elements belonging to the level 2 element were not found, then NEXT(LEVEL(3), EBS, PART_OF(T, LEVEL(2)) \& EMPTY) in rule 18 would be determined to be true. Next, in order to determine the value of the proposition REQUIRE(LEVEL_3_ELEMENT), the user would be queried to determine if he/she wants to add the level three values. If the answer is affirmative, the consequent of rule 18 would be initiated and the values would be accepted, assigned to the level two element, added to the database and the initialization rules would be initialized to determine if other elements are present. This would be done by the proposition, INITIALIZE(INITIALIZE(BELONG_TOL, J)). If other elements are present, the same process would be repeated.

If the user does not want to add the additional values, the antecedent conditions of rule 19, would be determined to be true and the consequent would be initiated. Since no values were added, no level three values have to be assigned to the level 2 element. Therefore, NOT BELONG_TO(LEVEL_3(G), LEVEL_2(T)) would be determined to be true. Although BELONG_TOL, J does not have to be initialized but, as in rule 18 , the 
initialization rules have to be initialized to determine if there are any other elements which have to be retrieved. Once it is determined that no other elements exist, the value of DEVELOPED(EBS_LEVEL_3) would be determined as being true and the development of the next level would commence.

IF

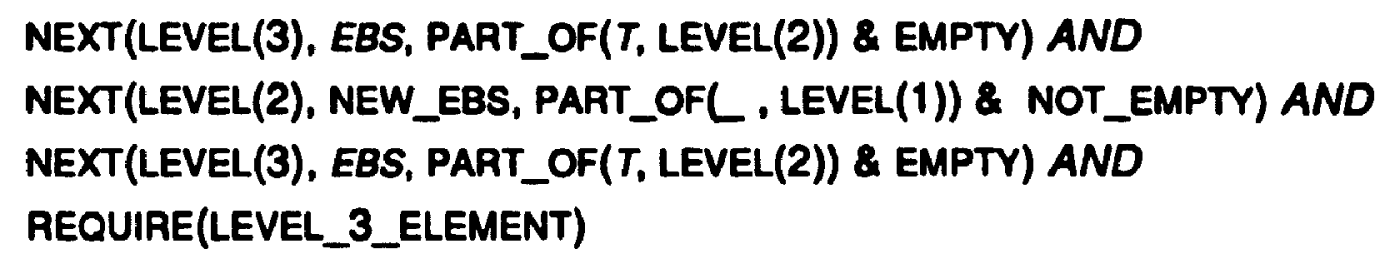

IF

NEXT(LEVEL(3), EBS, PART_OF(T, LEVEL(2)) \& EMPTY) AND NEXT(LEVEL(2), NEW_EBS, PART_OFL , LEVEL(1)) \& NOT_EMPTY) AND NEXT(LEVEL(3), EBS, PART_OF(T, LEVEL(2)) \& EMPTY) AND NOT REQUIRE(LEVEL_3_ELEMENT)

\section{THEN}

NOT BELONG_TO(USER_LEVEL_3(G), LEVEL_2(T)) AND NOT INITIALIZE(BELONG_TOL, J) AND INITIALIZE(INITIALIZE(BELONG_TOL, $L$ )).

Thus far it has been assumed that the member elements were present in the primary EBS. Now this assumption is relaxed. The member elements can be present in any of the EBSs. In order to accommodate this, new rules are introduced. These rules are similar to rules 11 through 13 , in that the goal rules depend on them. In this case, the secondary EBSs are split into two groups: one which contains the member element and another which 
consists of elements which may be related to the member elements. The first group is represented by the variable, EBS_S1, and the second is represented by the list EBS_S2. Thus, three rules are required:

rule 20 for determining and retrieving mutually exclusive elements;

rule 21 for determining and retrieving additive and non-mutually exclusive member elements; and rule (22) for retrieving the member elements only .

IF

PRESENT(EBS_NAME( (), EBS_S1, PART_OF(T, LEVEL(2)) AND PRESENT(EBS_NAME(H), EBS, EBS_S1(CHAR(ME), ELEM( $(\eta)$ AND PRESENT(EBS_NAME(H), EBS_S2, EBS_S1(CHAR(ME), ELEM(Y)

THEN

SELECT(EBS_NAME(J), EBS_S1, PART_OF(T, LEVEL(2)) AND SELECT(EBS_NAME(H), EBS, EBS_S1(CHAR(ME), ELEM(Y)) AND SELECT(EBS_NAME(H), EBS_S2, EBS_S1(CHAR(ME), ELEM(Y) AND BELONG_TO(LEVEL_3(Z), LEVEL_2(T)) AND $A D D(A L L$ (EBS_NAME( $Z$ ), NEW_EBS, 」).

IF

PRESENT(EBS_NAME(1), EBS_S1, PART_OF(T, LEVEL(2)) AND PRESENT(EBS_NAME( $(\eta), E B S$, EBS_S1(CHAR(A), ELEM( $(\eta))$ AND PRESENT(EBS_NAME( $(\eta), E B S \_S 2, E B S \_S 1(C H A R(A), \operatorname{ELEM}(\eta))$

THEN

SELECT(EBS_NAME( $(1)$, EBS_SI, PART_OF(T, LEVEL(2)) AND SELECT(EBS_NAME( $)$, EBS, EBS_S1(CHAR(A), ELEM( $\eta)$ AND SELECT(EBS_NAME(T), EBS_S2, EBS_S1(CHAR(A), ELEM(V)) AND BELONG_TO(LEVEL_3(Z), LEVEL_2(T)) AND ADD(ALL(EBS_NAME( $Z$ ), NEW_EBS, $)$.

IF

PRESENT(EBS_NAME( 1 ), EBS_S1, PART_OF(T, LEVEL(2)) AND NOT PRESENT(EBS_NAME(H), EBS, EBS_S1(CHAR(ME), ELEM( $(\eta)$ AND 
NOT PRESENT(EBS_NAME(H), EBS_S2, EBS_S1(CHAR(ME), ELEM(ク)

AND

NOT PRESENT(EBS_NAME(T), EBS, EBS_S1(CHAR(A), ELEM( $(\eta)$ AND

NOT PRESENT(EBS_NAME(T), EBS_S2, EBS_S1(CHAR(A), ELEM( $(\eta)$

THEN

SELECT(EBS_NAME( $(1)$, EBS_S, PART_OF(T, LEVEL(2)) AND

BELONG_TO(LEVEL_3(Z), LEVEL_2(T)) AND

$A D D(A L L$ (EBS_NAME( $Z$ ), NEW_EBS, _).

Three more initialization rules have also been introduced. The only difference between these and the ones presented earlier is in the name of the database where the next element may be present. These rules are given below:

IF

NEXT(LEVEL(3), EBS_S1, PART_CF(T, LEVEL(2)) \& NOT_EMPTY) THEN

INITIALIZE(BELONE_TOL. $\lrcorner)$ ).

IF

NEXT(LEVEL(3), EBS_S1, PART_OF(T, LEVEL(2)) \& EMPTY) AND NEXT(LEVEL(2), NEW_EBS, PART_OFL, LEVEL(1)) \& NOT_EMPTY) AND NEXT(LEVEL(3), EBS_S1, PART_OF(T, LEVEL(2)) \& EMPTY) AND REQUIRE(LEVEL_3_ELEMENT)

THEN

ACCEPT(G) AND

BELONG_TO(USER_LEVEL_3(G), LEVEL_2(T))AND

CREATE(ATTRIBUTE_VALUES) AND

ADD(ALL(EBS_NAME(G)), NEW_EBS, JAND

INITIALIZE(INITIALIZE(BELONG_TOL.」)).

IF

NEXT(LEVEL(3), EBS_S1, PART_OF(T, LEVEL(2)) \& EMPTY) AND NEXT(LEVEL(2), NEW_EBS, PART_OFL, LEVEL(1)) \& NOT_EMPTY) AND NEXT(LEVEL(3), EBS_S1, PART_OF(T, LEVEL(2)) \& EMPTY) AND NOT REQUIRE(LEVEL_3_ELEMENT) 


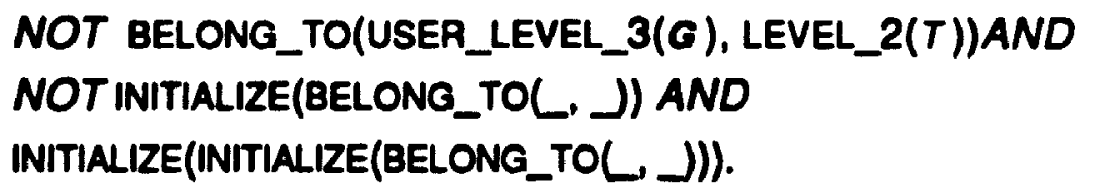

\subsection{Supoot WBS}

The representation for both single manipulation and multiple manipulations is the same and is presented below. The development of the Support WBS consists of three steps:

1) The addition of the support elements for the EBS elements, present in the newly developed EBS, which were retrieved from the reference EBSs.

2) The addition of the support elements for the EBS elements which were added externally.

3) The addition of additional support elements.

The addition of the support elements for the EBS elements, retrieved from the reference EBSs, is a two stage, bottom-up process. First an element from the newly developed EBS has to be matched with the element under the ELEM attribute in the suFport WBS. If the attempt is successful, the support activity, along with the values for all the other attributes, is transferred to the file which contains the new support WBS. It is possible that this support activity is present in a lower level, say level 4. In such a case the element would have an owner element in level 3 which, along with the values for all the attributes, would have to be added to the new support WBS. The level 3 element, in turn, would have an owner element in level $\mathbf{2}$ which also would have to be added. Level $\mathbf{2}$ is the highest level in the hierarchy for the support activities. Thus, in every case, the system would have to search for owner elements until it reaches level 2 and then add all the values, along with the values for the other attributes, to the new support WBS database. 
In case matching elements are not found, it is assumed that there are no support elements for that EBS element. Once the support elements have been added for all the EBS elements present in the newly developed EBS, which were retrieved from the reference EBSs, the user has the option to add the support elements for the externally added EBS elements. The user can add the support elements for these EBS elements by choosing from those present in the support WBS, and also by adding support activities using the keyboard.

Finally, if additional support activities have to be added for the EBS elements present in the newly developed EBS which were retrieved from the reference EBSs, the user can do so. This is done by first identifying the owner element to which the support activity belongs and then by identifying the EBS elements for which it is required.

This entire process is modeled by the rules given below. These rules contain some additional propositional functions of the form: MATCH(WHAT, WITH, WHERE), SUPPORT_FOR(EBS ELEMENT, SUFPORT ELEMENT), CHANGE_VALUE(MEMBER ELEMENT, OWNER ELEMENT), EXIST(OWNER ELEMENT, WHERE, MEMBER ELEMENT).

The italicized names are replaced by the names of the propositional functions, datafile or by a variable which would be instantiated by the name of a datafile. These are discussed below.

In MATCH(WHAT, WITH, WHERE), MATCH refers to matching the elements in two databases. WHAT refers to the element in newly developed EBS, which was retrieved from the reference EBSs and has to be matched. It is represented by EBS_NAME(E). WITH refers to the element with which the element in the EBS has to be matched. It is present in the 
reference support WBS, under the EBS ELEM attribute and is represented by EBS_ELEM(P). WHERE refers to the names of the support WBSs and is represented by the list SUPP_WBS. Thus to match an element in the NEW_EBS database with the element present under the EBS ELEM attribute in the support EBS, the following representation is used: MATCH(EBS_NAME(E), EBS_ELEM(P), SUPP_WBS).

Another propositional function, SUPPORT_FOR(EBS ELEMENT, SUPPORT ELEMENT), has been used to represent the relationship between the support activity and the EBS element for which it is required. EBS ELEMENT refers to the EBS element for which the support is required, and is represented by EBS_NAME(E). SUPPORT ELEMENT is the support activity which is required for the EBS element and is represented by SUPPORT_NAME(S) and USER_SUPPORT_NAME(S). While the former refers to the names of the support activities present in the support WBSs, the latter refers to the name of the support activity entered externally.

The CHANGE_VALUE(MEMBER ELEMENT, OWNER ELEMENT) propositional function refers to replacing the value of the owner elements with the values of the member elements. The member elements are represented by SUPPORT_NAME(S) and the owner elements by OWNE 2_SUPPORT_NAME(O). The values are changed by instantiating the list $S$ by the value which instantiated the list 0 .

Finally, EXIST(OWNER ELEMENT, WHERE, MEMBER ELEMENT) refers to determining if an owner element for a member element exists in a database. The owner element(s) is represented by, OWNER_SUPPORT_NAME(O), and the member element(s) by SUPPORT_NAME(S). WHERE refers to the database which is represented by the list, SUPP_WBS. 
Tuese propositional functions, along with those introduced in the previous sections, are used in the rules below. Rules 26 through 28 are the goal rules. The antecedents in each of the rules correspond to the three steps of the development mentioned earlier. The first proposition, ADDED_SUPPORT(REFERENCE_EBS_ELEMENTS), would be true if the support activities are added for the EBS elements present in the newly developed EBS, which were retrieved from the reference EBSs. These are referred to as REFERENCE_EBS_ELEMENTS.

The second, ADDED_SUPPORT(EXTERNAL_EBS_ELEMENTS), would be true if the support elements were added to the EBS elements entered externally. The externally entered EBS elements are referred to as EXTERNAL_EBS_ELEMENTS.

Finally, ADDED_EXT_SUPPORT(REFERENCE_EBS_ELEMENTS) would be true if the additional support elements were added to the EBS elements which were retrieved from the reference databases. However, in case no elements were entered extemally, NOT ADDED_SUPPORT(EXTERNAL_EBS_ELEMENTS) in rule 27 would be determined to be true. Further, if the user does not want to add additional support elements, NOT ADDED_EXT_SUPPORT(REFERENCE_EBS_ELEMENTS) in rule 28 would be determined to be true. Thus depending on which propositional functions are determined as being being true, one of the rules would be used.

IF

ADDED_SUPPORT(REFERENCE_EBS_ELEMENTS) AND

ADDED_SUPPORT(EXTERNAL_EBS_ELEMENTS) AND

ADDED_EXT_SUPPORT(REFERENCE_EBS_ELEMENTS)

THEN

DEVELOPED(SUPPORT_WBS).

IF

ADDED_SUPPORT(REFERENCE_EBS_ELEMENTS) AND 
NOT ADDED_SUPPORT(EXTERNAL_EBS_ELEMENTS) AND

ADDED_EXT_SUPPORT(REFERENCE_EBS_ELEMENTS)

THEN

DEVELOPED(SUPPORT_WBS).

IF

ADDED_SUPPORT(REFERENCE_EBS_ELEMENTS) AND

NOT ADDED_SUPPORT(EXTERNAL_EBS_ELEMENTS) AND

NOT ADDED_EXT_SUPPORT(REFERENCE_EBS_ELEMENTS)

THEN

DEVELOPED(SUPPORT_WBS).

The first step of the support WBS development process commences with an attempt to determine the value of the proposition

ADDED_SUPPORT(REFERENCE_EBS_ELEMENTS).

This is determined by the rules 29 and 30 . The antecedent in this rule would be true if the support elements for an EBS element, which was retrieved from the reference EBS, are determined. It's value in turn depends on rules 31 and 32 . The antecedent in rule 31 requires that the EBS element, present in the newly developed EBS, should match another present under the EBS ELEM attribute. If this is successful, the consequent would be initiated. The value of the support elements would instantiate the list $\mathbf{S}$ and the relationship between the EBS element and the support would be determined by SUPPORT_FOR(EBS_NAME(E), SUPPORT_NAME(S)), and it would be determined to be true. Next all the values would be added to the database.

The control would then be transferred to rule 33 and 34 by CHECK(BELONG_TO(SUPPORT_NAME(S), OWNER_SUPPORT_NAME(O))) to determine if the support elements which instantiated the list, $S$, have owner elements. In case they do, the relationship between them is established and the owner elements, along with the values of the other attributes, are added to the dutabase. Next the values are 
changed between the propositional functions, SUPPORT_NAME(S) and OWNER_SUPPORT_NAME(O),

i.e, the values which instantiated the list $O$ would now instantiate the list $\mathbf{S}$. This would result in determining if there are owner elements for these elements. This is done by initializing the propositional function,

(BELONG_TO(SUPPURT_NAME(S), OWNER_SUPPORT_NAME(O)),

in the rule itself. Thus the search for the owner elements would begin once again, but this time the system would search for a owner elements for the owner elements relrieved in the previous round. This process of determination, addition, revaluation and initialization would continue until there are no more owner elements. At this stage,

NOTEXIST(OWNER_SUPPORT_NAME(O), SUPP_WBS, SUPPORT_NAME(S)), would be determined to be true, the consequents would be initiated, and the control transferred back to the rule from where it was transferred, 31 .

$\mathbb{I F}$

THEN

SUPPORT_FOR(EBS_NAME(E), SUPPORT_NAME(S))

ADDED_SUPPORT(REFERENCE_EBS_ELEMENTS).

IF THEN

NDT SUPPORT_FOR(EBS_NAME(E), SUPPORT_NAME(S))

NOT ADDED_SUPPORT(REFERENCE_EBS_ELEMENTS).

IF

MATCH(EBS_NAME(E), EBS_ELEM(P), SUPP_WBS)

THEN

SUPPORT_FOR(EBS_NAME(E), SUPPORT_NAME(S)) AND

ADD(ALL(EBS_ELEM(P), NEW_SUPP, J AND

CHECK(BELONG_TO(SUPPORT_NAME(S), OWNER_SUPPORT_NAME(O))) AND 
CHECK(INITIALIZE(SUPPORT_FOR(EBS_NAME(E), SUPPORT_NAME(S))).

IF

NOT MATCH(EBS_NAME(E), EBS_ELEM(P), SUPP_WBS) AND THEN

NOT SUPPORT_FOR(EBS_NAME(E), SUPPORT_NAME(S)) AND CHECK(INITIALIZE(SUPPORT_FOR(EBS_NAME(E), SUPPORT_NAME(S))).

IF

EXIST(OWNER_SUPPORT_NAME(O), SUPP_WBS,SUPPORT_NAME(S)) THEN

BELONG_TO(SUPPORT_NAME(S), OWNER_SUPPORT_NAME(O))) AND ADD(ALL(OWNER_SUPPORT_NAME(O), NEW_SUPP, ) AND CHANGE_VALUE(SUPPORT_NAME(S), OWNER_SUPPORT_NAME(O)) AND INITIALIZE(BELONG_TO(SUPPORT_NAME(S), OWNER_SUPPORT_NAME(O))).

IF

NOTEXIST(OWNER_SUPPORT_NAME(O), SUPP_WBS, SUPPORT_NAME(S)) THEN

NOT (BELONG_TO(SUPPORT_NAME(S), OWNER_SUPPORT_NAME(O))).

After the owner elements have been determined and added, the control would be transferred to two other initialization rules, 35 and 36 , by

CHECK(INITIALIZE(SUPPORT_FOR(EBS_NAME(E), SUPPORT_NAME(S))),

in rule 31. This is done to determine the presence of another element in the EBS for which support elements are required. If it exists, then the antecedent of rule 35 would be determined to be true, and the propositional function

$$
\text { SUPPORT_FOR(EBS_NAME(E), SUPPORT_NAME(S)) }
$$

would be initialized and the attempt to match the element would commence again. This 
would continue until the support elements have been added for all the applicable elements. At this stage the antecedent condition of rule 36 would be determined to be true and the consequent would be initiated.

The above rules would be used if the support elements are located for the EBS elements present in the NEW_EBS database. However, it could be possible that some EBS elements do not have a support element. In this case the artecedent of rule 32 would be determined to be true and the consequent would be initiated establishing that there are no support element(s) for the EBS element and, as in the previous case, transfer the control to the initialization rules 35 and 36 .

IF

NEXT(EBS_NAME(E), NEW_EBS, NOT_EMPTY)

THEN

INITIALIZE(SUPPORT_FOR(EBS_NAME(E), SUPPORT_NAME(S)).

IF

NEXT(EBS_NAME(E), NEW_EBS, EMPTY)

THEN

NOT INITIALIZE(SUPPORT_FOR(EBS_NAME(E), SUPPORT_NAME(S))).

Once the support elements have been added for all the EBS elements which were retrieved from the reference EBSs, the support element can be added for the EBS elements entered using the keyboard. This is the second step of the support WBS development process and is represented by

\section{ADDED_SUPPORT(EXTERNAL_EBS_ELEMENTS)}

in the goal rules (26 - 28). It, in turn, involves two steps: first, adding the support elements which are already present in the support reference WBSs; and second, adding the support elements using the keyboard. 
To determine if support elements are to be added for the externally added EBS elements, the rules 37 through 40 are used. There are two propositional functions in the antecedents of these rules. In the first propositional function the list $E$, in USER_EBS_NAME(E), is instantiated by the names of the EBS elements added externally, and the variable $S$, in SUPPORT_NAME(S), is instantiated by the value of the support element. Similarly in the second propositional function, USER_SUPPORT_NAME(S), the variable $S$, is instantiated by the values of the support elements entered exte:nally. The four different possibilities, 1) add the support elements from the reference support WBSs and from the keyboard (rule 37); 2) only add the elements from the support reference WBSs (rule 38); 3) only add the elements using the keyboard (rule 39); and 4) do not add any elements (rule 40), are presented in the rules 37 through 40.

IF

SUPPORT_FOR(USER_EBS_NAME(E), SUPPORT_NAME(S)) AND

SUPPORT_FOR(USER_EBS_NAME(E), USER_SUPPORT_NAME(S))

THEN

ADDED_SUPPORT(EXTERNAL_EBS_ELEMENTS).

IF

SUPPORT_FOR(USER_EBS_NAME(E), SUPPORT_NAME(S)) AND

NOT SUPPORT_FOR(USER_EBS_NAME(E), USER_SUPPORT_NAME(S)) THEN

ADDED_SUPPORT(EXTERNAL_EBS_ELEMENTS).

IF

NOT SUPPORT_FOR(USER_EBS_NAME(E), SUPPORT_NAME(S)) AND

SUPPORT_FOR(USER_EBS_NAME(E), USER_SUPPORT_NAME(S))

THEN

ADDED_SUPPORT(EXTERNAL_EBS_ELEMENTS).

IF

NOT SUPPORT_FOR(USER_EBS_NAME(E), SUPPORT_NAME(S)) AND 


\section{NOT SUPPORT_FOR(USER_EBS_NAME(E), USER_SUPPORT_NAME(S)) THEN}

NOT ADDED_SUPPORT(EXTERNAL_EBS_ELEMENTS).

The value of

$$
\text { SUPPORT_FOR(USER_EBS_NAME(E), SUPPORT_NAME(S)) }
$$

depends on SELECT(SUPPORT_NAME(S), NEW_SUPP, _) in rule 41. Its value in turn depends on the antecedent in rule 42 . In order for the antecedent to be true, the externally entered elements should be present in the database NEW_EBS, and the user should require the addition of support elements, from the reference support WBS (REFERENCE_SUPPORT), for these elements.

If the values of PRESENT(USER_EBS_NAME(E), NEW_EBS, J and REQUIRE(REFERENCE_SUPPORT) are determined to be true, the consequent would be initiated. This would result in retrieving the values from the reference support WBS and presenting them for selection. The selected values would instantiate the variable $S$ in SUPPORT_NAME(S). Once this is done the value of SELECT(SUPPORT_NAME(S). NEW_SUPP, _, would be determined to be true. Thus the antecedent of rule 41 would be true and the consequent would be initiated. This would result in retrieving the EBS elements present in the NEW_EBS database which were added externally. The user can select any of the elements for which the support element selected earlier is required. Once the EBS element has been selected, the relationship between the EBS element(s) and the support elements would be established by SUPPORT_FOR(USER_EBS_NAME(E). SUPPORT_NAME(S)), and the EBS elements along with the support elements would be added to the database. Next the control would be transferred to the initialization rule 43 by

$$
\text { CHECK(INITIALIZE(USER_EBS_NAME(E), SUPPORT_NAME(S))). }
$$

This is done to determine if another support element is present in the reference support WBS and if the user wants to add more support for the EBS element. If both the conditions 
are true, SUPPORT_FOR(USER_EBS_NAME(E), SUPPORT_NAME(S)) would be initialized and the same process would be repeated for another support element.

If there are no more support elements or the user does not want to add more support elements from the reference support WBSs, the consequents of rules 44 and 45 respectively, would be initiated. This would result in the use of no more rules.

IF

SELECT(SUPPORT_NAME(S),NEW_SUPP, _) THEN

SELECT(USER_EBS_NAME(E), NEW_EBS,_) AND

SUPPORT_FOR(USER_EBS_NAME(E), SUPPORT_NAME(S)) AND

ADD(ALL(USER_EBS_NAME(E), NEW_SUPP)

CHECK(INITIALIZE(SUPPORT_FOR(USER_EBS_NAME(E), SUPPORT_NAME(S))).

IF

PRESENT(USER_EBS_NAME(E), NEW_EBS, _)AND

REQUIRE(REFERENCE_SUPPORT)

THEN

SELEOTT(SUPPORT_NAME(S), NEW_SUPP,_).

IF

NEXT(SUPPORT_NAME(S), NEW_SUPP, NOT_EMPTY) AND

MORE(REFERENCE_SUPPORT)

THEN

INITIALIZE(SUPPORT_FOR(USER_EBS_NAME(E), SUPPORT_NAME(S))).

IF

NEXT(SUPPORT_NAME(S), NEW_SUPP, EMPTY) THEN

NOT (SUPPORT_FOR(USER_EBS_NAME(E), SUPPORT_NAME(S))). 
IF

NEXT(SUPPORT_NAME(S), NEW_SUPP, NOT_EMPTY) AND

NOTMORE(REFERENCE_SUPPORT)

THEN

NOT INITIALIZE(SUPPORT_FOR(USER_EBS_NAME(E), SUPPORT_NAME(S))).

The above rules would be used if EBS elements were added using the keyboard. In case either EBS elements were not added externally, or the user did not want to add the reference support elements, the antecedent conditions of one of the two rules, 46 or $\mathbf{4 7}$ would be determined as being true and the consequent would be initiated. This would determine the antecedent of rule 48 as true and the consequent would oe initiated and the value of NOT SUPPORT_FOR(USER_EBS_NAME(E), SUPPORT_NAME(S)) would be determined to be true.

IF

NOT PRESENT(USER_EBS_NAME(E), NEW_EBS, _)

THEN

NOT SELECT(SUPPORT_NAME(S), SUPP_WBS, _).

IF

PRESENT(USER_EBS_NAME(E), NEW_EBS, 」 AND

NOT REQUIRE(REFERENCE_SUPPORT)

THEN

NOT SELECT(SUPPORT_NAME(S), SUPP_WBS, _).

IF

THEN

NOT SELECT(SUPPCiri_NAME(S), SUPP_WBS, _)

NOT SUPPORT_FOR(USER_EBS_NAME(E), SUPPORT_NAME(S)). 
After the value of SUPPORT_FOR(USER_EBS_NAME(E), SUPPORT_NAME(S)) has been determined, the value of

$$
\text { SUPPORT_FOR(USER_EBS_NAME(E), USER_SUPPORT_NAME(S)) }
$$

(rules 37 through 40 ) has to be determined. This is facilitated by the rules 49 and 50 . These rules allow the addition of the additional support elements for the externally entered EBS elements. These rules, in turn, depend on rules 51 or 52.

IF

BELONG_TO(USER_SUPPORT_NAME(S), SUPPORT_NAME(S)) OR

BELONG_TO(USER_SUPPORT_NAME(S), PROUECT_NAME) THEN

SELECT(USER_EBS_NAME(E), NEW_EBS, _) AND

SUPPORT_FOR(USER_EBS_NAME(E), USER_SUPPORT_NAME(S)) AND ADD(ALL(USER_SUPPORT_NAME(S), NEW_SUPP) AND INITIALIZE(SUPPORT_FOR(USER_EBS_NAME(E), USER_SUPPORT_NAME(S))).

IF

NOTBELONG_TO(USER_SUPPORT_NAME(S), SUPPORT_NAME(S)) AND NOT BELONG_TO(USER_SUPPORT_NAME(S), PROJECT_NAME)

THEN

NOT SUPPORT_FOR(USER_EBS_NAME(E), USER_SUPPORT_NAME(S)).

IF

PRESENT(USER_EBS_NAME(E), NEW_EBS, J AND

REQUIRE(EXTERNAL_SUPPORT) AND

NOT ADD(LEVEL__2)

THEN

SELECT(SUPPORT_NAME(S), SUPP_WBS, _) AND

ACCEPT(USER_SUPPORT_NAME(S)) AND

ESTABLISH(ATTRIBUTE_VALUES) AND

BELONG_TO(USER_SUPPORT_NAME(S), SUPPORT_NAME(S)). 
IF

PRESENT(USER_EBS_NAME(E), NEW_EBS, 」) AND

REQUIRE(EXTERNAL_SUPPORT) AND

ADD(LEVEL_2)

THEN

SELECT(PROJECT_NAME, NEW_EBS, _) AND
ACCEPT(USER_SUPPORT_NAME(S)) AND
ESTABLISH(ATTRIBUTE_VALUES) AND
BELONG_TO(USER_SUPPORT_NAME(S), PROJECT_NAME).

For the antecedent of rule 51 to be true, externally added elements must be present in the databases; the user should require the addition of additional support elements; and the additional support element should not be added in level 2, i.e, its owner element should be in level $\mathbf{2}$ or under. If these conditions are true, the consequent would be initiated and the user would have to select the support element under which this element would belong (51). Once this is done, the support element can be entered and would be accepted by the system. Next the values for all the attributes would be established and the relationship between the externally added support element and the owner element would be established.

However, in case the new support element being entered does not belong to a support element, i.e. is present in level 2, the user has to select the project name (rule 52), which forms the first level. This would indicate that the support element being added does not belong to one of the previous support elements and thus would be added in level 2. The other steps would be the same as in the previous case.

Once the relationship between the member element and the owner element has been established by either rule 51 or 52 , the antecedent condition of rule 49 would be determined to be true and the consequent would be initiated. The EBS elements which were added externally would be retrieved and presented for selection. These elements would instantiate the list $E$ in USER_EBS_NAME(E). Next the relationship between the EBS element and the 
support element would be established, the elements would be added to the database and SUPPORT_FOR(USER_EBS_NAME(E), USER_SUPPORT_NAME(S)) would be initialized to facilitate the addition of more support elements. This would carry on until no more support elements are required.

These rules, again, are used only when external EBS elements are present in the NEW_EBS database or when the user requires additional support elements. In case more support elements are not required or there are no externally added elements the antecedent conditions of rules 53 or 54 would be established as true and the consequents would be initiated.

IF

NOT PRESENT(USER_EBS_NAME(E), NEW_EBS, J

THEN

NOT BELONG_TO(USER_SUPPORT_NAME(S),SUPPORT_NAME(S)).

IF

PRESENT(USER_EBS_NAME(E), NEW_EBS, J AND

NOT REQUIRE(EXTERNAL_SUPPORT)

THEN

NOT BELONG_TO(USER_SUPPORT_NAME(S),SUPPORT_NAME(S)).

Finally, the third step of the WBS development process is undertaken. This is represented by ADDED_EXT_SUPPORT(REFERENCE_EBS_ELEMENTS) in the goal rules, and is determined by the rules below. These rules are similar to the rules used for adding the external support elements for the externally entered EBS elements.

IF

SUPPORT_FOR(EBS_NAME(E), USER_SUPPORT_NAME(S)) THEN 
ADDED_EXT_SUPPORT(REFERENCE_EBS_ELEMENTS).

IF

BELONG_TO(USER_SUPPORT_NAME(S), SUPPORT_NAME(S)) OR

BELONG_TO(USER_SUPPORT_NAME(S), PROJECT_NAME)

THEN

SELECT(EBS_NAME(E), NEW_EBS, _) AND

SUPPORT_FOR(EBS_NAME(E), USER_SUPPORT_NAME(S)) AND

ADD(ALL(USER_SUPPORT_NAME(S), NEW_SUPP) AND

INITIALIZE(SUPPORT_FOR(EBS_NAME(E), USER_SUPPORT_NAME(S))).

IF

NOTBELONG_TO(USER_SUPPORT_NAME(S), SUPPORT_NAME(S))

THEN

NOT SUPPORT_FOR(EBS_NAME(E), USER_SUPPORT_NAME(S)).

IF

REQUIRE(EXTERNAL_SUPPORT) AND

NOT ADD(LEVEL_2)

THEN

SELECT(SUPPORT_NAME(S), SUPP_WBS, _) AND

ACCEPT(USER_SUPPORT_NAME(S)) AND

ESTABLISH(ATTRIBUTE_VALUES) AND

BELONG_TO(USER_SUPPORT_NAME(S), SUPPORT_NAME(S)).

IF

REQUIRE(EXTERNAL_SUPPORT)AND

ADD(LEVEL_2)

THEN

SELECT(PRONECT_NAME, NEW_EBS, _) AND

ACCEPT(USER_SUPPORT_NAME(S)) AND

ESTABLISH(ATTRIBUTE_VALUES) AND

BELONG_TO(USER_SUPPORT_NAME(S), PROJECT_NAME). 
IF

PREsent(EBS_NAME(E), NEW_EBS, 」 AND

NOT

THEN

NOT BELONG_TO(USER_SUPPORT_NAME(S), SUPPORT_NAME(S)).

Once the values of the antecedents in the goal rules have been determined, the consequent would be initiated and DEVELOPED(SUPPORT_WBS) would be determined to be true. This would culminate the development process. 


\section{Knowledge Bases - Information Module}

\section{Knowledge base "Control"}

fact forward chaining is on

question topic is

"General Information".

"Types of WBSs" .

"WBS Dictionary and Coding" .

"WBS Dependent Activities",

"Quit"

question text Please select the topic about which you require information:

if topic is "General Information"

then command load Gen_Info

if topic is "Types of WBSs"

then command load WBS_Types

if topic is "WBS Dictionary and Coding" then command load Diction

if topic is "WBS Dependent Activities"

then command load WBS_DA

if topic is "Quit"

then command exit

query topic is

query options noreply, auto 


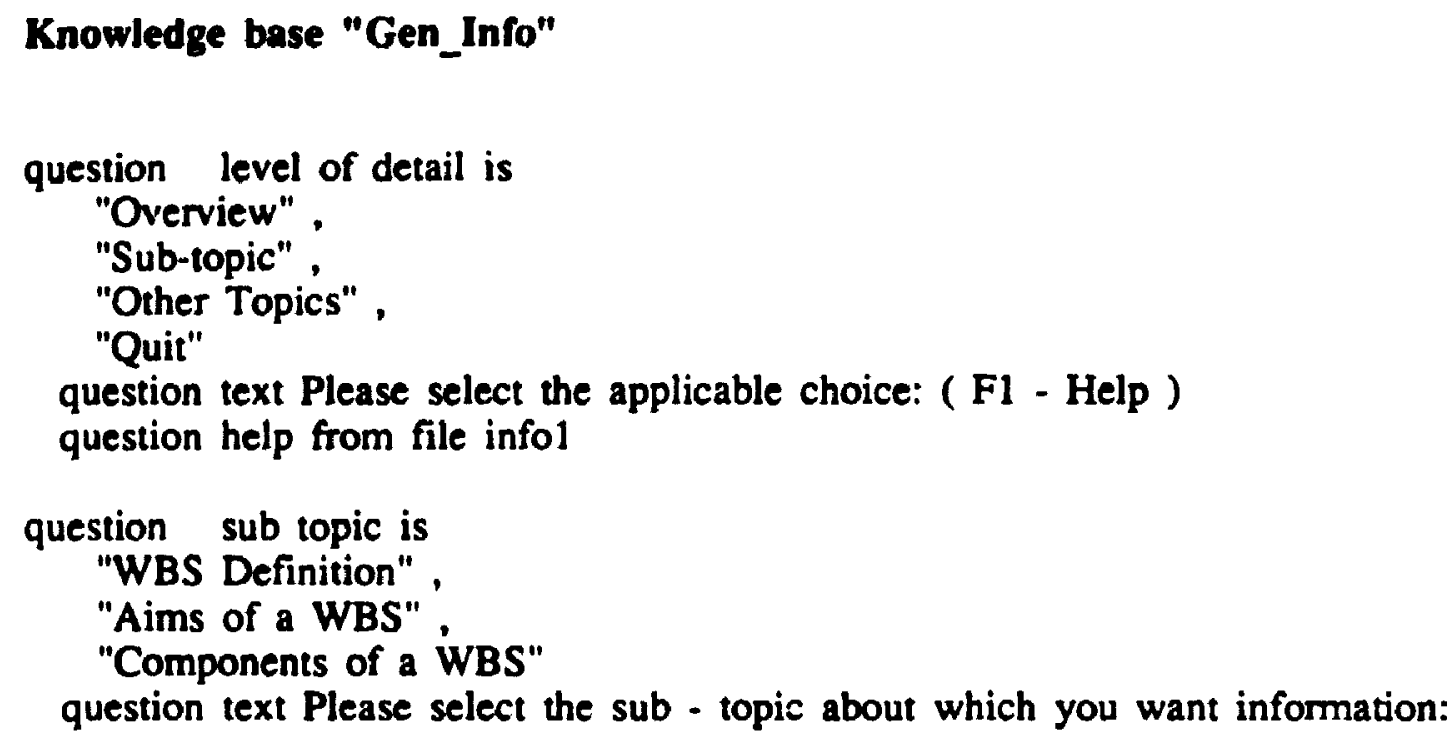

when level of detail is "Other Topics"

then command load control

when level of detail is "Quit"

then command exit

when level of detail is "Overview"

then report from file General

and command reset data

and check information

if level of detail is "Sub-topic"

and sub topic is "WBS Definition"

then report from file defini

and information is provided

and command reset data

and check information

if level of detail is "Sub-topic"

and sub topic is "Aims of a WBS"

then report from file aims

and information is provided

and command reset data

and check information

if level of detail is "Sub-topic"

and sub topic is "Components of a WBS" 
then report from file compon

and information is provided

and command reset data

and check information

query information is

query optic ns noreply , auto 
Knowledge base "WBS_Types"

question level of detail is

"Overview" ,

"Sub-topic" ,

"Other Topics" ,

"Quit"

question text Please select the applicable choice: (F1 - Help )

question help from file infol

question sub topic is

"Summary WBS" .

"Contract WBS" ,

"Project WBS"

question text Please select the sub - topic about which you want information:

when level of detail is "Other Topics"

then command load control

when level of detail is "Quit"

then command exit

when level of detail is "Overview"

then report from file Types

and command reset data

and check information

if level of detail is "Sub-topic"

and sub topic is "Summary WBS"

then report from file summary

and information is provided

and command reset data

and check information

if level of detail is "Sub-topic"

and sub topic is "Contract WBS"

then report from file contract

and information is provided

and command reset data

and check information

if level of detail is "Sub-topic"

and sub topic is "Project WBS" 
then report from file project

and information is provided

and command reset data

and check information

querv information is

query options noreply, auto 


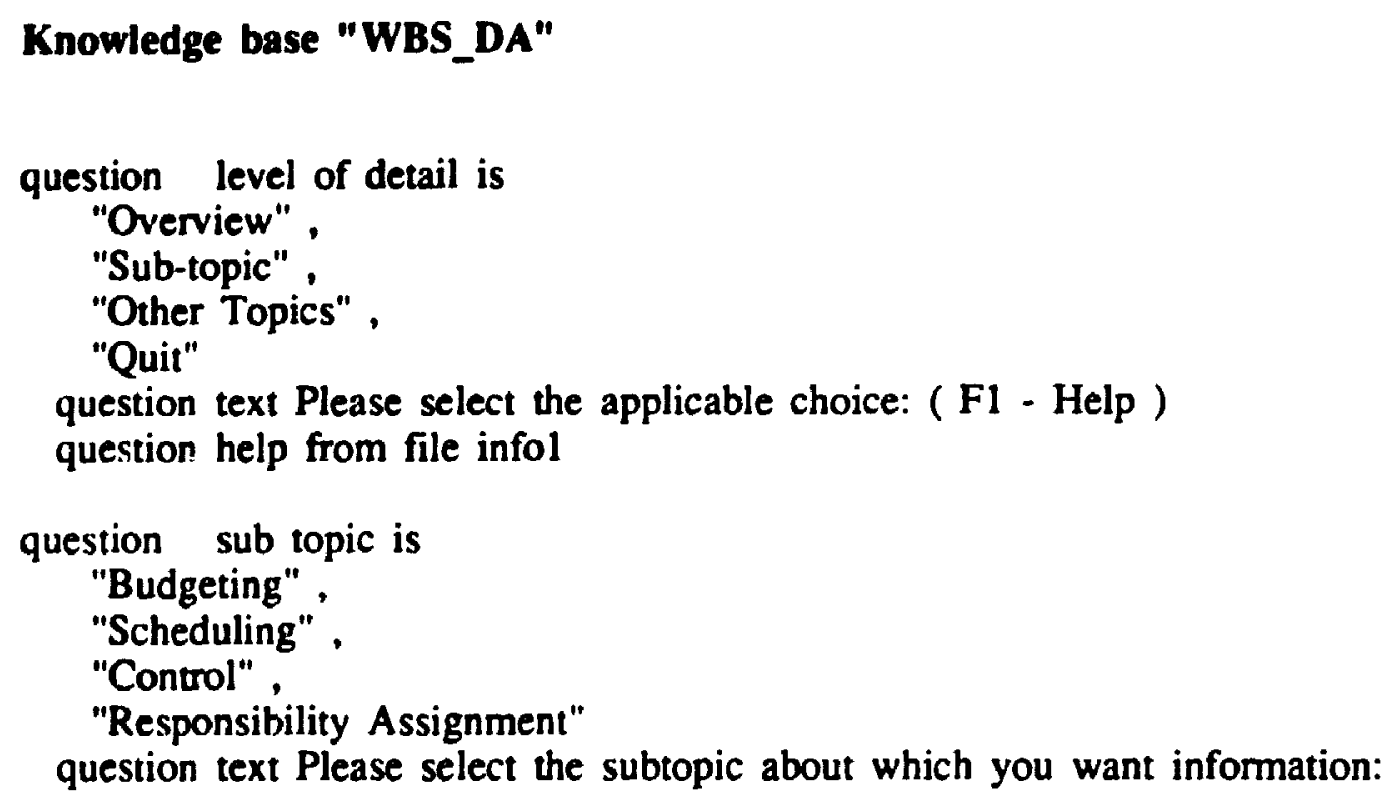

when level of detail is "Overview" then report from file depn_o and command reset data and check information

when level of detail is "Other Topics" then command load control

if level of detail is "Sub-topic" and sub topic is "Budgeting" then report from file budget and information is provided and command reset data and check information

if level of detail is "Sub-topic" and sub topic is "Scheduling" then report from file Schedul and information is provided and command reset data and check information

if level of detail is "Sub-topic" and sub topic is "Responsibility Assignment" then report from file Res_as and information is provided 
145

and command reset data and check information

if level of detail is "Subtopic" and sub topic is "Control" then report from file Control and information is provided and command reset data and check information

query information is query options noreply, auto 


\section{Knowledge base "WBS_DC"}

question level of detail is

"Overview" ,

"Sub-topic" ,

"Other Topics" ,

"Quit"

question text Please select the applicable choice: (F1 - Help) question help from file infol

question sub topic is

"WBS Dictionary" ,

"WBS Coding"

question text Please select the subtopic about which you want information:

when level of detail is "Overview"

then report from file dict_o

and command reset data

and check information

when level of detail is "Other Topics"

then command load control

if level of detail is "Sub-topic"

and sub topic is "WBS Dictionary"

then report from file diction

and information is provided

and command reset data

and check information

if level of detail is "Sub-topic"

and sub topic is "WBS Coding"

then report from file Code

and information is provided

and command reset data

and check information

if level of detail is "Sub-topic"

and sub topic is "Responsibility Assignment"

then report from file Res_as

and information is provided

and command reset data

and check information 
if level of detail is "Sub-topic"

and sub topic is "Control"

then report from file Control

and information is provided

and command reset data

and check information

query information is

query options noreply, auto 
File "General"

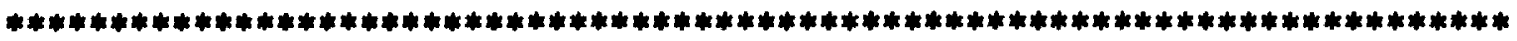

The WBS is a hierarchical representation of a project. It represents the project as a sum of its components and the relationships between them. It forms the basis for for nearly all the project management activities and is, thus regarded as one of the most important activities in project management.

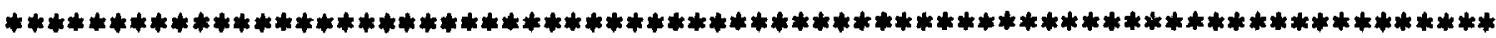

File "Defini"

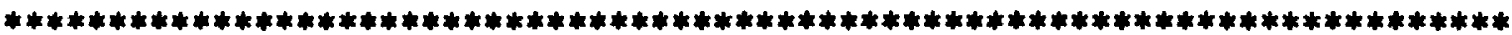

The WBS is an hierarchical representation of the project. It is a product-oriented family tree division of hardware, software, services and other work tasks which organises, defines and graphically displays the product to be produced, as well as the work to be done to develop it.

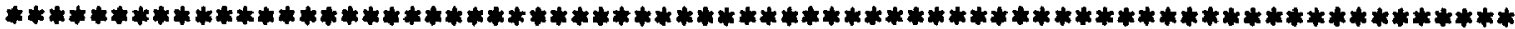

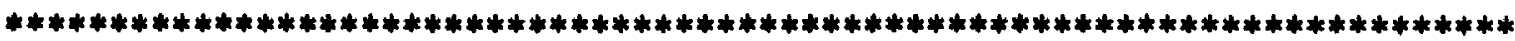

It is accordance with the systems approach i.e., the project is regarded as a system which can be decomposed into interrelated subsystems composed of hardware, software and services. The decomposition begins at the highest level - project - and continues until manageable subsystems (work packages) are achieved. These subsystems are at the lowest level and, as a rule of thumb, should not take more than eighty hours to complete. The summation of all the elements in a particular WBS level equals the elements in the next

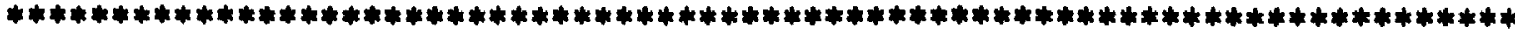


File "Aims"

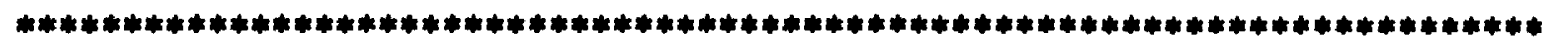

The purpose of the WBS is to provide a common source of of reference for all the project management activities and for all the functional groups involved in the project. Using the WBS as a common reference would result in better coordination between the various functional groups.

Assume that for a project, there are only two activities, budgeting and scheduling, required and also there are only two functional groups, Design \& Development and Manufacturing. Both the functional groups would use the same WBS for the two

activities, and be able to coordinate better because both would be using the same reference.

File "Compon"

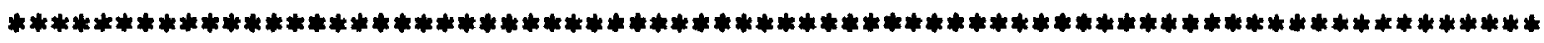

A WBS is always developed in terms of the hardware software and the services required for the project. It is not developed according to the functional structure of the project, i.e, R\&D, manufacturing etc.

A WBS can be regarded as a composition of two groups of components, the Equipment Breakdown Structure (EBS) and the Support WBS. The former is a hierarchical decomposition of the product to be developed, e.g., aircraft. The latter consists of the support components, e.g., training, required for the product or its components. 
File " Types"

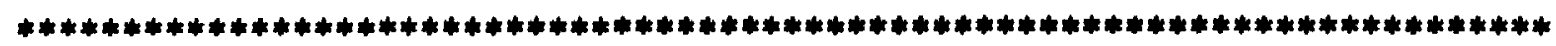

There are three types of WBSs, Summary WBS, Contract

WBS, and the Project WBS. The project WBS consists of the summary WBS and the contract WBS.

File "Summary"

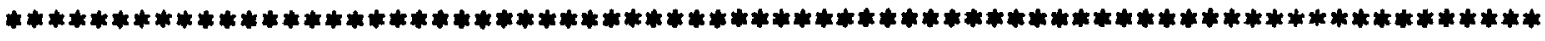

The summary WBS consists of the first three levels of a WBS. The first level consists of the name of project; the second level is composed of the major components of the project; and the third level consists of the sub-components belonging to the components in level 2.

In some cases, as in the DOD, some summary WBS standards are developed. These standards are then tailored to meet the requirements of project being underaken. This tailored version of the summary WBS is referred to as the project summary WBS.

The summary WBS forms the basis for the contract WBS. 
File "Contract"

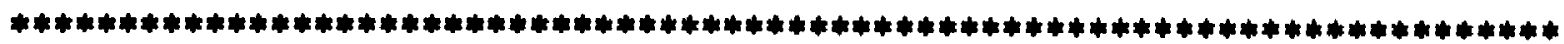

The contract WBS is an extension of the summary

WBS. It defines the scope of the work to be accomplished by the contractor. It consists of three or four levels. The first level of the contract WBS consists of sub-components present in level three of the summary WBS.

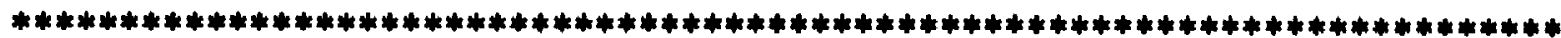

File "Project"

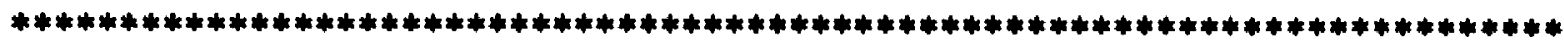

A project WBS is a composite of the Project Summary WBS and the contract WBS, in cases where summary WBS standards were developed. In cases where no summary WBS standards were developed, the summary WBS and the contract WBS developed for that project would make up the project WBS.

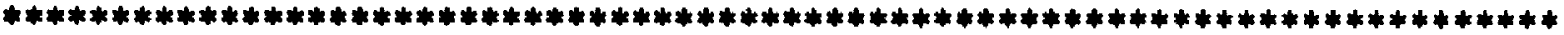

File "Depn_o"

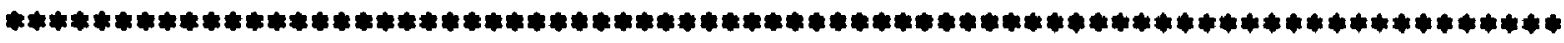

The WBS forms the basis for a number of project management activities such as scheduling, budgeting, control and responsibility assignment. The dependency of these activities is discussed in more detail under the sub-topics. 


\section{File "Budget"}

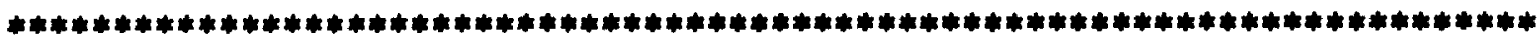

Budgeting is an important part of project management.

WBS facilitates the preparation of the budget.

This is true for both the top-down and the bottom-up approaches of budget preparation. In the former approach the budgetary assignments are primarily based on experience from previous projects. In the latter approach the sum of the budgets of the 'sub-tasks" forms the budget for the task. In this manner, the budget for project is estimated. The budget must be developed in accordance with the WBS to eliminate budgetary overlaps and to ensure no task is left unbudgeted.

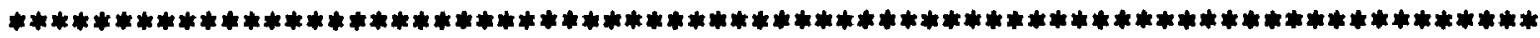

File "Schedul"

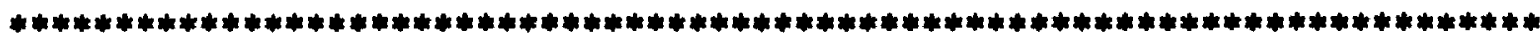

This is a very important aspect of project management and the development of PERT/CPM in $1957 / 1958$ facilitated automatic scheduling. WBS

forms the basis for the identification of all the activities and helps to ensure that all are accounted for. 
File "Res_as"

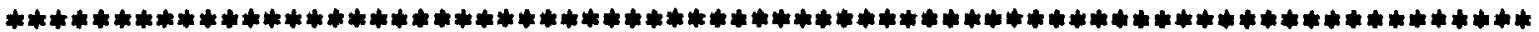

Responsibility assignment is a function of paramount importance in any project management assignment. The WBS forms the basis for this function. By interfacing the organizational structure with the WBS, it helps ensure the assignment of functional responsibilities for each task.

File "Control"

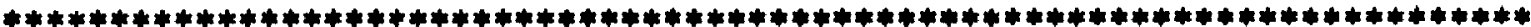

WBS also provides a means for "baseline project control".

Since WBS is considered to form the baseline for nearly all project management activities, it provides a basis for controlling performance (time and cost) using the project control system. The information used by the project control system consists of such items as progiess reports, productivity reports, earned value, all of which are collected and reporied via the WBS. This process ensures that all the data is consistent and can be traced back to the baseline. In essence the WBS is an integral part of the control system. 
Flle "Dict_o"

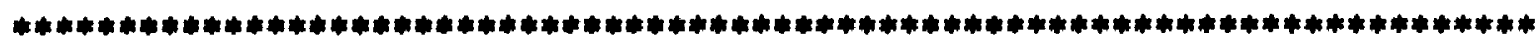

The WBS coding the dictionary facilitate proper management of a project. The former assists by identifying the relationships between the various elements in the WBS. The latter, on the other hand, provides a description for each element and thus helps maintain uniformity.

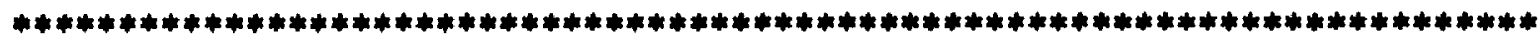

File "Diction"

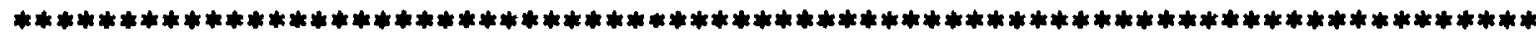

A WBS dictionary consists of the short descriptions of the elements in the WBS. These descriptions are usually a paragraph long and are agreed to by the project manager and the person doing the work. The WBS dictionary can help minimize the problems of poor communication and hence assist in proper management of the project.

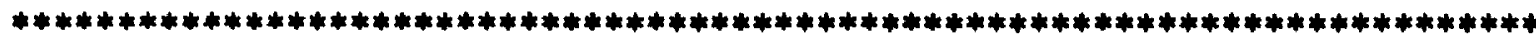

File "Code"

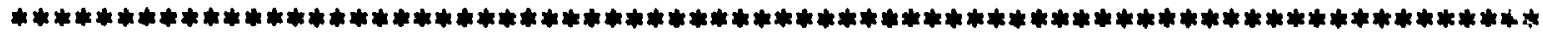

While a pictorial format for the WBS is suitable for summary level presentation, for day-to-day management a more compact format is required. This is facilitated by the using a decimal number identifier for each element. For instance an element in level 1 will have an 1.0 as its identifier, and its member elements in level 2 will have 1.1 to $1 . n$ as their identifiers. 
APPENDIX 5

Knowledge Base - Development Module

DOMAIN :: "WBS DEVELOPER"

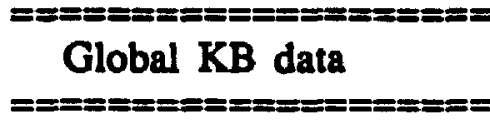

GOALS :: WBS_DEVELOPMENT

INITIALDATA :: NAME

PROMPTEVER :: (:LEFT 10 :RIGHT 70 :ATTR

(cyan) :LINE 6 This system will assist you in developing a WBS for an aircraft. The WBS development process consists of two parts: 1 ")" the development of the Equipment Breakdown Structure "(EBS)" and, 2 ")" the development of the Support WBS.)

TITLE :: (PRINT :ATTR

(QUOTE(CYAN)) "WBS Developer Copyright 1989, Jessie Chimni")

PARAMETERS :: CHOICE_OF_ACTION CODE ELEMENT_LEVEL_2_AS ELEMENT_LEVEL_3_AS

ELEMENT_LEVEL_4AF_AS ELEMENT_LEVEL_4CC_AS ELEMENT_LEVEL_4FC_AS ELEMENT_LEVEL_4NG_AS ELEMENT_LEVEL_4PA_AS ELEMENT_LEVEL_4PU_AS ELEMENT_LEVEL_4RE_AS ELEMENT_LEVEL_4WD_AS GOAL_EBS_DEVELOPMENT GOAL_SUPPORT_WBS MORE_2 MORE_3 MORE_4AF MORE_4CC MORE_4FC MORE_4NG MORE_4PA MORE_4PU MORE_4RE MORE_4WD NAME PRIMARY_PROJELT PROJECT_TYPE SECONDA!Y]

SECONDARY2 STATUS_LEVEL_1 STATUS_LEVEL_2 STATUS_LEVEL_3

STATUS_LEVEL_4 WBS_DEVELOPMENT

RULE GROUPS :: KB-RULES

KB-RULES :: RULE001 RULE002 RULE003 RULE004 RULE005 RULE006 RULE007 RULE008 RULE009 RULF010 RULE011 RULE012 RULE013 RULE014 RULE015 RULE016 RULE017 RULE018 RULE019 RULE020 RULE021 RULE022 RULE023 RULE024 RULE025 RULE026 RULE027 RULE029 RULE032 RULE035 RULE038 RULE041 RULE044 RULE047 RULE050 RULE052 RULE053 RULE054 RULE055 RULE056 RULE057 RULE058 RULE059 RULE060 RULE061 RULE062 RULE063 RULE064 RULE065 RULE066 RULE067 RULE068 RULE069 RULE070 RULE071 RULE072 RULE073 RULE074 RULE075

NUMBER OF RULES :: 59 


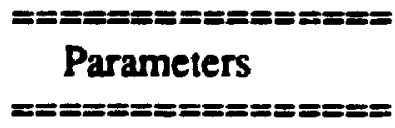

\section{CHOICE_OF_ACTION}

TRANSLATION :: the type of manipulation

PROMPT :: Select the desired action:

TYPE :: SINGLEVALUED

EXPECT :: "SINGLE MANIPULATION" "MUI.TIPLE MANIPULATIONS"

HELP :: Single manipulations refers to manipulating a WBS of a project which is similar to your project. Multiple manipulations refers to manipulating WBSs of two projects which closely resemble your project.

USED-BY :: RULE074 RULE073 RULE003 RULE004 RULE005 RULE072 RULE075

ODE

$====$

TRANSLATION :: the code for the element

TYPE :: SINGLEVALUED

ELEMENT_LEVEL_2_AS

$===\approx==========$

TRANSLATION :: the elements in level 2

PROMPT :: Select the second level element of the WBS:

TYPE :: SINGLEVALUED

EXPECT :: "AIR VEHICLF"

HELP :: There is only one element in level 2 and it must be selected.

ANTECEDENT-IN :: RULE013 RULE012 RULE019 RULE018 RULE017 RULE016 RULE015

RULE014

CONTAINED-IN :: RULE006 RULE008

USED-BY :: RULE006 RULE008

ELEMENT_LEVEL_3_AS

$==================$

TRANSLATION :: the third level of the WBS

PROMPT :: Select the third level elements of the WBS:

TYPE :: ASK-ALL

FXPECT :: DBASE-RETRIEVE "combine" QUAL C_LEV = 3 NAME

DEFAULT :: EMPTY

ANTEC:SDENT. IN :: RULE013 RULE012 RULE019 RULE018 RULE017 RULE016 RULE015 RULE014

USED-BY :: RULE009 RULE011 RULE017 RULE010 RULE020 RULE021 
RULE022 RULE023 RULE024 RULE025 RULE026 RULE027 RULE029 RULE032 RULE038 RULE041 RULE044 RULE047 RULE050 RULE035

\section{ELEMENT_LEVEL_4AF_AS}

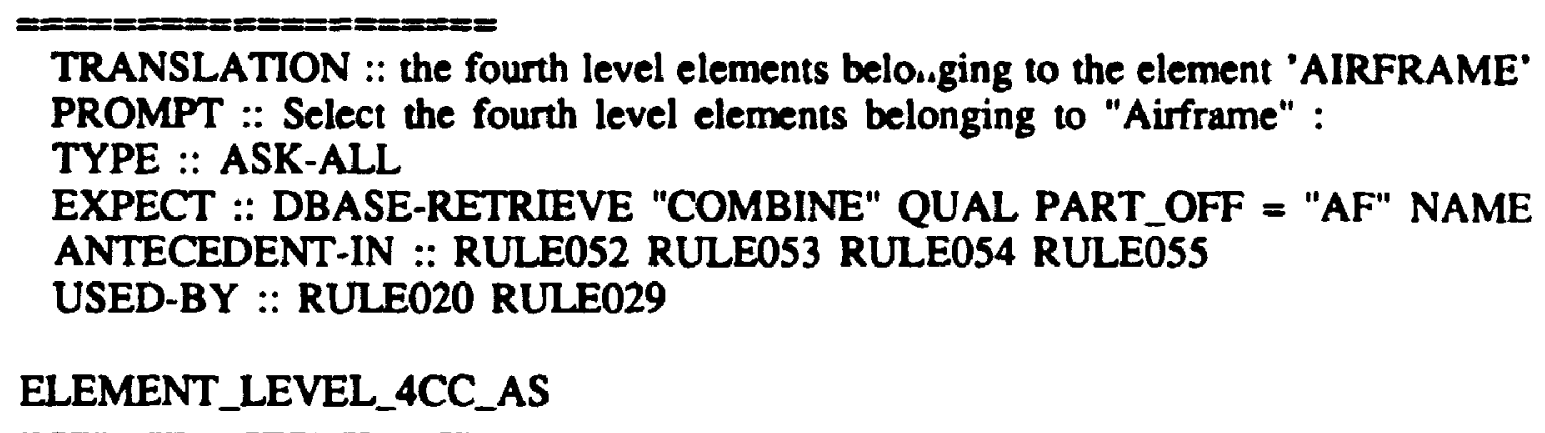

TRANSLATION :: the level 4 elements belonging to the third level element 'communications'

PROMPT :: Select the fourth level elements belonging to "Communications" :

TYPE :: ASK-ALL

EXPECT :: DBASE-RETRIEVE "COMBINE" QUAL PART_OFF = "CC" NAME ANTECEDENT-IN :: RULE056 RULE057

USED-BY :: RULE021 RULE032

\section{ELEMENT_LEVEL_4FC_AS}

$===============$

TRANSLATION :: the fourth level element belonging to 'Fire Control'

PROMPT :: Select the fourth level element belonging to "Fire Control" :

TYPE :: ASK-ALL

EXPECT :: DBASE-RETRIEVE "COMBINE" QUAL PART_OFF = "FC" NAME ANTECEDENT-IN :: RULE062 RULE063

USED-BY :: RULE024 RULE041

ELEMENT_LEVEL_4NG_AS

TRANSLATION :: the fourth level elements belonging to 'Navigation and Guidance'

PROMPT :: Select the fourth level elements for "Navigation and Guidance" :

TYPE :: ASK-ALL

EXPECT :: DBASE-RETRIEVE "COMBINE" QUAL PART_OFF = "NG" NAME

ANTECEDENT-IN :: RULE060 RULE061

USED-BY :: RULE023 RULE038

ELEMENT_LEVEL_4PA_AS

$========$

TRANSLATION :: the level four elements belonging to 'Penetration Aids' PROMPT :: Select the fourth level elements belonging to "Penetration Aids" : TYPE :: ASK-ALL

EXPECT :: DBASE-RETRIEVE "COMBINE" QUAL PART_OFF = "PA" NAME 


\author{
ANTECEDENT-IN :: RULE064 RULE066 RULE065 \\ USED-BY :: RULE02S RULE044 \\ ELEMENT_LEVEL_4PU_AS \\ $=================$ \\ TRANSLATION :: the fourth level elements belonging to 'Propulsion Unit' \\ PROMPT :: Select the fourth level elements belonging to "Propulsion Unit" : \\ TYPE :: ASK-ALL \\ EXPECT :: DBASE-RETRIEVE "COMBINE" QUAL PART_OFF = "PU" NAME \\ ANTECEDENT-IN :: RULE058 RULE059 \\ USED-BY :: RULE022 RULE035 \\ ELEMENT_LEVEL_4RE_AS
}

TRANSLATION :: the fourth level level belonging to the element 'reconnaissance equipment'

PROMPT :: Select the fourth level elements belonging to "Reconnaissance Equipment" :

TYPE :: ASK-ALL

EXPECT :: DBASE-RETRIEVE "COMBINE" QUAL PART_OFF = "RE" NAME ANTECEDENT-IN :: RULE068 RULE067

USED-BY :: RULE027 RULE050

ELEMENT_LEVEL_4WD_AS

$===================$

TRANSLATION :: the fourth level element belonging to the element 'Weapons Delivery'

PROMPT :: Select the fourth level elements belonging to "Weapons Delivery" :

TYPE :: ASK-ALL

EXPECT :: DBASE-RETRIEVE "COMBINE" QUAL PART_OFF = "WD" NAME ANTECEDENT-IN :: RULE070 RULE069

USED-BY :: RULE026 RULE047

GOAL_EBS_DEVELOPMENT

$===================$

TRANSLATION :: the goal to develop the equipment breakdown structure

TYPE :: SINGLEVALUED

USED-BY :: RULE001 RULE074 RULE073 RULE075

UPDATED-BY :: RULE002

GOAL_SUPPORT_WBS

$============$

TRANSLATION :: the goal of developing the support WBS

TYPE :: SINGLEVALUED

USED-BY :: RULE001

UPDATED-BY :: RULE074 RULE073 RULE075 
MORE_2

TRANSLATION :: additional elements for this level are required

PROMPT :: Do you want to add additional elements for the this level?

TYPE :: YES/NO

USED-BY :: RULE009 RULE011 RULE007 RULE010 RULE006 RULE008

MORE_3

TRANSLATION :: additional elements for the third level are required

PROMPT :: Do you want to add additional elements to this level?

TYPE :: YES/NO

USED-BY :: RULE009 RULE011 RULE007 RULE071 RULE010

MORE_4AF

$=====$

TRANSLATION :: you want to include additional elements in the fourth level belonging to "airframe"

PROMPT :: Do you want to enter additional elements under "Airframe" ?

TYPE :: YES/NO

USED-BY :: RULE020 RULE029

MORE_4CC

TRANSLATION :: add additional elements in the fourth level belonging to 'communications' in the third level

PROMPT :: Do you want to enter additional fourth level elemients under 'Communications'?

TYPE :: YES/NO

USED-BY :: RULE021 RULE032

MORE_4FC

TRANSLATION :: additional fourth level elements belonging to 'Fire Control' in the third level

PROMPT :: Do you want to enter additional fourth level elements under 'Fire Control'?

TYPE :: YES/NO

USED-BY :: RULE024 RULE041

MORE_4NG

TRANSLATION :: additional fourth level elements belonging to "Navigation and Guidance" in the third level

PROMPT :: Do you want to enter additional elements under 'Navigation and Guidance'? 


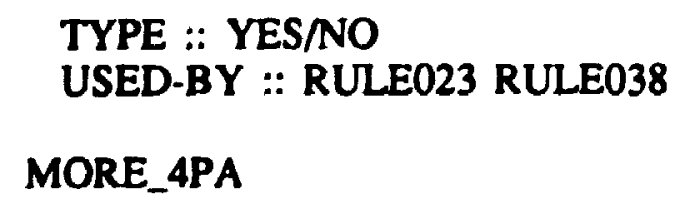

TRANSLATION :: additional fourth level elements belonging to the element 'Propulsion Unit'

PROMPT :: Do you want to add additional fourth level elements under 'Propulsion Unit'?

TYPE :: YES/NO

USED-BY :: RULE022 RULE035

MORE_4RE

$=======$

TRANSLATION :: include additional elements in the fourth level belonging to "Reconnaissance Equipment"

PROMPT :: Do you want to add additional fourth level elements under TYPE :: YES/NO

USED-BY :: RULE027 RULE050

MORE_4WD

$=======$

TRANSLATION :: additional fourth level elements belonging to 'Weapons Delivery' a third level element

PROMPT :: Do you want to add additional fourth level elements under "Weapons

TYPE :: YES/NO Delivery" ?

USED-BY :: RULE026 RULE047

NAME

TRANSLATION :: the name of the WBS being developed

PROMPT':: Please enter a name for the WBS being developed:

TYPE :: SINGLEVALUED

EXPECT :: SINGLE-LINE-INPUT

HELP :: Enter the name of the project for which you want to develop the WBS.

CONTAINED-IN :: RULE006 RULE008 
DEFAULT :: "NEW WBS"

PRMMARY_PROJECT

TRANSLATION :: the first project which is being used to develop the WBS

PROMPT :: Please choose the primary project

TYPE :: SINGLEVALUED

EXPECT :: "AIRCRAFT SYSTEM - 1" "AIRCRAFT SYSTEM - 2"

HELP :: This WBS will be used to structure your WBS.

USED-BY :: RULE005 RULE072

PROJECT_TYPE

TRANSLATION :: the type of project to which your WBS is related

PROMPT :: Please choose the project to which your project is related:

TYPE :: SINGLEVALUED

EXPECT :: "AIRCRAFT SYSTEM - 1" "AIRCRAFT SYSTEM - 2"

USED-BY :: RULE074 RULE073 RULE003 RULE004

SECONDARY1

$======$

TRANSLATION :: the second project being used for developing your WBS

PROMPT :: Choose the second project which you would like to manipulate:

TYPE :: SINGLEVALUED

EXPECT :: "AIRCRAFT SYSTEM - 1"

HELP :: This WBS will the source for extra elements for your WBS.

USED-BY :: RULEOOS

SECONDARY2

TRANSLATION :: the second project being used for developing your WBS

PROMPT :: Choose the second project which you would like to manipulate:

TYPE :: SINGLEVALUED

EXPECT :: "AIRCRAFT SYSTEM - 2"

HELP :: This WBS will the source for extra elements for your WBS.

USED-BY :: RULE072

STATUS_LEVEL_1

TRANSLATION :: how many and which WBS "(" s ")" should be selected for manipulation

TYPE :: SINGLEVALUED

USED-BY :: RULE002

UPDATED-BY :: RULE003 RULE004 RULE005 RULE072

STATUS_LEVEL_2 
TRANSLATION :: the elements constituting the second WBS level TYPE :: SINGLEVALUED

USED-BY :: RULE002

UPDATED-BY :: RULE006 RULE008

STATUS_LEVEL_3

$=============$

TRANSLATION :: the elements constituting the third WBS level

TYPE :: SINGLEVALUED

USED-BY :: RULE002

UPDATED-BY :: RULE009 RULE011 RULE007 RULE010

STATUS_LEVEL_4

TRANSLATION :: the elements constituting the fourth WBS level

TYPE :: MULTIVALUED

USED-BY :: RULE002

UPDATED-BY :: RULE071 RULE020 RULE021 RULE022 RULE023 RULE024

RULE025 RULE026 RULE027 RULE029 RULE032 RULE038 RULE041

RULE044 RULE047 RULE050 RULE035

WBS_DEVELOPMENT

$=============$

TRANSLATION :: the development of the WBS

TYPE :: SINGLEVALUED

UPDATED-BY :: RULE001

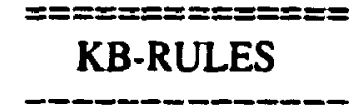

RULFO01

$=======$

IF ::GOAL_EBS_DEVELOPMENT $=$ ACHIEVED AND GOAL_SUPPORT_WBS $=$ ACHIEVED

THEN :: WBS_DEVELOPMENT = COMPLETE

RULE002

$==== \pm$ STATUS_LEVEL_1 = DETERMINED AND STATUS_LEVEL_2 = DETERMINED AND STATUS_LEVEL_3 = SATISFIED AND

STATUS_LEVEL_4 $=$ SATISFIED

THEN :: GOAL_EBS_DEVELOPMENT = ACHIEVED

RULE003 


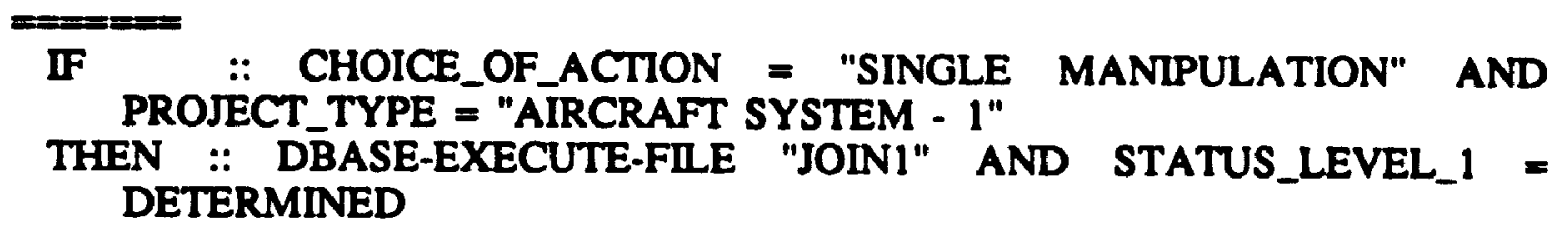

RULE004

IF $::$ CHOICE_OF_ACTION = "SINGLE MANIPULATION" AND PROJECT_TYPE = "AIRCRAFT SYSTEM - 2"

THEN :: DBASE-EXECUTE-FILE "JOIN2" AND STATUS_LEVEL_1 = DETERMINED

RULE005

IF $::$ CHOICE_OF_ACTION = "MULTIPLE MANIPULATIONS" AND
PRIMARY_PROJECT = "AIRCRAFT SYSTEM - 2" AND SECONDARY1 =
"AIRCRAFT SYSTEM - 1"
THEN :: DBASE-EXECUTE-FILE "JOIN3" AND STATUS_LEVEL_! =
DETERMINED

RULE006

$===$

IF :: ELEMENT_LEVEL_2_AS = "AIR VEHICLE" AND ! MORE_2

THEN :: STATUS_LEVEL_2 = DETERMINED AND DBASE-APPEND "TRANS" LEVEL $=1$ NAME $=$ NAME AND DBASE-APPEND "TRANS" LEVEL $=2$ NAME = ELEMENT_LEVEL_2_AS AND DBASE-EXECUTE-FILE "COPY"

RULE007

$===-=$

IF :: ELEMENT_LEVEL_3_AS != "Empty" AND MORE_2 AND MORE_3

THEN :: STATUS_LEVEL_3 = SATISFIED AND DBASE-EXECUTE AND DBASE-EXECUTE-FILE "COPY" AND DBASE-EXECUTE-FILE "MORE" AND DBASE-EXECUTE-FILE "ADD"

RULE008

IF :: ELEMENT_LEVEL_2_AS = "AIR VEHICLE" AND MORE_2

THEN :: DBASE-APPEND "TRANS" LEVEL $=1$ NAME = NAME AND DBASE-APPEND "TRANS" LEVEL $=2$ NAME = ELEMENT_LEVEL_2_AS AND DBASE-EXECUTE FILE "COPY" AND DBASE-EXECUTE-FILE "MORE" AND STATUS_LEVEL_2 = DETERMINED

RULE009

IF :: ELEMENT_LEVEL_3_AS != "Empty" AND ! MORE_2 AND MORE_3

THEN :: STATUS_LEVEL_ 3 = SATISFIED AND DBASE-EXECUTE AND 
DBASE-EXECUTE-FLE "COPY" AND DBASE-EXECUTE-FILE "MORE"

RULE010

$==$

IF :: ELEMENT_LEVEL_3_AS !="" AND ! MORE_2 AND ! MUR!!3

THEN :: STATUS_LEVEL_3 = SATISFIED AND DBASE-EXEC:UTE AND DBASE-EXECUTE-FLE "COPY"

\section{RULE011}

$=====$

IF :: ELEMENT_LEVEL_3_AS != "Empty" AND MORE_2 AND ! MORE_3 THEN :: STATUS_LEVEL_3 = SATISFIED AND DBASE-EXECUTE AND DBASE-EXECUTE-FILE "COPY" AND DBASE-EXECUTE-FILE "ADD"

RULE012

$==$

IF $::$ ELEMENT_LEVEL_2_AS = "AIR VEHICLE" AND ELEMENT_LEVEL_3_AS = "NAVIIGATION AND GUIDANCE" THEN :: DBASE-BUFFER-APPEND AND DBASE-APPEND "TRANS" LEVEL = 3 NAME = "NAVIGATION AND GUIDANCE"

ANTECEDENT :: YES

RULE013

$======$

IF $::$ ELEMENT_LEVEL_2_AS = "AIR VEHICLE" AND ELEMENT_LEVEL_3_AS = "AIRFRAME"

THEN :: DBASE-BUFFER-APPEND AND DBASE-APPEND "TRANS" LEVEL = 3 NAME = "AIRFRAME"

ANTECEDENT :: YES

RULE014

$======$
IF
ELEMENT_LEVEL_3_AS $=$ "PROPULSION UNIT" THEN :: DBASE-BUFFER-APPEND AND DBASE-APPEND "TRANS" LEVEL = 3 NAME = "PROPULSION UNIT"

ANTECEDENT :: YES

RULE015

$======$

IF $::$ ELEMENT_LEVEL_2_AS = "AIR VEHICLE" AND ELEMENT_LEVEL__3_AS = "COMMUNICATIONS"

THEN :: DBASE-BUFFER-APPEND AND DBASE-APPEND "TRANS" LEVEL = 3 NAME = "COMMUNICATIONS"

ANTECEDENT :: YES

RULE016 

IF $::$ ELEMENT_LEVEL_2_AS $=$ "AIR VEHICLE" AND ELEMENT_LEVEL_3_AS ="FIRE CONTROL"
THEN :: DBASE-BUFFER-APPEND AND DBASE-APPEND "TRANS" LEVEL = 3 NAME = "FIRE CONTROL"
ANTECEDENT :: YES

\section{RULE017}

IF $:$ ELEMENT_LEVEL_2_AS = "AIR VEHICLE" AND ELEMENT_LEVEL_3_AS = "RECONNAISSANCE EQUIPMENT" THEN :: DBASE-BUFFER-APPEND AND DBASE-APPEND "TRANS" LEVEL = 3 NAME = "RECONNAISSANCE EQUIPMENT" ANTECEDENT :: YES

RULE018

RULE019
IF $:$ ELEMENT_LEVEL_2_AS = "AIR VEHICLE" AND ELEMENT_LEVEL_3_AS = "WEAPONS DELIVERY" THEN :: DBASE-BUFFER-APPEND AND DBASE-APPEND "TRANS" LEVEL = 3 NAME = "WEAPONS DELIVERY" ANTECEDENT :: YES

RULE020

RULE021
IF $::$ ELEMENT_LEVEL_3_AS = "COMMUNICATIONS" AND ELEMENT_LEVEL_4CC_AS != "EMPTY" AND MORE_4CC THEN :: STATUS_LEVEL_4 = SATISFIED AND DBASE-EXECUTE AND DBASE-EXECUTE-FILE "COPY" AND DBASE-EXECUTE-FILE "MORE" UTILITY :: 9


RULE022

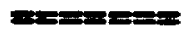

IF $::$ ELEMENT_LEVEL_3_AS = "PROPULSION UNIT" AND ELEMENT_LEVEI_4PU_AS != "EMPTY" AND MORE_4PU

THEN :: STATUS_LEVEL_4 = SATISFIED AND DBASE-EXECUTE AND DBASE-EXECUTE-FLE "COPY" AND DBASE-EXECITTE-FILE "MORE" UTILITY :: 8

RULE023

$\underline{I=E=}=$

IF :: ELEMENT_LEVEL_3_AS = "NAVIGATION AND GUIDANCE" AND ELEMENT_LEVEL_4NG_AS != "EMPTY" AND MORE_4NG

THEN :: STATUS_LEVEL_4 = SATISFIED AND DBASE-EXECUTE AND DBASE-EXECUTE-FILE "COPY" AND DBASE-EXECUTE-FILE "MORE" UTILITY :: 7

RULE024

$======$

IF $::$ ELEMENT_LEVEL_3_AS = "FIRE CONTROL" AND ELEMENT_LEVEL_4FC_AS != "EMPTY" AND MORE_4FC

THEN :: STATUS_LEVEL_4 = SATISFIED AND DBASE-EXECUTE AND DBASE-EXECUTE-FILE "COPY" AND DBASE-EXECUTE-FILE "MORE" UTILITY :: 6

RULEO25

$======$

IF $::$ ELEMENT_LEVEL_3_AS = "PENETRATION ADDS" AND ELEMENT_LEVEL_4PA_AS ! = "EMPTY" AND MORE_4PA

THEN $\because:$ STATUS_LEVEL_4 = SATISFIED AND DBASE-EXECUTE AND DBASE-EXECUTE-FILE "COPY" AND DBASE-EXECUTE-FILE "MORE" UTILITY :: 5

RULE026

$=======$

IF $::$ ELEMENT_LEVEL_3_AS = "WEAPCNS DELIVERY" AND ELEMENT_LEVEL_4WD_AS != "EMPTY" AND MORE_4WD

THEN :: STATUS_LEVEL_4 = SATISFIED AND DBASE-EXECUTE AND DBASE-EXECUTE-FILE "COPY" AND DBASE-EXECUTE-FILE "MORE" UTLITY :: 4

\section{RULE027}

IF :: ELEMENT_LEVEL_3_AS = "RECONNAISSANCE EQUIPMENT" AND ELEMENT_LEVEL_4RE_AS != "EMPTY" AND MORE_4RE

THEN :: STATUS_LEVEL_4 = SATISFIED AND DBASE-EXECUTE AND DBASE-EXECUTE-FILE "COPY" AND DBASE-EXECUTE-FILE "MORE" UTILITY :: 3 
RULE029

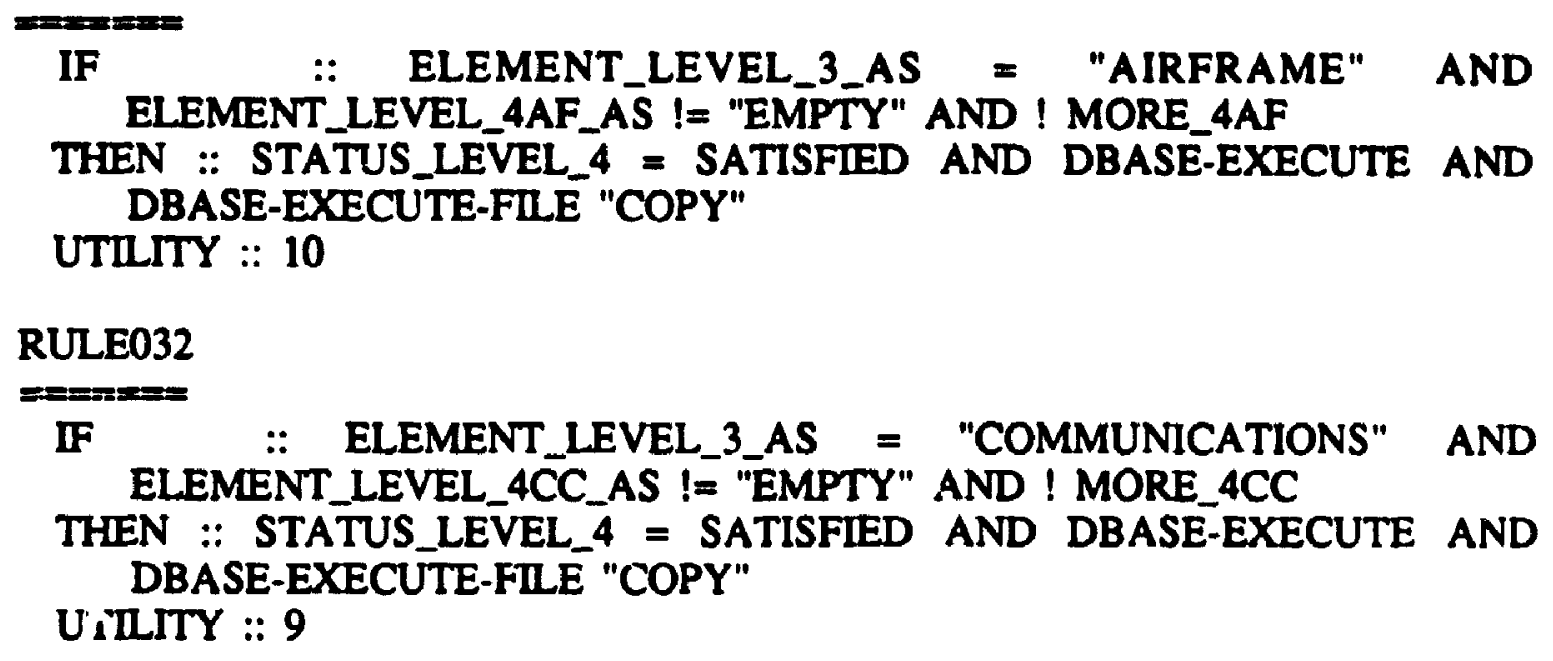

RULE035
IF $::$ ELEMENT_LEVEL_3_AS = "PROPULSION UNIT" AND ELEMENT_LEVEL_4PU_AS != "EMPTY" AND ! MORE_4PU THEN :: STATUS_LEVEL_4 = SATISFIED AND DBASE-EXECUTE AND DBASE-EXECUTE-FİLE "COPY" UTILITY :: 8
RULE038
$====$
IF :: ELEMENT_LEVEL_3_AS = "NAVIGATION AND GUIDANCE" AND ELEMENT_LEVEL_4NG_AS != "EMPTY" AND ! MORE_4NG THEN :: STATUS_LEVVEL_4 = SATISFIED AND DBASE-EXECUTE AND DBASE-EXECUTE-FILE "COPY" UTIITY :: 7
RULE041

\section{RULE044}

IF :: ELEMENT_LEVEL_3_AS = "PENETRATION AIDS" AND ELEMENT_LEVEL_4PA_AS ! = "EMPTY" AND ! MORE_4PA THEN :: STATUS_LEVEL 4 = SATISFIED AND DBASE-EXECUTE AND DBASE-EXECUTE-FILE "COPY" 
UTILITY :: 5

RULE047

$=x====$

IF $::$ ELEMENT_LEVEL_3_AS = "WEAPONS DELIVERY" AND ELEMENT_LEVEL_4WD_AS != "EMPTY" AND ! MORE_4WD

THEN :: STATUS_LEVEL_4 = SATISFIED AND DBASE-EXECUTE AND DBASE-EXECUTE-FILE "COPY"

UTILITY :: 4

RULE050

$\Rightarrow=0$

IF :: ELEMENT_LEVEL_3_AS = "RECONNAISSANCE EQUIPMENT" AND ELEMENT_LEVEL_4RE_AS != "EMPTY" ANT! MORE_4RE

THEN :: STATUS_LEVEL_4 = SATISFIED AND DRASE-EXECUTE AND DBASE-EXECUTE-FILE "COPY" UTILITY :: 3

RULE052

$======$

IF :: ELEMENT_LEVEL_4AF_AS = "AIR INDUCTION SYSTEM"

THEN :: DBASE-BUFFER-APPEND AND DBASE-APPEND "TRANS" LEVEL = 4 NAME = "AIR INDUCTION SYSTEM" ANTECEDENT :: YES

RULE053

$======$

IF :: ELEMENT_LEVEL_4AF_AS = "BASIC STRUCTURE"

THEN :: DBASE-BUFFER-APPEND AND DBASE-APPEND "TRANS" LEVEL = 4 NAME = "BASIC STRUCTURE"

ANTECEDENT :: YES

RULE054

$======$

IF :: ELEMENT_LEVEL_4AF_AS = "FURNISHINGS"

THEN :: DBASE-BUFFER-APPEND AND DBASE-APPEND "TRANS" LEVEL = 4 NAME = "FURNISHINGS"

ANTECEDENT :: YES

RULE055

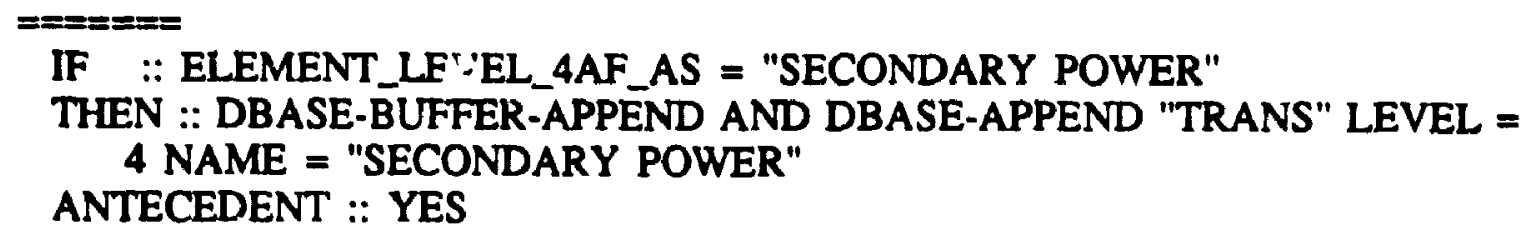

RULE056 
두을

IF :: ELEMENT_LEVEL_4CC_AS = "DATA LINK"

THEN :: DBASE-BUFFER-APPEND AND DBASE-APPEND "TRANS" LEVEL = 4 NAME = "DATA LINK"

ANTECEDENT :: YES

RULE057

IF :: ELEMENT_LEVEL_4CC_AS = "INTERCOM"

THEN :: DBASE-BUFFER-APPEND AND DBASE-APPEND "TRANS" LEVEL = 4 NAME = "INTERCOM"

ANTECEDENT :: YES

RULE058

IF :: ELEMENT_LEVEL_4PU_AS = "ENGINE"

THEN :: DBASE-BUFFER-APPEND AND DBASE-APPEND "TRANS" LEVEL = 4 NAME = "ENGINE"

ANTECEDENT :: YES

RULE059

$=====$

IF :: ELEMENT_LEVEL_4PU_AS = "THRUST REVERSER"

THEN :: DBASE-BUFFER-APPEND AND DBASE-APPEND "TRANS" LEVEL = 4 NAME = "THRUST REVERSER"

ANTECEDENT :: YES

RULE060

\section{$===== \pm=$}

IF :: ELEMENT_LEVEL_4NG_AS = "RADAR"

THEN :: DBASE-BUFFER-APPEND AND DBASE-APPEND "TRANS" LEVEL = 4 NAME = "RADAR"

ANTECEDENT :: YES

RULE061

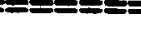

IF :: ELEMENT_LEVEL_4NG_AS = "ALTIMETER"

THEN :: DBASE-BUFFER-APPEND AND DBASE-APPEND "TRANS" LFVEL = 4 NAME = "ALTIMETER"

ANTECEDENT :: YES

RULE062

IF :: ELEMENT_LEVEL_4FC_AS = "NAVIGATION \& AIR DATA SYSTEMS" THEN :: DBASE-BUFFER-APPEND AND DBASE-APPEND "TRANS" LEVEL = 4 NAME = "NAVIGATION \& AIR DATA SYSTEMS"

ANTECEDENT :: YES 


\section{RULE063}

$======$

IF :: ELEMENT_LEVEL_4FC_AS = "BOMBING COMPUTER"

THEN :: DBASE-BUFFER-APPEND AND DBASE-APPEND "TRANS" LEVEL = 4 NAME = "BOMBING COMPUTI:R"

ANTECEDENT :: Y'S

\section{RULE064}

$=======$

IF :: ELEMENT_LEVEL_4PA_AS = "ELECTRONIC TRANSMITTERS"

THEN :: DBASE-BUFFER-APPEND AND DBASE-APPEND "TRANS" LEVEL = 4 NAME = "ELECTRONIC TRANSMITTERS"

ANTECEDENT :: YES

\section{RULE065}

$=======$

IF :: ELEMENT_LEVEL_4PA_AS = "JAMMING TRANSMITTERS"

THEN :: DBASE-BUFFER-APPEND AND DBAS -APPEND "TRANS" LEVEL = 4 NAME = "JAMMING TRANSMITTERS"

ANTECEDENT :: YES

\section{RULE066}

$======$

IF :: ELEMENT_LEVEL_4PA_AS = "SEARCH RECEIVERS"

THEN :: DBASE-BUFFER-APPEND AND DBASE-APPEND "TRANS" LEVEL = 4 NAME = "SEARCH RECEIVERS"

ANTECEDENT :: YES

\section{RULE067}

$===== \pm=$

IF :: ELEMENT_LEVEL_4RE_AS = "SENSORS"

THEN :: DBASE-BUFFER-APPEND AND DBASE-APPEND "TRANS" LEVEL = 4 NAME = "SENSORS"

ANTECEDENT :: YES

RULE068

$======$

IF :: ELEMENT_IEVEL_4RE_AS = "TERRAIN FOLLOW_NG DEVICES"

THEN :: DBASE-BUFFER-APPEND AND DBASE-APPEND "TRANS" LEVEL = 4 NAME = "TERRAIN FOLLOWING DEVICES"

ANTECEDENT :: YES

RULE069

$== \pm==$

IF $::$ ELEMENT_LEVEL_4WD_AS = "LAUNCHERS"

THEN :: DBASE-BUFFER-APPEND AND DBASE-APPEND "TRANS" LEVEL = 
4 NAME $=$ "LAUNCHERS"

ANTECEDENT :: YES

RULE070

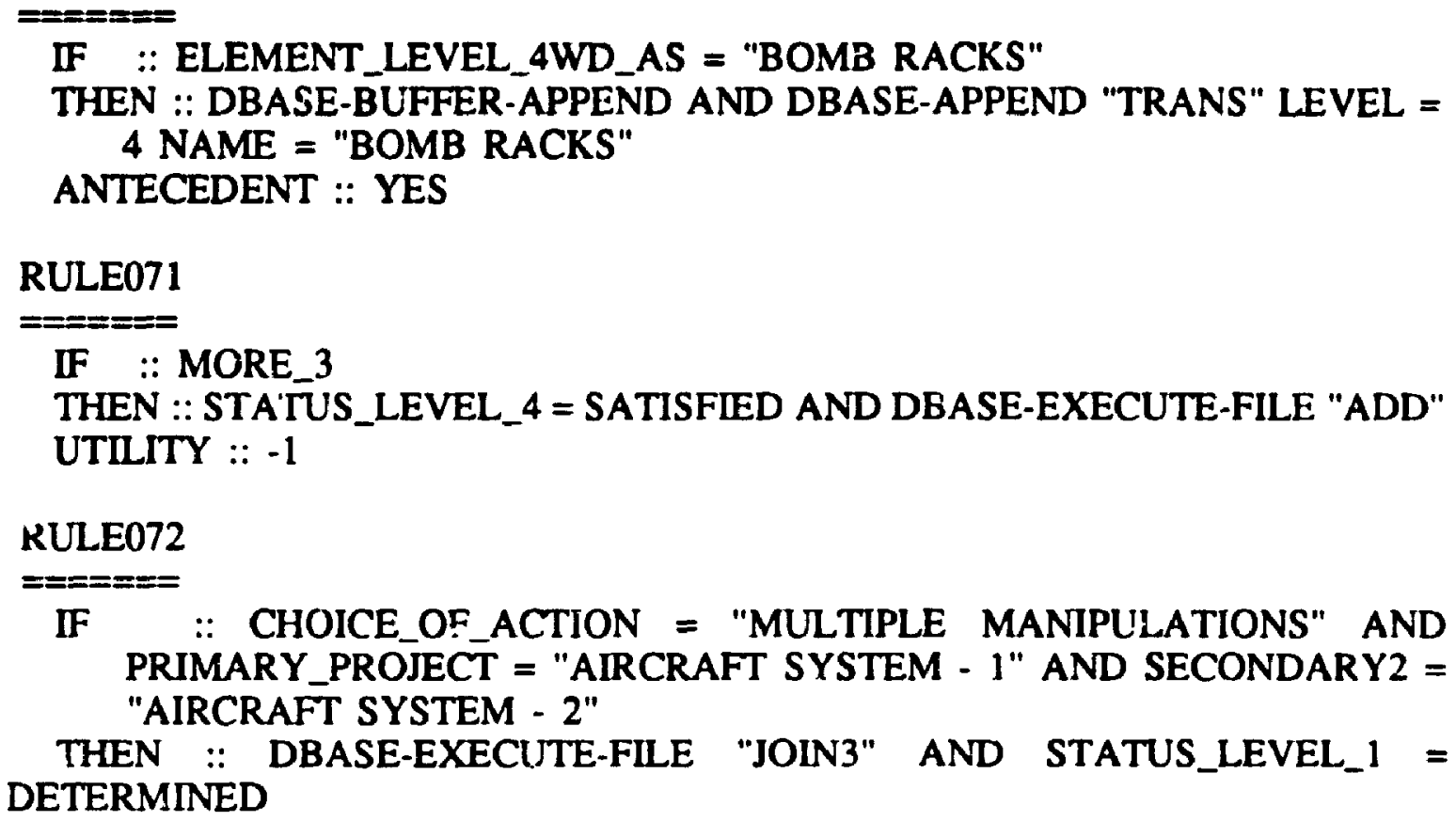

RULE073
IF $::$ CHOICE_OF_ACTION $=$ "SINGLE MANIPULATION" AND PROJECT_TYPE = "AIRCRAFT SYSTEM - 2" AND GOAL_EBS_DEVELOPMENT $=$ ACHIEVED

THEN :: DBASE-EXECUTE-FILE "CONT2" AND GOAL_SUPPORT_WBS = ACHIEVED

RULE074 $======$
IF $:$ CHOICE_OF_ACTION = "SINGLE MANIPULATION" AND
PROJECT_TYPE = "AIRCRAFT SYSTEM - $1 "$ AND
GOAL_EBS_DEVELOPMENT = ACHIEVED
THEN :: DBASE-EXECUTE-FILE "CONT1" AND GOAL_SUPPORT_WBS =
ACHIEVED

RUL.E075

IF $::$ CHOICE_OF_ACTION = "MULTTPLE MANIPULATIONS" AND

THEN :: DBASE-EXECUTE-FILE "CONT3" AND GOAL_SUPPORT_WBS = ACHIEVED 


\section{APPENDIX 6}

\section{Data and Progrim Files}

\section{Data File}

1) Classas.dbf -

2) AS-1.dbf -

3) AS-2.dbf -

4) Temp.dbf -

5) Combine.dbf -

6) Trans.dbf -

7) New_WBS.dbf -

8) Supcl_As.dbf -

9) Sup_AS1.dbf -

10) Sup_AS2.dbf -

11) Sup_Temp.dbf -

12) Sup_Comb.dbf -

13) New_Sup.dbf -

\section{Conter:}

consists of :ne EBS element; belonging to the aircraft class.

consists of the elements peculiar to the aircraft, "Aircraft Systen - 1".

consis's of the elements peculiar to the aircraft, "Aircraft System - 2".

lised for storing the elements from the class and the other EBS(s). These elements are later sorted and stored in a new datafile Combine.dbf.

stores sorted elements of the class and the elements from one or both of the EBSs. This is the datafile from which PC Easy retrieves the elements.

the selected elements are added to this database temporarily. After they have been added, along with the values for the other attributes, they are added to the datafile New_WBS.dbf.

it stores the new EBS.

consists of the support elements belonging to the aircraft support class.

consists of the support elements for "Aircraft System - 1".

consists of the support elements for "Aircraft System - 2".

used for storing the elements from the class and the other support WBS(s). These elements are later sorted and stored in a new datafile Sup_Comb.dbf.

stores sorted elements of the class and the elements from one or both of the Support WBSs.

it stores the new support WBS.

\section{Program Files}
1) Join1.prg
2) Join2.prg
3) Join3.prg
4) Copy.prg
5) More.prg 

6) Add.prg
7) Cont1.prg
8) Cont2.prg
9) Cont3.prg
10) Sup_jn1.prg
11 Sup_jn2.prg
12) Sup_jn3.prg
13) Supp_dev.prg
14) Control.prg
15) Extra.prg
16) Add_s_el.prg
17) Level2.prg
18) Lev3.prg
19) level3.prg
20) EBS1.prg
21) EBS2.prg
22) EBS.prg
23) Display.prg
24) Display2.prg 


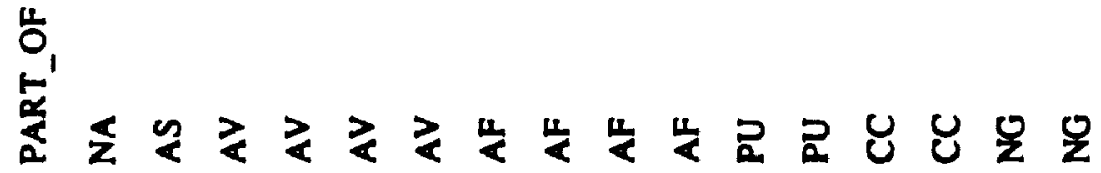

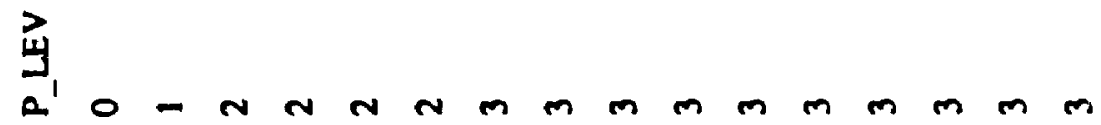

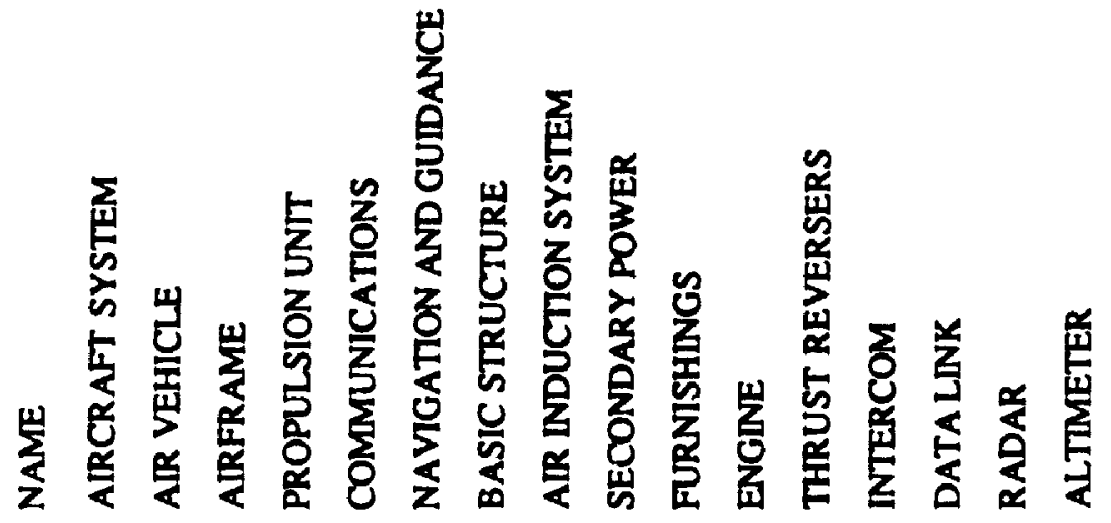

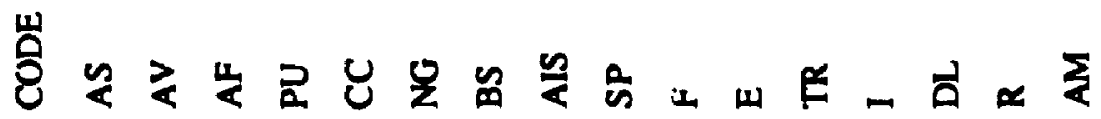
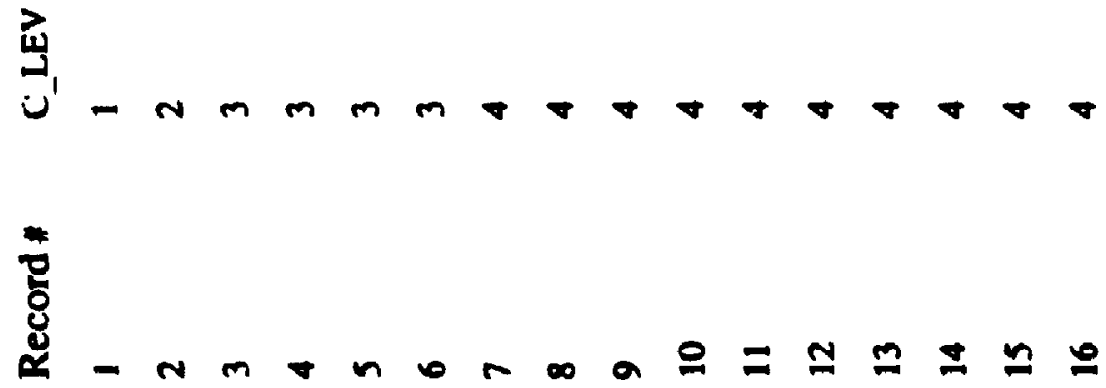


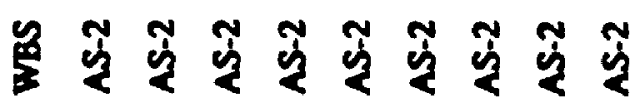

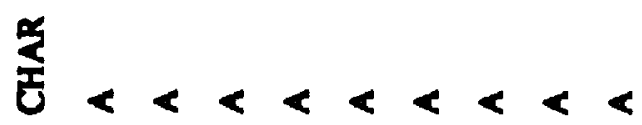

t

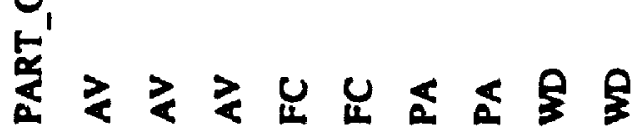

3............

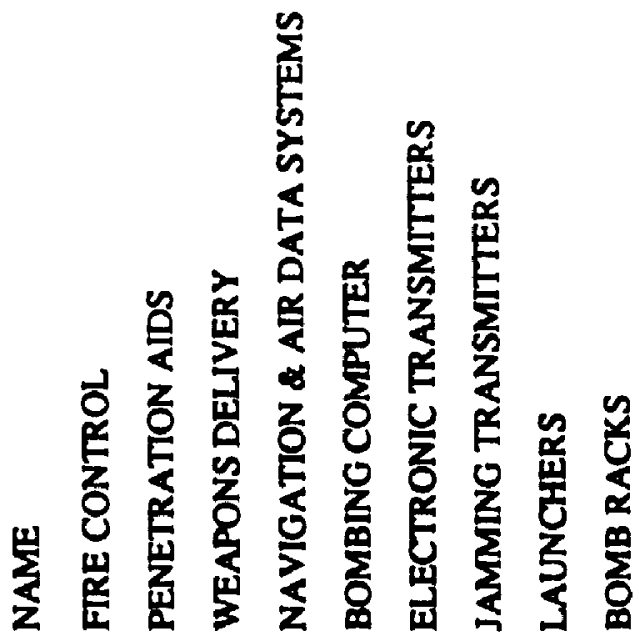

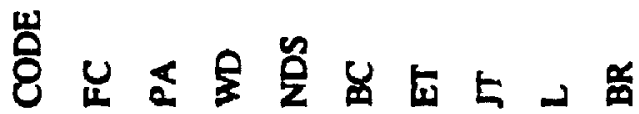

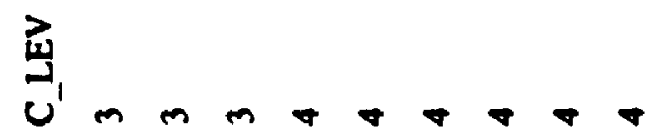

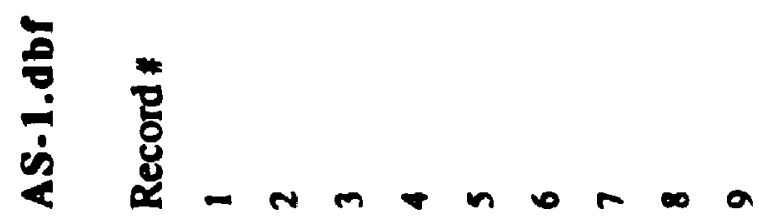




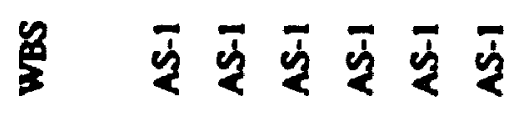

176
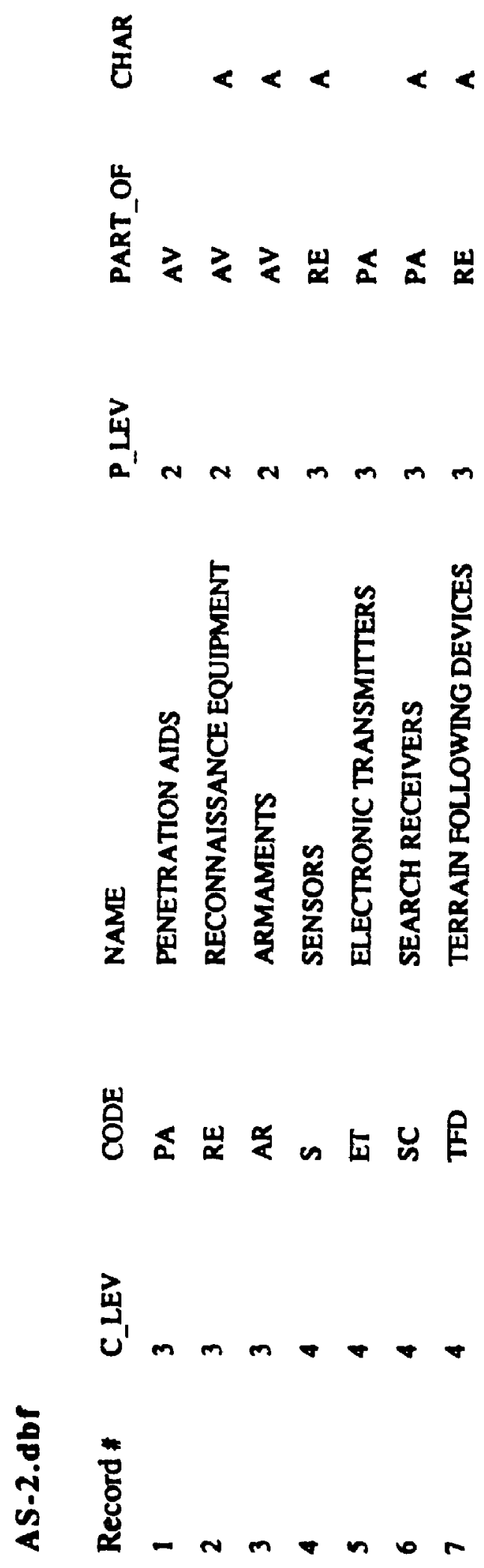


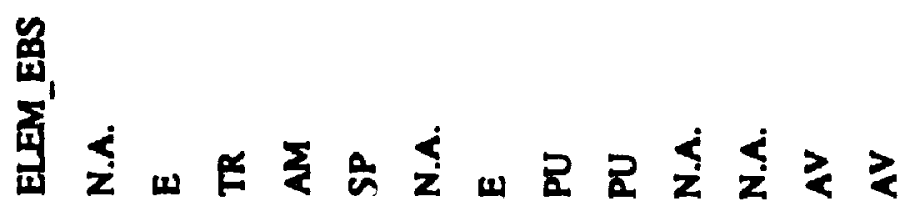

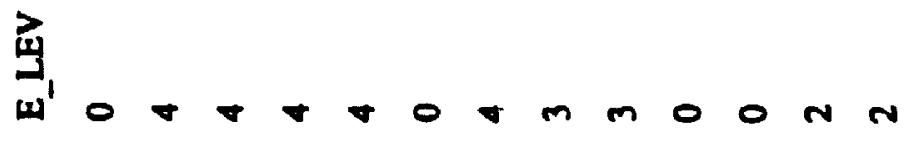

案

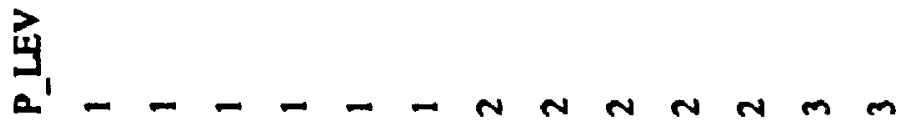

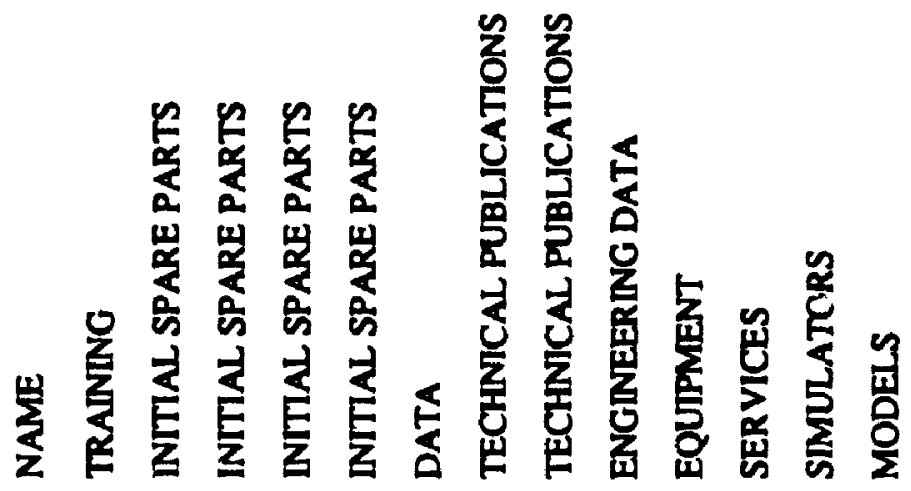

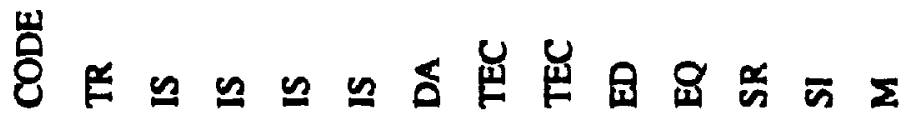

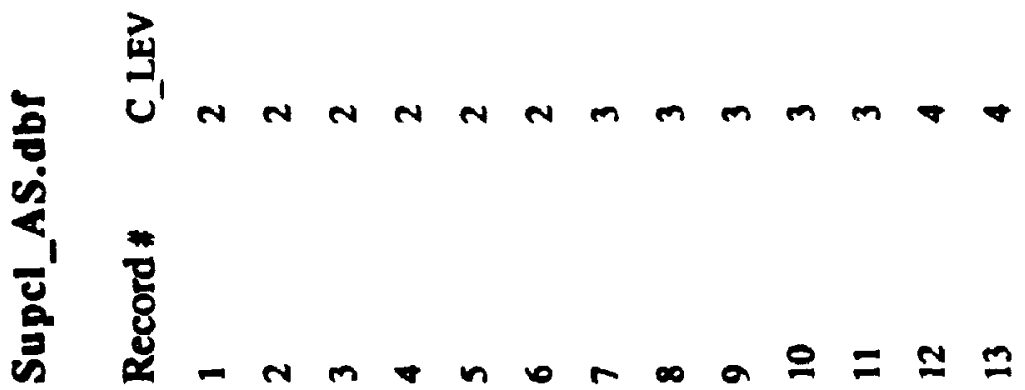




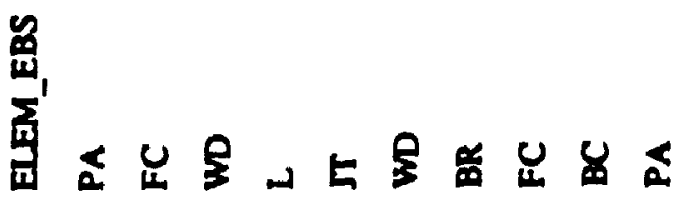

$\stackrel{4}{4} m m+\infty m+m$

"艹

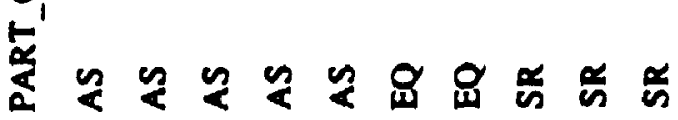

$\vec{\theta}_{1}=-\infty-m m m m$

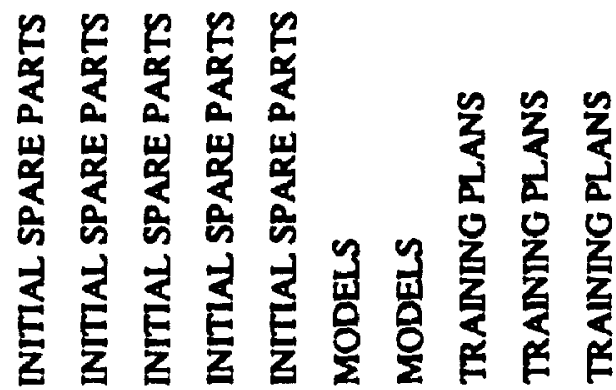

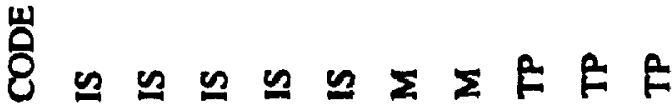

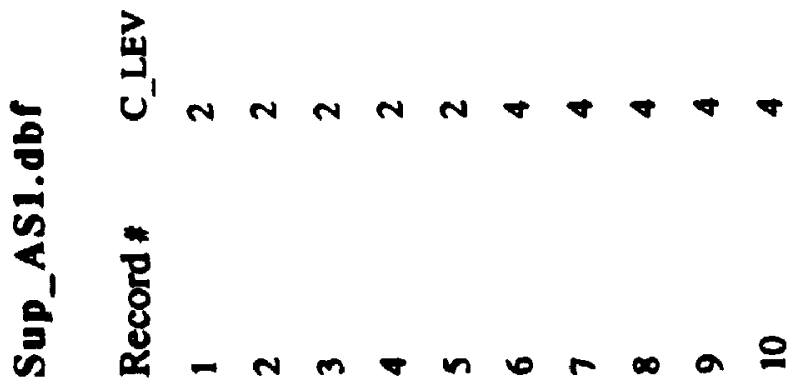




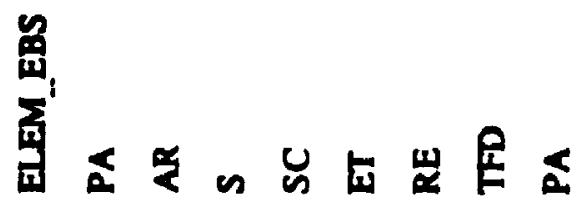

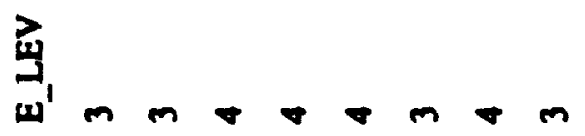

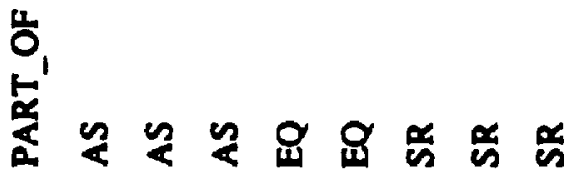

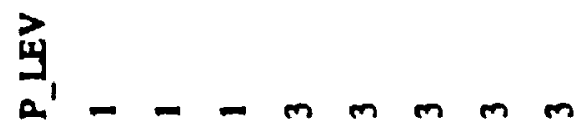

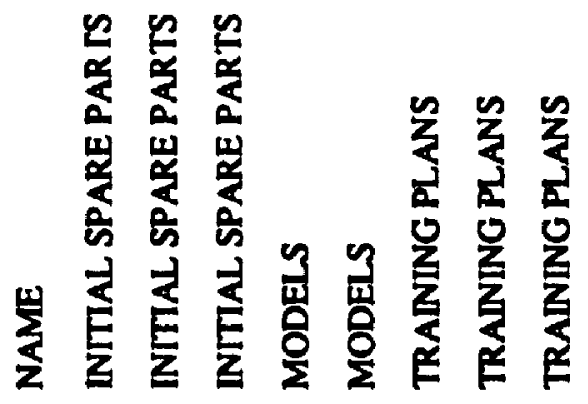

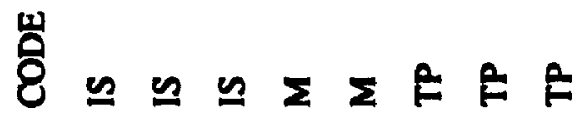

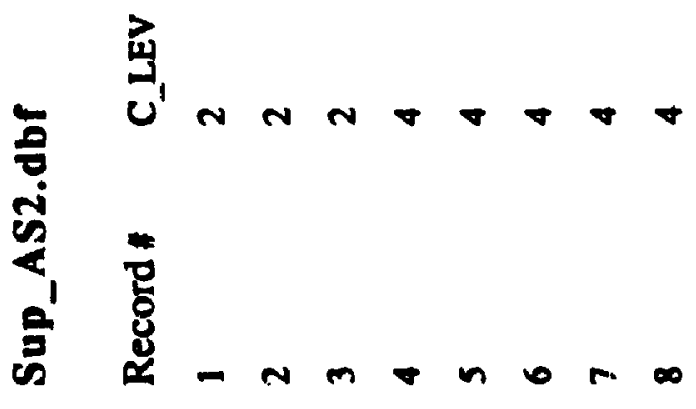


File "Join1.prg"

- Accessed from the Development Module - rule 3 (appendix 3)

*THIS PROGRAM JOINS THE CLASS AND THE AIRCRAFT-1 DATABASES AND

-THEN SORTS THEM ON TWO FIELDS. IT ALSO DELETES ALJ, THE

* ELEMENTS

"IN THE "TRANS" DATAFILE, SO THAT IT IS EMTTY WHEN ELEMENTS ARE

*ADDED TO IT. FOR THIS PROGRAM TO WONK, IT IS

*NECESSARY TO HAVE AN EMPTY DATABASE - TEMP.

SET ECHO OFF

SET TALK OFF

CLEAR ALL

ERASE COMBINE.DBF

USE TEMP

APPEND FP. Givi CLA.JSAS

APPENT, FROM A.5-1

CLEAR ALL

USE TEMP

SORT ON C_LEV, CODE/A TO COMBINE

USE

USE TEMP

DELETE ALL

PACK

USE

USE TRANS

DELETE ALL

PACK

CLEAR ALL

USE NEW_WBS

DELETE ALL

PACK

QUIT 
File "Join2. prg"

- Accessed from the Development Module - rule 4 (appendix 3)

-THIS PROGRAM JOINS THE CLASS AND THE AIRCRAFT-2 DATABASES AND -THEN SORTS THEM ON TWO FIELDS. FOR THIS PROGRAM TO WORK, IT

*IS NECESSARY TO HAVE AN EMPTY DATABASE - TEMP.

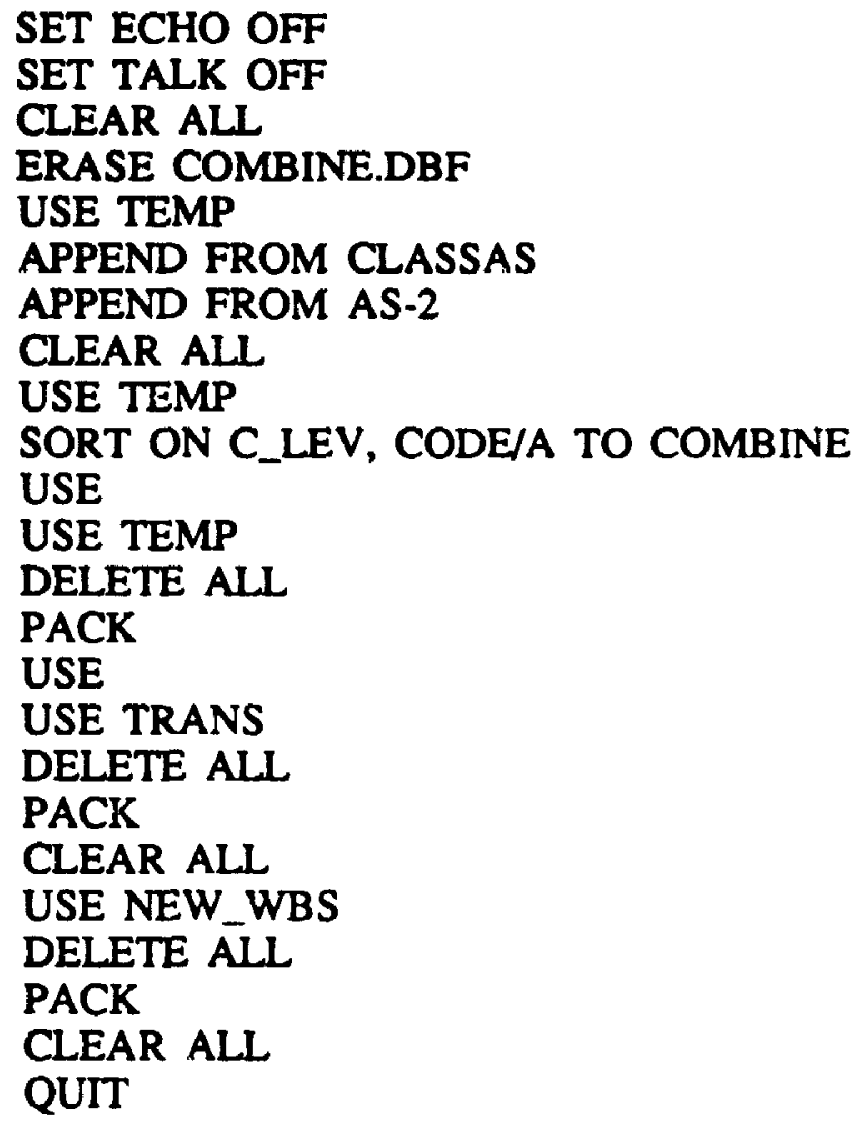


File "Join3.prg"

* Accessed from the Development Module - rules 5 and 72 (appendix 3)

-THIS PROGRAM JOINS TIIE CLASS AND THE AIRCRAFT-1 DATABASES AND -THEN SORTS THEM ON TWO FIELDS. FOR THIS PROGRAM TO WORK, IT *IS NECESSARY TO HAVE AN EMPTY DATABASE - TEMP.

SET ECHO OFF

SET TALK OFF

CLEAR ALL

ERASE COMBINE.DBF

USE TEMP

APPEND FROM CLASSAS

APPEND FROM AS-2 FOR CHAR = "A"

APPEND FROM AS-1 FOR CHAR = "A"

CLEAR ALL

USE TEMP

SORT ON C_LEV, CODE/A TO COMBINE

USE

USE TEMP

DELETE ALL

PACK

USE

USE TRANS

DELETE ALL

PACK

USE

USE NEW_WBS

DELETE ALL

PACK

Cl.EAR ALJ,

QUIT 


\section{File "Copy.prg"}

- Accessed from the Development Module - cules 6 to 11, 20 to 27, 29, 32, 35, 38,

* 41, 44, 47 \& 50 (appendix 3) THIS PROGRAM APPENDS THE RECORDS FROM

" THE FILE "COMBINE" TO "NEW WBS" FOR A MATCHING RECORD IN

* TR ANS. TRANS IS THE TRANSFER FILE TO WHICH SELECTED ELEMNTS

* ARE ADDED FROM THE KNOWLEDGE BASE.

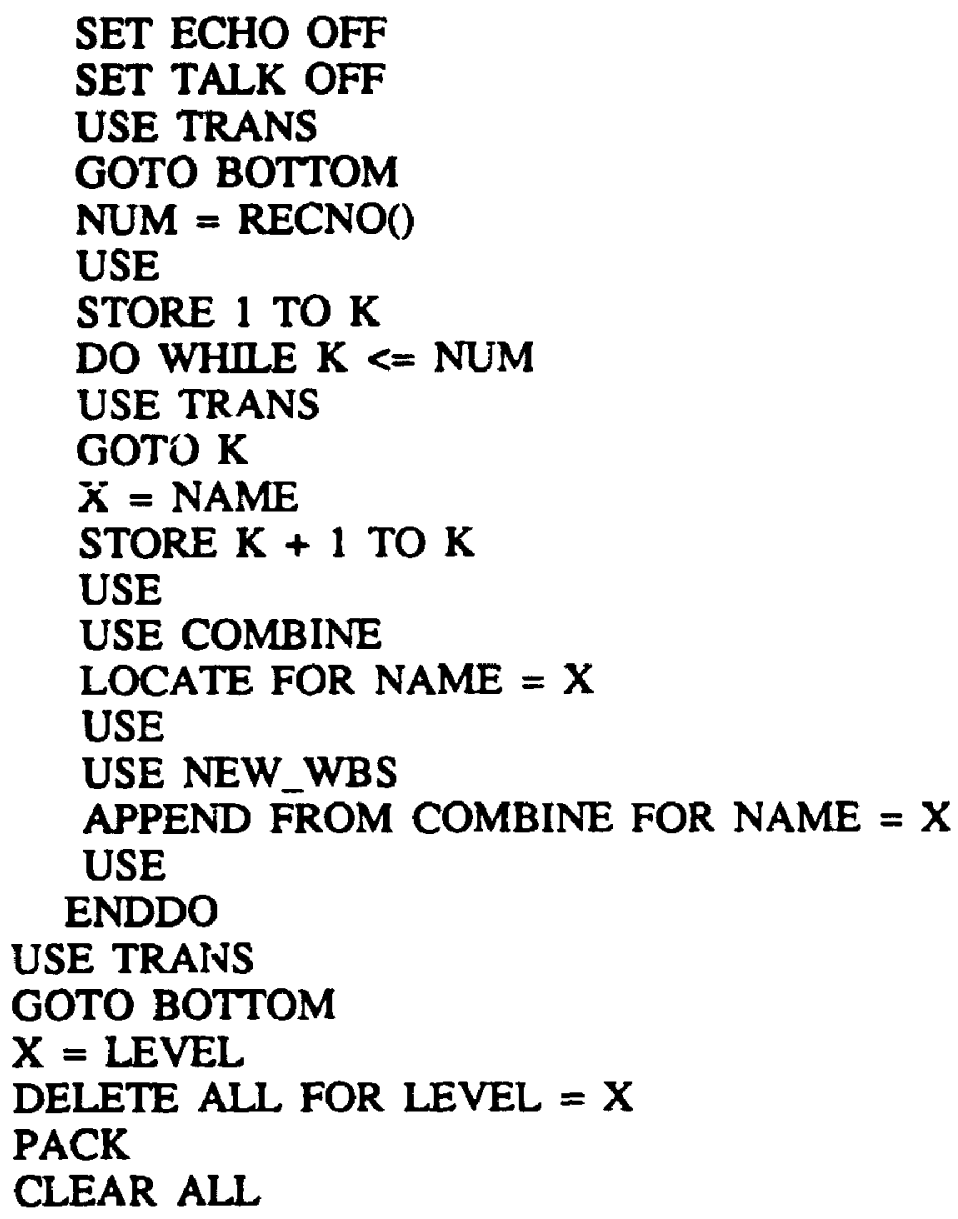



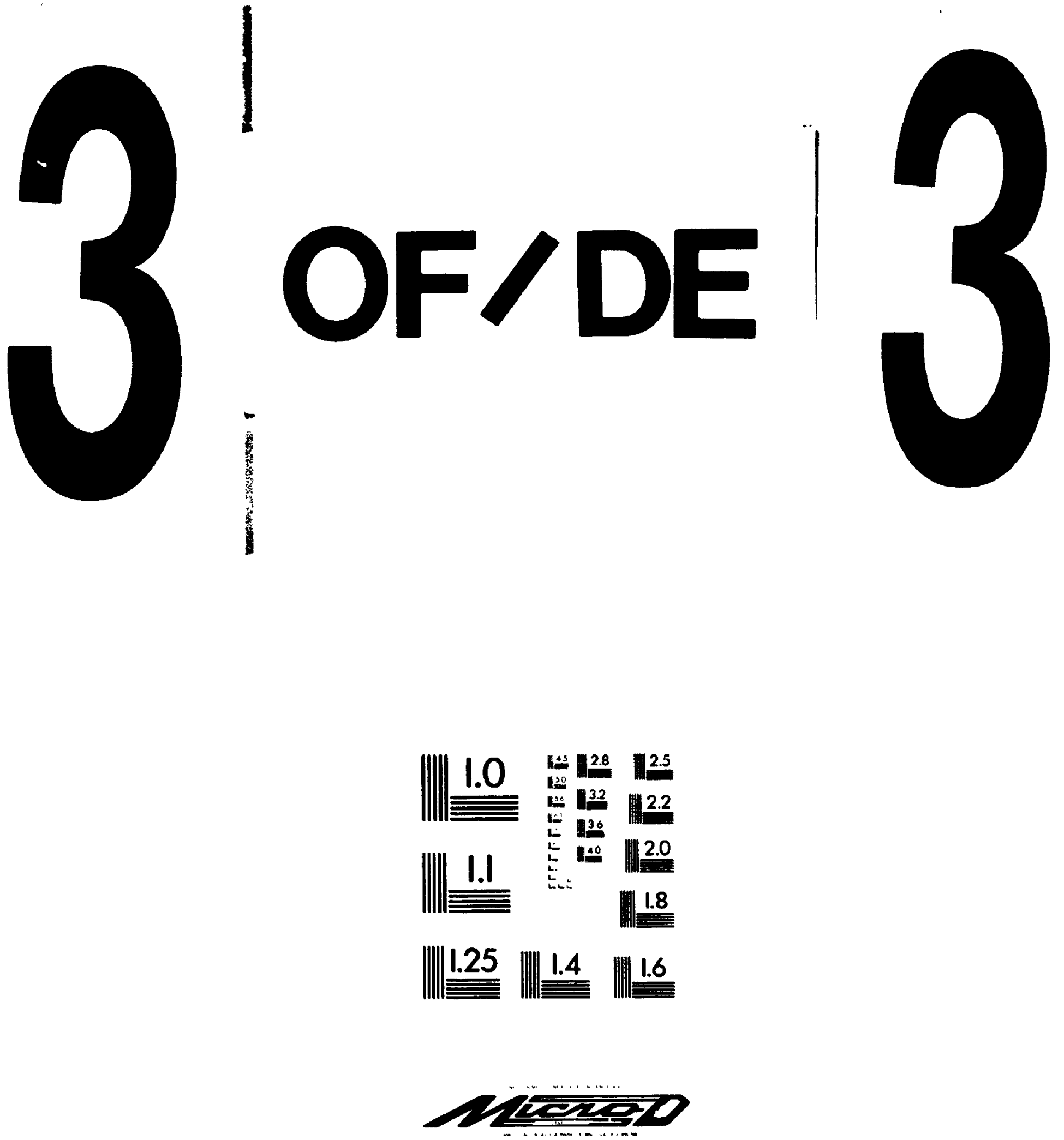


\section{File "More.prg"}

* Accessed from the nevelopment Module - by rules 7, 8, 9, and 20 to 27 (appendix

* 3) This program allows the user to input additional elements to the

*EW_WBS file

SET TALK OFF

SET echo OFF

SET BELL OFF

USE NEW_WBS

GOTO BOTTOM

$X=$ C_LEV

$\mathrm{Z}=\mathrm{C}$ LEV -1

$P=$ PART_OFF

NAME $=$ SPACE(25)

CODE $=$ SPACE(3)

ANSWER $=$. Y.

DO WHILE ANSWER

CLEAR

APPEND BLANK

DO WHILE NAME = SPACE(25). AND. CODE $=$ SPACE(3)

@ 1,1 SAY "RECORD \#" + STR(RECNO(),2)

@ 5, 15 SAY "THE ADDITIONAL LEVEL " + STR(X,1) + " ELEMENT "

@ 6, 15 SAY "YOU WANT TO ADD IS" GET NAME PICTURE "@S10"

@ 8, 15 SAY "THE CODE FOR THIS ELEMENT IS" GET CODE PICTURE I "AAA"

@ 12,15 SAY "IF YOU WANT TO ADD MORE ELEMENTS ENTER 'Y'"

@ 13, 15 SAY "ELSE ENTER 'N' TO QUIT" GET ANSWER PICTURE "L"

READ

ENDDO

N_CODE = "\#" + TRIM(CODE)

REPLACE FOR C_LEV $=0$ CODE WITH N_CODE, C_LEV WITH X, P_LEV

WITH Z, PART_OFF WTTH P

ENDDO

QUIT 
File "Add.prg"

- Accessed from the Development Module - rules 7, 11 and 71 (appendix 3)

*This program allows the user to input elements for the

* additional elements entered in the previous level.

"In addition it will add '" to the code entered by the user.

SET ECHO OFF

SET TALK OFF

SET BELL OFF

CLEAR ALL

STORE "

" TO X

USE NEW_WBS

GOTO BOTTOM

$L=C_{-}$LEV -1

NUM $=$ RECNO()

USE

USE NEW_WBS

LOCATE FOR C_LEV $=\mathbf{L}$

$\mathrm{K}=\mathrm{RECNO}()$

$\mathbf{M}=\mathbf{L}$

DO WHILE $K<=$ NUM

USE NEW_WBS

GOTO $\mathrm{K}$

$X=$ NAME

$M=C \_L E V$

IF $\mathbf{L}=\mathbf{M}$

USE

USE COMBINE

LOCATE FOR NAME $=X$

IF EOF()

USE

USE NEW_WBS

GOTO $\mathrm{K}$

$E=$ C_LEV

$Z=C_{-}$LEV +1

ELEMENT $=" " n+$ TRIM(NAME) + " "

$\mathrm{CD}=\mathrm{CODE}$

ANS $="$ "

CLEAR

DO WHILE ANS = " "

@ 10,15 SAY "You added an additional element, " + ELEMENT

@ 11, 15 SAY "in level " + STR(E,1) + "."

@ 12, 15 SAY "Do you want to add level " + STR $(Z, 1)+$ " element?"

@ 14, 25 SAY "ANSWER ? (YNN)" GET ANS PICTURE "L"

READ

ENDDO

IF ANS \$ "Yy" 
ANSWER $=$. T.

CLEAR

DO WHILE ANSWER

CLEAR

USE NEW_WBS

APPEND BLANK

@ 1, 1 SAY "RECORD \#" + STR(RECNO(),2)

@ 10, 15 SAY "PLEASE ADD THE LEVEL " + STR $(Z, 1)$ + " ELEMENT" GET NAME PICTURE

"!!!!!!!!!!!!!!!!!!!!!!!!!!!!!!!!!!!!!"

@ 12, 15 SAY "THE CODE FOR THIS ELEMENT IS" GET CODE PICTURE

"AAA"

@ 1?, 15 SAY "IF YOU WANT TO ADD MORE ELEMENTS ENTER ' $Y$ '"

@ 18, 15 SAY "ELSE ENTER 'N' TO QUIT" GET ANSWER PICTURE "L"

READ

N_CODE = "\#" + TRIM(CODE)

REPLACE FOR C_LEV = 0 CODE WITH N_CODE, C_LEV WITH Z, P_LEV WITH E, PART_OFF WITH CD

ENDDO

USE

ENDIF

ELSE

USE

ENDIF

ENDIF

STORE K + 1 TO K

ENDDO

QUIT 


\section{File "Cont1.prg"}

- This program executes the following command files after rule 74 is fired in the PC

- Easy KB (appendix 3). Next it determines if EBS elements were input by the user.

* If they were, the useris queried if he/she wants to add the suppport elemets for

* them. Based on the response, other files are executed.

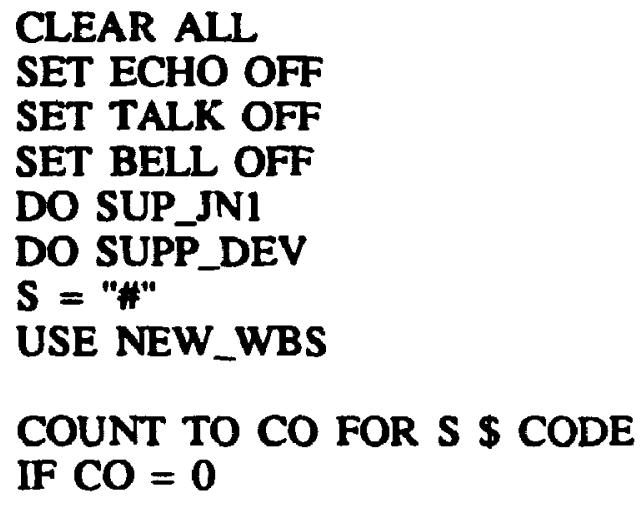

DO CONTROL

\section{ELSE}

ANSWER = " "

@ 10,15 SAY "You have added some additional elements to the EBS."

@ 11,15 SAY "Do you want to add support elements for these elements?"

@ 14, 25 SAY "Answer ? (Y/N)" GET ANSWER PICTURE "L"

\section{READ}

IF ANSWER \$ "yY"

DO EXTRA

ELSE

DO CONTROL

DO CONTROL

ENDIF

\section{ENDIF}




\section{File "Cont2.prg"}

- This program executes the following command files after rule 73 is fired in the PC

- Easy KB (appendix 3). Next it determines if EBS elements were input by the user.

* If they were, the useris queried if he/she wants to add the suppport elemets for

* them. Based on the response, other files are executed.

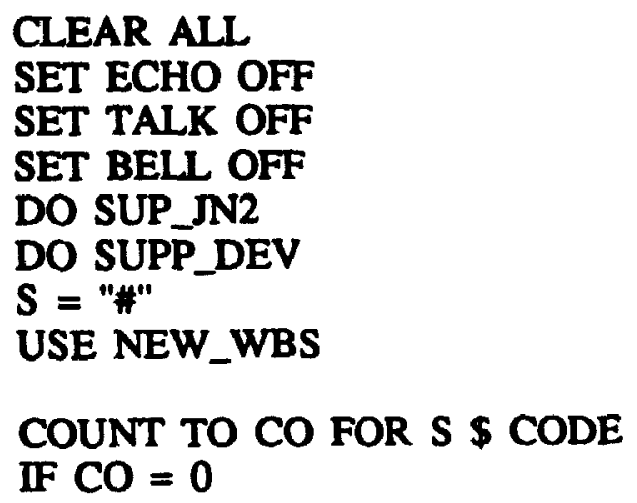

DO CONTROL

\section{ELSE}
ANSWER = " "
@ 10, 15 SAY "You have added some additional elements to the EBS."
@ 11, 15 SAY "Do you want to add support elements for these elements?"
@ 14, 25 SAY "Answer? (Y/N)" GET ANSWER PICTURE "L"

\section{READ}

IF ANSWER \$ "yY"

DO EXTRA

DO CONTROL

ELSE

DO CONTROL ENDIF

ENDIF 


\section{File "Cont3.prg"}

- This program executes the following command files after rule 75 is fired in the PC

- Easy KB (appendix 3). Next it determines if EBS elements were input by the user.

* If they were, the useris queried if he/she wants to add the suppport elemets for

* them. Based on the response, other files are executed.

CLEAR ALL

SET ECHO OFF

SET TALK OFF

SET BELL OFF

DO SUP_JN3

DO SUPP_DEV

$\mathrm{S}=$ "\#"

USE NEW_WBS

COUNT TO CO FOR S \$ CODE

IF $\mathrm{CO}=\mathbf{0}$

DO CONTROL

ELSE
ANSWER $=$ " "

\section{READ}
IF ANSWER \$ "YY"
DO EXTRA
DO CONTROL
ELSE
DO CONTROL ENDIF

@ 10, 15 SAY "You have added some additional elements to the EBS."

@ 11, 15 SAY "Do you want to add support elements for these elements?"

@ 14, 25 SAY "Answer ? (Y/N)" GET ANSWER PICTURE "L"

ENDIF 
File "Sup jn1.prg"

*Executed from cont1.prg

*THIS PROGRAM JOINS THE SUPPORT_CLASS AND THE

*SUPPORT_AIRCRAFT-1 DATABASES AND THEN SORTS THEM ON THREE

*FIELDS. FOR THIS PROGRAM TO WORK, IT IS

*NECESSARY TO HAVE AN EMPTY DATABASE - SUP_ TEMP.

SET ECHO OFF

SET TALK OFF

CLEAR ALL

ERASE SUP_COMB.DBF

USE SUP_TEMP

APPEND FROM SUPCL_AS

APPEND FROM SUP_AS1

CLEAR ALL

USE SUP_TEMP

SORT ON E_LEV/D, ELEM_EBS/D, P_LEV/D TO SUP_COMB

USE

USE SUP_TEMP

DELETE ALL

PACK

USE 
File "Supjn2.prg"

* Executed from cont2.prg

*THIS PROGRAM JOINS THE SUPPORT_CLASS AND THE

-SUPPORT_AIRCRAFT-2 DATABASES AND THEN SORTS THEM ON THREE

*FIELDS. FOR THIS PROGRAM TO WORK, IT IS

*NECESSARY TO HAVE AN EMPTY DATABASE - SUP_TEMP.

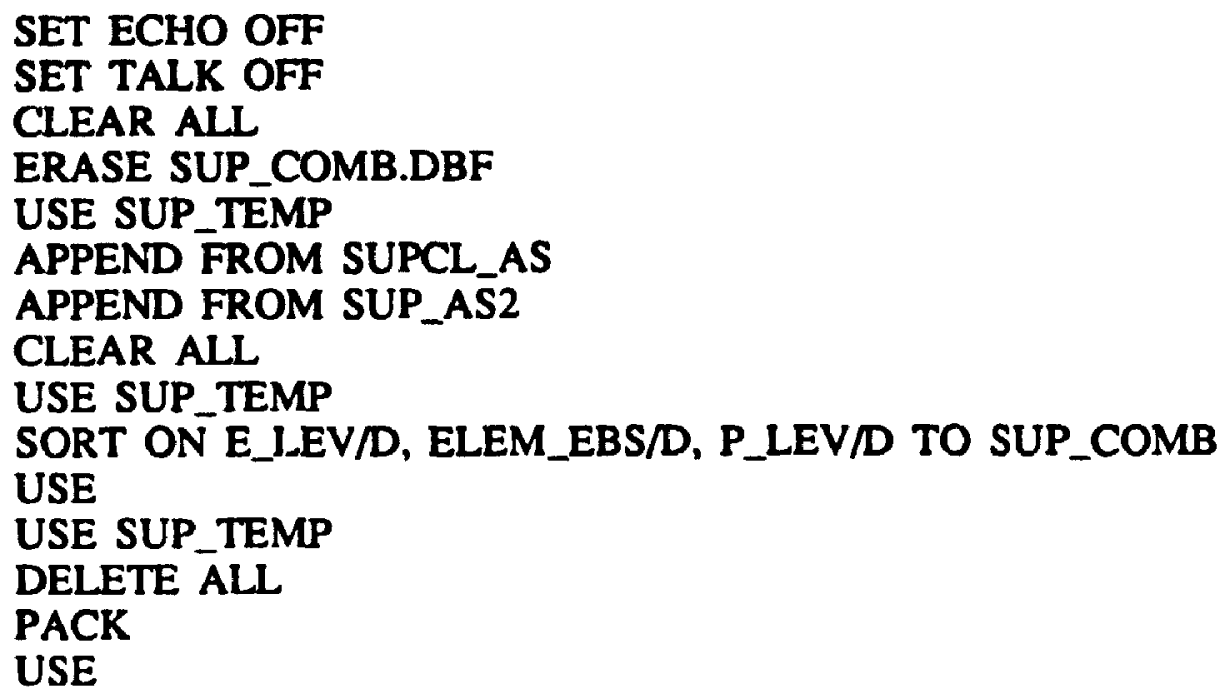


File "Sup_jn3.prg"

* Executed from cont3.prg

*THIS PROGRAM JOINS THE ClASS AND THE AIRCRAFT-1 AND

*AIRCRTAFT-2 DATABASES AND THEN SORTS THEM ON THREE FIELDS.

"FOR THIS PROGRAM TO WURK, IT IS NECESSARY TO HAVE AN EMPTY

*DATABASE - TEMP.

SET ECHO OFF

SET TALK OFF

CLEAR ALL

ERASE SUP_COMB.DBF

USE SUP_TEMP

APPEND FROM SUPCL_AS

APPEND FROM SUP_AS2 FOR CHAR = "A"

APPEND FROM SUP_AS1 FOR CHAR = "A"

CLEAR ALL

USE SUP_TEMP

SORT ON E_LEV/D, ELEM_EBS/D, P_LEV/D TO SUP_COMB

USE

USE SUP_TEMP

DELETE ĀLL

PACK

USE 
File "Supp_dev.prg"

-This program develops the support WBS which is stored in NEW_SUP.

It is executed from files cont1.prg, cont2.prg and cont3.prg

SET ECHO OFF

SET TALK OFF

CLEAR ALL

USE NEW_SUP

DELETE ALL

PACK

CLEAR ALL

CLEAR

STORE

" TO Z

STORE "N.A." TO L

USE SUP_COMB

$\mathbf{N}=\mathbf{0}$

STORE 1 TO $\mathrm{N}$

GOTO BOTTOM

NUM $=$ RECNO()

DO WHILE $\mathbf{N}<=$ NUM

USE SUP_COMB

GOTO N

$X=$ ELEM_EBS

IF $\mathrm{X}=\mathrm{L}$

SKIP

ELSE

IF $\mathbf{X}=\mathbf{Z}$

SKIP

ELSE

$\mathbf{Z}=\mathbf{X}$

USE

USE NEW_WBS

LOCATE FOR CODE $=X$

IF .NOT. EOF().

USE NEW_SUP

ENDIF

APPEND FROM SUP_COMB FOR ELEM_EBS $=X$

\section{ENDIF}

ENDIF

$\mathbf{N}=\mathbf{N}+1$

ENDDO

*This part of the program selects the elemnts which have "N.A." as *element_ebs and adds those elements to the New_Sup which have

*member elements in it (New_S、.). 


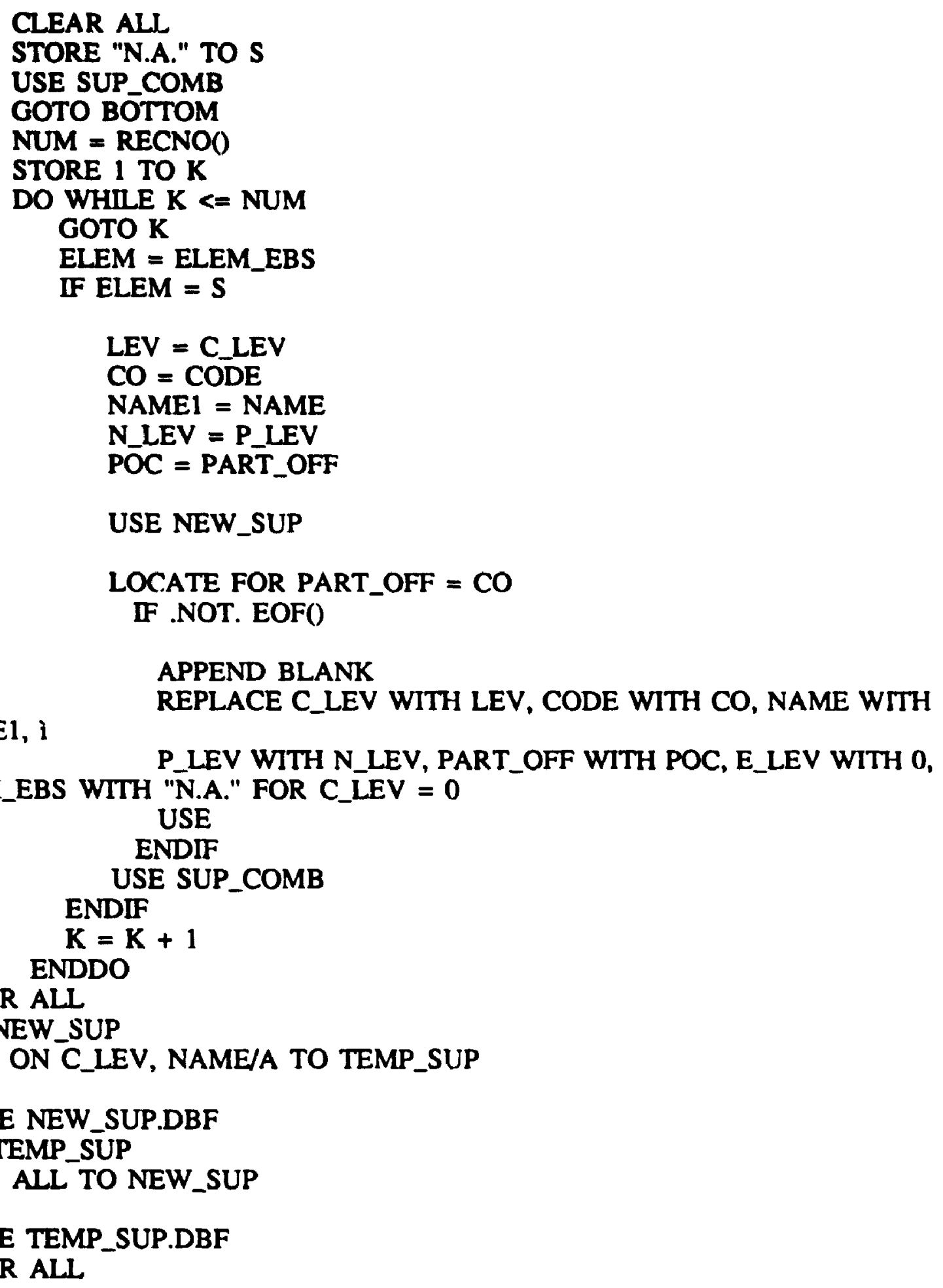


File "Control.prg"

- Accessed from - cont1.prg, cont2.prg and cont3.prg

- Controls the execution of the files to add additional support elements and to display the EBS.

SET ECHO OFF

SET TALK Off

SET BELL OFF

CLEAR ALL

CLEAR

USE NEW_SUP

$L=1$

LEVEL $=L+1$

DO WHILE LEVEL $<=3$

LOCATE FOR C_LEV = LEVEL .AND. ELEM_EBS = "N.A."

IF EOF()

LEVEL = LEVEL + 1

$\mathbf{N}=\mathbf{0}$

ELSE

N = LEVEL

LEVEL = LEVEL + 1

ENDIF

ENDDO

IF $\mathbf{N}>=2$

ANSWER $=" *$

DO WHILE ANSWER = " "

@ 10, 17 SAY "Do you want to add additional support elements"

@ 11, 17 SAY "to the Support WBS ?"

@14, 27 SAY "Answer ? (Y/N)" GET ANSWER PICTURE "L"

READ

ENDDO

IF ANSWER \$ "Yy"

DO ADD_S_EL

ELSE

DO DISPLAY

ENDIF

ELSE

DO DISPLAY

ENDIF

CLEAR 
ANSWER $=. T$.

DO WHIIE ANSWER

CLEAR

@ 10, 15 SAY "Do you want to add more support elements to"

@ 11, 15 SAY "any other elements in the EBS ?"

@ 14, 20 SAY "Answer? (Y/N)" GET ANSWER PICTURE "L" READ

IF ANSWER \$ "yY"

DO ADD_S_EL ANSWER $=. T$.

ELSE

DO DISPLAY

ENDIF

ENDDO 
File "Extra.prg"

*Executed from file cont1.prg, cont2.prg and cont3.prg

*This program allows to add support elements for the additional

*elements added to the EBS.

SET ECHO OFF

SET TALK OFF

SET BELL OFF

CLEAR ALL

CLEAR

STORE "

" TO A, N, C

SELECT 1

USE NEW_WBS ALIAS WBS

SELECT 2

USE NEW_SUP ALIAS SUPPORT

GOTO BOTTOM

NUM $=$ RECNO()

STORE 1 TO Z

CLEAR

SELECT 2

DO WHILE $Z<=$ NUM

SELECT 2

GOTO Z

* $N$ is the name of the element in the support WBS

LEV $=$ C_LEV

$\mathbf{N}=\mathbf{N A M E}$

$\mathrm{CO}=\mathrm{CODE}$

POC $=$ PART_OFF

B_LEV = P_LEV

$A=E L E M \_E B S$

IF $A \circlearrowright$ "N.A."

IF $N \ll C$

CLEAR

ANS $=" "$

DO WHILE ANS $="$ "

@ 10, 20 SAY " Do you want to add " + trim(N) + " for any of"

@ 11, 20 SAY " the additional EBS elements you input?"

@ 15, 30 SAY "Response? (Y/N)" GET ANS PICTURE "L" READ

ENDDO

CLEAR

IF ANS \$ "yY"

SIGN = "\#"

RESPONSE $="$ " 


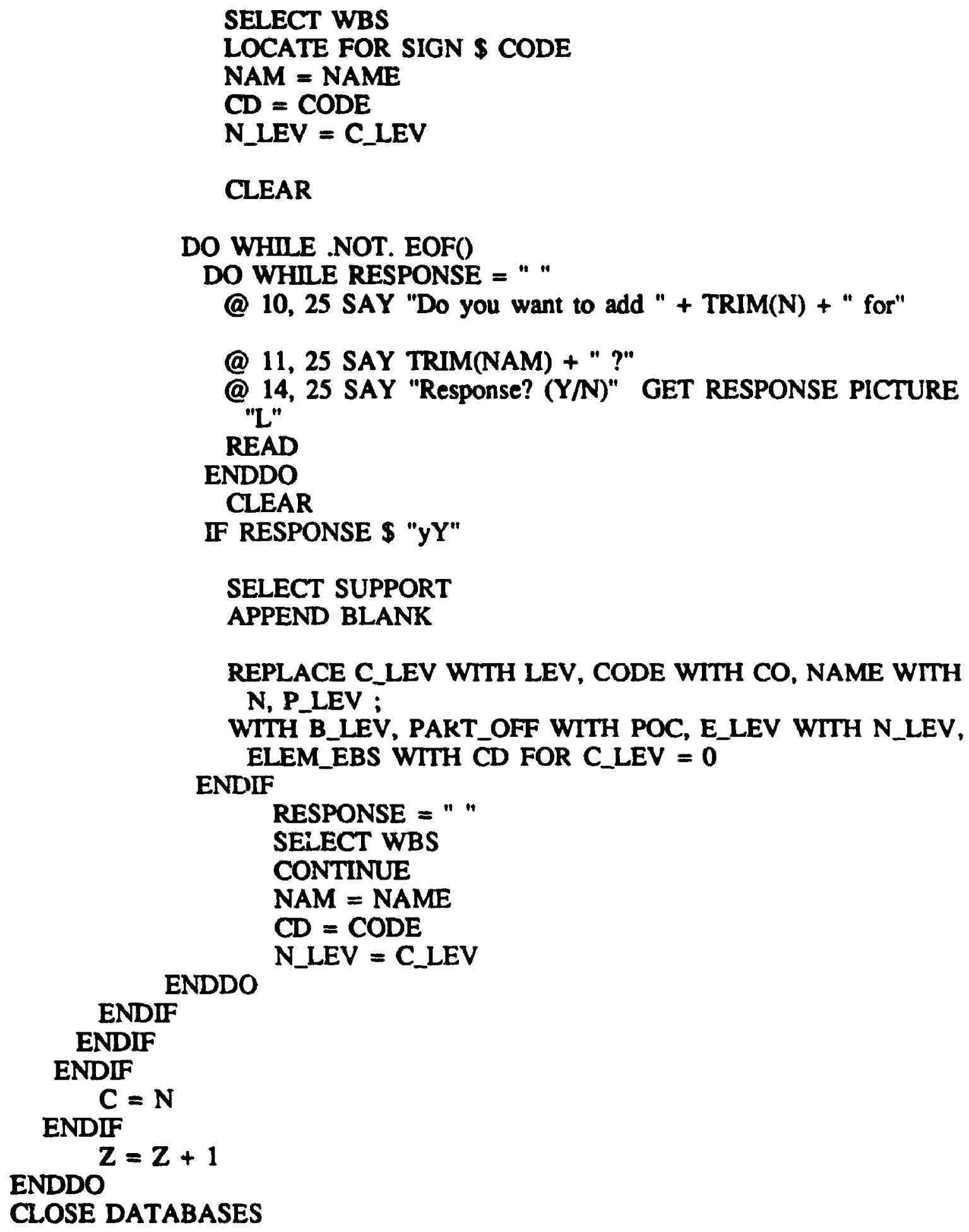

REPLACE C_LEV WITH LEV, CODE WITH CO, NAME WITH N, P_LEV :

WTTH B_LEV, PAKT_OFF WITH POC, E_LEV WTTH N_LEV, ENDIF ELEM_EBS WTTH CD FOR C_LEV $=0$

$$
\begin{aligned}
& \text { RESPONSE =" " } \\
& \text { SEiECT WBS } \\
& \text { CONTINUE } \\
& \text { NAM = NAME } \\
& \text { CD }=\text { CODE } \\
& \text { N_LEV }=\text { C_LEV }
\end{aligned}
$$


File "Add_s_el.prg"

* Accessed from Control.prg. Alllows for the input of the additional support element

*and its level. Based on the level, it transfers the control to the appropriate files.

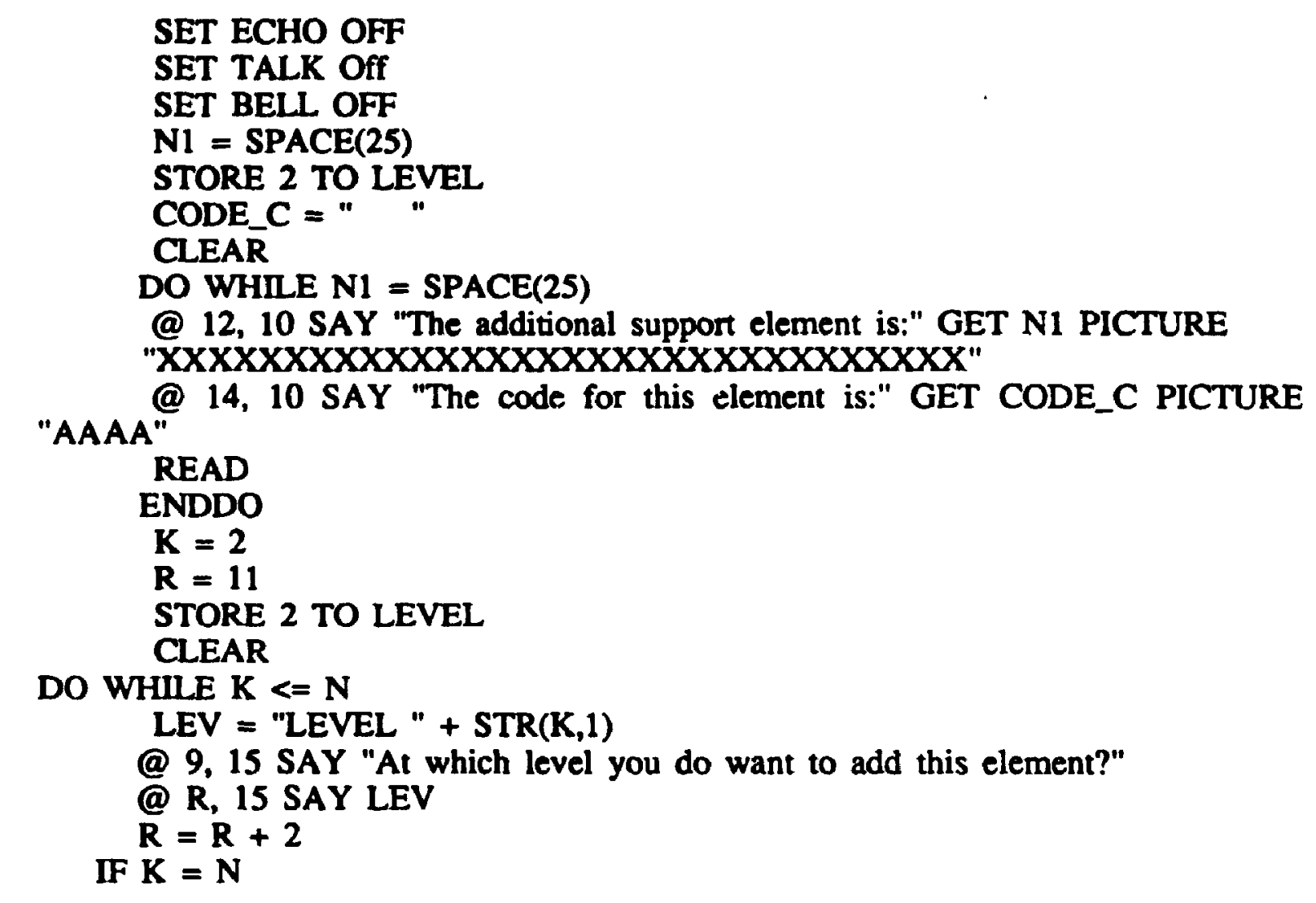

STORE 2 TO LEVEL

CLEAR

@ 12,10 SAY "The additional support element is:" GET N1 PICTURE

"XXXXXXXXXXXXXXXXXXXXXXXXXXXXXXXX"

READ

ENDDO

STORE 2 TO LEVEL

LEV = "LEVEL " + STR(K,1)

@ R, 15 SAY LEV

$\mathbf{R}=\mathbf{R}+2$

@ R, 15 SAY "LEVEL? (e.g, 2)" GET LEVEL PICTURE "9" RANGE 2, N READ

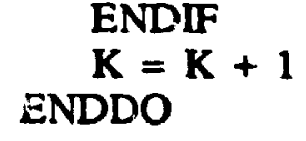
ENDIF

ENDDO

N_CODE = "\#" + TRIM(CODE_C)

PA_LEV = LEVEL - 1

DO CASE

CASE LEVEL $=2$

DO LEVEL2

CASE LEVEL $=3$

DO LEVEL3

ENDIF

ENDCASE 


\section{File "Level2.prg"}

* executed from add_s_el.prg

* If the additional support element is to be present in level 2, and does not have an

* element in level three, then the EBS elements, for which it is required, can be

* selected. If it does have an element in level 3, then thelevel 2 element is added to

" the database, file "lev3.prg" is executed.

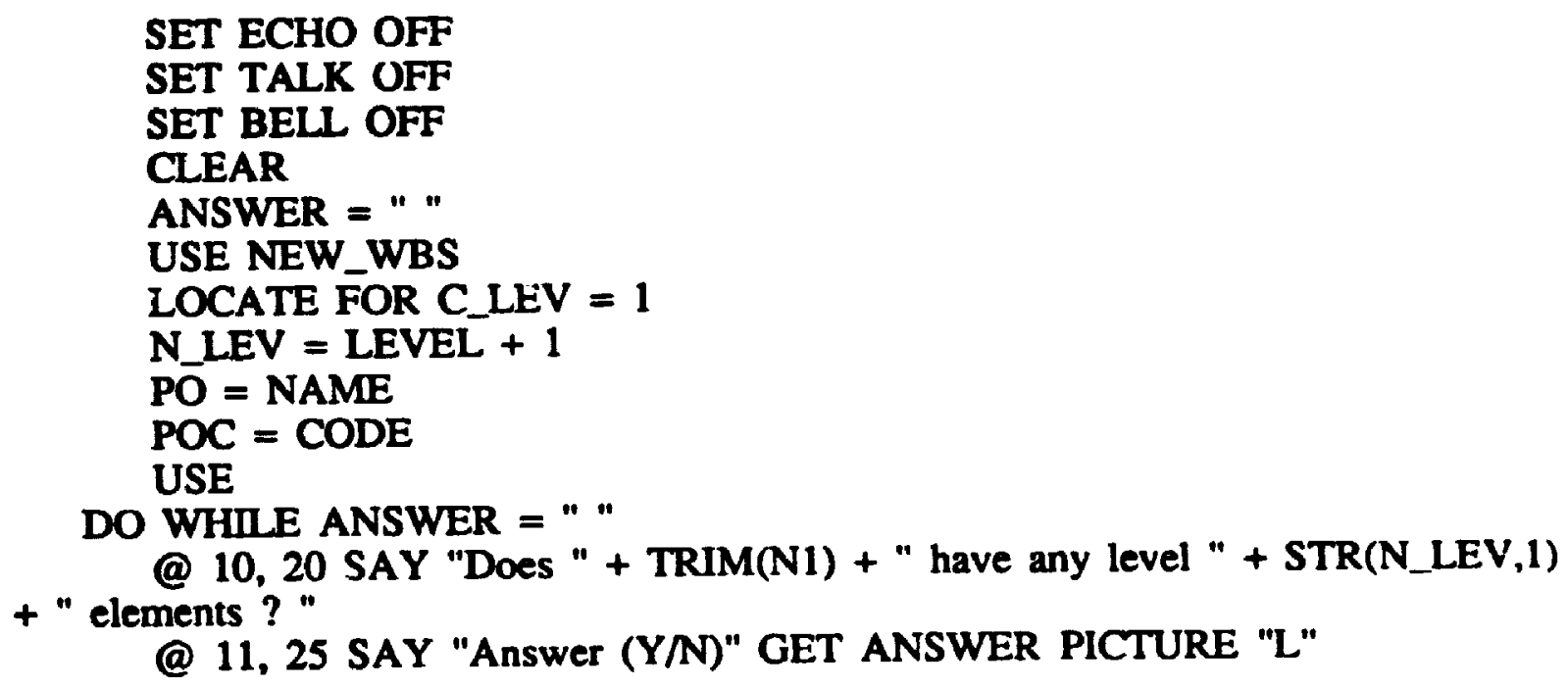

@ 11, 25 SAY "Answer (YNN)" GET ANSWER PICTURE "L"

READ

\section{ENDDO}

IF ANSWER \$ "nN"

CLEAR

@ 10, 20 SAY "You should now add the EBS elements"

@ 11, 20 SAY "for which " + TRIM(N1) + " is required."

WAIT

USE NEW_WBS

$\mathbf{S}=$ "\#"

COUNT TO C FOR S \$ CODE

USE

IF $C=0$

\section{ELSE}

DO EBS

SELECTION $=1$

CLEAR

@ 10,15 SAY "Choose the EBS categories to who's elements"

@ 11, 15 SAY "you would want to add " + TPIM(N1) + "."

@ 13, 15 SAY "1> EBS elements input via the keyboard" 
@ 14, 15 SAY "2> EBS elements selected from within the system." @ 15, 15 SAY "3> Both of the above"

RANGE 1, 3

@ 17, 25 SAY "Choice ? $(1,2,3) "$ GET SELECTION PICTURE "9"

\section{READ}

DO CASE

CASE SELECTION $=1$

DO EBS1

CASE SELECTION $=2$

DO EBS2

CASE SELECTION $=3$

DO EBS

ENDCASE

ENDIF

ELSE

USE NEW_SUP

APPEND BLANK

REPLACE C_LEV WITH LEVEL, CODE WITH N_CODE, NAME

WITH N1, P_LEV WITH PA_LEV, PART_OFF WTTH POC, E_LEV WITH 0,

ELEM_EBS WTTH "N.A" FOR C_LEV $=0$

USE

DO LEV3

ENDIF 


\section{File "Lev3.prg"}

* Accessed through - level2. It allows for the addition of the level 3 element for the

" level 2 element entered in file "level2.prg". Next the EBS elements for which the

* support element is required can be selected.

\section{SET TALK OFF}

SET ECHO OFF

STORE N1 TO PO

STORE N_CODE TO POC

STORE 3 TO LEVEL

ANSWER $=. T$.

DO WHILE ANSWER

N1 = SPACE(25)

CODE $=$ SPACE(4)

CLEAR

DO WHIIE N1 = SPACE(25). AND. CODE = SPACE(4)

@ 10,15 SAY "Input the level three element belonging to "

@ 11, 15 SAY TRIM(PO) + ":" GET N1 PICTURE "!!!!!!!!!!!!!!!!!!!!!!!!!!!!!"

PICTURE "AAAA"

@ 13,15 SAY "Input the code for this element" GET CODE

READ

ENDDO

N_CODE = "\#" + TRIM(CODE)

PA_LEV = LEVEL - 1

CLEAR

@ 10, 20 SAY "Since this is a prototype, support WBS is"

@ 11, 20 SAY "restricted to three levels. You should now"

@ 12, 20 SAY "add the EBS elements for which " + trim(N1)

@ 13, 20 SAY "is required."

WAIT

USE NEW_WBS

$S=" \# "$

COUNT TO CO FOR S \$ CODE 


\title{
USE NEW_WBS \\ IF $\mathrm{CO}=0$ \\ ELSE

\author{
DO EBS
}

\section{SELECTION $=1$}

CLEAR

@ 10,15 SAY "Choose the EBS elements to which "

@ 11, 15 SAY "you would want to add " + TRIM(N1) + "."

@ 13, 15 SAY "1> EBS elements input via the keyboard."

@ 14, 15 SAY "2> EBS elements selected from within the system."

@ 15, 15 SAY "3> Both of the above."

RANGE 1, 3

@ 17, 15 SAY "Choice ? $(1,2,3) "$ GET SELECTION PICTURE "9"

\author{
READ \\ DO CASE \\ CASE SELECTION $=1$ \\ DO EBS1 \\ CASE SELECTION $=2$ \\ DO EBS2 \\ CASE SELECTION $=3$ \\ DO EBS \\ ENDCASE \\ ENDIF \\ CLEAR \\ @ 10,15 SAY "Do you want to enter any more level 3 elements" \\ @ 11, 15 SAY "under " + TRIM(PO) + " ?" \\ @ 14, 25 SAY "Answer ? (Y/N)" GET ANSWER PICTURE "L" \\ READ
}


File "Level3.prg"

* executed from add_s_el.prg

* If the additional support element is to be present in level 3 ( the parent element in

* level 2 is from the reference support WBS) then the EBS elements, for which it is

* required, can be selected.

SET ECHO OFF

SET TALK OFF

CLOSE DATABASES

USE NEW_SUP

GOTO TOP

COUNT TO COU FOR C_LEV = 2 .AND. ELEM_EBS = "N.A."

LOCATE FOR C_LEV $=2$.AND. ELEM_EBS $=$ "N.A."

PA_LEV $=$ C_LEV

PO $=$ NAME

$P O C=$ CODE

LEVEL $=3$

IF $\mathrm{COU}=2$

CONTINUE

PA1_LEV $=$ C_LEV

PO1 $=$ NAME

$\mathrm{POCl}=\mathrm{CODE}$

CLEAR

ANSWER $=1$

@ 10, 22 SAY "Select the elements to which the level 3"1

@ 11, 22 SAY "element you want to add belongs:"

@ 12, 20 SAY "1> " + TRIM(PO)

@ 13, 20 SAY "2> " + TRIM(PO1)

@ 15, 27 SAY "Answre ? $(1,2)$ " GET ANSWER PICTURE "9" RANGE 1,2 READ

IF ANSWER $=2$

$$
\begin{aligned}
& \text { PA_LEV = PA1_LEV } \\
& P O=P O 1 \\
& P O C=P O C 1
\end{aligned}
$$

ENDIF

ELSE

CLEAR

@ 10, 17 SAY "There is only one possible owner element, " + TRIM(PO) +","

@ 11, 17 SAY "in level 2. The additional support element"

WAIT

@ 12, 17 SAY "will be added under this element." 
ENDIF

\section{CLEAR}

@ 10,15 SAY "Since this is a prototype, the support WBS"

@ 11, 15 SAY "restricted to three levels. You should now"

@ 12,15 SAY "add the EBS elements for which " + TRIM(N1)

@ 13,15 SAY "is required."

WAIT

ANSWER $=. T$.

DO WHILE ANSWER

USE NEW_WBS

$S=" \# "$

COUNT TO CO FOR S \$ CODE

USE

IF $\mathrm{CO}=0$

DO EBS

ELSE

SELECTION $=1$

CLEAR

@ 10,15 SAY "Choose the EBS categories to who's elements"

@ 11,15 SAY "you would want to add " + TRIM(N1) + "."

@ 13, 15 SAY "1> EBS elements input via the keyboard."

@ 14, 15 SAY "2> EBS elements selected from within the system."

@ 15, 15 SAY "3> Both of the above."

RANGE 1, 3

@ 17, 15 SAY "Choice ? $(1,2,3) "$ GET SELECTION PICTURE "9"

READ

DO CASE

CASE SELECTION $=1$

DO EBS1

CASE SELECTION $=2$

DO EBS2

CASE SELECTION $=3$

DO EBS

ENDCASE

ENDIF

CLEAR

@ 10, 15 SAY "Do you want to add more level 3 support"

@ 11, 15 SAY " elements under " + TRMM(PO) + " ?" 
@ 14, 20 SAY "Answer ? (Y/N)" GET ANSWER PICTURE "L"

READ

IF ANSWER \$ "Yy"

N1 $=$ SPACE(25)

CODE $=$ SPACE(4)

CLEAR

DO WHILE N1 = SPACE(25) .AND. CODE = SPACE(4)

@ 10, 15 SAY "Input the level three element belonging to"

@ 11, 15 SAY TRIM(PO) + ":" GET N1 PICTURE "@S10!"

@ 13, 15 SAY "Input the code for this element:" GET CODE PICTURE "AAAA"

READ

ENDDO

N_CODE = "\#" + TRIM(CODE)

ENDIF

ENDDO 


\section{File "EBS1.prg"}

* Executed from files level2.prg, lev3.prg and level3.prg.

* This program allows to add the additional support elements only

*to the EBS elements input by the user.

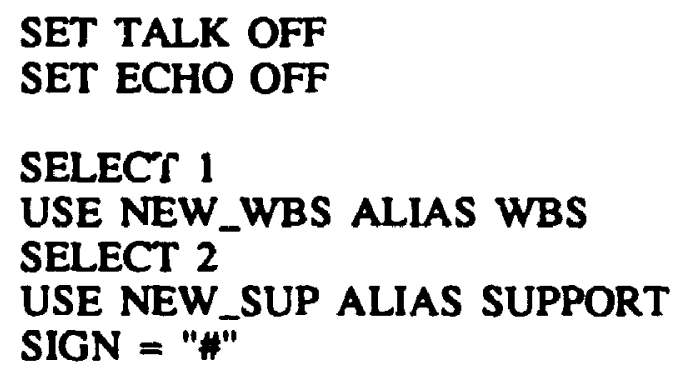

SELECT WBS

DO WHILE .NOT. EOF().

SELECT WBS

$$
\begin{aligned}
& \text { N3 }=\text { NAME } \\
& \text { C3 }=\text { CODE } \\
& \text { L3 }=\text { C_LEV }
\end{aligned}
$$

IF S \$ C3

$$
\text { CLEAR }
$$

@ 10, 15 SAY " Do you want to add " + TRIM(N1) + " for " +

@ 13, 25 SAY "ANSWER ? (YNN)" GET ANSWER PICTURE "L"

\section{READ}

IF ANSWER = "Y"

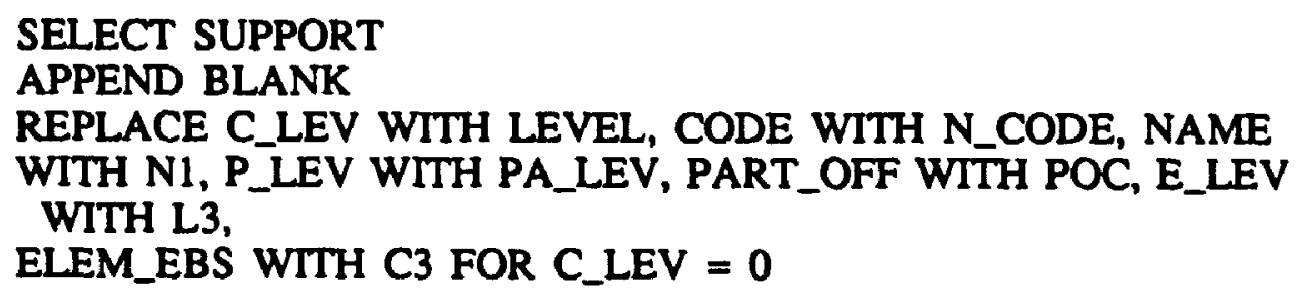

ENDIF

\section{ENDIF}

SELECT WBS

IF .NOT. EOF()

SKIP 


\section{ENDIF}

ENDDO 
File "EBS2.prg"

* Executed from files level2.prg, lev3.prg and level3.prg.

* This program allows to add the additional support elements selected

* from within the system.

SET TALK OFF

SET ECHO OFF

SELECT 1

USE NEW_WBS ALIAS WBS

SELECT 2

USE NEW_SUP ALIAS SUPPORT

SIGN = "\#"

DO WHIIE .NOT. EOF().

SELECT WBS

$$
\begin{aligned}
& \text { N3 }=\text { NAME } \\
& \text { C3 }=\text { CODE } \\
& \text { L3 }=\text { C_LEV }
\end{aligned}
$$

IF .NOT. S \$ C3

CLEAR TRIM(N3) + "?"

@ 10, 15 SAY " Do you want to add " + TRIM(N1) + " for " +

@ 13, 25 SAY "ANSWER ? (YNN)" GET ANSWER PICTURE: "L"

READ

IF ANSWER = "Y"

SELECT SUPPORT

APPEND BLANK

REPLACE C_LEV WITH LEVEL, CODE WTTH N_CODE, NAME

WITH N1, P_LEV WITH PA_LEV, PART_OFF WTTH POC, E_LEV WITH L3,

ELEM_EBS WITH C3 FOR C_LEV $=0$

ENDIF

ENDIF

SELECT WBS

IF .NOT. EOF()

SKIP

ENDIF

ENDDO 
RETURN 
File "EBS.prg"

* Executed from files level2.prg, lev3.prg and level3.prg.

- Allows addition of support element to any EBS element.

SET TALK OFF

SET ECHO OFF

SELECT 1

USE NEW_WBS ALIAS WBS

SELECT 2

USE NEW_SUP ALIAS SUPPORT

L3 $=0$

SELECT WBS

DO WHILF. .NOT. EOF().

SELECT WBS

$$
\begin{aligned}
& \text { N3 }=\text { NAME: } \\
& \text { C3 }=\text { CODE } \\
& \text { L3 }=\text { C_LEV }
\end{aligned}
$$

CLEAR

TRIM(N3) + "?"

@ 10, 15 SAY " Do you want to add " + TRIM(N1) + " for " +

@ 13, 25 SAY "ANSWER ? (Y/N)" GET ANSWER PICTURE "L"

\section{READ}

IF ANSWER = "Y"

SELECT SUPPORT

APPEND BLANK

REPLACE C_LEV WITH LEVEL, CODE WITH N_CODE, NAME WITH N1, P_LEV WITH PA_LEV, PART_OFF WITH POC, E_LEV WITH L3,

ELEM_EBS WTTH C3 FOR C_LEV $=0$

ENDIF

SELECT WBS

IF .NOT. EOF()

SKIP

ENDIF

ENDDO

RETURN 
File "Display.prg"

*Executed from file control.prg

* This program displays the EBS and executes file display2.prg

SET ECHO OFF

SET TALK Off

CLOSE DATABASES

CLEAR

$A=\operatorname{SPACE}(25)$

$\mathrm{C}=\operatorname{SPACE}(25)$

$X=\operatorname{SPACE}(25)$

$Y=$ SPACE(25)

$\mathrm{Z}=\operatorname{SPACE}(25)$

$T=5$

USE TRANS

GOTO TOP

$A=$ NAME

USE

$@ 2,10$ SAY $* * * * * * * * *$ THE FIRST LEVEL OF WBS ********** @ 5,35 SAY A

WAIT

USE

CLEAR

@ 10,17 SAY 'The EBS will be displayed first followed'i

@ 11,27 SAY 'by the Support WBS.'

WAIT

CLEAR

USE NEW_WBS

GOTO TOP

DO WHILE .NOT. EOF()

IF C_LEV $=2$

$\bar{X}=$ NAME

@ 2,10 SAY $\wedge \wedge \wedge \wedge \wedge \wedge \wedge \wedge \wedge$ THE SECOND LEVEL OF EBS $\wedge \wedge \wedge \wedge \wedge$ $\wedge \wedge \wedge \wedge$

@ T, 33 SAY X

$T=T+2$

ENDIF

IF .NOT. EOF()

SKIP

ENDIF 
ENDDO

WAIT

USE

USE NEW_WBS

COUNT TO C FOR C_LEV $>0$

$\mathrm{NUM}=\mathrm{C}$

$\mathrm{K}=1$

$\mathrm{D}=6$

N1 $=\operatorname{SPACE}(25)$

N2 $=$ SPACE(25)

DO WHILE $K \ll$ NUM

GOTO K

IF C_LEV = 2

N1 = NAME

$\mathrm{Cl}=\mathrm{CODE}$

LOCATE FOR PART_OFF $=\mathrm{Cl}$

CLEAR

IF EOF()

\# \#'

@ 2,10 SAY \# \# \# \# \# \# \# \# \# THIRD LEVEL OF EBS \# \# \# \# \# \# \# TRIM(N1) +"."

@ 10,15 SAY 'THERE ARE NO THIRD LEVEL ELEMNTS FOR "' + ENDIF

DO WHIIE .NOT. EOF()

N2 = NAME

\#”

@ 2,10 SAY \# \# \# \# \# \# \# \# \# THIRD LEVEL OF WBS \# \# \# \# \# \# \# \#

@ 4,15 SAY 'THE THIRD LEVEL ELEMENTS FOR "' + TRIM( ARE:'

@ D,30 SAY N2

CONTINUE

$\mathrm{D}=\mathrm{D}+2$

ENDDO

WAIT

ENDIF

$\mathbf{K}=\mathbf{K}+\mathbf{1}$

$D=6$

ENDDO 
USE

USE NEW_WBS

$D=6$

COUNT TO C FOR C_LEV > 0

NUM $=\mathrm{C}$

N1 $=\operatorname{SPACE}(25)$

N2 $=$ SPACE(25)

$K=1$

DO WHILE $K \ll$ NUM

GOTO $\mathrm{k}$

IF C_LEV $=3$

N1 $=$ NAME

$\mathrm{Cl}=\mathrm{CODE}$

LOCATE FOR PART_OFF $=\mathrm{Cl}$

CLEAR

IF EOF()

\#\#\#\#\# \#

@ 2,10 SAY '\# \# \# \# \# \# \# \# FOURTH LEVEL OF EBS \# \# \# $"$ + TRIM(N1) + "."

@ 10, 15 SAY 'THERE ARE NO FOURTH LEVEL ELEMENT FOR

ENDIFi

DO WHILE .NOT. EOF()

N2 = NAME

@ 2,10 SAY \#\# \# \# \# \# \# \# \# FOURTH LEVEL OF EBS \# \# \# \# \#\# \# \#

@ 4, 15 SAY 'THE FOURTH LEVEL ELEMENTS FOR "' + TRIM(N1) + "' ARE:"

@ D, 33 SAY N2

$K=K+1$

ENDIF

CONTINUE

$\mathrm{D}=\mathrm{D}+2$

ENDDO

WAIT

$\mathrm{D}=6$

ENDDO

CLOSE DATABASES

DO DISPLAY2 
File "Display2.prg"

*Executed from file control.prg

*This program displays the support wbs. Before displaying it

*sorts it so as to suit the program.

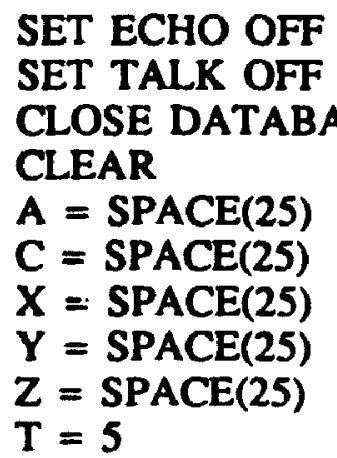

CLOSE DATABASES

CLEAR

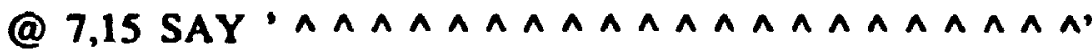

@ 10,25 SAY '"SUPPORT WBS BEGINNING"'

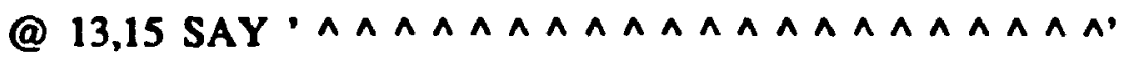

WAIT

CLEAR

USE NEW_SUP

SORT ON C_LEV, NAME TO TEMP_SUP

USE

ERASE NEW_SUP.DBF

USE

USE TEMP_SUP

COPY ALL TO NEW_SUP

USE

ERASE TEMP_SUP.DBF

CLOSE DATABASES

USE NEW_SUP

DO WHILE .NOT. EOF()

IF C_LEV $=2$

$$
X=\text { NAME }
$$

IF $X \diamond A$

@ 2,7 SAY $\wedge \wedge \wedge \wedge \wedge \wedge \wedge \wedge \wedge$ THE SECOND LEVEL OF SUPPORT WBS $\wedge \wedge$ $\wedge \wedge \wedge \wedge \wedge \wedge \wedge$ '

@ T,35 SAY X

$$
T=T+2
$$




\section{ENDIF}

\section{ENDIF}
IF .NOT. EOF()
SKIP
ENDIF

$$
\begin{aligned}
& A=X \\
& \text { ENDDO } \\
& \text { WAIT } \\
& \text { USE } \\
& D=6 \\
& \text { USE NEW_SUP } \\
& \text { GOTO BOTTOM } \\
& \text { NUM = RECNOO } \\
& K=1 \\
& \text { N1 }=\text { SPACE(25) } \\
& \text { N2 }=\text { SPACE(25) } \\
& A=\operatorname{SPACE}(25)
\end{aligned}
$$

DO WHILE $K \ll$ NUM

GOTO $\mathrm{K}$

IF C LEV $=2$

N1 $=$ NAME

$\mathrm{Cl}=\mathrm{CODE}$

LOCATE FOR PART_CFF $=\mathrm{Cl}$

IF EOF()

IF N1 $\diamond$ A

CLEAR

$* * * * * * * 1$

@ 2,7 SAY ********* THIRD LEVEL OF SUPPORT WBS * * TRIM(N1) +"':

@ 10, 10 SAY 'THERE ARE NO THIRD LEVEL ELEMNTS FOR "' + WAIT

$A=\mathrm{N} 1$

ENDIF

ELSE

\section{CLEAR}

DO WHILE .NOT. EOF()

N2 = NAME

IF $\mathbf{N} 2 \circlearrowright \mathbf{Y}$ 

ARE:'

@ 4,15 SAY 'THE THIRD LEVEL ELEMENTS FOR "' + TRIM(N1) + "

@ D,35 SAY N2

\author{
$\mathbf{Y}=\mathbf{N} 2$ \\ CONTINUE \\ $\mathrm{D}=\mathrm{D}+2$ \\ ELSE \\ CONTINUE \\ ENDIF \\ ENDDO \\ WAIT \\ ENDIF \\ ENDIF \\ $\mathbf{K}=\mathbf{K}+\mathbf{1}$ \\ $D=6$ \\ ENDDO
}

$$
\begin{aligned}
& \text { USE } \\
& \text { USE NEW_SUP } \\
& D=6 \\
& \text { GOTO BOTTOM } \\
& \text { NUM = RECNO() } \\
& \text { N1 }=\text { SPACE(25) } \\
& \text { N2 }=\text { SPACE }(25) \\
& A=\text { SPACE }(25) \\
& Y=\text { SPACE }(25) \\
& \text { K }=1
\end{aligned}
$$

DO WHILE $K \ll=$ NUM

GOTO $\mathrm{K}$

IF C_LEV $=3$

N1 = NAME

$\mathrm{C} 1=\mathrm{CODE}$

LOCATE FOR PART_OFF $=\mathrm{Cl}$

IF EOF()

IF $\underset{\text { CLEAR }}{\longrightarrow} \mathrm{A}$

WBS \#\#\#\#\#\#\#\#\#'

@ 2,7 SAY \# \# \#\#\#\#\# \# \# FOURTH LEVEL OF SUPPORT "' + TRIM(NI) + "'.'

@ 10, 15 SAY 'THERE ARE NO FOUKTH LEVEL ELEMENT FOR 
WAIT

$A=$ N1

ENDIF

ELSE

N2 = NAME

CLEAR

DO WHIIE .NOT. EOFO

N2 = NAME

IF $\mathbf{N} 2 \diamond \mathbf{Y}$

@ 2, 7 SAY '\#\#\#\#\#\#\#\#\#FOURTH LEVEL OF SUPPORT WBS

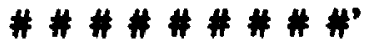

@ 4, 15 SAY 'THE FOURTH LEVEL ELEMENTS FOR "' + TRIM(N1)

+ "' ARE:'

@ D, 35 SAY N2

$\mathbf{Y}=\mathbf{N} 2$

CONTINUE

$$
\begin{aligned}
& \mathrm{D}=\mathrm{D}+2 \\
& \text { ELSE }
\end{aligned}
$$

CONTINUE

\section{ENDIF}

ENDDO

WAIT

ENDIF

\section{ENDIF}

$\mathbf{K}=\mathbf{K}+\mathbf{1}$

$D=6$

ENDDO

CLOSE DATABASES

QUIT 
sc- 1

WBS DEVELOPER

This system will assist you in developing a WBS for an aircraft. The WBS development process consists of two parts: 1) The development of the equipment breakdown structure (EBS); and 2) the development of the Support WBS.

* END - RETURN/ENTER to continue

$\mathrm{sc}-2$

WBS DEVELOPER

Please enter the name of of the WBS:

1. Use the arrow keys or the first letter of the Item to position the cursor.

2. Press RETURN/ENTER to continue.

SC -3

WBS DEVELOPER

Please enter the name of of the WBS:

Bomber - 234

1. Use the arrow keys or the first letter of the hem to position the cursor.

2. Press RETURN/ENTER to continue. 


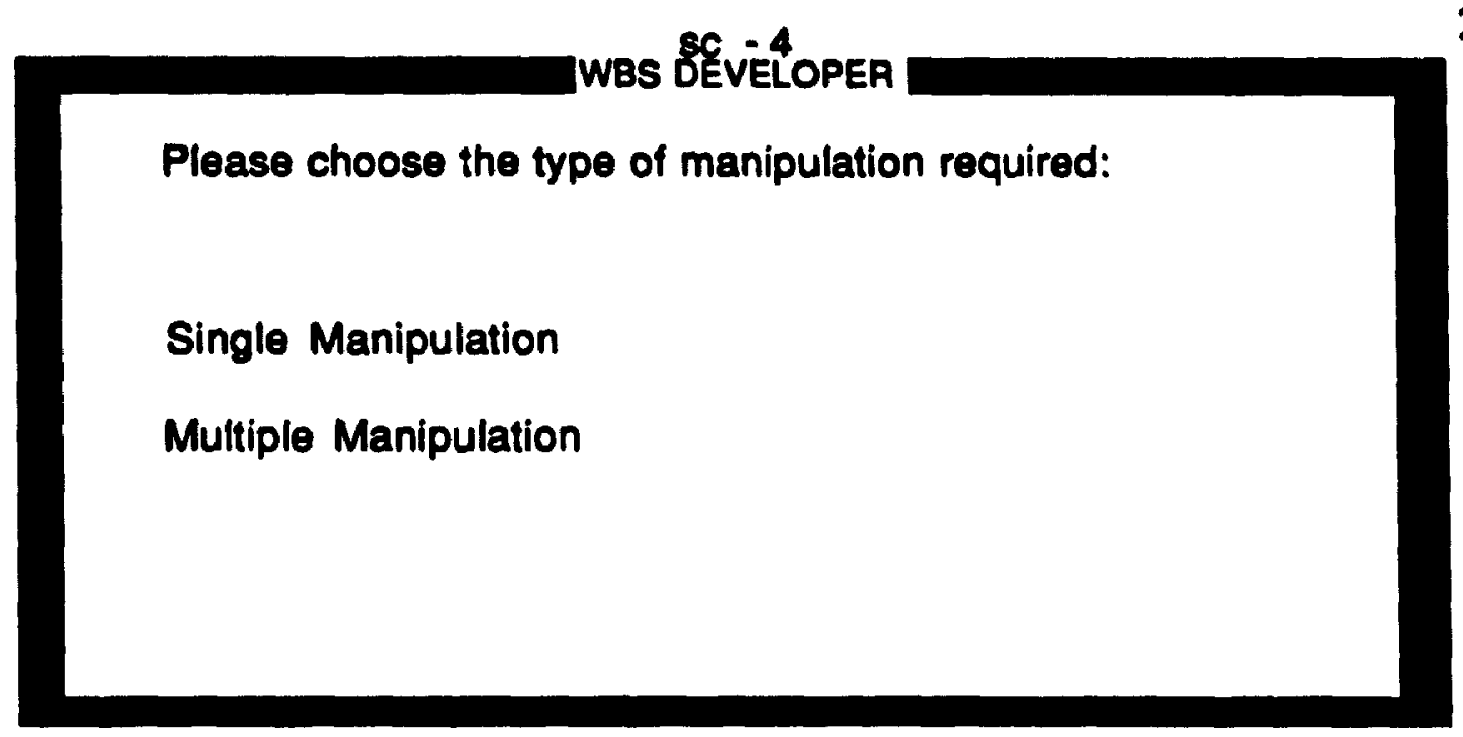

SC- 5

WBS DEVELOPER

Please choose the type of manipulation required:

Single Manipulation

Multiple Manipulation

$5 C \cdot 6$

WBS DEVELOPER

Please choose the Primary WBS:

Aircraft System - 1

Aircraft System - 2

1. Use the arrow keys or the first letter of the hem to position the cursor.

2. Press RETURNENTER to continue. 
Please choose the Primary WBS:

Aircraft System - 1

Aircraft System - 2

1. Use the arrow keys or the first letter of the Hem to position the cursor.

2. Press RetURN/ENTER 10 continue.

$$
\text { sc }-8
$$

WBS DEVELOPER

Please choose the Secondary WBS:

Aircraft System - 1

1. Use the arrow keys or the first letter of the item to pusition the cursor.

2. Press RETURN/ENTER to continue.

$$
\text { SC- } 9
$$

WBS DEVELOPER

Please choose the Secondary WBS:

Aircraft System - 1

1. Use the arrow keys or the first letter of the hem to position the cursor.

2. Press RETURNENTER to continue. 
Please select the second level elements of this WBS:

Airvehicle

1. Use the arrow keys or the first letter of the hem to position the cursor.

2. Press RETURNENTER to continue.

SC- 11

WBS DEVELOPER

Please select the second level elements of this WBS:

Airvehicle

1. Use the arrow keys or the first letter of the fitem to position the cursor.

2. Press RETURN/ENTER to continue.

\section{$S C-12$}

WBS DEVELOPER

Do you want to add additional Level 2 elements ?

Yes

No

1. Use the arrow keys or the first letter of the item to position the cursor.

2. Press RETURN/ENTER to continue. 
Do you want to add additional Level 2 elements ?

Yes

No

1. Use the arrow keys or the first letter of the Mem to position the cursor.

2. Press RETURNENTER to continue.

SC -14

WBS DEVELOPER

Please select the third level elements belonging to Air Vehicle in second level:

Yes

4 - Air Frame

$\leftrightarrow$ - Propulsion Unit

$\rightarrow$ Communications

$\rightarrow$ - Navigation And Guidance

$\downarrow \rightarrow$ Fire Control

1. Use the arrow keys or the first letter of the item to position the cursor.

2. Select all applicable responses.

3. Press RETURN/ENTER to continue.

\section{WBS DEVELOPER}

Please select the third level elements belonging to Air Vehicle in second level:

\section{Yes}

$\uparrow \leftrightarrow$ - Fire Control

$1 \rightarrow$ Penetration Aids

- Weapons Delivery Equipment

$\leftrightarrow$ - Reconnaissance Equipment

4 - Armament

1. Use the arrow keys or the first letter of the hem to position the cursor.

2. Select all applicable responses.

3. Press RETURN/ENTER to continue. 
Please select the third level elements belonging to Air Vehicle in second level:

Yes
- Air Frame
- Propulsion Unit
- Communications
- Navigation And Guidance
a Fire Control

1. Use the arrow keys or the first letter of the item to position the cursor.

2. Select all applicable responses.

3. Press RETURN/ENTER to continue.

\section{sc -17}

WBS DEVELOPER

Please select the third level elements belonging to Air Vehicle in second level:

\section{Yes}

$\uparrow \quad$ Fire Control

- Penetration Aids

- Weapons Delivery Equipment

- Reconnaissance equipment

- Armament

1. Use the arrow keys or the first letter of the item to position the cursor.

2. Select all applicable responses.

3. Press RETURN/ENTER to continue.

\section{$S C-18$}

WBS DEVELOPER

Do you want to add additional Level 3 elements ?

Yes

No

1. Use the arrow keys or the first letter of the item to position the cursor.

2. Press RETURN/ENTER to continue. 
Do you want to add additional Level 3 elements?

Yes

No

1. Use the arrow keys or the first letter of the hem to position the cursor.

2. Press RETURN/ENTER to continue.

sc -20

Please Enter the name of the additional element

which you want to add:

Please enter the code for this element:

Enter $\mathrm{Y}$ if you want to continue, $\mathrm{N}$ to quit:

Answer (Y/N)

1. Use the arrow keys or the first letter of the item to position the cursor.

2. Press RETURN/ENTER to continue.

SC -21

WBS DEVELOPER

Please Enter the name of the additional element which you want to add: Antisubmarine Warfare

Please enter the code for this element: $A W$

Enter $Y$ if you want to continue, $\mathbf{N}$ to quit:

Answer $(Y / N) \quad N$

1. Use the arrow keys or the first letter of the item to position the cursor.

2. Piess RETURN/ENTER to continue. 
Please select the fourth level elements belonging to Aiffame in level 3:

Yes

- Basic Structure

- Secondary Power

- Furnishings

$\leftrightarrow$ - Air Induction System

1. Use the arrow keys or the first letter of the item to position the cursor.

2. Select all applicable responses.

3. Press RETURNENTER to continue.

$S C-23$

WBS DEVELOPER

Please select the fourth level elements belonging to Airfame in level 3:

Yes

- Basic Structure

- Secondary Power

- Air Induction System

- Furnishings

1. Use the arrow keys or the first letter of the hem to position the cursor.

2. Select all applicable responses.

3. Press RETURN/ENTER to continue.

SC -24

WBS DEVELOPER

Do you want to add additional Level 4 elements for Airframe in level 3 ?

Yes

No

1. Use the arrow keys or the first letter of the hem to position the cursor.

2. Press RETURN/ENTER to continue. 
Do you want to add additional Level 4 elements for Airframe in level 3 ?

\section{Yes}

No

1. Use the arrow keys or the first letter of the item to position the cursor.

2. Press RETURN/ENTER to continue.

$S C-26$

WBS DEVELOPER

Please select the fourth level elements belonging to Propulsion Unit in level 3:

Yes

$\leftrightarrow$ - Engine

- Thrust Reversers

1. Use the arrow keys or the first letter of the item to postion the cursor.

2. Select all applicable responses.

3. Press ReTUJNEENTER to continue.

\section{SC -27}

WBS DEVELOPER

Please select the fourth level elements belonging to Propulsion Unit in level 3:

Yes

- Engine

- Thrust Reversers

1. Use the arrow keys or the first letter of the ftem to position the cursor.

2. Select all applicable responses.

3. Press RETURN/ENTER to continue. 
Do you want to add additional Level 4 elements belonging to Propulsion Unit in Level 3 ?

Yes

No

1. Use the arrow keys or the first letter of the hem to postition the cursor.

2. Press RETURNENTER to continue.

sc- 29

WBS DEVELOPER

Do you want to add additional Level 4 elements belonging to Propulsion Unit in Level 3?

Yes

No

1. Use the arrow keys or the first letter of the hem to position the cursor.

2. Press RETURN/ENTER to continue.

SC -30

IWBS DEVELOPER

Please select the fourth level elements belonging to

Communication in level 3:

Yes

- Intercom

- Data Link

1. Use the arrow keys or the first letter of the hem to position the cursor.

2. Select all applicable responses.

3. Press RETURNVENTER to continue. 
Please select the fourth level elements belonging to Communication in level 3:

Yes

- Intercom

- Data Link

1. Use the arrow keys or the first letter of the item to position the cursor.

2. Select all applicable responses.

3. Press RETURN/ENTER to continue.

sc -32

WBS DEVELOPER

Do you want to add additional Level 4 elements belonging to Communications in Level 3 ?

Yes

No

1. Use the arrow keys or the first letter of the litem to position the cursor.

2. Press RETURN/ENTER to continue.

Sc - 33

WBS DEVELOPER

Do you want to add additional Level 4 elements belonging to Communications in Level 3 ?

Yes

No

1. Use the arrow keys or the first letter of the hem to position the cursor.

2. Press RETURN/ENTER to continue. 
Please select the fourth level elements belonging to Navigation and Guidance in level 3:

Yes

$\longrightarrow$ - Radar

$\leftrightarrow$ - Altimeter

1. Use the arrow keys or the first letter of the hem to position the cursor.

2. Select all applicable responses.

3. Press RetURN/ENTER to continue.

$8 C-35$

WBS DEVELOPER

$+$

Please select the fourth level elements belonging to Navigation and Guidance in level 3:

Yes

- Radar

- Altimeter

1. Use the arrow keys or the first letter of the item to position the cursor.

2. Select all applicable responses.

3. Press RETURN/ENTER to continue.

\section{$\mathrm{SC}-36$ \\ WBS DEVELOPER}

C.: ou want to add additional Level 4 elements belonging to Navigation and Guidance in Level 3 ?

Yes

No

1. Use the arrow keys or the first letter of the item to position the cursor.

2. Press RETURNENTER 10 continue. 
Do you want to add additional Level 4 elements belonging to Navigation and Guidance in Level 3?

Yes

No

1. Use the arrow keys or the first letter of the litem to position the cursor.

2. Press RETURN/ENTER to comtinue.

$$
\mathrm{sC}-38
$$

WBS DEVELOPER

Please select the fourth level elements belonging to

Fire Control in level 3:

Yes

- Bombing Computer

- Navigation and Air Data Systems

1. Use the arrow keys or the first letter of the item to position the cursor.

2. Select all applicable responses.

3. Press AETURN/ENTER to continue.

$$
\text { SC - } 39
$$

WBS DEVELOPER

Please select the fourti level elements belonging th Fire Control in level 3:

Yes

- Bombing Computer

- Navigation and Air Data Systems

1. Use the arrow keys or the first letrer of the hem to position the cursor.

2. Select all applicable responses.

3. Press RETURNENTER to continue. 
Do you want to add additional Level 4 elements belonging to Fire Control in Level 3 ?

Yes

No

1. Use the arrow keys or the first letter of the them to position the cursor.

2. Press RETURNENTER to continue.

Sc -41

WBS DEVELOPER

Do you want to add additional Level 4 elements belonging to Fire Control in Level 3?

Yes

No

1. Use the arrow keys or the first letter of the item to position the cursor.

2. Press RETURN/ENTER to continue.

\section{SC -42}

WBS DEVELOPER

Please select the fourth level elements belonging to Penetration Aids in level 3:

Yes

$\leftrightarrow$ - Electronic Transmitters

$\leftrightarrow$ - Jamming Transmitters

$\leftrightarrow$ - Search Receivers

1. Use the arrow keys or the first letter of the item to position the cursor.

2. Select all applicable responses.

3. Press RETURN/ENTER to continue. 
Please select the fourth level elements belonging to

Penetration Aids in level 3:

Yes

- Electronic Transmitters

- Jamining Transmitters

- Search Receivers

1. Use the arrow keys or the first letter of the Hem to postion the cursor.

2. Select all applicable responses.

3. Press RetURNENTER to continue.

Do you want to add additional Level 4 elements belonging to Penetration Aids in Level 3?

Yes

No

1. Use the arrow keys or the first letter of the ftem to position the cursor.

2. Press RETURNVENTER to continue.

$\mathrm{sc}-45$

WBS DEVELOPER

Do you want to add additional Level 4 elements belonging to Penetration Aids in Level 3?

Yes

No

1. Use the arrow keys or the first letter of the Hem to position the cursor.

2. Press RETURN/ENTER to continue. 
Please select the fourth level elements belonging to Weapons Delivery in level 3:

Yes

- Launchers

Bomb Racks

1. Use the arrow keys or the first letter of the hem to position the cursor.

2. Select all applicable responses.

3. Press RETURNENTER to continue.

SC- 47

WBS DEVELOPER

Please select the fourth level elements belonging to

Weapons Delivery Equipment in level 3:

Yes

- Launchers

- Bomb Racks

1. Use the arrow keys or the first letter of the Hem to position the cursor.

2. Select all applicable responses.

3. Press RETURN/ENTER to continue.

SC. 48

WBS DEVELOPER $"$

Do you want to add additional Level 4 elements belonging to Weapons Delivery Equipment in Level 3?

Yes

No

1. Use the arrow keys or the first letter of the ltem to position the cursor.

2. Press RETURN/ENTER to continue. 
Do you want to add additional Level 4 elements belonging to Weapons Delivery Equipment in Level 3?

Yes

No

1. Use the arrow keys or the first letter of the Hem to position the cursor.

2. Press RETURNENTER to continue.

$$
\text { SC } \cdot 50
$$

WBS DEVELOPER

Please select the fourth level elements belonging to Reconnaissance Equipment in level 3:

Yes

- Search Receivers

- Sensors

1. Use the arrow keys or the first letter of the hem to position the cursor.

2. Select all applicable responses.

3. Press RETURN/ENTER to continue.

$$
\text { SC }-51
$$

WBS DEVELOPER

Please select the fourth level elements belonging to

Reconnaissance Equipment in level 3:

Yes

- Search Recievers

- Sensors

1. Use the arrow keys or the first letter of the item to position the cursor.

2. Select all applicable responses.

3. Press RETURN/ENTER to continue. 
Do you want to add additional Level 4 elements belonging to Reconnaissance Equipment in Level 3?

Yes

No

1. Use the arrow keys or the first letter of the them to position the cursor.

2. Press RETURNENTER 10 continue.

SC- 53

WBS DEVELOPER

Do you want to add additional Level 4 elements belonging to Reconnaissance Equipment in Level 3?

Yes

No

1. Use the arrow keys or the first letter of the them to position the cursor.

2. Press RETURN/ENTER to continue.

SC -54

WBS DEVELOPER

There are no level 4 elements for "Armaments" in level 3. Do you want to add the level four velues?

Answer $(Y / N)$

1. Use the arrow keys or the first letter of the item to position the cursor.

2. Press RETURNENTER to continue. 
There are no level 4 elements for "Armaments" in level 3. Do you want to add the level four velues?

$$
\text { Answer }(Y / N) \quad N
$$

1. Use the arrow keys or the first letter of the fitem 10 position the cursor.

2. Press RETURNENTER to continue.

$$
\text { SC- } 56
$$

\section{WBS DEVELOPER}

You added an additional element " Antisubmarine Warfare" in level 3. Do you want to add level 4 elements belonging to it?

$$
\text { Answer }(\mathrm{Y} / \mathrm{N})
$$

1. Use the arrow keys or the first letter of the item to position the cursor.

2. Press RFiURN/ENTER to continue.

$$
\text { SC }-57
$$

WBS DEVELOPER

You added an additional element "Antisubmarine Warfare" in level 3. Do you want to add level 4 elements belonging to it?

$$
\text { Answer }(\mathrm{Y} / \mathrm{N}) \mathrm{N}
$$

1. Use the arrow keys or the first letter of the inem to position the cursor.

2. Press RETURNENTER to continue. 
You added additional EBS elements. Do you want to add some of the reference support elements for them?

$$
\text { Answer (Y/N) }
$$

1. Use the artow keys or the first letter of the them to position the cursor.

2. Press RETURN/ENTER to continue.

You added additional EBS elements. Do you want to add some of the reference support elements for them?

$$
\text { Answer }(\mathrm{Y} / \mathrm{N}) \mathrm{N}
$$

1. Use the arrow keys or the first letter of the item to position the cursor.

2. Press RETURN/ENTER to continue.

$$
S C-60
$$

WBS DEVELOPER

Do you want to add additional support activities to the support WBS?

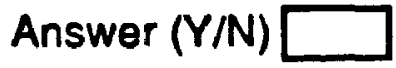

1. Use the arrow keys or the first letter of the them to position the cursor.

2. Press RETURN/ENTER to continue. 
SC- 61

239

TBS DEVELOPER

Do you want to add additional support activities to the support WBS?

Answer $(\mathrm{Y} / \mathrm{N})$

N

1. Use the arrow keys or the first letter- of the Item to position the cursor.

2. Press RETURN/ENTER to continue. 
0
$\frac{1}{2}$
$\frac{2}{2}$
$\frac{1}{2}$

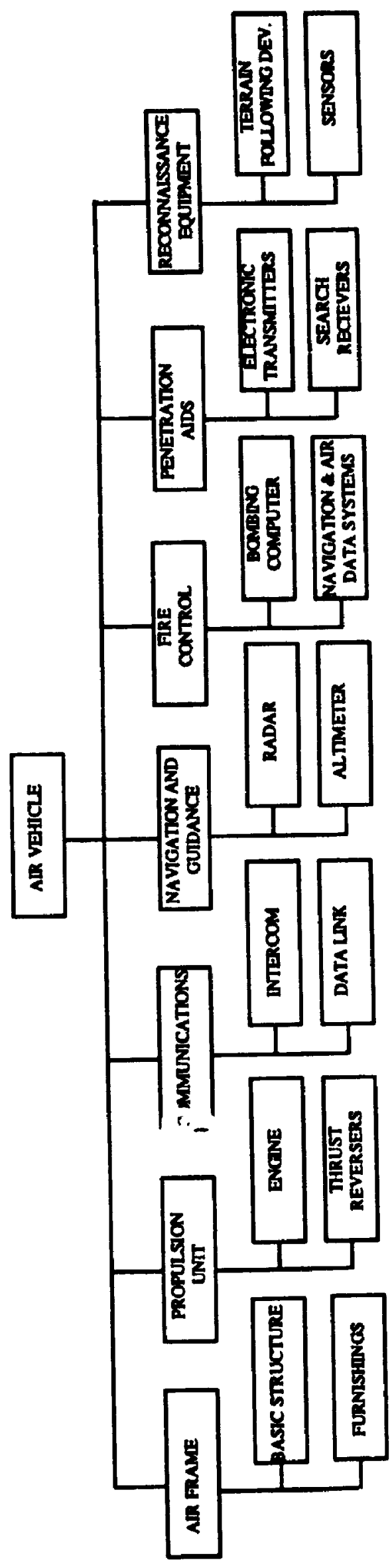

통 


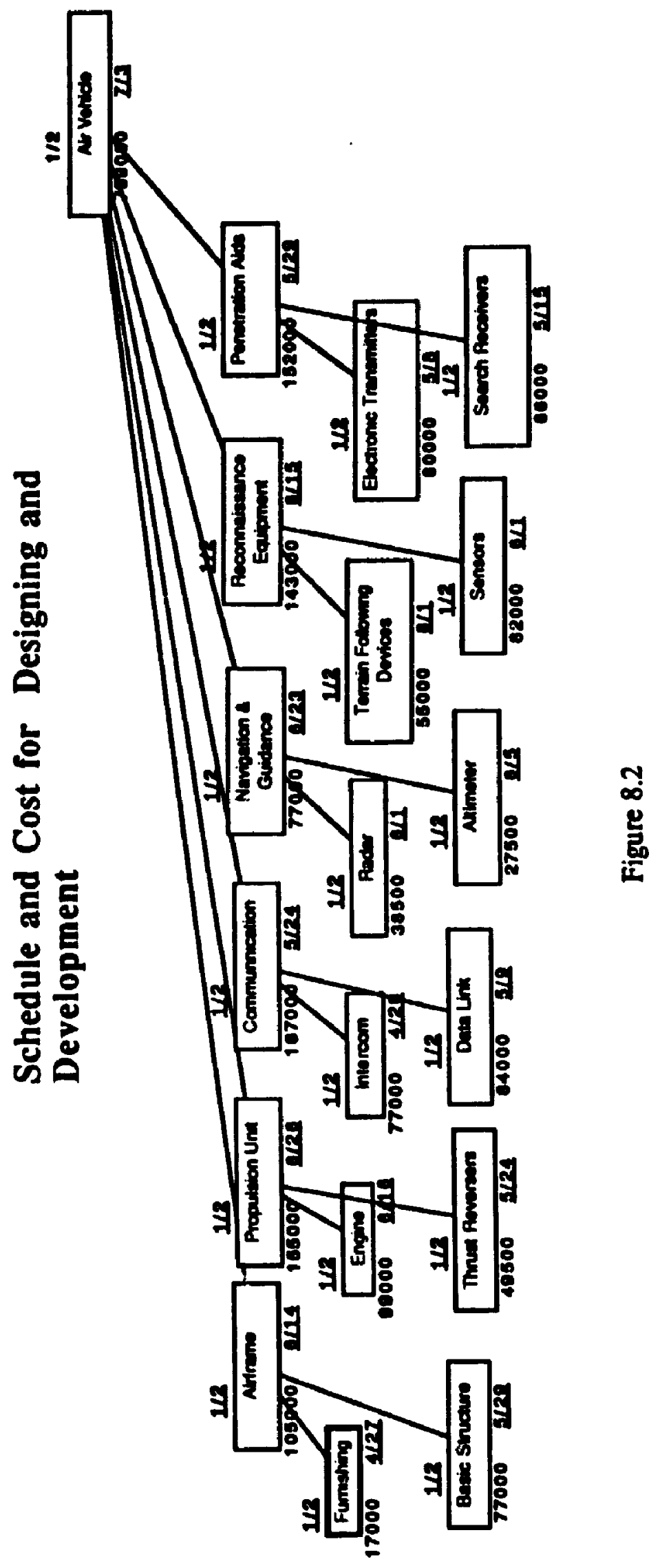




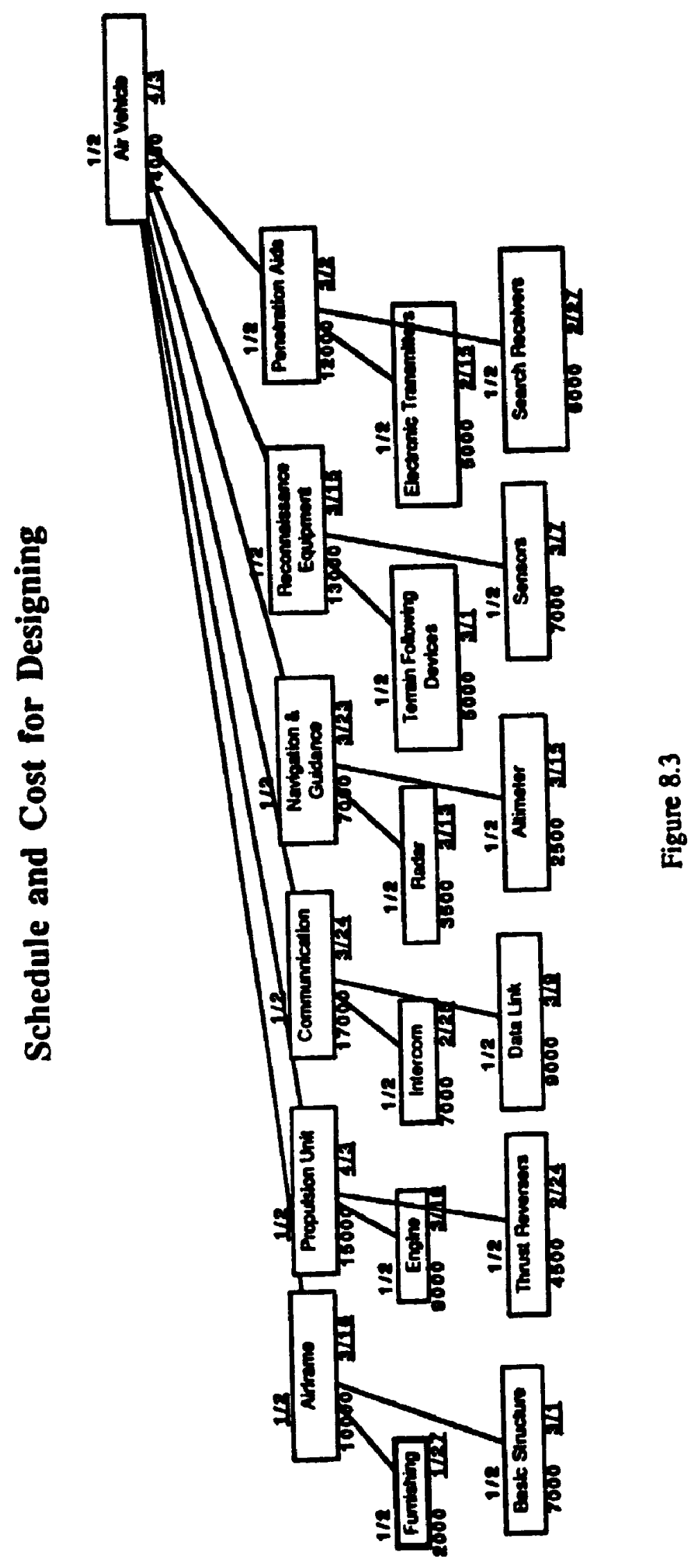




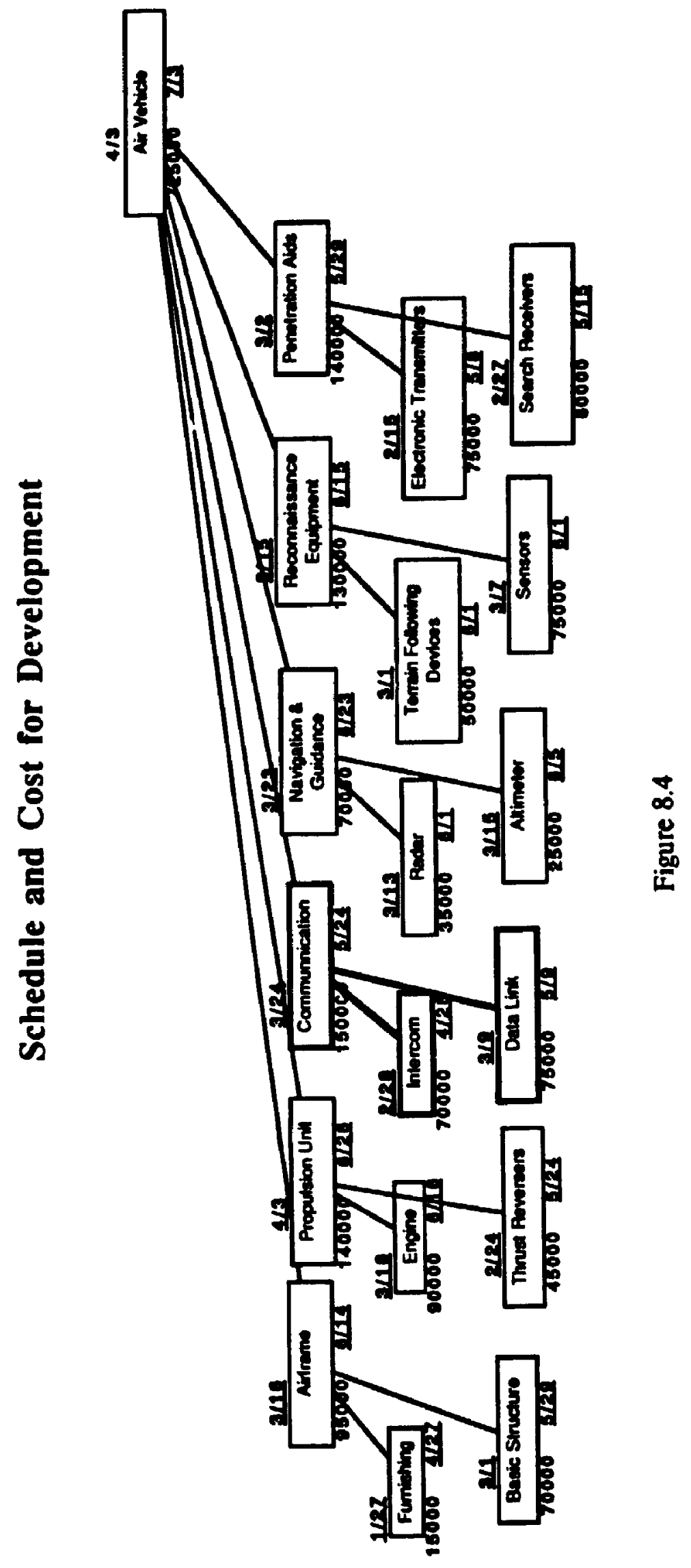

243 


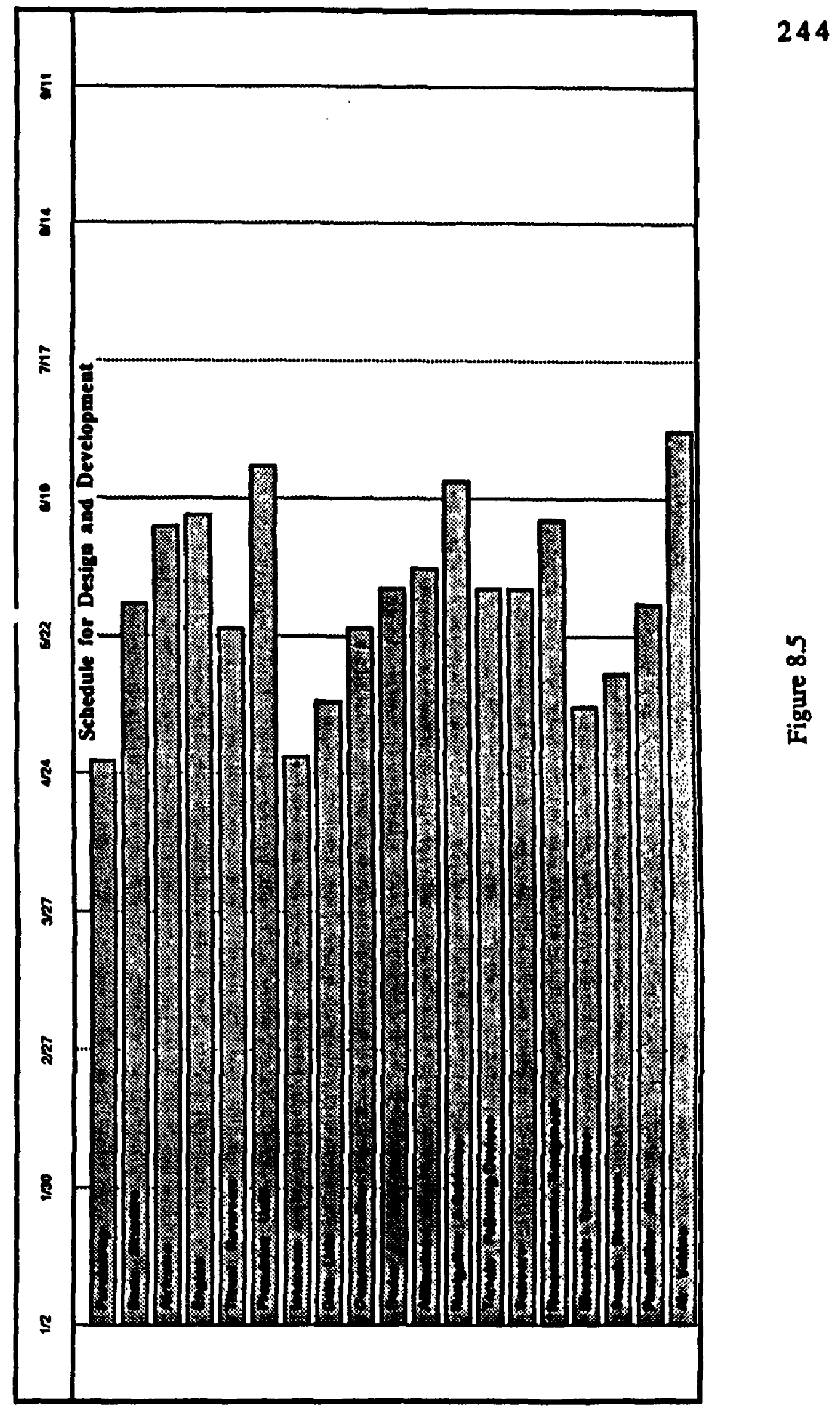




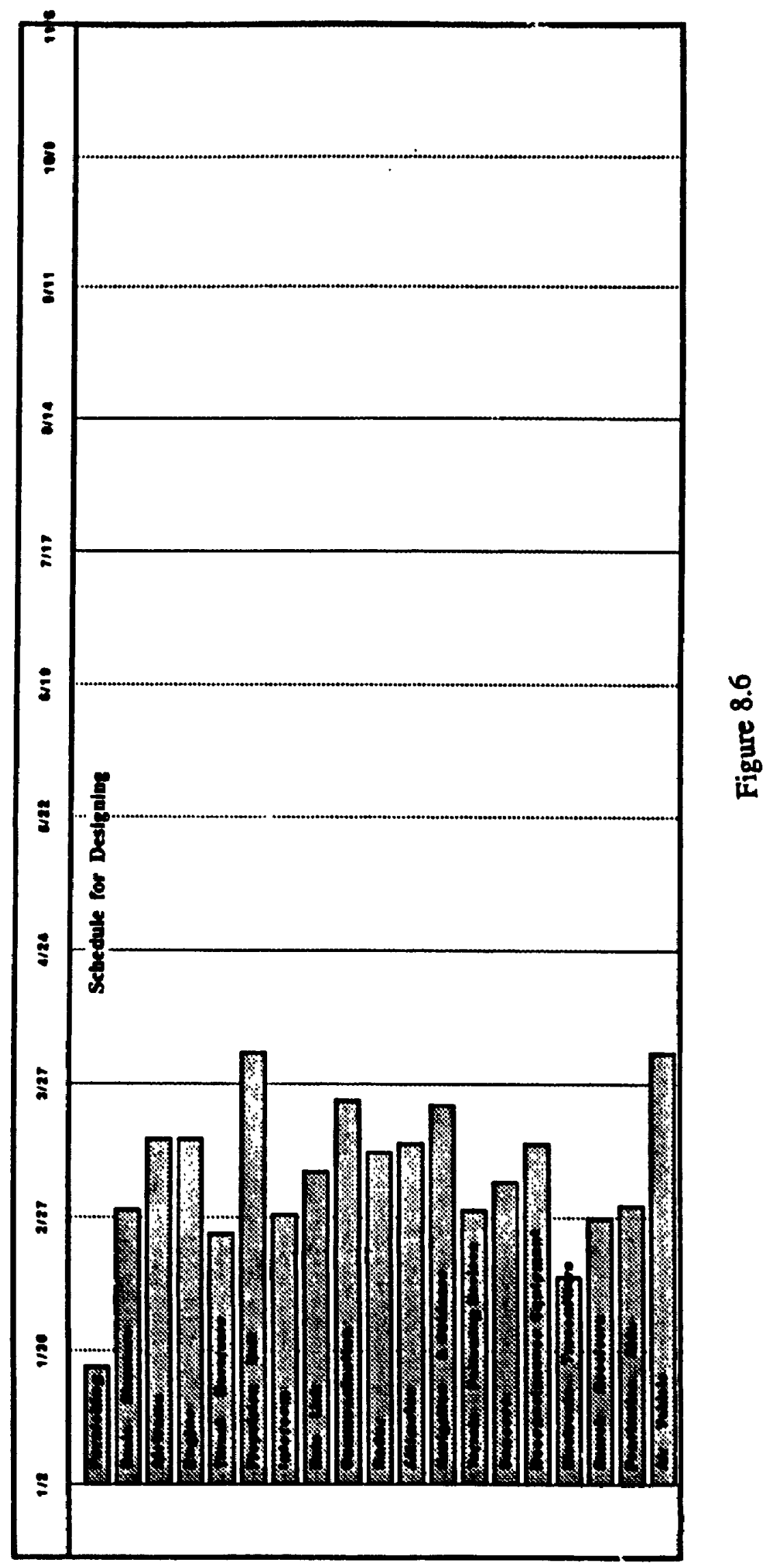




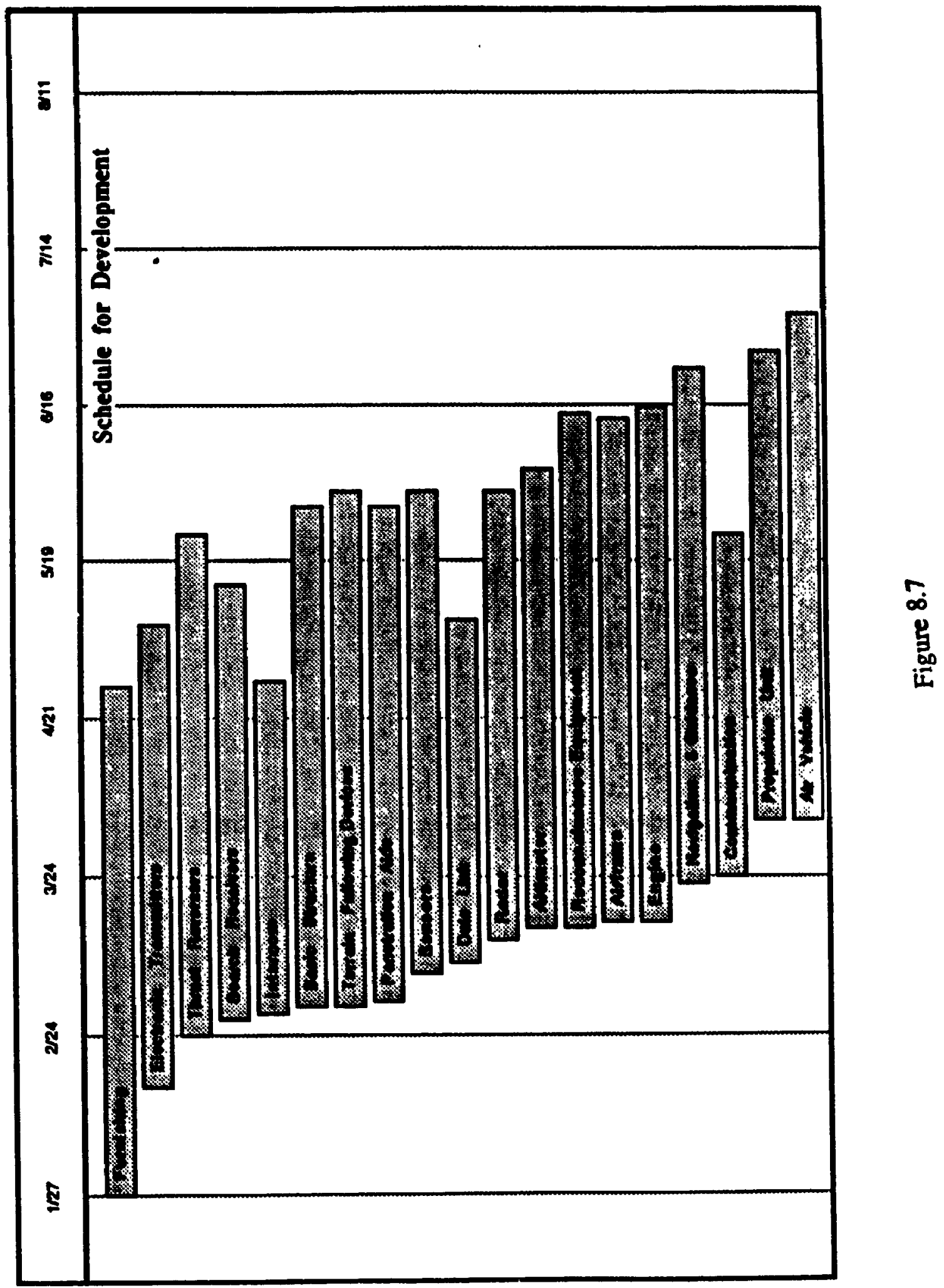




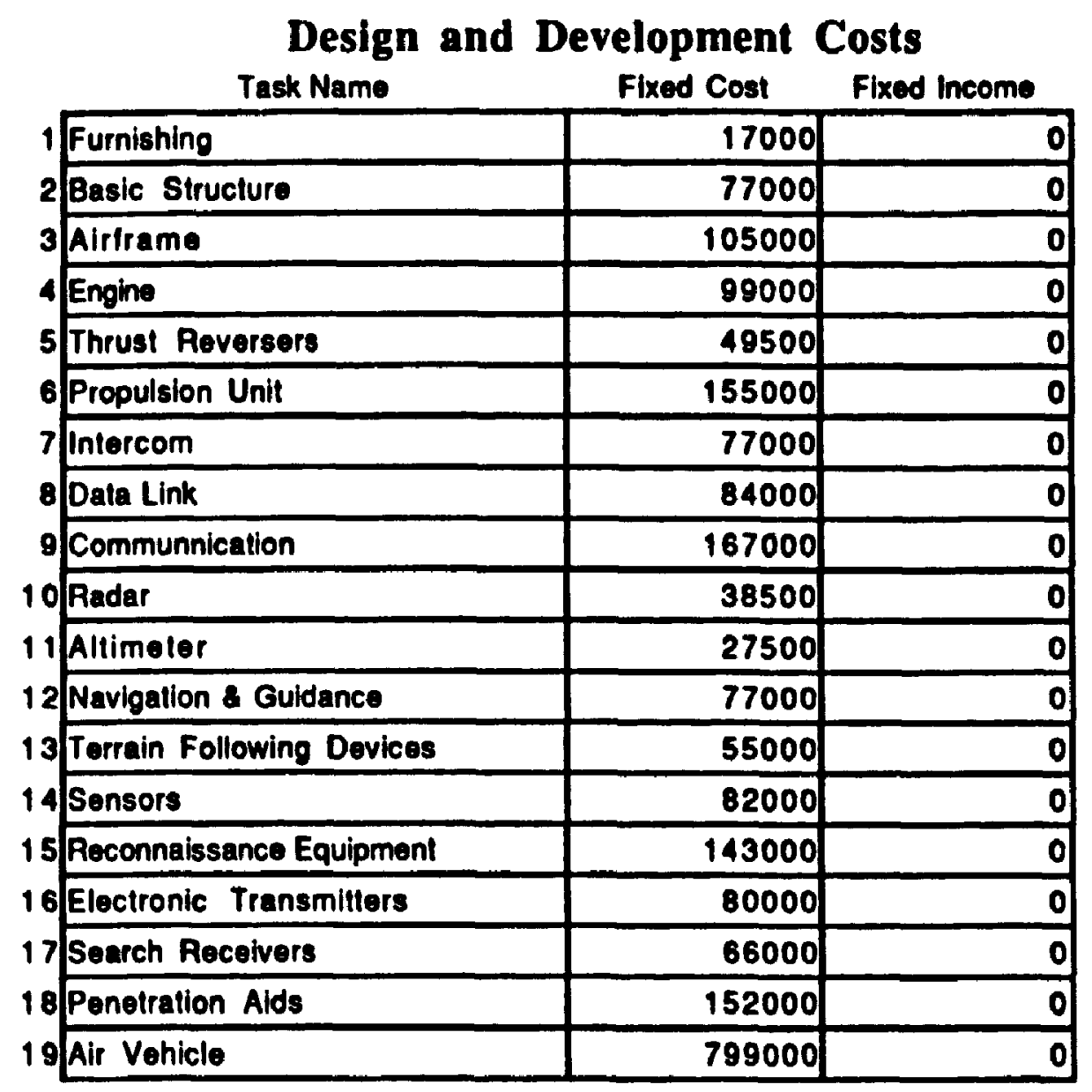

Figure 8.8 


\section{Cost of Designing}

Task Name

Fixed Cost

Fixed Income

\begin{tabular}{|c|c|c|}
\hline Furnishing & 2000 & 0 \\
\hline Basic Structure & 7000 & 0) \\
\hline Alrfreme & 10000 & 0 \\
\hline Engine & 9000 & 0 \\
\hline Thrust Reversers & 4500 & 0 \\
\hline Propulsion Unit & 15000 & 0 \\
\hline Intercom & 7000 & 0 \\
\hline Data Link & 9000 & 0 \\
\hline Communnication & 17000 & 0 \\
\hline Radar & 3500 & 0 \\
\hline Altimeter & 2500 & 0 \\
\hline Navigation \& Guidance & 7000 & 0 \\
\hline Terrain Following Devices & 5000 & 0 \\
\hline Sensors & 7000 & 0 \\
\hline Reconnaissance Equipment & 13000 & 0 \\
\hline Electronic Transmitters & 5000 & 0 \\
\hline Search Receivers & 6000 & 0 \\
\hline Penetration Aids & 12000 & 0 \\
\hline Air Vehicle & 74000 & 0 \\
\hline
\end{tabular}

Figure 8.9 


\section{Development Costs}

\begin{tabular}{|c|c|c|c|}
\hline & Tesk Name & Fixed Cost & Fixed Income \\
\hline 1 & Furnishing & 15000 & $\mathbf{0}$ \\
\hline 2 & Basic Structure & 70000 & 0 \\
\hline 3 & Airframe & 95000 & 0 \\
\hline 4) & Engine & 90000 & 0 \\
\hline 5 & Thrust Reversers & 45000 & 0 \\
\hline 6 & Propulsion Unit & 140000 & 0 \\
\hline 7 & Intercom & 70000 & 0 \\
\hline 8 & Data Link & 75000 & 0 \\
\hline 9 & Communnication & 150000 & 0 \\
\hline 10 & Radar & 35000 & 0 \\
\hline 11 & Altimeter & 25000 & 0 \\
\hline 12 & Navigation \& Guidance & 70000 & 0 \\
\hline 13 & Terrain Following Devices & 50000 & 0 \\
\hline 14 & Sensors & 75000 & 0 \\
\hline 15 & Reconnaissance Equipment & 130000 & 0 \\
\hline 16 & Electronic Transmitters & 75000 & 0 \\
\hline 17 & Search Receivers & 60000 & 0 \\
\hline 18 & Penetration Aids & 140000 & C \\
\hline 19 & Air Vehicle & 725000 & c \\
\hline
\end{tabular}

Figure 8.10 


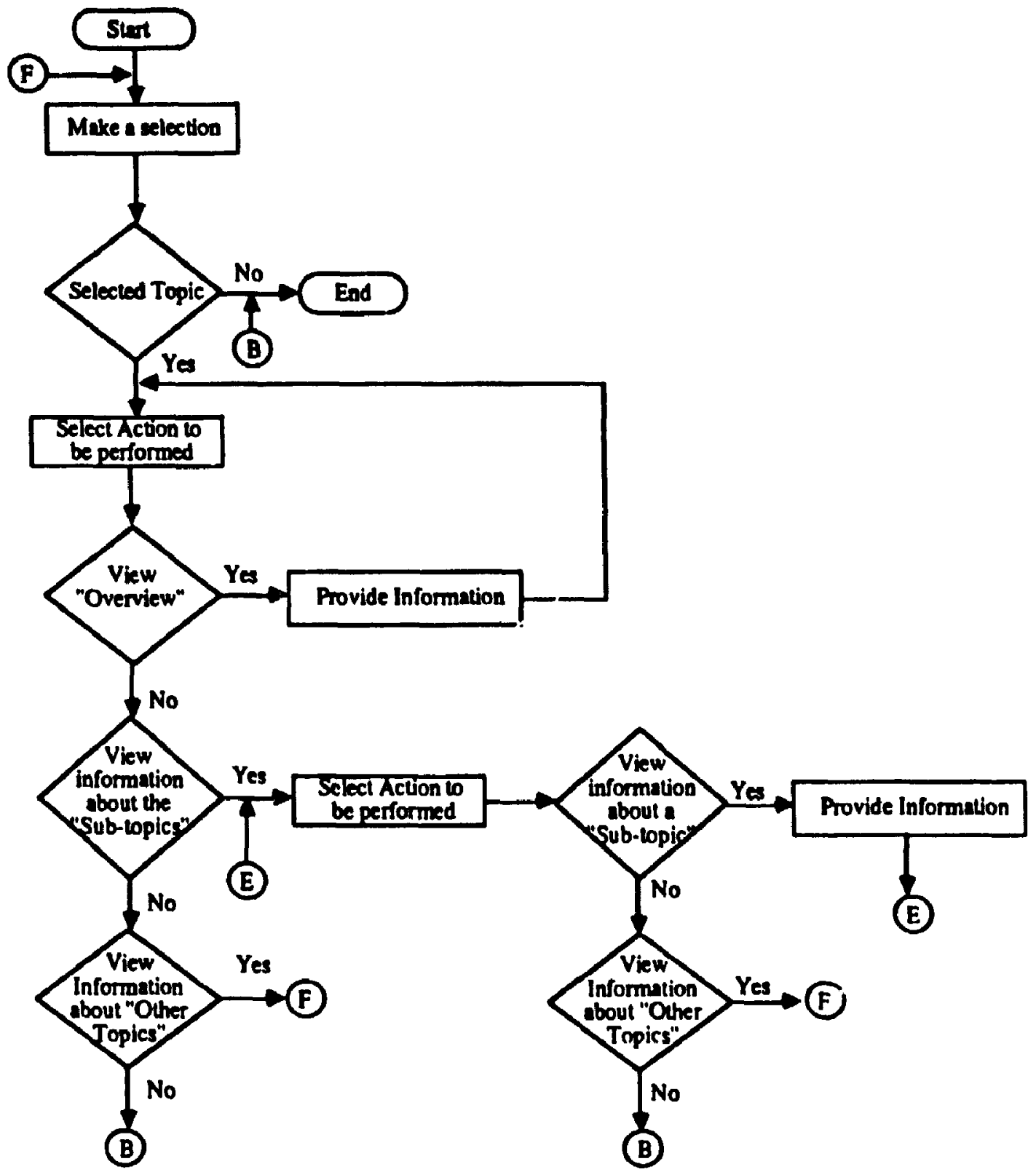




\section{System Flow Chart of the Development Module}

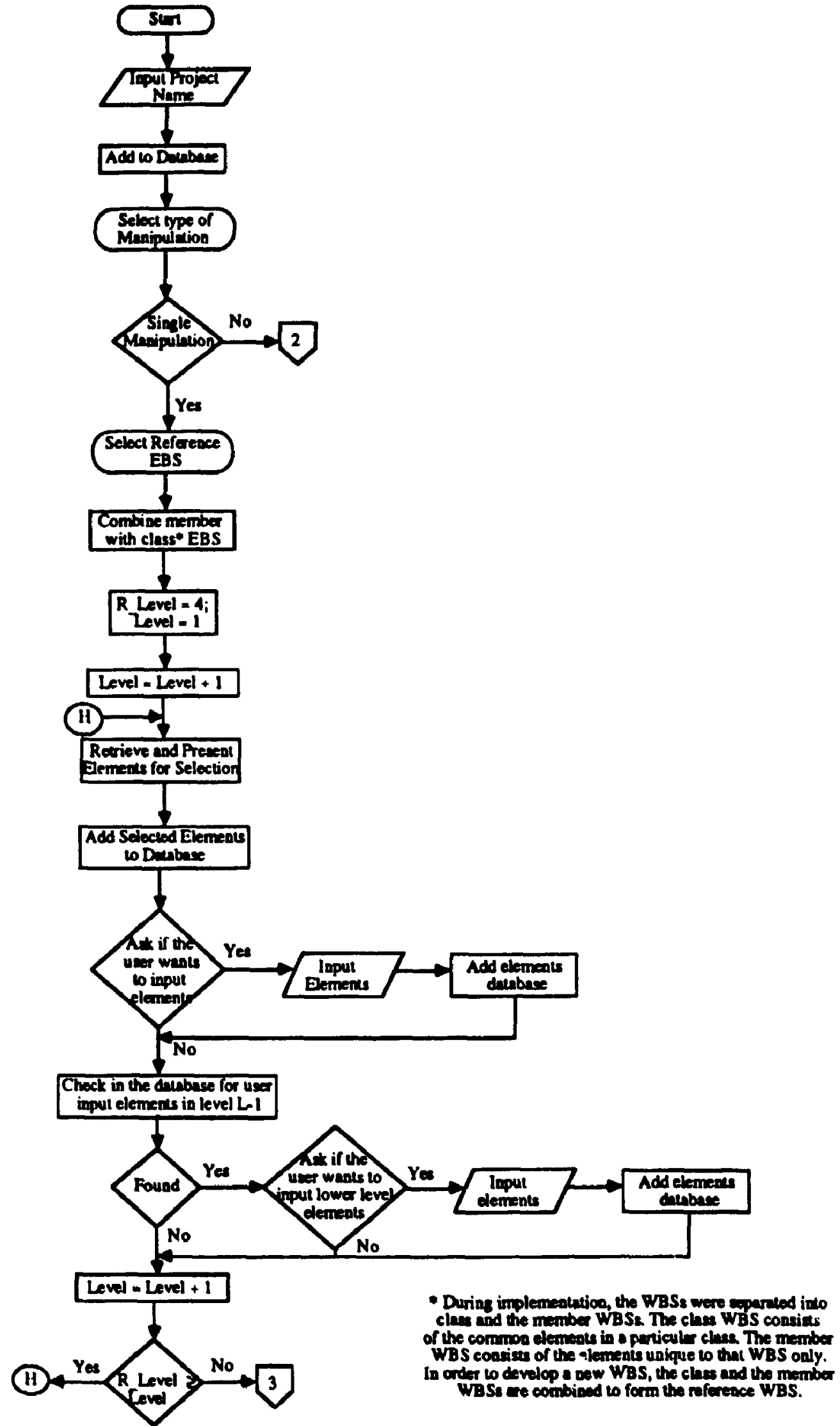




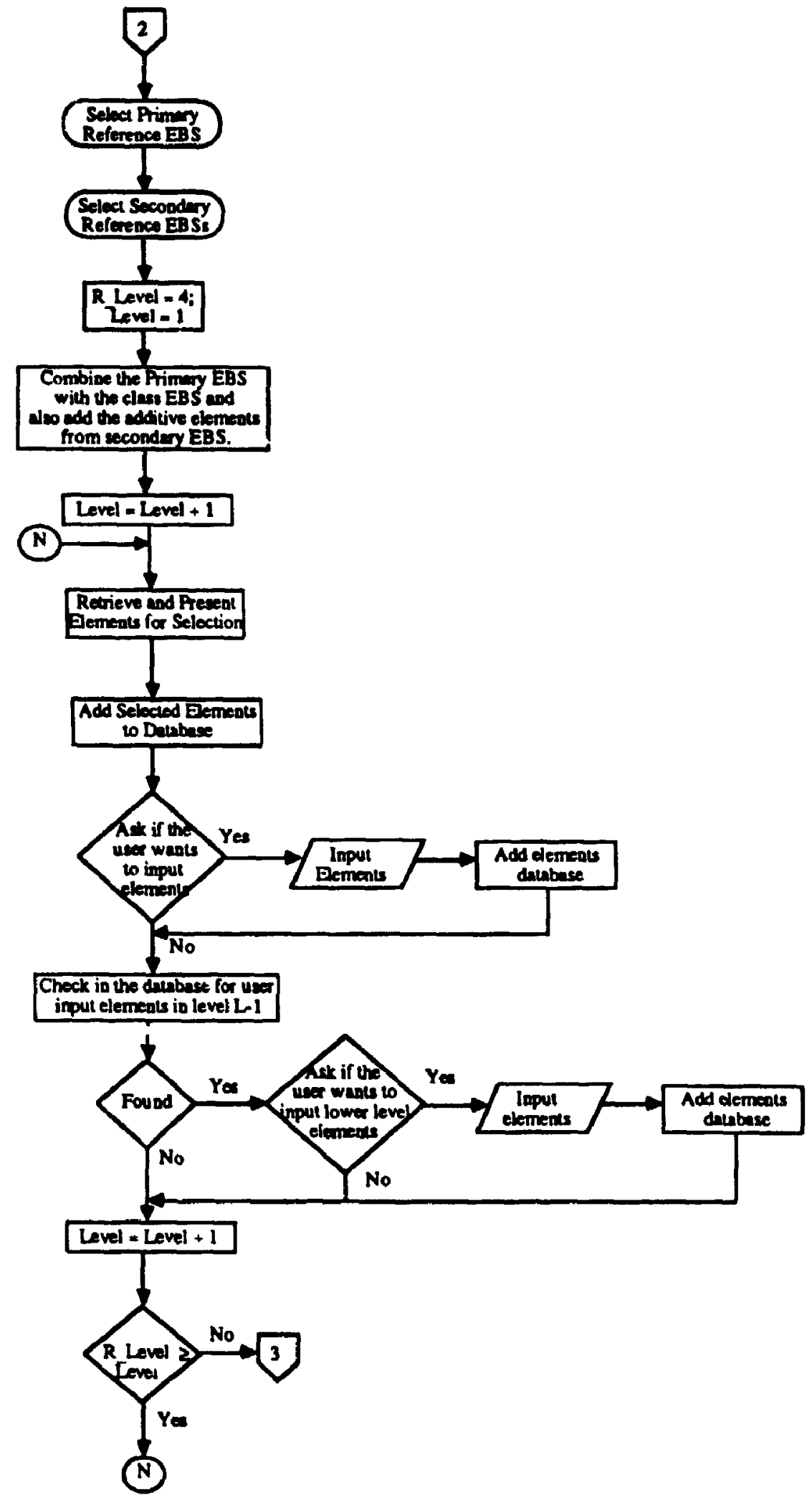




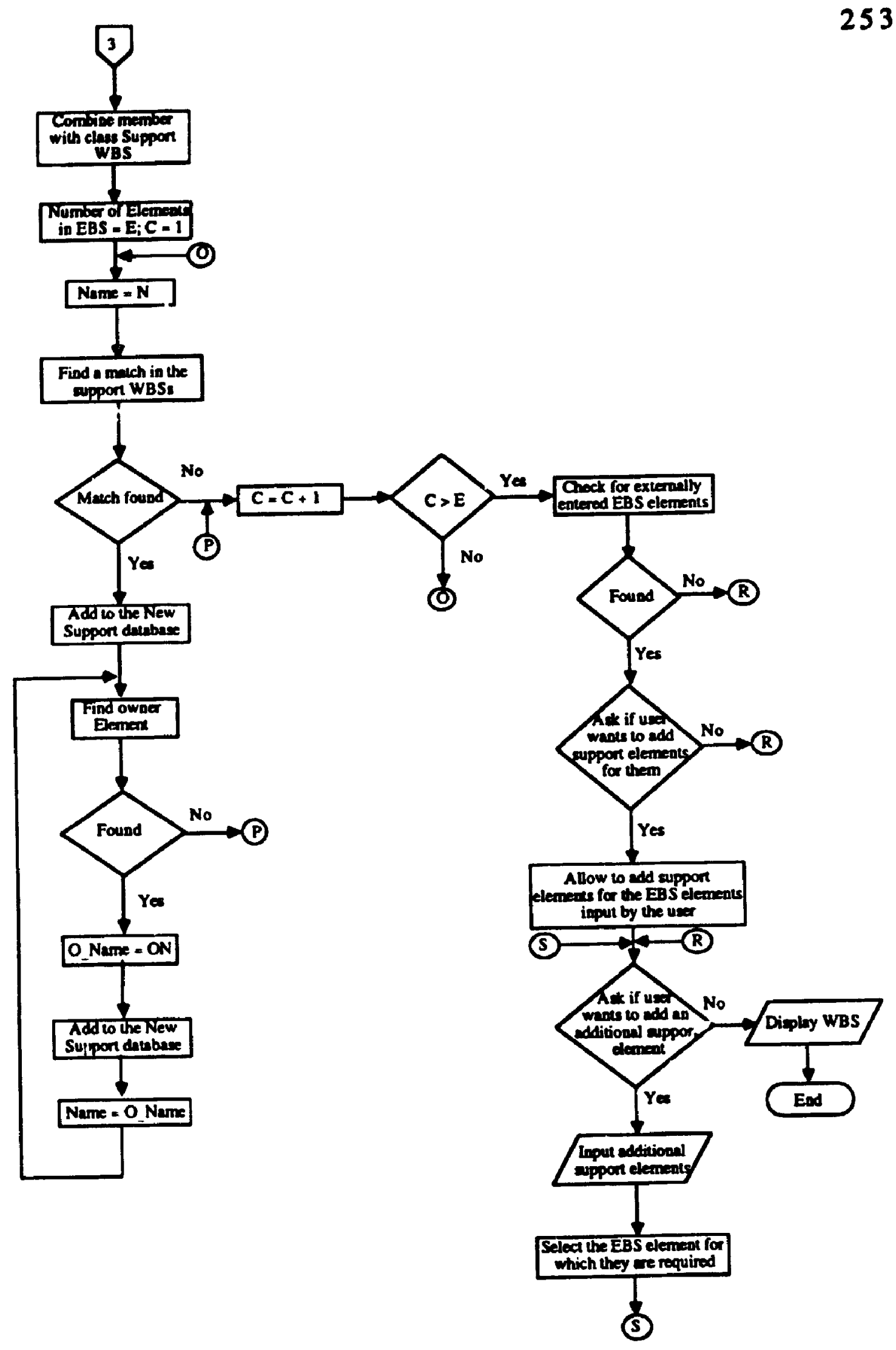




\section{APPENDIX 11}

\section{USER MANUAL}

The prototype runs on IBM microcomputers having minimum of $640 \mathrm{~K}$ of main memory (RAM). It consists of two modules, Information and Development. The Information module is developed in Xi Plus (Expertech) and the development module in PC Easy (Texas Instruments). The direction for using these modules are given below:

\section{Information Module}

In order to run this module, a copy of Xi plus, version 2 is required. Follow the instructions given in the Xi plus manual to install the application. Once it has been installed, create a sub-directory IPROTOTYP in the sub directory IXIP. Next copy the files from the prototype disk, which are present in the sub-directory IPROTOTYPINFORMAT, to the subdirectory IXIPIPROTOTYP. Copy the file, info.bat from the sub-directory IPROTOTYP into the IXIP sub-directory.

To access the the information module type INFO, and press the <ENTER> key. Once inside the module, it is very easy to use. Use the arrow keys to move between the various items. An item can be selected any number of times. Press <ENTER> to select an item. Select "Quit" to quit the module.

\section{Development Module}

In order to run this module, a copy of PC Easy, version 2.01 is required. Follow the instructions given in the PC Easy manual to install the application. After it has been installed, install dBase III, version 1, in the PC Easy sub-directory. Next copy all the files from the prototype disk which are present in the the sub-directory IPROTOTYPIDEVELOP into the LPC EASY sub-directory.

To access the development module type CONSULT DEVELOP. Use the arrow keys to move between the items. In cases where there is more than one item presented for selection, use the right and left arrow keys to select or deselect the items. After you have selected the items, press <ENTER>. Due to limitations of PC Easy, at least one of the items has to be selected to be added to the database. Therefore, do not press <ENTER> without selecting at least one item 
You will notice that in some instances, the screen flickers. This is because of the interface between dBase and PC Easy. During the flickering the data is being exchanged between the two applications, dBase and PC Easy. Do not press any key during this process. Wait until the next screen is presented before pressing any key. In cases where you input additional elements in a level, press the <ENTER > key, after making each entry, to move to the next one.

Due to the user friendly nature of the modules, this is the only assistance you require to use the prototype. 

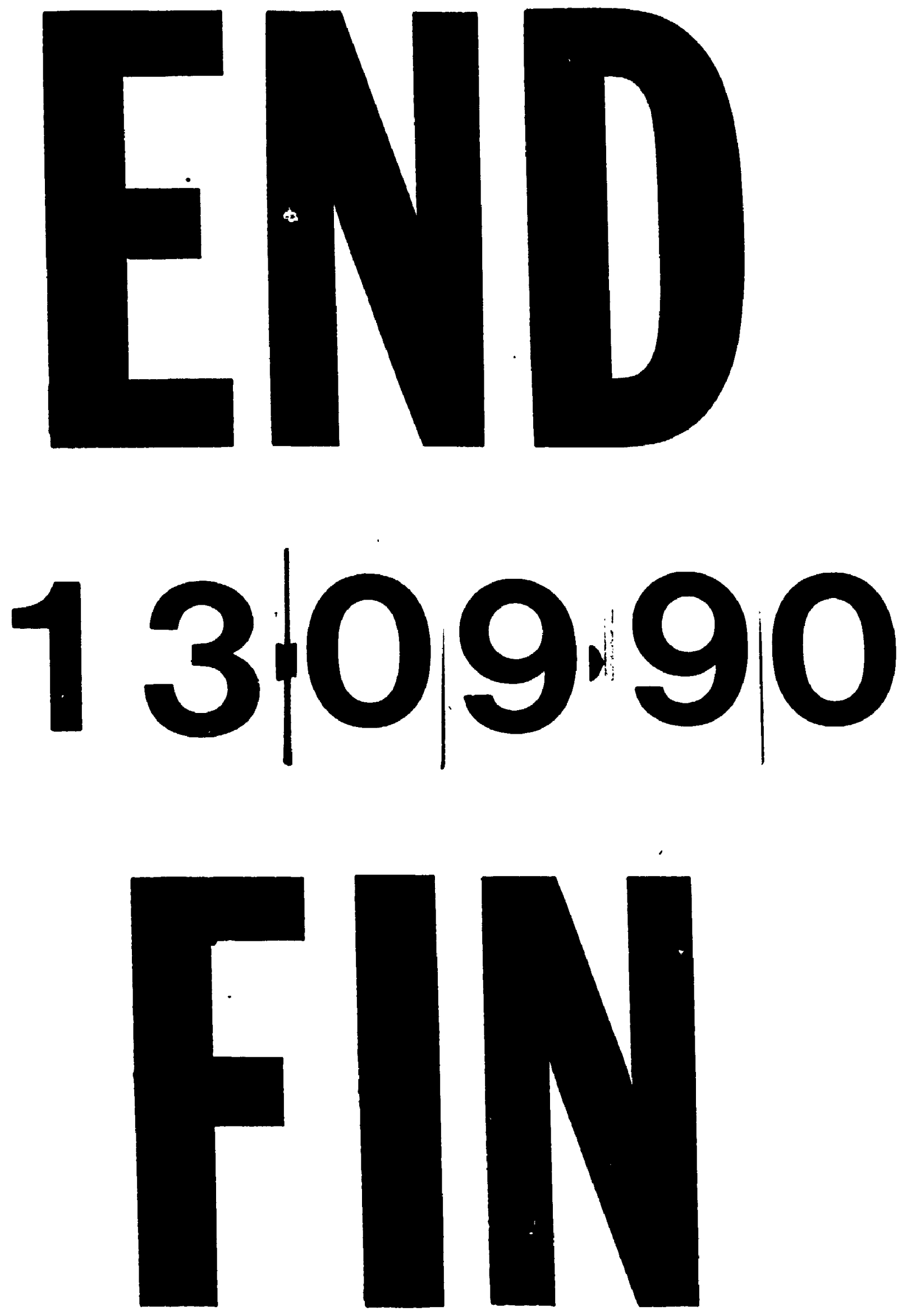